
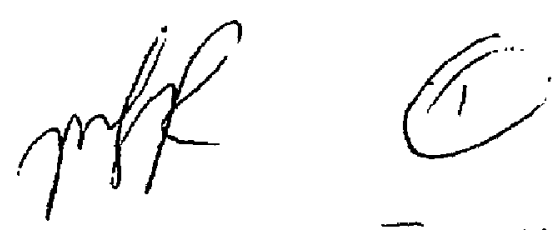

$$
D\}\{-1061=0
$$

$$
I-3 / 306
$$

UCID--20153

DE85 012833

\title{
Helium-Cooled Molten-Salt Fusion Breeder
}

\author{
R. W. Moir, J. D. Lee, F. J. Fulton, F. Huegel,
}

W. S. Neef, Jr., A. E. Sherwood, D. H. Berwald, R. H. Whitley, C. P. C. Wong, J. H. Devan, W. R. Grimes, and S. K. Ghose

December 1984

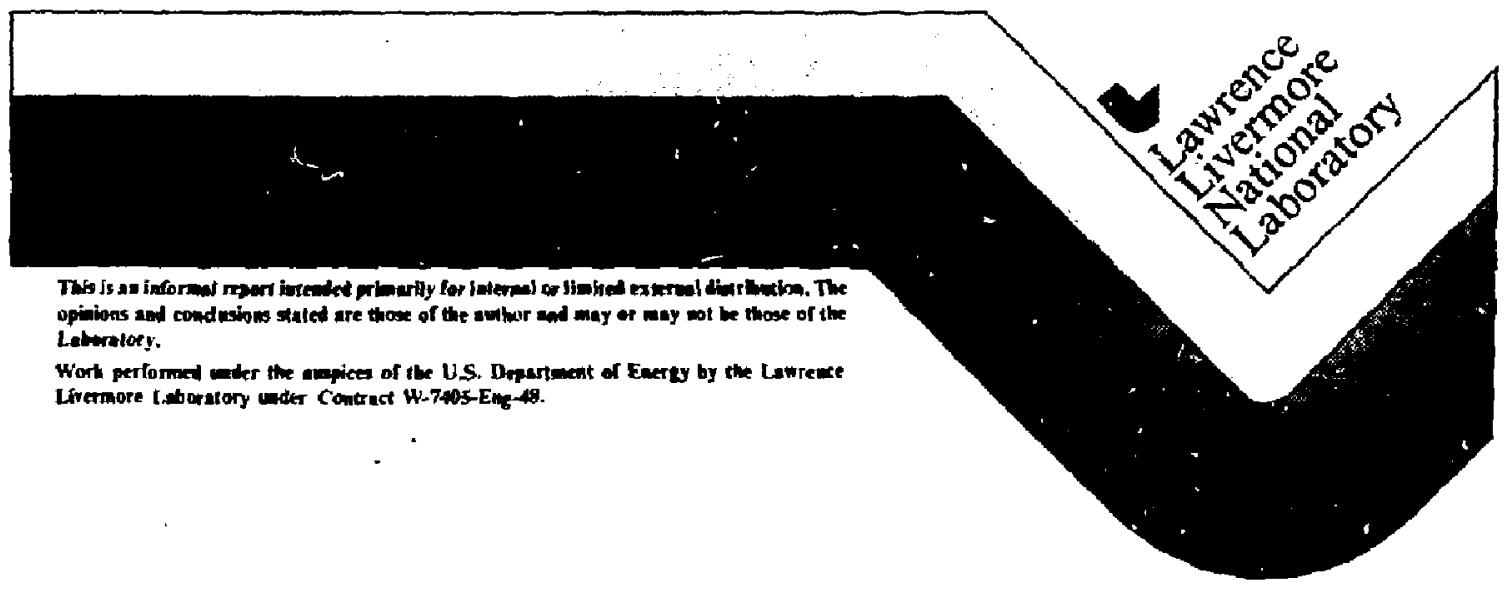

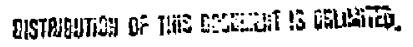


R. W. MOIR, J. D. LEE, F. J. FULTON, F. HUEGEL,

W. S. NEEF, Jr., A. E. SHERHOOD

University of California, Lawrence Livermore National Laboratory

L.ivermore, CA 94550

D. H. BERWALD, R. H. WHITLEY

TRK Energy Developraent Group

Redondo Beach, CA 90278

UCID--20153

Redondo Beach, CA 90278

DE85 012833

C. P. C. WONG

GA Technologies, Inc.

SaA Diego, CA 92138

J. H. DEVAN, W. R. GR IMES

0ak Ridge National Laborator:

0ak R idge, TN 37830

S. K. GHOSE

Becntel Group, Inc.

Sen irancisco, CA 94119

December 1984

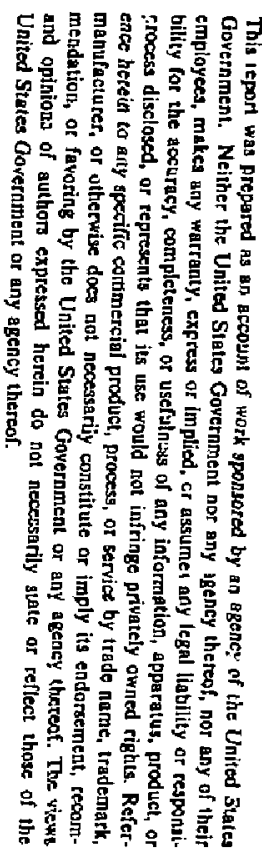




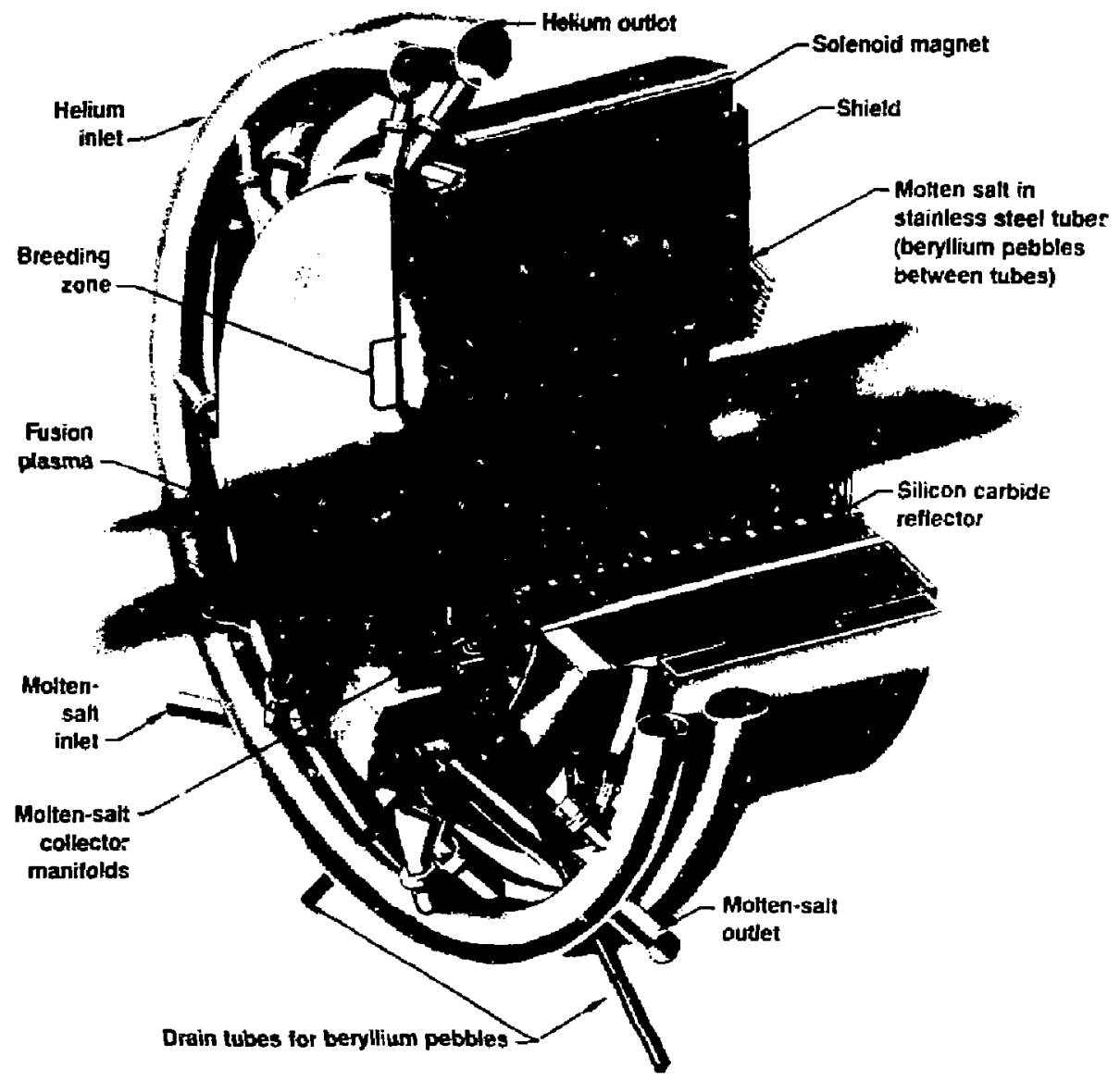

A helium-cooled molten-salt blanket. 
HEL IUM-COOLED MOLTEN-SALT FUSION BREEDER

\section{CONTENTS}

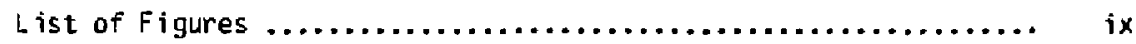

List of Tables .................................. $x i$

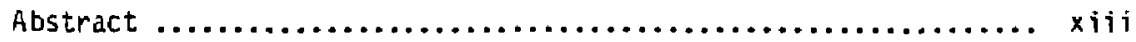

E'scutive Sumary ...............................

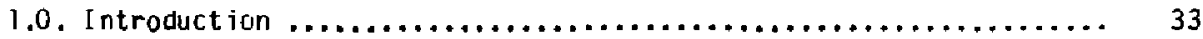

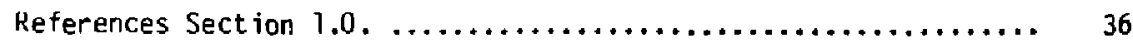

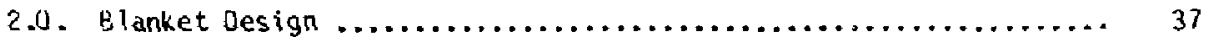

2.1. Mechanical Design .......................... 37

2.1.1. Pebble/Tube System - Sa\}t Volume and Cost ......... 41

2.1.2. Module Enc Hall ........................... 43

2.1.3. Alternate Blanket and Tube Designs .............. 47

2.1.4. Tokamak Blankets ....................... 48

2.1.5. Beryllium Pebble Fabrication Technologies .......... 53

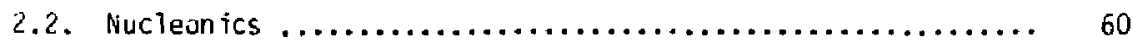

2.2.1. Introduction and Summar ; ..................... 60

2.2 .2 . Unit cell ............................. 61

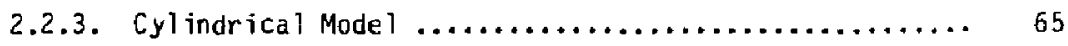

2.2.4, B1 anket Performance Estimate ................. 66

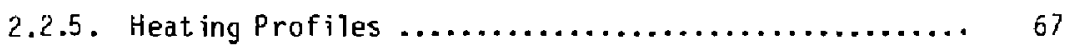

2.3. Thermal Hydraulics .......................... 70

2.3.1. Sait in Molier State (No F rozen Layer) ............ 70

2.3.2. Frozen Salt Layer ....................... 75

2.7. Material Selection and Materials Properties ............. 83

2.4.1. Salt Composition and Propert ies ................ 83

2.4.2. Chcice of Austenitic Steel .................. 84

2.4.3. Analys is of Relevant Corrosion Data ............. 84

2.4.4. Corrosion Properties of Reference Blanket .......... 89 
2.5. Start-Up Scenario ............................ 97

2.6. Safety ................................... 94

2.7. Frozen $5 a 7 t-L$ ayer Issues .......................... 94

2.8. Technology of Tungsten Permeation Barriers .............. 100

References Section $2.0 . \ldots \ldots \ldots \ldots \ldots \ldots \ldots \ldots \ldots \ldots . \ldots \ldots . \ldots \ldots$

3.0. Tritium Permeation and Recovery ........................ 107

3.1. Introduction ............................... 11 1

3.2. Tritium Toxicity ............................. 114

3.3. Tritium Pressure in a Multi-layer Cylindrical Wall ....... 116

3.3.1. Steady-State Permeation Equations

Without Axial Flow ...................... 116

3.3.2. Mass-Transfer Res istances in Molten Salt ........ 120

3.3.3. Pressure Profiles in Absence of Molten Salt ...... 121

3.3.4. Radial Flux Equation for Tritium .............. 125

3.4. Tritium Split Between Wall Permieation and

Reactor. Tube Flow ........................... 126

3.4.1. Model Assumptions and Mass-Balance Integral ..... 126

3.4.2. A Henry's Law Barrier as Flux Limiter ........... 129

3.4.3. A Sievert's Law Barrier as Flux Limiter ......... 130

3,5. Tritium Permeation Rate to Helium-Coolant Loop .......... 132

3.6. Tritium Permeation into the Steam-Water Loop ........... 135

3.6.1. For Well-Mixed Tank Model ................... 135

3.6.2. For Range of Design Options ................ 140

3.3. Process Concepts for Tritium Recovery from Fluid Loops .... 143

3.7.1. From Molten Salt by Flash Evaporization ......... 143

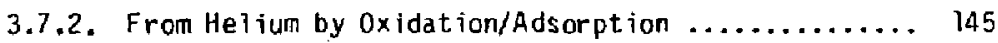

3.7.3. Tritiated Water Purge or Isotopic Separation ...... 146

3.8. Tritium Inventory in Fluid Systems and Tube Wal is ....... 147

3.9. Surmary and Recommendations ..................... 149

References Section $3.0 . \ldots \ldots \ldots \ldots \ldots \ldots \ldots \ldots \ldots \ldots \ldots \ldots \ldots . \ldots \ldots$

4.0. Moiten-Salt Reprocessing ........................... 555

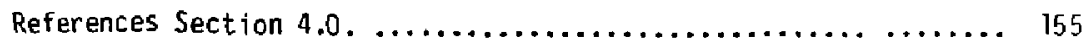


5.0. Balance of $P$ lant Cons iderations ....................... $35 \%$

5.1. General Plant Arrangement ...................... 157

5.2. Blanket Heat Transport ......................... 160

5.3. Tritium Permeation in Steam Generators ............... 175

References Section $5.0 . \ldots \ldots \ldots \ldots \ldots \ldots \ldots \ldots \ldots \ldots \ldots \ldots \ldots \ldots . \ldots \ldots$

6.U. Integrated Performance and Economics .................... 179

6.1. Overview ....................................... 179

6.2. Symbiotic Economics .......................... 180

6.3. Comparison of Results with Reference Case .............. 185

6.3.1. Molten Salt Advantages .................. 187

6.3.2. Fusion Breeder Performance and Costs ........... 190

6.3.3. Economics of Symbiotic

Electricity-Generation Systems ............ 193

6.4. Conciusions ................................ 200

References Section $6.0 . \ldots \ldots \ldots \ldots \ldots \ldots \ldots \ldots \ldots \ldots \ldots \ldots \ldots . \ldots \ldots \ldots$

7.0. Technical Issues ................................ 203

7.1. Tritium Management .......................... 203

7.2. Berylitium Feasibility ....................... 203

7.3. Material Compatibility - Corrosion, Mass Transport ....... 203

7.4. Reprocessing ............................. 204

7.5. Neutron Economy ............................ 204 


\section{LIST OF FIGLRES}

1. One midule of a helium-cooled molten-salt blanket. ........... 3

2. Cross section of a helium-cooled molten-salt blanket. ......... 4

3. Cross section of the molten-salt breeding blanket. ........... 6

4. Helium coolant and temperature of salt tube vs position in blanket. ................................. g

5. Start-up scenario. ................................ 11

6. Permeability of various metals to tritium. ................ 15

7. Permeation geometry and materials. ....................... 16

8. Tritium-recovery system flow jheet. $\ldots \ldots \ldots \ldots \ldots \ldots \ldots \ldots \ldots \ldots, 17$

9. Cost of beryllium pebbles. .......................... 20

30. Diagram of plant, showing arrangement of buildings. $\ldots \ldots \ldots \ldots \ldots, 22$

11. Heat transport system (overhead view). ................. 2 '

1\%. Heat transport system (side view). ..................... 25

13. Steam generator arrangement. ......................... 26

1-1. Helium-cooled molten-salt fusion breeder using beryllium as neutron multiplier. ........................... 35

$2-1$. Ring headers for the supply and return helium. ........... 38

2-2. Molten-salt breeding blantet (cross section). ............. 39

2-3. Molten-salt breeding blanket showing support hangers and salt tubes. ............................. 40

2-4. Alternate design for module end. ...................... 44

2-5. Axially oriented salt pipes. ....................... 46

2-6. Tokamak module and piping arrangements. ................ 49

2-7. Poloidal pod orientation. ............................. 50

2-8. Detail of blanket cross section for poloidal pod orientation. ................................... 51

?-9. Blanket cross section of poloidal pod orientation. $\ldots \ldots \ldots \ldots \ldots, 52$

2- 10. Anntial beryllium cost versus pebble size. ................ 59

2-11. Unit cell calculational model for molten salt blanket. ....... 62

2-12. Power densities in berylilum/moiten-salt blanket. .......... 69 
2-13. Helium coolant and salt-tube temperature vs position in blanket. ................................ 71

2.14. Spatial volumetric power generation in molten-sa1t tube. ..... 74

2-15. Tube temperatures as a function of tube diameter. ......... 76

2-16. Temperature distribution for moiten-satt tube. ............. 78

2-17. Temperature of molten-salt tube and thickness of molten ....... 79

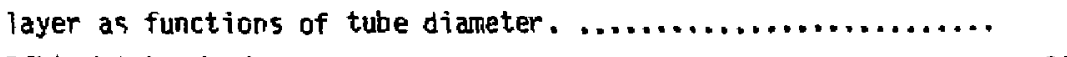

2-18. Ribbed-tube design. .............................. 81

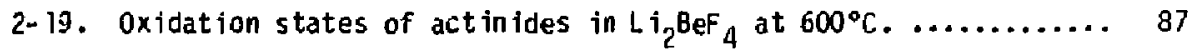

2-20. Pourbaix diagram for structural metals in $\mathrm{LiF}_{-\mathrm{BeF}_{2}}-\mathrm{ThF}_{4}, \ldots \ldots .88$

2-21. Start-up scenario. ............................. 92

3-1. Permeability of various materials. ................... il2

3-2. Permeation gesmetry and materials. .................... 117

3.3. Model for tritium split in reactor tube. $\ldots \ldots \ldots \ldots \ldots \ldots \ldots \ldots, 128$

3-4. Tritium process ing loops, showing principal flows only. ..... 136

$3-5$. Tritium recovery-system flow sheet. .................. 144

5-1. Diagram of plant, showing arrangement of buildings. ........ 158

5-2. Heat-transport and power-conversion systems of bianket....... if?

5-3. Heat transport system, showing piping and equipment

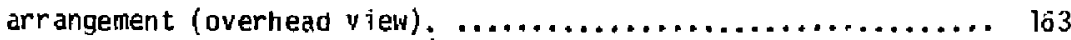

5-4. Heat transport system, showing piping and equipment

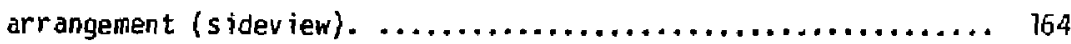

$5-5$. Steam generator arrangement. ...................... 166

5-6. Steel vessel steam generator for high-temperature gas reactor. ................................... 167

5-7. Temperature profile for steam generator. ................ 174

6-1. A fusion-fission electricity-generation system. ........... 181

6-2. Reference fusion breeder with liquid-metal-cooled blanket. .... 186 


\section{LIST OF TABLES}

I. Plant parameters for the descr ibed fusion-breeder design. ..... 2

I1. Technolagies employed in the fusion-breeder design. .......... 2

III. Beryllium requirements for the molten-salt blanket. ......... 5

IV. Calculated breeding performance. $\ldots \ldots \ldots \ldots \ldots \ldots \ldots \ldots \ldots \ldots \ldots$

V. Composition and properties of blanket salt. ............... 12

VI. Heat-transport system of blanket. ..................... 23

VII. Economic analysis. ............................... 28

2-1. Nominal pebble/ tube parameters. ....................... 41

2-2. Beryllium requirements for the molten-salt blanket. ......... 43

2-3. Est imated costs of components for process ing beryllium pebbles. ............................... 57

2-4. Nuclear performance of the unit cell (MSHE series). ......... 63

2-5. Comparison of unit cell data for molten-salt/berylliumv he $i$ ium ce?l and reference beryllium/ thor ium/ lithium ce $11 . . . .664$

2-6. Cylindrical-model TART calculations, .................... 66

2-7. Power density in new Be-MS-Fe blanket at unit first-wall loading (first estimate). ........................ 68

2-8. Est imated helium- loop pumping-power distr ibution. .......... 82

2-9. Composition and properties of the blanket salt, using three

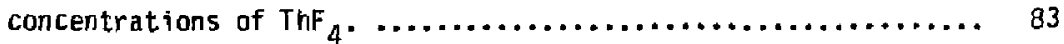

$2-10$. Electrode potentials of container materials in $\mathrm{Li}_{2} \mathrm{BeF}_{4}$

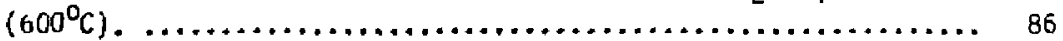

2-11. Operating conditions of stainless steel thermal-convection

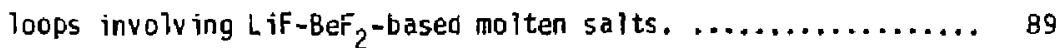

3-1. Nomenclature and symbols for Section $3.0 . \ldots \ldots \ldots \ldots \ldots \ldots \ldots$ T0 8

3-2. Equations represent ing tritium permeation data in metals. ..... 113

3-3. Thermal regime for molten-salt reactor tube. ............. 122

3-4. Tritium permeation from molten-salt reactor tubes without

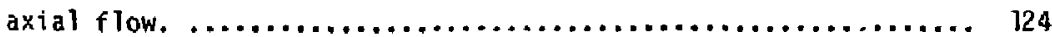

3-5. Permeation from the inolten-salt loop for three design options. 
3-6. Size comparison of loops for molten-salt reactor, orocessing, and coolant. ........................... 137

3-7. Tritium permeation through bare steel heliurn/steamheat axchangers. ...................................... 139

3-8. Comparison of tritium permeation rates into the steam/water system. ............................... 142

3-9. Tritium inventory in fluid systems and in steel tube walls. .................................... 148

5-1. Heat-transport system of blanket. .................... 161

b-2. Parameters for hot-leg header of helium-transport loop. ...... 170

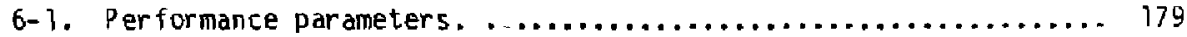

6-2. Financial input data for breeder and light-water reactors. .... 182

6.3. Market penetration analys is for a $U_{3} 0_{8}$-fueled LWR. .......... 184

6-4. Typical reprocess ing economics. ........................ 188

6-5. Fusion-breeter performance comparison. .................. 191

6-6. Fusion-breeder cost comparison. ..................... 192

6-7. Comparison of utility ownersh ip and government ownersh ip for the referencs lithiumberyllium fusion breeder. ......... 995

6-8. Comparison of cost data for a symbiotic system. ............ 197

6-9. Molten-salt fusion-breeder cost data. .................. 198

6-10. Comparison of data for lithiun-blanket or moltrn-salt reactor type and ownership. ............................... 199 


\section{HELIUH-C,OOLED MOLTEN-SALT FUSIOAI BREEDER}

\section{EXECUTIVE SUMMARY}

In this report we describe a fusion breeder design that is based on molten-salt technology. This design evolved fron earliar concepts ${ }^{1-3}$ with design changes being incorporated to avoid prior problems. For example, steal was substituted for molybdenum arid graphite coatings were eliminated. The beryllium, rather than being in large, 5-cm-diam cylindrical rods, $500 \mathrm{~cm}$ long, is now to be in small l-cm-diam radiation-damage-resistant spheres. This report was summarized recent, ly in a paper presented to the American Nuclear Society. ${ }^{4}$ The fusion neutron source for this design is the tandem mirror, but other fusion concepts such as the tokamak could equally well have been employed. The particular tandem mirrer design is based on a nre-riarS design ${ }^{5}$. The plant parameters are given in Table I. The technologies used are 1 isted in Table II.

\section{BLANKET DESIGN}

The blankei comept uses high-pressure helium as the coolant and beryllium spheres as the neutron miltiplier. A?l the fertile material for breeding both tritium and fissile fuel is in the form of molten fluoride salts if lithium and thorium that flow slowly through an array of tubes (see Figs. 1 and 2).

The molten-fluoride salt, whose composition is given in Table II, is stable to both therma? and radiation decomposition tecause of the raf!dity of recombination. Corrosion rates of iron-based alloys are $10 \mathrm{~d}$ when the 5 alt is maintained in a recuci.g state. A similar salt, with somewhat differing nele fractions, was used at Oak Ridge National Laboratory in a molten-sait reactor that operated successfully for several years. The uranium produced by neutron transmutation of $\mathrm{ThF}_{4}$ is in the form of $\mathrm{UF}_{4}$. Upon reacting with excess fluorine in an external tank, the $\mathrm{UF}_{4}$ is converted to $\mathrm{UF}_{6}$, which is volatile and easily separatec. This process is called fluorination. $\mathrm{JF}_{6}$ is a standard form of uranium used in the industry.

To acquire a high enough heat capacity tu cool the blanket efficiently, helium must be at a prrssure of about $5 \mathrm{MPz}$ (50 atmos.) Heiium neither absorbs neutrons nor promotes self-welding row:tions that might interfere with the free flow of the beryllium spheres as they are removed for remanufacturing 
Table I. Plant parameters for the described fusion-breeder design.

\begin{tabular}{|c|c|c|}
\hline$P_{\text {nuclear }}$ & $4440 \mathrm{MH}$ & , \\
\hline Pfusion & $3000 \mathrm{MW}$ & \\
\hline Palpha particle & $600 \mathrm{MW}$ & \\
\hline Pblanket & $3840 \mathrm{MH}$ & \\
\hline Pelectric & $1380 \mathrm{MH}_{\mathrm{e}}$ & \\
\hline$P_{\text {wall load }}$ & $2 \mathrm{~m} / \mathrm{m}^{2}$ & \\
\hline Length of blanket & $127 \mathrm{~m}$ & \\
\hline First wafl radius & $1.5 \mathrm{~m}$ & \\
\hline$F_{\text {net }}$ & $0.6^{\mathrm{a}}$ & \\
\hline$M$ & $1.6^{\mathrm{a}}$ & \\
\hline $\begin{array}{l}\text { Fissile production } \\
\text { Total cost }\end{array}$ & $\begin{array}{l}6380 \mathrm{~kg} 233 \mathrm{U} / \text { year at } 80 \% \\
\text { capacity factor } \\
9486 \pi \mathrm{M}\end{array}$ & \\
\hline
\end{tabular}

aF $_{\text {net }}$ is fissile atoms bred/triton consumed; $M$ is the snergy released in the blanket per triton consumed divided by $14 \mathrm{MeV}$.

Table II. Technologies employed in the fusion-breeder design.

\begin{tabular}{ll}
\hline Cooling & Helium \\
Structural material & 316 type stainless steel \\
Neutron multiplier & Beryllium pebbles \\
Tritium and fissile breeder & Molten salt: Lif 70 mol\% $+\mathrm{BeF}_{2} 12 \mathrm{~mol} \%+$ \\
& $\mathrm{ThF}_{4} 18 \mathrm{mol \% .}$ \\
Neutron reflector & $\mathrm{sic}$
\end{tabular}




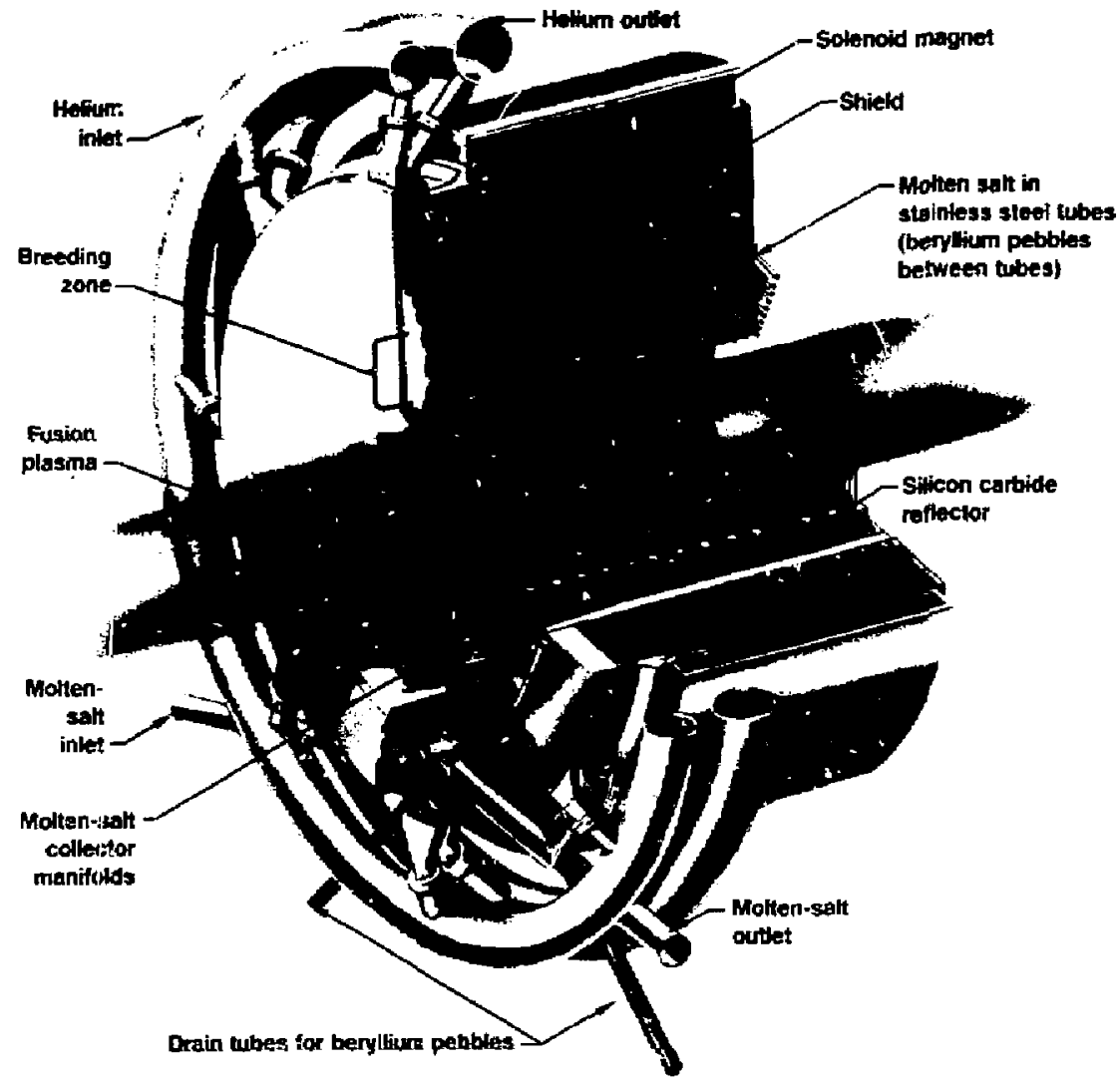

Figure 1. One module of a helium-cooled molten-salt blanket. Helium under 5-MPa firessure flows from the inlet ring header to the apex of each pod, then radially outward through the blanket to the outlet ring header, and thence to heat exchangers for generating electricity. The revenue from the sale of the electricity can be used to reduce the cost of the fissile material prociuced. Being a nonconductor, helium can flow unimpeded through the strong magnetic field generated in a magnetic fusion reactor. 


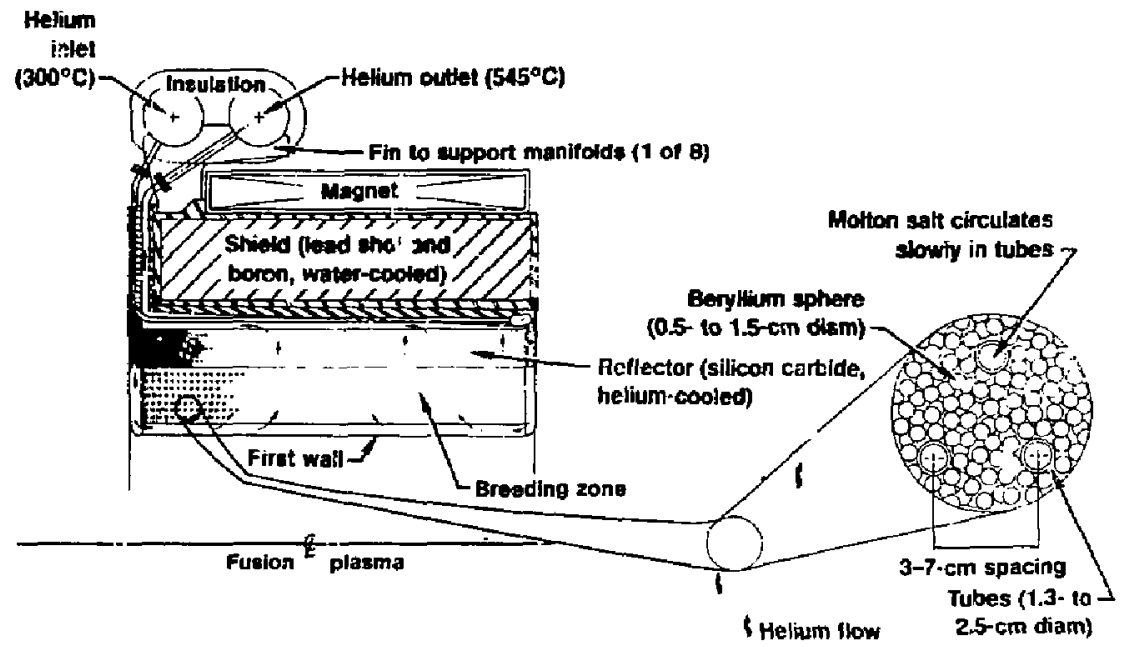

Figure 2. Cross section along the axis of one segment of a helium-cooled molten-salt blanket, showing details of the arrangement of the helium flow and the arrangement of beryllium spheres and tubing for the molten salts. 
and are recycled back to the reactor. Some parameters describing the blanket and the beryllium pebbles are given in Table III.

Table III. Beryllium requfrenents for the molten-salt blanket.

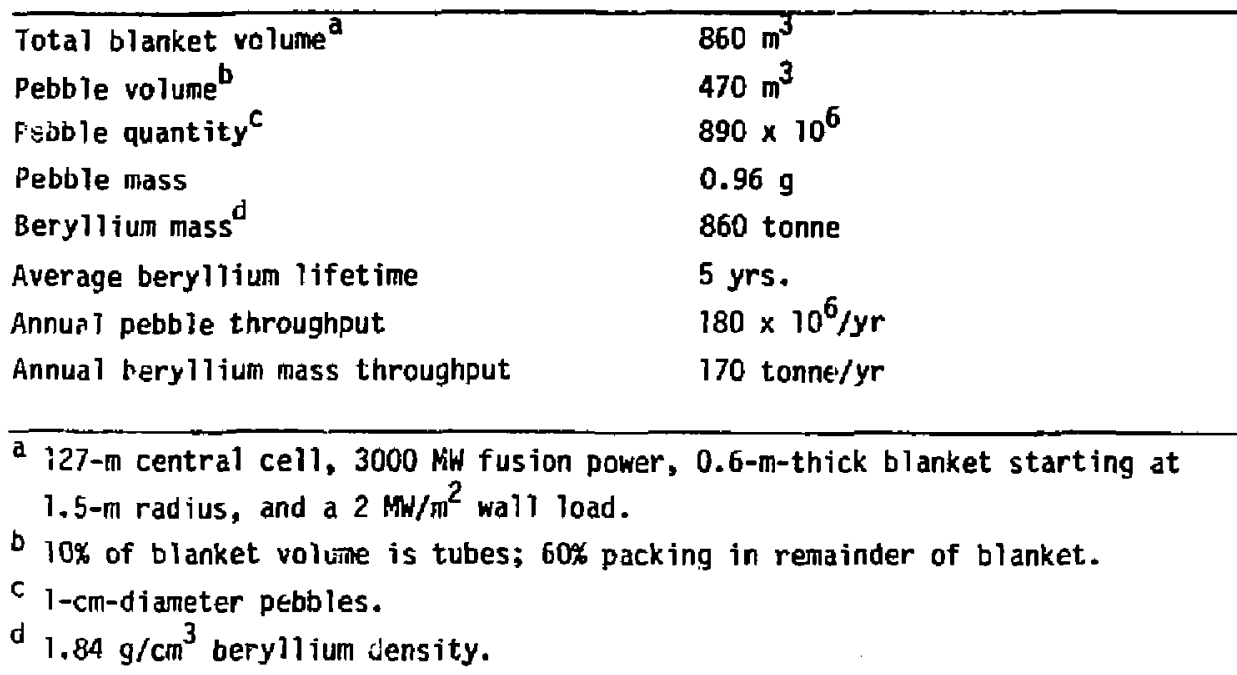

Each neuiron multiplication reaction in beryllium yields two neutrons and two alpha particles (helium nuclei). Most of these helium atoms remain trapped in the beryllium lattice, taking up space but not contributing to the bonding that holds the lattice together. The resulting stress that causes the beryllium spheres to expand would eventually break them apart if it were allowed to cont inue.

Because any break-up of the beryllium spheres would yield smaller particles that could plug the channels through which the helium flows and thus produce hot spots in the blanket, it is important to remove the beryllium spheres periodically before this can happen. We have verified experimentally that the spheres will flow freely, without bridging or blocking, if they are no larger than half the space between the tubes. To avoid any possible obstruction because of sweliing of the beryllium, we made the spheres $1 \mathrm{~cm}$ in diameter (one-third the distance between the tubes). Figure 3 depicts the arrangements for adding and removing beryllium spheres.

$$
-5-
$$




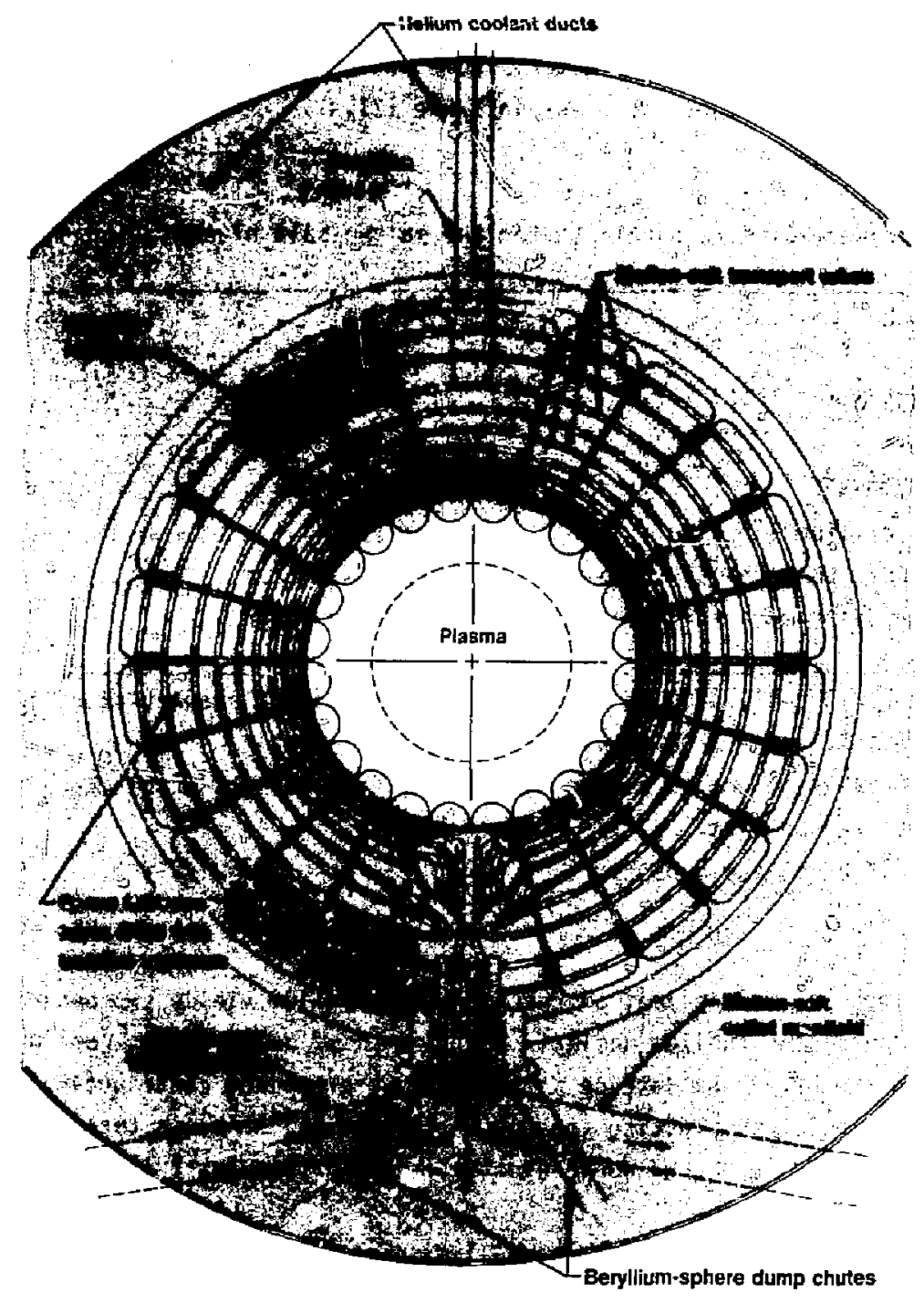

Figure 3. Cross section of the molten-salt breeding blanket. Neutron multiplication takes place in a bed of beryllium spheres. Breeding of tritium and uranium-233 takes place in the molten fluoride salts of lithium and thorium that are circulating in an array of steel tubes embedded in the beryliium spheres. The continuous flow permits continuous extraction of uranium-233 and tritium to minimize wasteful fission reactions. 
Because the fertile material is constantly circulating, it is possible in this design to use a continuous processing system to recover bred tritium and uranium-233 from the molten salts. He selected fluorination, which removes uranium-233 but leaves protoactinium and many of the fission products. 6 More complex processes that do remove fission products, suct, as reductive extraction and metal-transfer treatments, turn out to be unnecessary. 7 Continuous processing allows the amount of uranium-233 to be kept low to ininimize unwanted fission reactions.

In addition to its many advantages, this blanket design has a few disadvantages. One is that the flat side walls of each modnle are not made stiff enough to support the internal pressure of $5 \mathrm{MPa}$. Instead, they are made thin, each one being supported by the adjacent wall pressing in from the other side. This means that ali the modules are interdependent; none can be removed for service without depressurizing the entire system. Another consequence of this enornous pressure that forces adjacent module walls together is the possibility that they may self-weld after a time. If this happened, it would be impossible to remove one module without causing damage to the other. To prevent this, it may be necessary to insert thin ceramic spacers of alumina, for example, to keep the walls apart.

NUCLEONICS

Breeding performance is predicted with the aid of Monte Carlo transport codes (see Table IV). The modeling of the blanket takes into account the heterogeneous nature of the blanket, the effect of structural material and resonant self-shielding. The uncertainty, because of the combined effects of modeling nuclear data and methods, is guessed to be as high as $\pm 25 \%$ for $F_{\text {net }}$. Breeding is sensitive to the amount of structural material, mostly $\mathrm{Fe}, \mathrm{Cr}$, and $\mathrm{Ni}$. By increasing the steel structural fraction in the blanket irom 3\% to $5 \%$, the net breeding goes from 0.65 to 0.6$]$. Because of the low atom fraction of thorium and $6_{L i}$ in the blenket, parasitic neutron capture in structural material mandates low structural fraction blanket designs. Recent and ongoing work on the nuclear data on berylium suggest that the old data resulted in an overest imate of net breeding. An experiment underway at the Idaho National Engineering Laboratory using the manganese bath method to measure neutron multiplication and an experiment recently completed at LLNL, should reduce this uncertainty substantially. 
Table IV. Calculated breeding performance.

\begin{tabular}{ll}
\hline$T$ & $1.0^{\mathrm{a}}$ \\
$F_{\text {net }}$ & $0.6^{\mathrm{a}}$ \\
$E(M e V)$ & 22.4 \\
$M(E / 14)$ & 1.6
\end{tabular}

$a_{\text {Atoms }}$ bred per triton consumed.

THERMAL HYDRAULICS.

The amount of heat generated in the salt, in the tube walls, and in the beryllium is calculated by neutron and gamma-ray transport codes at several radial locations. Heat-transfer coefficients are estimated for tubes with roughened surfaces in a pebble bed, based on separate data from close-packed tubes (cross flow) and from pebble beds $\left(h=0.2 \mathrm{~W} / \mathrm{cm}^{2} \mathrm{C}\right.$ ). Then the temperature of the sait-steel interface of the tubes is calculated (see Fig. 4). The inlet helium temperature is $300^{\circ} \mathrm{C}$ and the outlet is $545^{\circ} \mathrm{C}$. The calculated maximum steel temperature is only slightly over $550^{\circ} \mathrm{C}$. The concern over temperature variations around each tube and thus hot spots is largely alleviated by the averaging effect of the flowing salt. The salt is force-circulated at about $0.1 \mathrm{~ms}^{-1}$ and internally convects at a similar speed because of gravity and a density gradient caused by the temperature gradient in the sait. He have considered the pros and cons of having a frozen salt layer on the inside of the tube (i.e., tube temperature kept below the salt freezing point) and generally favor the no-frozen layer case. We recommend heat-transfer measurements be carried out in a pebble bed with pipes and helium crossflow to reduce the uncertainty in predicting temperatures at various places.

A start-up scenario was devised for situations where the inlet helium temperature $\left(300^{\circ} \mathrm{C}\right)$ is substantially below the melting temperature of the salt $\left(530^{\circ} \mathrm{C}\right)$. Before the fusion reactions are turned on, the helium is circulated through the blanket after going through a preheater, thus raising the entire blanket to the $545^{\circ} \mathrm{C}$ inlet temperature, which is identical to the operating outlet temperature. Preheated molten salt is then introduced into the 


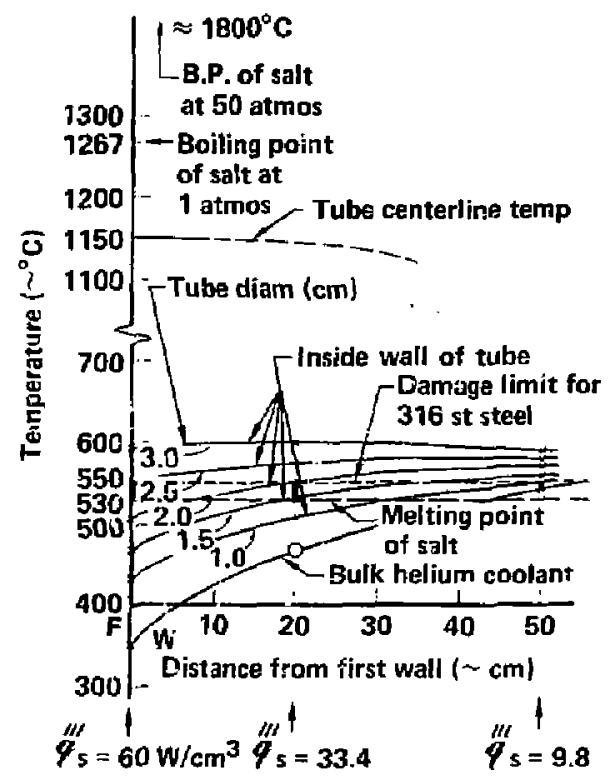

Figure 4. Helium coolant and temperature of salt tube as a function of position in blanket $\left(\Gamma=2.0 \mathrm{MH} / \mathrm{m}^{2}\right.$ at first wall. 
blanket. As the fusion reaction rate is brought up, the heliun circulation rate is adjusted and the preheater turned down. Figure 5 shaws the start-up conditions. Shutdown is accomplished by draining the salt and reducing the helium circulation rate. Freeze-up is easily prevented by the 5alt's heat capacity and residual nuclear decay heat. The salt drain tanks are cooled by heat pipes; thus, the emergency cooling is accomplished entirely by passive means.

\section{MATERIALS SELECTION AND PROPERTIES}

From a neutronics point of view, we would like to maximize the ThF 4 concentration: however, higher $\mathrm{ThF}_{4}$ concentrations rajses the melting temperature. The molten-:a1t reactor experimental work used $12 \%$ molar $\mathrm{ThF}_{4}$. We considered using $27 \% \mathrm{ThF}_{4}$; however, the present design uses an intermediate composition of $18 \%$ which gives a melting point of $530^{\circ} \mathrm{C}$. Some properties of the salt are given in Table $V$.

We chose austenitic steel for this design. The maximum operating temperature is $550^{\circ} \mathrm{C}$, arbitrarily chosen to avoid excess he lium embritt lement. The lifetime is $100 \mathrm{dpa}$ (about $8 \mathrm{MW} \cdot \mathrm{yr} / \mathrm{m}^{2}$ or $5.7 \mathrm{yr}$ at $2 \mathrm{MW} / \mathrm{m}^{2}$ and $70 \%$ availability), after which time runaway swelling is predicted. There is no minimum temperature, as there is no ductile-bri+tle transition above room temperature. Also, no special heat treatment of welds is necessary.

Corrosion of steel is governed by reaction of the chromium of the steel with the salt and is limited by the oxidation potential of the salt and the solid state diffusion of chromium in the steel. Experiments show that for $3: 6$ type stee 1 and U UF $_{4}: \mathrm{UF}_{3}$ ratio of 10 in the salt which is a reducing 5 tate, the corrosion will only be $2 \mu \mathrm{m} / \mathrm{yr}$. Steel with less chromium will corrode at a slower rate.

On the basis both of acceptable mechanical properties $10110 w i n g$ high-fluence neutron exposures and of acceptable corrosion resistance, we expect the use of 316 steel in contact with uranium-fluoride salts under controlled oxidation conditions to be feasible. 


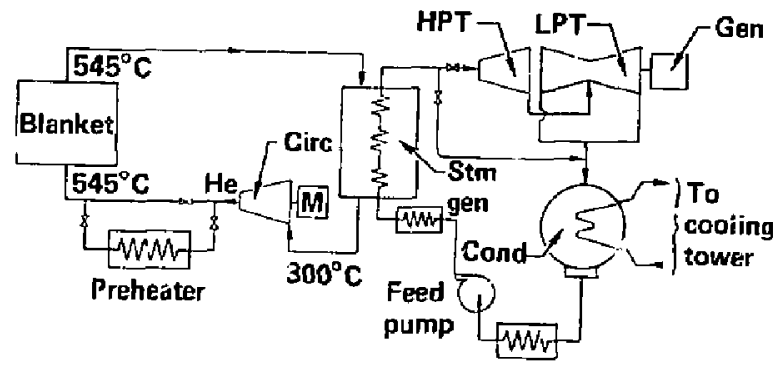

Figure 5. Start-up scenario. 
Tabie V. Composition and properties of blanket salt.

\begin{tabular}{|c|c|c|c|}
\hline Composition (mole $x_{0}$ ): & & . & \\
\hline Lif & 72 & 70 & 71 \\
\hline $\mathrm{BeF}_{2}$ & 16 & 12 & 2 \\
\hline $\operatorname{ThF}_{4}$ & 12 & 18 & 27 \\
\hline Liquidus $\left({ }^{\circ} \mathrm{C}\right)$ & 500 & 530 & 565 \\
\hline \multicolumn{4}{|l|}{ Properties at $600^{\circ} \mathrm{C}$ : } \\
\hline Density $\left(y / c r^{3}\right)$ & 3.35 & 3.87 & 4.52 \\
\hline \multicolumn{4}{|l|}{ Liq. heat capacity } \\
\hline$\left(\mathrm{cal} / \mathrm{g}^{\circ} \mathrm{C}\right)$ & 0.33 & & 0.23 \\
\hline Viscosity (centipoise) & 12 & & $15-25$ \\
\hline Vapor pressure (torr) & $<0.1$ & & - \\
\hline \multicolumn{4}{|l|}{ Thermal conductivity } \\
\hline$\left(w /{ }^{\circ} \mathrm{C} \mathrm{cm}\right)$ & 0.011 & & 0.007 \\
\hline \multicolumn{4}{|l|}{ Heat of fusion } \\
\hline$\langle\mathrm{cal} / g\rangle$ & 63 & & 54 \\
\hline \multicolumn{4}{|l|}{ Elec. conductivity } \\
\hline$(\Omega-\mathrm{cm})$ & 2.12 & & - \\
\hline \multicolumn{4}{|l|}{ Expansion on melting } \\
\hline (voly) & & & 25 \\
\hline
\end{tabular}


A study of tritium permeation and recovery from molten salt for the fusion breeder is reported in Ref. 8. This study assumes tritium to be a gas dissolved in molten salt, with TF formation suppressed. Tritium permeates readily through the hot steel tubes of the reactor and steam generator and will leak into the steam system at the rate of about $1 \mathrm{~g} /$ day in the absence of special permeation barriers, assuming that $1 \%$ of the helium coolant flow rate is processed for tritium recovery at $90 \%$ efficiency per pass. Tritiated water in the steam system is a personnel hazard at concentration levels well below $1 \mathrm{ppm}$ and this level would soon be reached without costly isotopic processing. Alternatively, including a combination of permeation barriers on reactor and steam generator tubes and moiten salt, we estimate that processing will reduce the leak rate into the steam system by over two orders of magnitude. For the option with the lowest estimated leak rate, $55 \mathrm{ci} / \mathrm{d}$, it may be possible to purge the steam system continuously to prevent tritiated water bui?dup. At best, isotopic separation of dilute tritiated water may not be necessary and for higher leak-rate options the isotopic processing rate can be reduced.

The proposed permeation barrier for the reactor tubes is a 10-um layer of tungsten which, in principle, will reduce tritium permeation by a factor of about 300 below the bare-steel rate. The 10- $\mu \mathrm{m}$ tungsten barrier on the inside of the tubes is made by chemical vapor deposition (CVD). The reaction $\mathrm{WF}_{6}+3 \mathrm{H}_{2} \rightarrow \mathrm{W}+6 \mathrm{HF}$ proceeds when the temperature is raised to the range of 400 to $600^{\circ} \mathrm{C}$. The amount of material is 50 smal $\left.165,000 \mathrm{lbs}\right)$ that the material cost (\$4M) is not important. Stainless steel will require a coating such as nickel to obtain a good bond. The techniques will require further development; however, there is quite a lot of industrial practice in CVD upon which to base this deveiopment. A relatively thick $1-m$ aluminum sleeve was selected to suppress permeation through the steam generator tubes. This gave a calculated reduction of more than a factor of 500 relative to bare steel, including a factor of 30 because of an assumed oxide layer. This is essentially a brute-force approach that may well be improved upon by the development of more sophisticated permeation barriers.

To gain a better understanding of permeation effects, we derived equations describing steady-state tritium permeation for a multilayer tube wall within the blanket region. A layer of frozen salt is included, along 
with fluid boundary-layer resistances. Calculations of the partial-pressure distribution show significant differences for tubes irradiated at different power densities. Molten-salt boundary-layer resistance can be important in the absence of a good permeation barrier or for a low-power tube coated with a

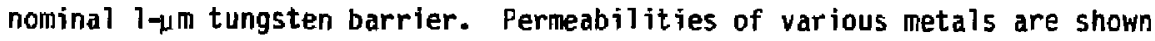
in Fig. 6. This nominal permeation barrier will dominate the flow resistance, however, for medium or high power density tubes closer to the first wat 1. Examination of the radial flux equation shows a complicated dependence on upstreim partial pressure, which reduces to a linear dependence at low pressures where Henry's Law materiais become flux limiters and a square-root dependence at high tritium partial pressures where Sievert's Law materials are flux limiting.

An analytical model was developed to establish the tritium split between wall permeation and reactor-tube flow. Permeation barriers are shown in Fig. 7. "The barriers are shown on the outside of the tuides but could equaily well be on the inside. For the molten-salt tubes, the inside barrier would greatly reduce the tritium inventory in the tube walls and further reduce the already low corrosion rate. The tritium fraction escaping through the tube walls was quantified for limiting cases of Henry's Law and Sievert's Law barriers as flux limiters. All parameters of design interest are explicitiy included: tritium generation rates and solubility in salt, tube geometry, barrier permeation parameters, and molten-salt processing rate and recovery efficiency.

The tritium-recovery system flow sheet is shown in Fig. 8. Because of the low solubility of tritium in the reducing salt, a simple flash separator will allow removal of the tritium and other noncondensible gases, mainly helium. Tritium removal from helium is virtually a standard system. The bulk of the tritium is recovered as a hydride on a getter bed, with final cleanup accomplished by catalyzed oxidation and adsorption. The molten-salt system pressure ( $49 \mathrm{~atm})$ is kept just below the helitum pressure (50 atm). The flash separator will operate at below 1 atmosphere pressure. The molten-salt pump must raise the pressure back up to $49 \mathrm{~atm}$. The pumping system needs more design work. 


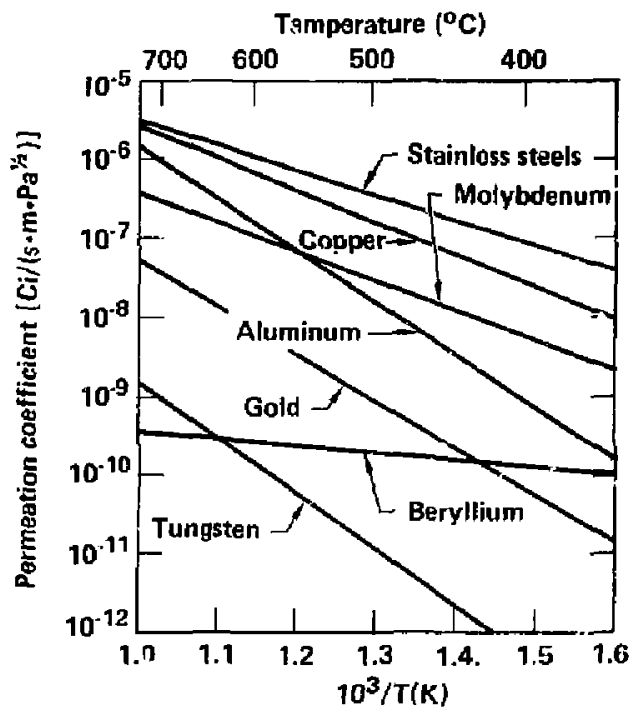

Figure 6. Permeability of various metals to tritium. 


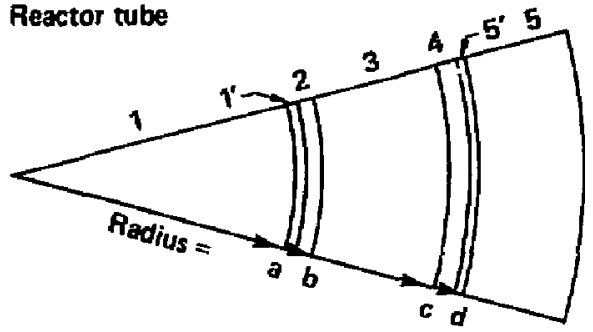

1 Molten salt

1 Molten salt boundary layer

2 Frozen salt

3 Stainless steel tube

4 Permeation barriar (tungsten)

$5^{+}$Helium gas boundary layer

5 Helium gas
Steam generator tube

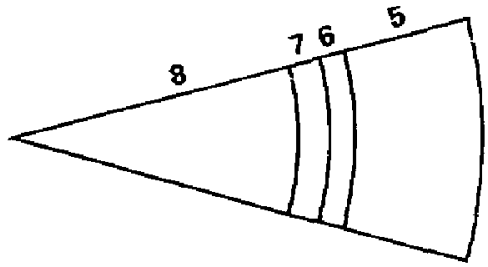

5 Helium gas

6 Permeation barrier (aluminum)

7 Stainless steel tube

8 Water/steam

Figure 7. Permeation geometry and materials. 


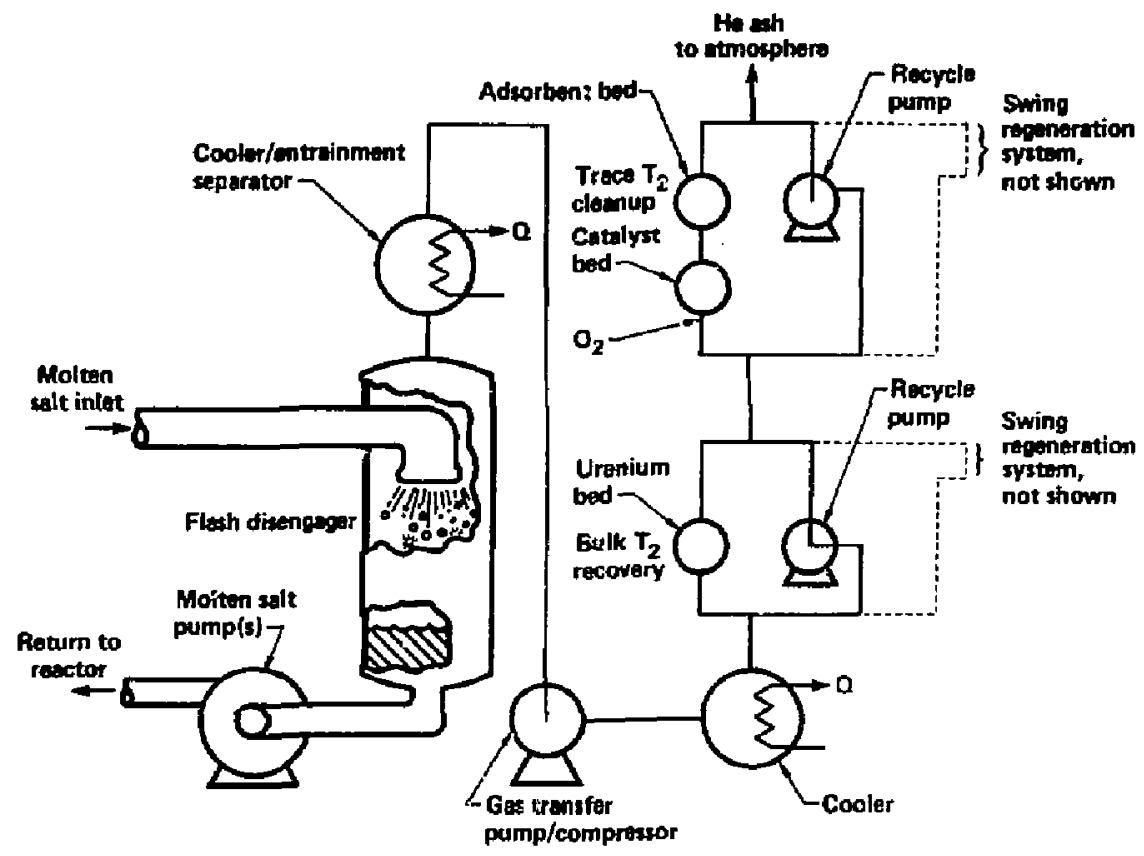

Figure 8. Tritium-recovery system flow sheet. 
Finally, some definitive experimental work on the kinetics of tritium-gas conversion to tritiated water at low concentrations in helium is called for. Popular opinion has oscillated over the last decade from an initial optimism that thermodynamics would reduce the gas concentration to $n i$, ' to a current pessimism that predicts no gas conversion at all in the main helium loop. The critical experiments remein to be done, both with "clean" walls and particulate-free helium and in the presence of catalytic surfaces or other reaction promoters. The challenge is to demonstrate a method of drastically reducing tritium-gas partial pressure in the intermediate heTium loop, and thus suppress permeation into the steam system.

The intermediate helium heat transfer loop has been treated as a wel1mixed tank for analytical purposes, with tritium input from the molten salt tubes, with partial tritium recovery in a 51 ipstream process loop, and with Sievert's Law tritium-permeation loss to the steam system.

A combination of effective tritium permeation barriers is required on both blanket and steam-generator tubes. Together with substantial process rates for molten salt and helium systems, the barriers hold tritium permeation into the steari system to $55 \mathrm{Ci} / \mathrm{d}$. If this can be done, it may be feasible to simply purge the steam system of incoming tritium with only minor environmental impact and personnel hazard from steam leaks and without the costiy and hazardous isotopic processing to separate tritiated and ordinary water.

Although we have focused attention on a tungsten barrier because of $i$ is remarkably low tritium permeability, we should also consider beryllium and other low-permeability materials such as ceramics and cermets in barrier development. Other materials or alloys may prove to be superior to tungsten, but probably at the price of greater thickness of coating.

The diffusivity of tritium gas dissolved in malten salt will need to be measured, especially to verify whether or not the fluid boundary-layer barrier is realistic.

\section{BERYLLIUM-PEBBLE FABRICATION}

Each beryllium pebble is a solid sphere of $1 \mathrm{~cm}$ nominal diameter and weighing $0.96 \mathrm{~g}$. A nominal mass of 900 tonnes requires about $900 \mathrm{million}$ pebbles for the initial inventory. See Table III for sumary of beryllium 
parameters.. For an assumed average pebble lifetime of two calendar years, the annual throughput of the hot beryllium fabrication plant will be $180 \times 10^{6}$ pebbles/yr or 180 tonnes/yr. However, with efficient recycie, the actual beryllium requirement associated with beryllium pebble remanufacture might be 1 to $10 x$, or 2 to 20 tonne/yr.

The selected pebble fabrication process involves the development of an automated li:ie that will cold press pebbles, vacuun sinter them, hot forge them to full density, and vacuum anneal them. To automate this process, a free flowing beryllium powder is required.

Equipment for production of spherical beryllium is simple: mechanical presses and powder feeders to make cold pressed compacts, automated vacuum sintering furnaces ior pressureless sintering, mechanical presses for hot sizing the sintered compacts, and an automated vacuum furnace for annealing the forged compact. ${ }^{9}$

For fabrication of pebbles too damaged to reinsert into the blanket after an irradiation period, we would vacuum melt the hot pebbles and use an automated atomization irocess (modeled after the Brush Wellman process) to first remanufacture the bery 117 um powder prior to the cold-press step. We do not exclude the possibility of removing the helium gas by vacuum heating, which would result in about $30 \%$ volumetric swelling. These en larged pebbles might then be pressed back into size possibly by pressure-less sintering. The entire process will require provision for shielding and remote maintenance. In addition, hooding requirements as per OSHA limits $\left(2 \mu \mathrm{g} / \mathrm{m}^{3}\right)$ must be maintained to 1 imit airborne contamination.

Given a conservative two-year beryllium lifetime, ${ }^{2,8}$ assuming an autcmated plant that operates $24 \mathrm{hr} / \mathrm{da}, 7 \mathrm{da} / \mathrm{wk}$, and operates $85 \%$ of the time with no rejects, the production rate must be 110 balls per minute. W'ile this is a high production rate for beryllium parts, it is low for some powder metal industries (e.g., tantalum capacitor manufacturers produce thousands of parts/minute). The beryilium reprocessing line is estimated to lose 7 to $10 \%$ of the beryliium throughput, so a small feedstream is required. With a free-flowing powier, the losses might be reduced below $1 \%$.

Preliminary cost estimates for the beryllium fabrication-process required to provide beryllium pebbles for the reference tandem mirror fusian breeder ${ }^{9}$ were developed during 1982. These cost estimates were adapted to the present case and an annuat cost estimate for various assumption was made (see Fig. 9). 


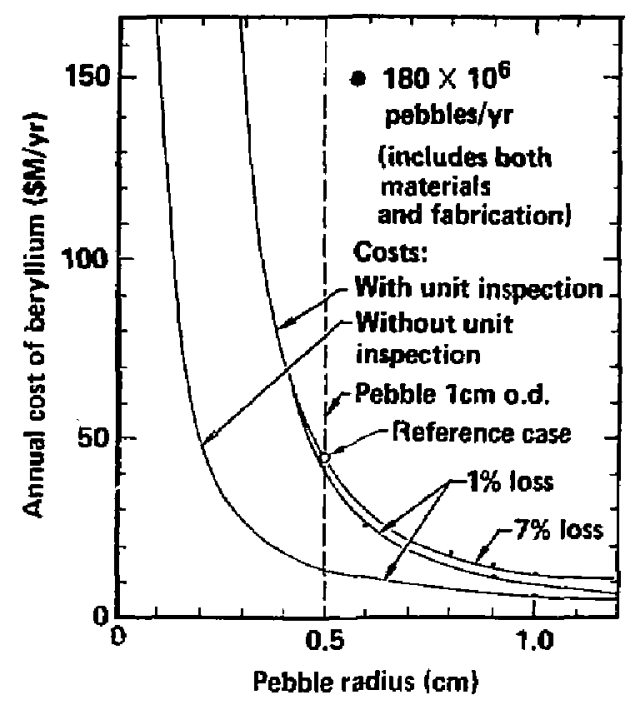

Figure 9. Cost of beryllium pebbles.

The only special equipment needed for the process line is the air handing system for containing the berylitum powder. The die life should be comparable to other powder metallurgy products $(500,000$ to $1,000,000$ parts/die with punches redressed every 2500,000 parts). Production of a free-flowing beryllium powder suitable for automated operations requires further development. This might be achieved by a new powder manufacturing technique at Brush Wellman (spherical powder) or the use of binders that can be totally removed during a bake-out prior to sintering. Development of a pressing technique to produce a uniform dense sphere that can be pressure-less sintered to 90 to $95 \%$ of theoretical density is also required. The pressed sphere must be strong enough to permit automated handing. We may need to develop an efficient inspection/test capability if an adequate process reliability cannot be achieved. The technology for remoting the fabrication process is expected to be straightforward, but further study is required. 
We have selected the fluorination process to remove ${ }^{233} \mathrm{U}$ from the salt 51 in stream. We find it unnecessary to use the more complex reductive extraction of fission products. Molten salt reprocessing applied to the fusion breeder is well discussed in Ref, 8 , therefore, we will simply add a few thoughts here.

A study ${ }^{9}$ of three levels of molten salt reprocessing has been carried out recently. The simplest level is fluorination only, which removes $233_{\mathrm{U}}$ but not protactinium or many fission products. The next level is both fluorination and reductive extraction in which both uranium and proctactinum are removed along with small amounts of fission products. The final level is the addition metal transfer treatment which removes most of the rare earth fission products.

Employing the second and third levels of reprocessing was found to have negligible effect on breeding rates and decay afterheat, except at months after reactor shut down. Therefore, our choice of employing fluorination only has been reaffirmed.

HEAT TRANSPORT AND BALANCE OF PLANT

The general arrangement or Key Plan of the plant, shown in Fig. 10, takes advantage of the linear nature of the tandem mirror. One side of the reactor building is open for rapid construction access, and the other side contains al1 the process and energy conversion facilities. The Key Plan emphasizes the arrangement of the Fusion Island buildings, which consist of reactor building, steam-generator building, molten-salt processing building, tritium pracessing building, and hot cell.

A separated construction approach is adopted where the safety-related Fusion Island buildings are built to "safety" standards and all others to comercial standards. However, in view of the unique safety features of fusion, it is proposed that new "safety" standards be developed for the fusion breeder. These safety standards need not be as stringent as the nuclear standards for fission-plant nuclear-island buildings. 


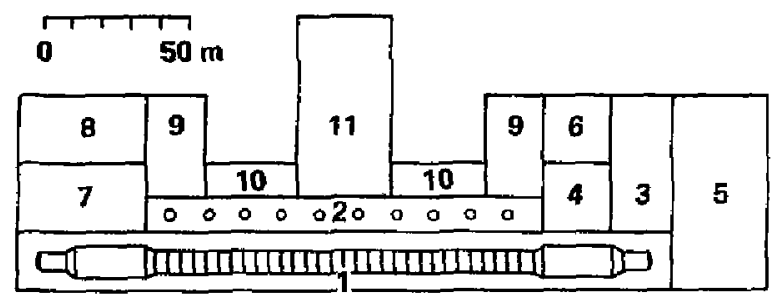

Figure 10. Diagram of plant arrangement: (1) Reactor building, (2) steam generator building, (3) tritium processing building, (4) molten salt processing building, (5) hot cel1, (6) radwaste building, (7) component cooling building, (8) plant auxiliary building, (9) power supply building, (10) cryogenics building, and (11) turbine building.

The blanket heat-transport system uses helium as the coolant and transport medium. The major parameters of this system are listed in Table VI, and piping and equipment arrangement are shown in Figs. 11 and 12. The entire central cell is divided into 30 modules and ten independent heat-transport loops remove heat from the blanket $\left(3,840 \mathrm{MN}_{t}\right.$ total). Each loop serves three central cell modules and consists of a steam generator and a helium circulator. The loops are not completely independent but rather must have an interconnect to equalize pressure in case one module depressurizes. The steam generators envisioned here are based upon design features similar to those currently proposed for small high-temperature gas-cooled reactors (HTGR). The features of these factory-assembled steam generators include steel pressure :essels, helical coiled water/steam tubes, and once-through steam generation (Fig. 13). Other est imated steam generator parameters include:

$\begin{array}{lccc} & \begin{array}{c}\text { Surface } \\ \text { area }\left(\mathrm{m}^{2}\right)\end{array} & \begin{array}{c}\text { Tube size } \\ (0.0 \mathrm{~mm})\end{array} & \begin{array}{c}\text { Tube-wall } \\ \text { thickness }(\mathrm{mm})\end{array} \\ \text { Economizer } & 2,315 & 25.4 & 4 \\ \text { Evaporator } & 1,810 & 25.4 & 4 \\ \text { Superheater } & 1,715 & 25.4 & 5\end{array}$


Table VI, Heat-transport system of blanket.

\begin{tabular}{|c|c|}
\hline Thermal power: & \\
\hline Total blanket & $3,840 M W_{t}$ \\
\hline Adcied by hel ium circulator & $110 \mathrm{MW}_{\mathrm{t}}$ \\
\hline 81anket modules (no.) & 30 \\
\hline Steam generators (no.) & 10 \\
\hline Helium circulators (no.) & 10 \\
\hline Thermal power of each steam generator & $395 \mathrm{MH}_{\mathrm{t}}$ \\
\hline Hel ium temperature: & \\
\hline Blanket outlet/steam-generator inlet & $545^{\circ} \mathrm{C}$ \\
\hline Blanket inlet/helium-c, irculator outlet & $300^{\circ} \mathrm{C}$ \\
\hline Steam generator outlet/hel ium-circulator inlet & $293^{\circ} \mathrm{C}$ \\
\hline Heliur. pressure: & \\
\hline At circulator outlet & $5,000 \mathrm{kPa}$ \\
\hline At circulator inlet & $4,875 \mathrm{kPa}$ \\
\hline Helium pressure drop: & \\
\hline Blanket & $55 \mathrm{kPa}$ \\
\hline Steam generator & $50 \mathrm{kPa}$ \\
\hline Piping & $20 \mathrm{kPa}$ \\
\hline Total & $125 \mathrm{kPa}$ \\
\hline Helium pumping power: & \\
\hline Total & $110 \mathrm{MH}_{\mathrm{e}}$ \\
\hline Per circulator & $\begin{array}{c}11 \mathrm{MW} \\
(15,000-h p \text { motor })\end{array}$ \\
\hline Helium flow rate: & \\
\hline Total & $3,000 \mathrm{~kg} / \mathrm{s}$ \\
\hline Per module & $100 \mathrm{~kg} / \mathrm{s}$ \\
\hline Per circulator & $300 \mathrm{~kg} / \mathrm{s}$ \\
\hline Steam-out let temperature & $510^{\circ} \mathrm{C}$ \\
\hline Steam-out let pressure & $16.9 \mathrm{MPa}$ \\
\hline Feedwater-inlet temperature & $193.3^{\circ} \mathrm{C}$ \\
\hline Feedwater-inlet pressure & $19.0 \mathrm{MPa}$ \\
\hline Steam $f$ low rate/steam generator & $159 \mathrm{~kg} / \mathrm{s}$ \\
\hline
\end{tabular}




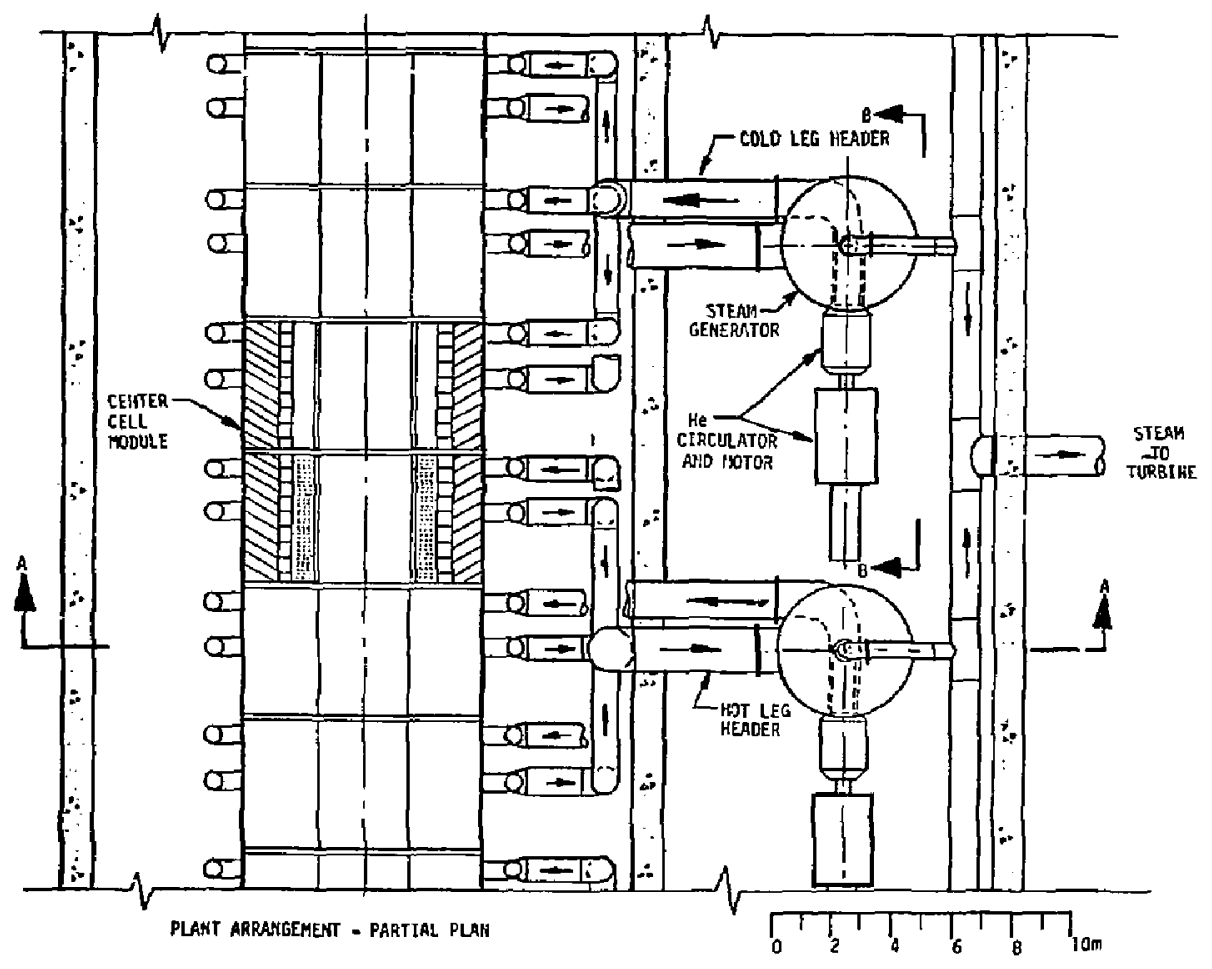

Figure 11. Heat transport system, showing piping and equipment arrangement (overhead view). 


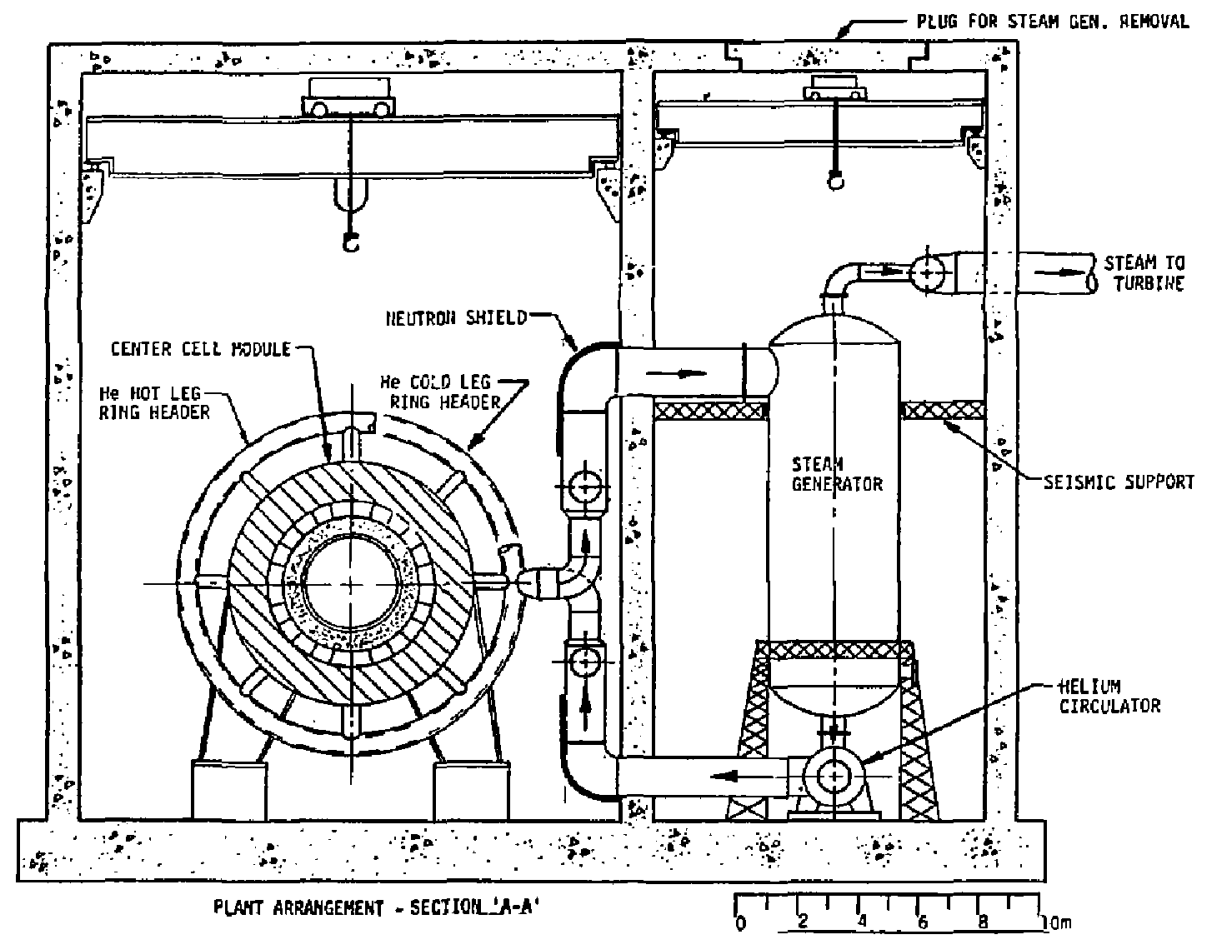

Figure 12. Heat transport system, showing piping and equipment arrangement (side view). 
(a)

$25.4 \mathrm{~mm}$
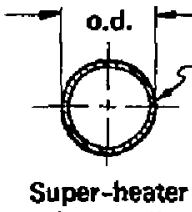
tube detail

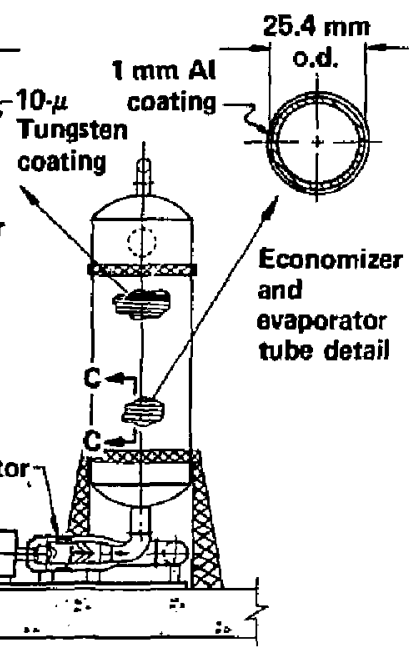

(b)

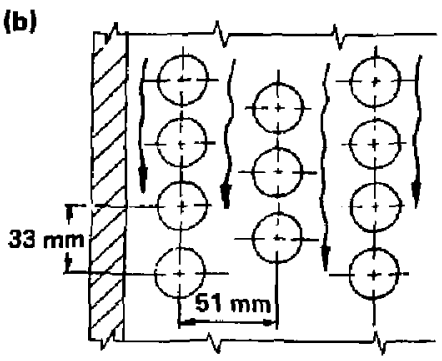

Tube spacing dete:I 'C.C'

(c)

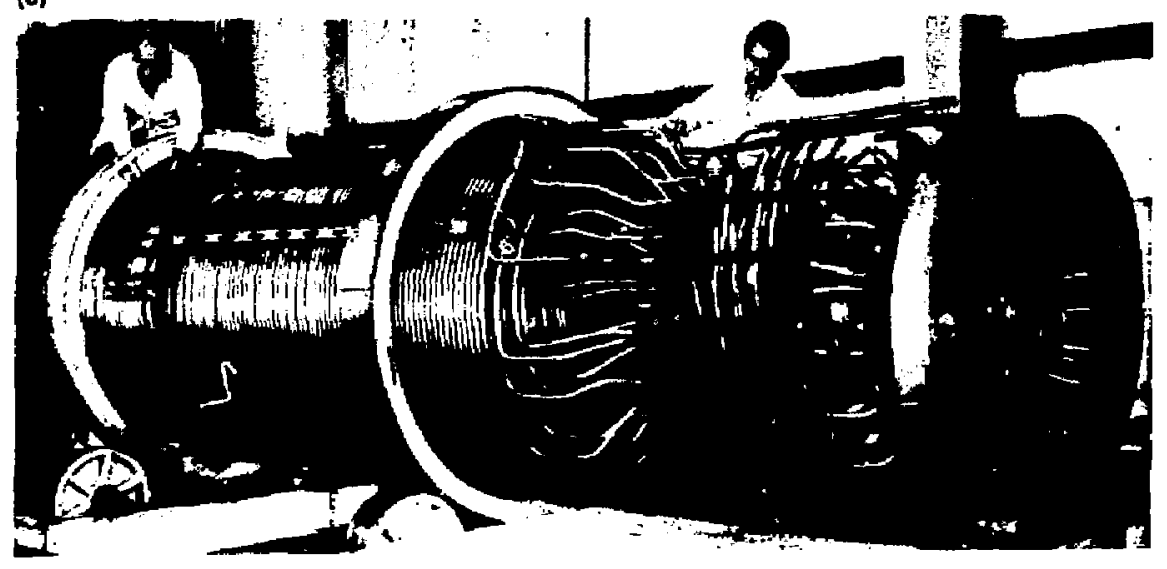

Figure 13. Steam generator arrangement. (a) Section 'B-B', (b) Typical tube sparing detail, (c) Fort Sait Vrain steam generator. 
To keep the wall thickness of the steam-generator vessel low, the helium flow path may be arranged so that the cooled helium $\left(293^{\circ} \mathrm{C}\right)$ from the economizer section exhaust is in contact with the wall. Helium piping in a heiium-cooled system is a very important element because of its cost and its impact on building sizes (thermal expansion requirement) and pumping power. Because of low density of helium, large size pipes are required. In this study the largest pipe size is 1 imited to $1.5-\mathrm{m}$ 0.d. To keep the wall thickness low, internal insulation is used.

Steam power-cycle parameters, listed in Table VI, are primarily based upon helium temperature and state-of-the-art steam generator technology and its cost. Without the benefits of a cost tradeoff, we assume a reasonable temperature difference $(\Delta T)$ between helium and steam and a reasanable pinch point (lowest $T$ ) at the economizer/evaporator interface. Standard steam conditions $\left(169.9 \mathrm{MPa}, 510^{\circ} \mathrm{C}\right)$ consistent with the current turbine-generator practice are used. Tritium permeation through steam-generator tubes is a major safety and economics concern. Two potential permeation barriers have been identified--tungsten and aluminum. When steam-generator tube surfaces are coated with either $10 \mathrm{~m}$ of tungsten or $1 \mathrm{~mm}$ of aluminum, the desired resistance to permeation is obtained. Aluminum coating on the inside surfaces is in contact with steam and may cause corrosion, while tungsten coating on the inside surfaces may exfoliate and cause damage to the turbine blades. Tungsten coating on the outside surfaces also may exfoliate and cause damage to the helium circulator impeller. Aluminum coating on the outside surfaces is not suitable in the hottest (superheater) section of the steam generator, where aluminum in contact with the hot helium $\left(545^{\circ}\right)$ is too malleable. In general, aluminum with a much higher coefficient of thermal expansion than steel may tend to separate from the steel tubes, greatly reducing the heattransfer coefficient. Use of alonized steel (surface alloy of aluminum on steel base) may alleviate these problems; however, its permeation-resistive characteristics are not known. I aruition to these potential problems, suitable methods of achieving the appropriate coating (uniform and reliable) are not available. Thus, much work, both theoretical and experimenta], is needed to develop suitable permeation barriers. 


\section{INTEGRATED PERFORYANCE AND ECONOMICS}

The overa1l performance and cost of the molten-salt fusion-breeder reactor are estimated and are combined with sfmilar data for ${ }^{233} \mathrm{U}$-burning LWR fission reactors to estimate the costs of electricity and bred fuel for a symbiotic electricity-generation system consisting of the fusion breeder, its LWR clients, and the associated fuel-cycle facilities. The performance parameters used to describe the molten-salt fusion breeder are given in Table 1 .

The results of the economics amalysis for two cases are given in Table VII: utility owned and government owned. The rationale for government awnership is the precedent set by government ownership of isotope-enrichment plants (diffusion and centrifuge plants); and since the fusion breeder in effect replaces an enrichment plant, it may be treated the same. The alternate may be for a consortium of utilities to own fusion breeders in order to have fuel-supply assurance.

Table VII. Economic analys is.

\begin{tabular}{|c|c|c|}
\hline Cost analysis ${ }^{\mathrm{a}}$ & $\begin{array}{l}\text { Utjlity } \\
\text { financed }\end{array}$ & $\begin{array}{l}\text { Gnvernment } \\
\text { financed }\end{array}$ \\
\hline Total plant capital cost (\$M) & 4867 & 4867 \\
\hline Breeder/LWR cost ratio & 2.35 & 2.35 \\
\hline Total fixed-charge rate $(\phi / y r)$ & 15.05 & 9.05 \\
\hline Effective breeder/LWR cost ratio & 2.35 & 1.41 \\
\hline Year-one cost of elec. $\left(m i 1 / \mathrm{kW}_{\mathrm{e}} \mathrm{e}^{-h}\right)$ & 50.8 & 46.9 \\
\hline Avg. PV cost of elec. $\left(\mathrm{mil} / \mathrm{kW} \mathrm{e}^{-h)}\right.$ & 31.0 & 28.9 \\
\hline Year-one cost of ${ }^{233} \mathrm{U}(\mathrm{\$} / \mathrm{g})$ & 72.5 & 29.2 \\
\hline Avg. PV cost of $233 u(\$ / g)$ & 38.6 & 15.6 \\
\hline
\end{tabular}


The difference in our araiysis is the capital charge rate appropriate. to the two cases, $9 \%$ and $15 \%$. Another assumption is that electricity prices over the 30-year plant lite are set by a fixed i.WR cost but by a fuel cost whose $\mathrm{U}_{3} \mathrm{O}_{8}$ component rises $2 \mathrm{~W} / \mathrm{yr}$ in real terms because of resource depletion.

The average present-value cost of fuel produced is $\$ 16 / 9$ if government, owned and $\$ 39 / 9$ if ut 11 ity owned. A price for ${ }^{233} \mathrm{U}$ of $\$ 39 / 9$ is equiva? ant to about $\$ 56 / \mathrm{kg}$ of $\mathrm{U}_{3}{ }^{0} \mathrm{~B}$. The fusion-breeder cost estimate of $\$ 4857 \mathrm{M}$ is 2.35 times an LWR cost and is based on a tandem mirror design prior to the more recent MARS ${ }^{5}$ (Mirror Advanced Reactor) design. Design improvements may lead to lower costs and substantially reduce the sales price of $233_{\mathrm{k}}$. The following conclusions result from modeling the potential economic performance of fusion breeders:

- The molten-salt fusion breeder could be economical at todaj's price of uranium $(55 \$ / \mathrm{kg})$ regardless of ownership.

- With government awnership, the molten-salt fusion breeder could break even in the first year of operation and produce a multi-billion dollar benefit over its operating lifetime.

- Bigger benefits accrue for the molten-sali fusion-breeder operation at higher breeding and/or higher blanket-energy multiplication and lower plant cost.

- A 20\% breeding decrase is clearly tolerable.

- Some issues yet to be addressed include the potential impacts of lower ihR SWU costs, iligher LWR fuel reprocessing costs, and $t l$ : 1ike.

TECHNICAL ISSUES

Iritium Management. Permeat ion barrier development and demonstration is the critical $R$ \& D need. Tritium will need to be removed from toth molten salt and helium loops. Recovering tritium from molten salt has yet to be demrastrated but should be manageable since the partial pressure is high. Process technology is known for recovering tritium from helium al though a lerge increase in scale witl be required. The key is to have good permeation barrieis on salt tutes and on steam generator tubes, thus easing requirements for both salt and heli'sm process systems; single-pass process efficiencies can be moderate, and only a smalt fraction of the circulating helium must be 
processed. Chemical vapor deposition of tungsten on steel needs development work. Failure to develop effective barriers shifts the burden of processing tritium into the steam/water system. Isotopic processing of tritiated water then becones a high priorijty $R \& D$ requirement. Isotope separation will be more difficult and costly, and the steam system must be kept leak-free : avoid personnel hazards from tritiated water vapor. A successful barrier development effort could avoid both the need for water processing and the hazards that accompany tritiated water systems.

Beryllium Feasibility. Beryllium-beryilium self-welding and beryllium-steel welding at the contact points are issues needing experimental iavestigation. This is the objective of a planned set of capsule tests at ORNL. The ability of the beryllium balls to stand up under neutron radiation is maximized by design (small size), however, irradiation data are needed. Beryllium swelling--leading to jambing, cracking, chipping, and flying missiles that might darnage circulars--needs investigation. Some of this can be done in fission reactors, for example, the tests carried out in EBR-II and the planned neutron radiation-induced creep tests.

Material Compatibility. We predict the stee (type 316) will have a long lifetime in contact with the salt if it is kept in a reducing state. Corrosion tests with molten salt in a flowing loop would prove the predicted compatibility. Irradiation tests in a fission reactor should be carried out. to verify the chemical compatibility of salt and steel.

Reprocessing. Removal of uranium by fluorination is fairly we1] understood but needs demonstrating on a reasonable scale. Removal of fission products is not needed from a point of view of neutron economy. From a safety point of view, removal of fission products is desirable but only partially effective. It entails salt/metal reduction, which must be scaled up from smajl batch tests to larger continuous processing and requires developing refractory metal piping. We do not believe this renoval processing is necessary. Therefore, development and demonstration of a cont inuous fluorinator is the only imporiant reprocessing $R \& D$ need. 
Meutron Economy. The breeding performance of the moiten-sait design is very sensitive to parasitic absorption in structural material (principally iron, chromium, and nicke1). This is due to the low concentration of thorium in the salt (only $7 x$ of the salt atoms are thorium). It is necessary to make better calculations of the nuclear performance and to emphasize designs that minimize structural material. Alternatives to steel should be considered. Finally, experimental verification of tritium and fissile breeding should be carried out with a point 14-meV neutron source.

CONCLUSION

The molten-salt fusion breeder design appears workable if the tritium containment and recovery of multiple distributed barrier: and two-stream processing works as predicted. We have identified a nutaber of $R \& D$ items that should be studied to increase aur confidence level. However, the feasibility of making tritium barriers should be given the top $R$ \& D priority. The breeding is $6400 \mathrm{~kg} /$ year of $233 \mathrm{U}$ at a cost of $\$ 40 / \mathrm{g}$ for plants costing 2.35 times an LWR if utility owned or $\$ 16 / 9$ if government owned and supports 14 LWRs of equal thermal power. The design was carried out for a tanden mirror but should work equally well for a tokamak. 


\section{REFERENCES}

1. L. M. L.idsky, "Fission Fusion Symbiosis: General Considerations and a Specific Example," Proc. Br. Nucl. Energy Soc. Nucl. Fus ion Reactor Conf. (Culham Laboratory, 1969), pp. 4 T-53,

2. V. L. Blinkin and V. M. Novikov, "Optimal Symbiotic Moltien-Salt Fission-Fusion System," IAE 2119, Kurchatov Inst itut, Mo:scow, USSR, 1977.

3. J. D. Lee, "The Beryllium/Holten Salt Blanket", Proc. Third US/USSR Symposium on Fusior -Fission, Princeton, MJ, 1979, and a 150 in Lawrence Livermore Nationai Laboratory, UCRL-82663 (1979); R. W. Moir et al., Tandem Mirror Hybrid Reactor Design Study, Lawrence Livermore National Laboratory, UC10-18808 (1980); also J. 0. Lee et al., Feasibility Study of a Fission-Suppressed Tandem-Mirror Hybrid Reactor, Lawrence Livermore National Laboratory, UCID-19327 (1982).

4. R. W. Moir et a1., Design of a Helium-Cooled Molten-Salt Fusion Breeder, Lawrence Livermore National Laboratory, UCRL-92024 (1985); Inyited paper for Am. Nucl. Sac. Meeting, San Francisco, CA, March 1985 (to be published in Fusion Technology).

5. B. G. Logan et a1., MARS-Mirror Advanced Reactor, Lawrence Livermore National Laboratory, UCRL-63480 (1984).

6. J. D. Lee et al., Feasibility Study of a Fission-Suppressed Tandem Mirror Hybrid Reactor, Lawrence Livermore Nationa Laboratory, UCID-19327 (1982), Section VIIB, "MoTten Salt Fuel Reprocessing" by Warren Grimes.

7. F. A. Patterson-Hine, J. W. Davidsan, and D. E. Klein, "Contributions to the Thermal Power of Continuousiy Processed TMHR Molten Salt Blankets," Proc. 10th Symp. Fusion Engineering, Philadelphia, PA, 1983, p 988.

8. A. W. Sherwood, Iritium Permeation and Recovery for the Hel ium.Cooled Molten-Salt Fusion Breeder, Lawrence Livermore National Laboratory, uCID-2014) (1984).

9. D. H. Berwald et al., Fission-Suppressed Hybrid Reactor - The Fusion Breeder, Lawrence Livermore National Laboratory, UCID-19638 (i S.82). 
In 1969, Lidsky proposed ${ }^{1-1}$ a fusion breeder design in which a $\mathbf{L}_{\mathrm{Li}}$ and a thorium-bearing molten salt $\left(\mathrm{LiF}+\mathrm{BeF}_{2}+\mathrm{ThF}_{4}\right)$ was circulated through the blanket so that the bred material could be continuously processed from a small slip stream. He enployed liquid $Z_{L i}$ as the neutron multiplier. The thorium-bearing salt was placed behind the neutron multiplier zone with a graphite region in between to slow down the neutrons, thus suppressing fast fission. The concentration of bred ${ }^{233} \mathrm{U}$ was kept low by continuous processing so that thermal fissioning was suppressed. The predicted local breeding ratio $(T+F)$ was 1.45 , where $(T+F)$ is defined as the number of tritons and fissile atoms produced per triton burned. The structural material was the molybednum alloy $T Z M$, and the cooling was both by liquid 1 ithium and by molten salt. More recent calculations ${ }^{1-2}$ gave a breeding ratio of 1.36 . Improvements to overcome the low breeding ratio and the complex and difficult-to-build design led us to the present design.

In 1977, B 1 irikin and Novikov ${ }^{1-3}$ suggested replacing the ${ }^{7} \mathrm{~L} i$ neutron multiplier with beryllium. This two-zone design gave a local breeding ratio of 1.63. In 1978, Lee $\mathrm{e}^{1-4}$ reported on a homogeneous one-zone design using beryilium in which the local breeding ratio was 2.2. A rather detailed study $^{i-5}$ in 1979 of this design verified the basic ideas and came up with a breeding ratio of 1.7 . The study uncovered problems with fabrication of TZM, radiation damage to the beryllium and to the graphite cladding of the beryllium, as well as other problems. In 1981, a design ${ }^{1-6}$ with steel was used to contain the molten salt. Here corrosion was predicted to be virtualiy eliminated by keeping the steel cool. However, $7_{L i}$ was used instead of berylium to reduce excess neutrons. This fact together with the two-zone design resulted in a breeding ratio of 1.5 , which was lower than desired.

DeVan in 1982 suggested using a barren salt $\left(\mathrm{LiF}+\mathrm{BeF}_{2}\right)$, at a higher pressure than the fertile salt between the beryllium and its cladding, so that small inevitable leaks would not aJ low molten salt to contact the beryllium. This would avoid letting uranium deposit out on the beryllium, which if it could happen would lead to hot spots. Lee later suggested using helium as the coolant with the thorium-containing salt in pipes. The particular helium-cooled pipe arrangement we are now considering is similar to the design of Cheng et al. 1-7. 
Corrosion is inhibited by maintaining the salt in a reducing state, where tritium is in the form of $T_{2}$ rather than $T F$, and the corrosion rate of stee 7 is low. The beryllium is in the form of small ( $\sim$ l-cm-diam) pebbles that are tolerant of radiation damage. All of these innovations, put together, eliminated the disadyantages found in the 1979 study.

The present sianket design is shown in Fig. 1-1. This design concept is promising in that it could produce a relatively low-technology, high-performing, yet economical fusion breeder, which is the subject of the following chapters of this report. 

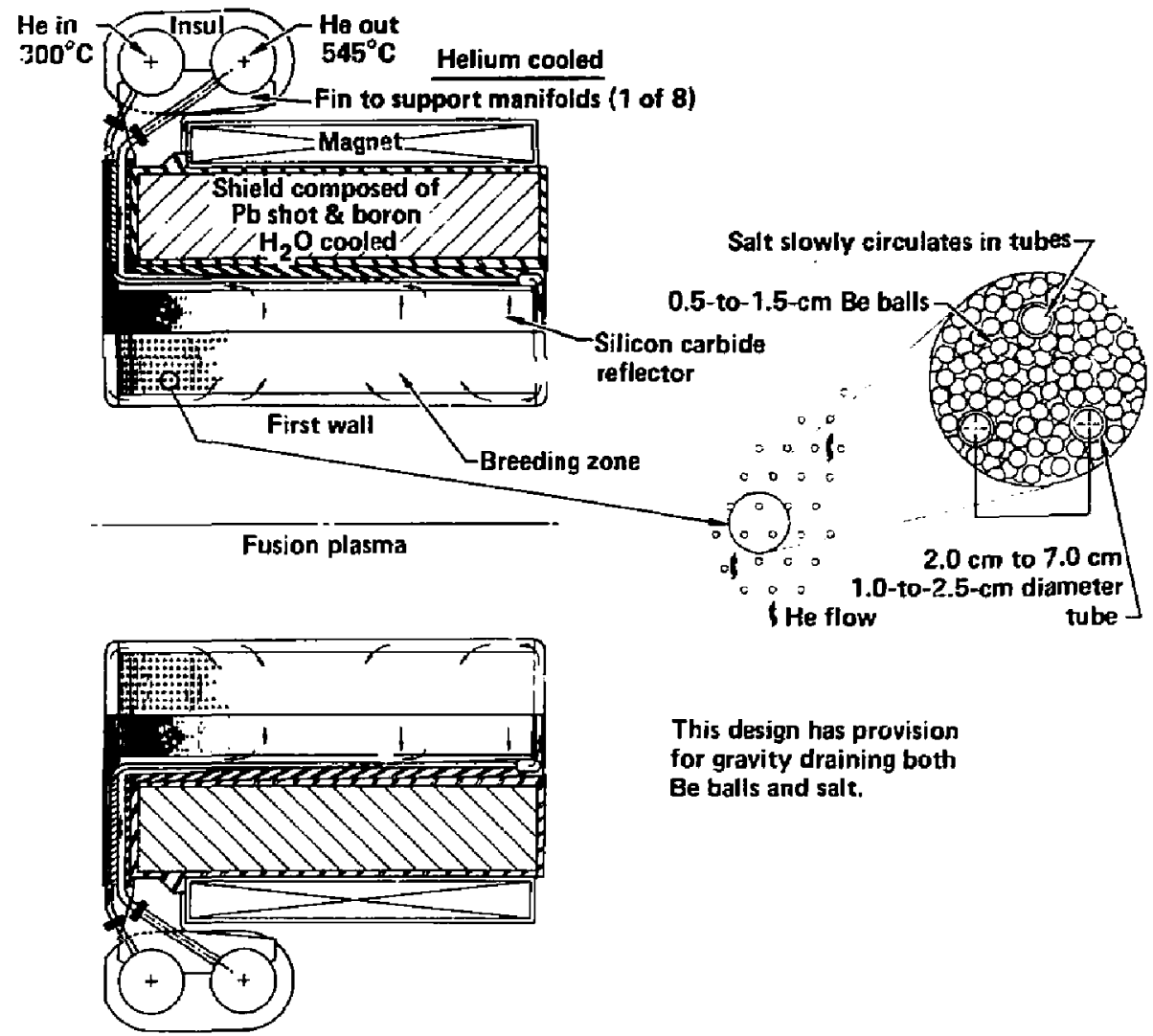

This design has provision for gravity draining both Be balls and salt.

Figure 1-1. Helium-cooled molten-salt fusion breeder that uses beryl1ium as a neutron multiplier. 
1-1. L. M. Lidsky, "Fission-Fusion Symbiosis: General Considerations and a Specific Example," Proc. Nucl. Fusion Reactor Conf., Culham Laboratory, 1969 (Br. Nuc1. Energy Soc., Cutham Laboratory, 1969), Report CLM-MFE, pp. 4i-53.

1-2. A. A. Benedetti, LLNL, unpublished calculations, 1983.

1-3. V. L. Blinkin and V. M. Novikov, "Optimal Symbiotic Molten-Salt

Fission-Fusion System," IAE 2119, Kurchatov Institute, Moscow (1977).

1-4. J. D. Lee, "The Beryllium/Molten Salt Blanket," Proc. Third US/USSR Symposium on Fusion-Fission, Princeton, 1979; also Lawrence Livermore Nationa1 Laboratory, UCRL-82663 (January 1979).

1-5. R. W. Moir et al., Tandem Mirror Hybrid Reactor Design Study, Final Report, Lawrence Livermore National Laboratory, UCID-18808 (1980).

1-6. J. D. Lee et al., Feasibility Study of a Fission-Suppressed Tandem-Mirror Hybrid Reactor, Lawrence Livermore National Laboratory, UCID-19327 (1982).

1-7. E. T. Cheng, C. P. C. Wong, R. L. Creedon, and K. R. Schultz, "A iew Fusion Breeder Blanket Design Approach Utilizing a Thorium Multiplier," summary submitted for presentation at 1983 Am. Nuclear Soc. Annual Meeting, Detroit, Michigan (June 1983). 


\subsection{BLANKET DESIGN}

\subsection{MECHANICAL DESIGN}

The blanket design has several unique features. A single coolant, helium, is used. It flows axially along the first wall, having been piped there first (see Fig. 2-1). The helium then passes through a diffuser and flows radially outward through a bed of beryllium balls and salt-filled tubes, which serve as the tritium and $\mathrm{U}-233$ breeding zone. Next, encountering the neutron reflector zone, the helium continues on its outward radial path through holes in the reflector and grooves in the reflector-block faces. Upon reaching the shield inner boundary, the helium is collected in ducts and carried out to a ring manifold located near one end of a blanket module ( see Fig. 2-2). The shield uses water as its coolant and does not contribute its energy to the main thermodynamic cycle.

The pipes that carry molten salt through the breeding zone enter at the bottom of the blanket, go azimuthally around the plasma, and return to the bottom of the blanket where collection manifolds pass out through the shield (see Fig. 2-3). A vent valve will be included at the top of each pipe loop to aid gravity drainage of the salt tubes during ractor shutdown. The many salt tubes encircling the first wall require that the blanket modules not be separable into "pod" subassemblies but rather be assembled and leak tested as a complete unit.

The empty space between salt tubes is to be filled as completely as possible with neutron-multiplying material. Ber:llium balls will be poured into the blanket from the top. The structure must be configured to allow those balls to flow freely into the breeding zone, completely filling the space between the tubes and any other structural elements. The beryllium balls are expected to swell and perhaps crack during service. The used balls can be changed by draining them by gravity through ball-exit chutes lacated on either side of the molten salt manifolds at the bottom of the blanket. Some balls may not exit by gravity and will be trapped in nooks and crannies inside the hlanket. These can be left behind. New or reprocessed balls will replace the bails that do drain out (estimated to be over 95\% of the balls). The old cnes will continue to swell and crack but not to the detriment of blanket performance. 


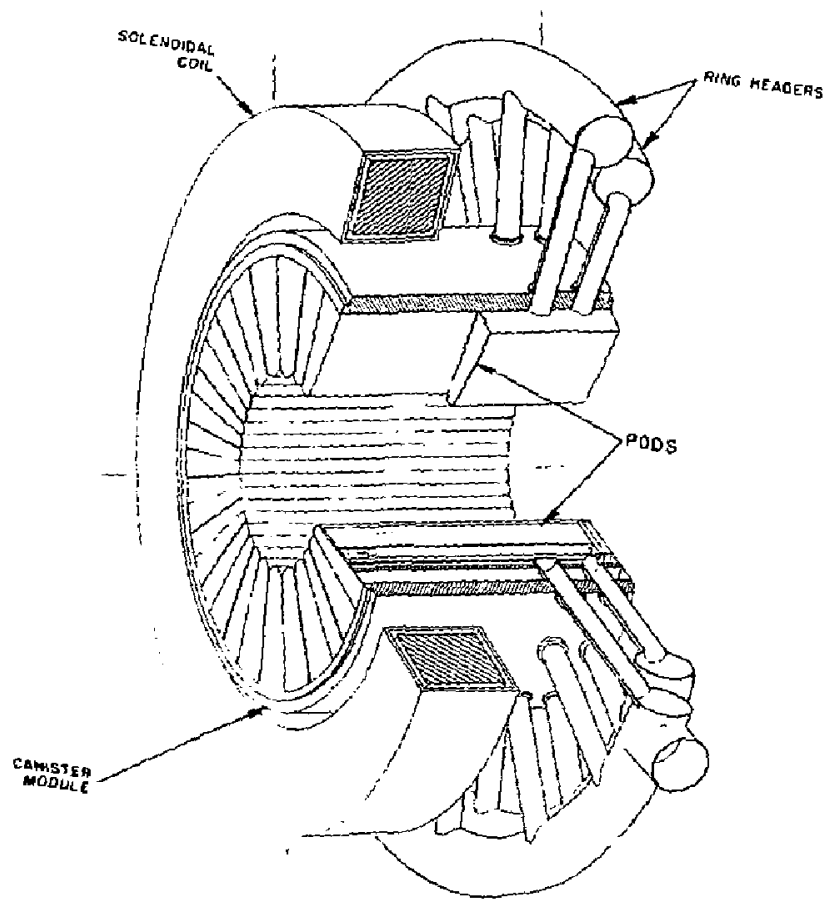

Figure 2-1. Ring headers for the supply and blanket than those shown in Fjgs. $2-2$ and $2-3$. 


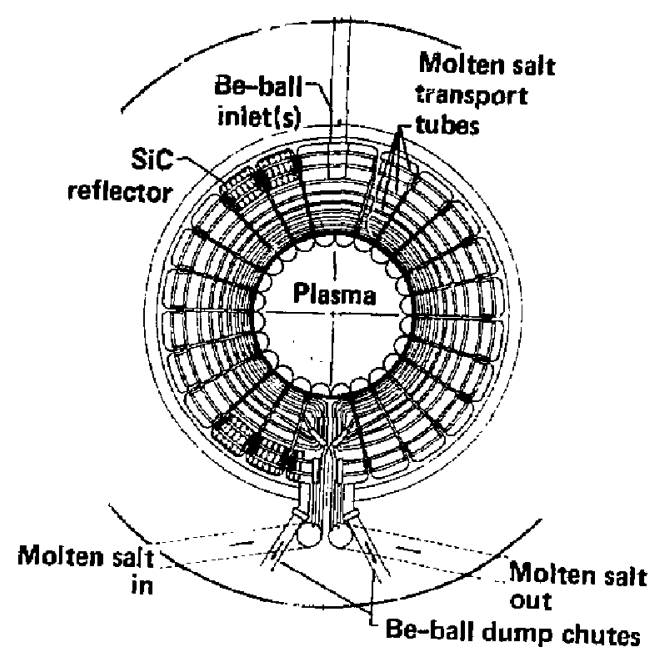

Space between tubes filled with beryllium balls

Figure 2-2. Molten-salt breeding blanket. (Cross section looking down axis of central cel1.) 


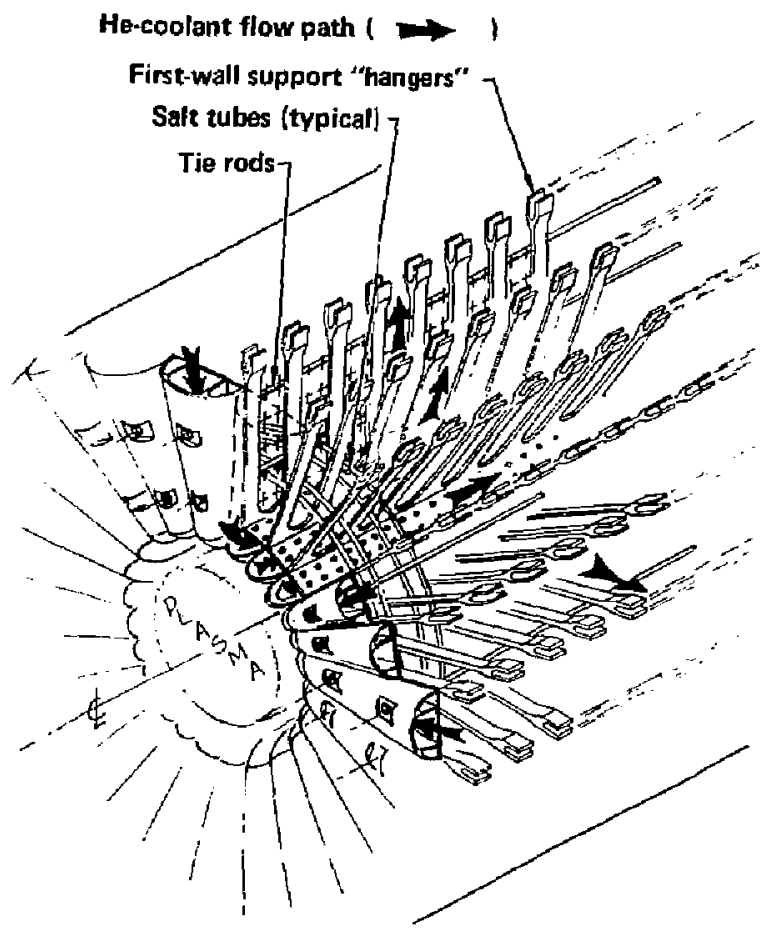

Figure 2-3. Molten-salt breeding blanket showing support hangers and salt tubes. 


\subsubsection{PEBBLE/TUBE SYSTEM - SALT YOLUME AND COST}

The salt tubes immersed in the bed of berylium balls must be spaced so the balls can flow either into or out of the tubed region with no bridging resulting in flow stoppage. In flow tests we found that if the ba!ls are no larger in diameter than one-half of the free space between the tube walls, free flow will occur. Since some balls may crack or stell and develop imperfections of shape, we prefer the ball diameter to not exceed one-third of that free space. The nominal values we have choren are given in Table 2-1.

Table 2-1. Nominal pebble/tube parameters

\begin{tabular}{ll}
\hline Tube o.d. & $1.7 \mathrm{~cm}$ \\
Tube spacing & $4.7 \mathrm{~cm}$ \\
Tube wall thickness & $0.5 \mathrm{~mm}$ \\
Pebble diameter & $1.0 \mathrm{~cm}$ \\
\hline
\end{tabular}

The tubes are held in place by clips attaching them to the radial spokes that tie the first waIl to the cylinder just outside the reflector. This cylinder is the main structure preventing the first wall from buckting. Figure 2-3 shows the radial spokes and a few of the salt tubes. The width of the spokes may require some tubes to be slightiy bent to get the most uniform salt distribution and also avoid the spoke.

The tube diameter is large enough so that freeze-up of the salt will not occur and small enough so that the centerline temperature will stay well below the boiling point. These limits are discussed in the thermal hydraulic section. The tube spacing is picked on the basis of nucleanics. Too large a spacing will give parasitic loss of neutrons in the beryllium and too small a spacing will displace beryllium and reduce fast neutron multiplication. The tube wall thickness is chosen to reduce parasitic absorption in the steel and 
yet be thick enough to avoid the buckling caused by the helium pressure (50 atm) being higher than the salt pressure (49 atm normally but 1 atm under depressurized conditions). The pebble size is picked to be large enough to avoid excessive pumping power but small enough to freely flow between the pipes.

Axial tie rods in this design restrain the ends of the blanket module. Otherwise $50 \mathrm{~atm}$ of helium could nat be structurally contained. These rods represent about $3.5 \%$ of the blanket volume. The salt tubes are $1 \%$ of the blanket volume and module sidewalls are about $1.5 \%$. Salt $\left(\mathrm{LiF}+\mathrm{BeF}_{2}+\mathrm{THF}_{4}\right)$ is 9.5\% and beryllium balls are 53\% of this breeding zone. (The region between sa1t tubes is assumed to be 60\% beryllium and $40 \%$ helium coolant.) Table 2-2 gives $t y_{1}$ cal blanket parameters emphasizing beryllium requirements.

\section{Tube Failure Rate}

With so many steel tubes in the blanket, the question of failure rate must be considered. For a triangular array having naminal spacing of $4.7 \mathrm{~cm}$, there would be 80,000 tubes in the complete blanket. Each tube would be approximately $11-m$ long. If we can tolerate one failure in five years, the failure rate per tube per hour of operation must be less than $4 \times 10^{-10}$. The helium pressure outside the tube will be about one atmosphere higher than the salt pressure within the tubes. Small cracks (at welds for example) would allow helium to leak into the salt but would not constitute a fallure. A large crack might result in excessive helium ieakage and force a shutdown and module change. This would have little overall consequence other than economic if the occurrence was infrequent. An offsec tube break could cause molten salt contamination of the helium-coolant loop. This would require shutdown and clean-up. Analysis should be carried out to determine tolerable crack sizes and to estimate tube failure rates. Analysis should also be carried out to determine the operational contaminztion limits of leaks of helium into moiten salt and vice versa.

\section{Salt Volume and Cost}

The salt tubes constitute $9.1 \%$ of the $60-\mathrm{cm}$ thick blanket, assuming no salt in the reflector region. The blanket volume is $860 \mathrm{~m}^{3}$, so the salt volume $w 11$ be $78 \mathrm{~m}^{3}$ in the blanket region. The salt in the processing system and piping must be added to this. The amount of salt in the prior 
Table 2-2. Beryllium requirements for the molten-salt blanket.

\begin{tabular}{ll}
\hline Total blanket volume & \\
Pebble volume $^{\mathrm{b}}$ & $860 \mathrm{~m}^{3}$ \\
Pebble quantity $^{\mathrm{c}}$ & $470 \mathrm{~m}^{3}$ \\
Pebble mass & $890 \times 10^{6}$ \\
Beryllium mass & $0.96 \mathrm{~g}$ \\
Average beryllium lifetime & 860 tonne \\
Annual pebble throughput & 5 years \\
Annual beryllium mass throughput & $180 \times 10^{6} / \mathrm{yr}$ \\
& 170 tonne/yr
\end{tabular}

\footnotetext{
a $327-m$ long central cell (3000 MW fusion power) with 0.6-m-thick blanket starting at $1.5-\mathrm{m}$ radius. Wall load is $2 \mathrm{MW} / \mathrm{m}^{2}$.

b Tubes represent $10 \%$ of blanket valume, with $60 \%$ packing in remainder of blanket

$C_{\text {Pebbles are } 1} \mathrm{~cm}_{\mathrm{i}}$ in diameter.

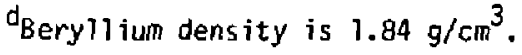

design was $1152 \mathrm{~m}^{3}$ or 15 times more: The present greatly reduced amount of salt should reduce the reprocessing cost and also allow removal of more fission products. Based on $\$ 166,500 / \mathrm{m}^{3}$ for the $12 \mathrm{mo} 1 \% \mathrm{hhF}_{4}$ salt (see Ref. $2-1$, the cost of the salt in the blanket would only be $\$ 13 M$, implying the salt could be replaced on a fairly short interval (less than 4 years), thereby reducing the radioactive inventory.

\subsubsection{MODULE END WALL}

In all blanket designs difficult structurai problems occur at module ends. A combination of end cover plates and coolant supply ducts is employed to minimize parasitic capture of neutrons. We bring coolant to the first wall by using the contoured end plates as coolant gas ducts (see Fig. 2-4). The coolant turns upon reaching the first wall and flows axially from each end of the module. The diffuser plate then allows the flow to turn another 90 deg and enter the pebble bed when the helium gas flows radially, thereby cooling the entire bianket. 


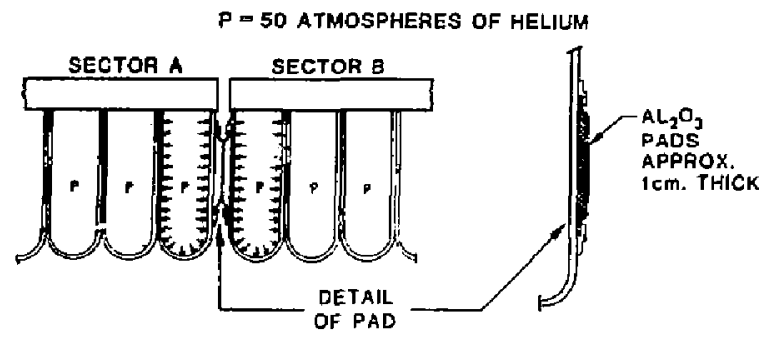

Figure 2-4. Alternate design for module end.

The large axial force on the end plates can be resisted by a combination of structural members. It must be realized that no axial force can be transmitted through the spokes. There is no web to carry axial tension in any of the 24 spoke planes.

The first wall is continuous from end to end but is subject to large pressure force radially inward. Also the first wall is thin to minimize neutron heating and is not intended to carry large axial loads. Corrugations of the first wall permit swelling as a result of neutron fluence. Those corrugations render the wall incapable of transmitting large force.

The outer cylinder to which the first-wall stabilizing spokes attach is a stout axial support that would support all of the axial pressure force if the force could be transmitted to it. Unfortunately, the bending load is very large, resulting from trying to cantilever the wedge-shaped end plates (ducts) from the outer cylinder. The metal thickness required for such attachment may cause restrictions in the coolant flow area at the duct entry. We are studying this problem. In the meantime we show two long tie rods through each end plate. These rods terminate at the corresponding end plate at the opposite end of the blanket module (see Fig. 2-4). The wedge-shaped end piate is configured with a deep bending cross section to stiffen it. This also permits it to carry the bending associated with a beam that has a rigid support at the outer one end, has two other intermediate support points (tie rads), and also has a short cantilevered segment at inner end where it joins the first wall. 
An alternate module-end-support solution would allow the end modules of one sector to support those of the adjacent sector. Consideration must be given to tolerance accumulation, which can cause overstress of module sidewalls. Also unintentional "cold welding" of walls in contact could occur. which would prevent disassembly without damaging the module end-wall in contact with a neighboring sector. Both of these unpleasant effects $c$ an be overcome by the following suggestion. An aluminum oxide plate (or several smaller pads) can be mounted on the end walls of modules in adjacent sectors. The thickness of the aluminum oxide pad can be selected just before final assembly to compensate for tolerance build-up in the manufactured condition. Alternatively a pressurized cushion could be used in conjunction with the aluminum oxide plate to take up the tolerance. The ceramic pads will not weld under vacuum. Pad spacing and area must be controlled to minimize any local wall bending stresses in an unsupported area. The space occupied by these thin ceramic pads can be small. Valuable breeding volume is conserved and parasitic neutron capture minimized. This alternate design is shown schematicaly as Fig. 2-5. Further work is needed on design of the module end support. 


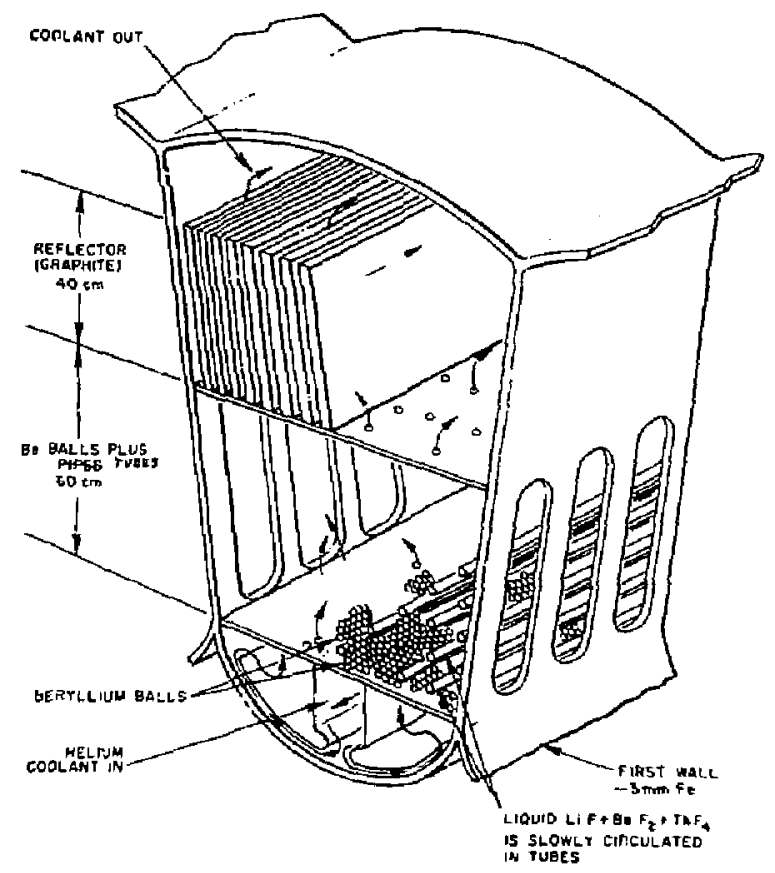

Figure 2+5. Axiaily orjented salt pipes. 


\subsubsection{TANDEM MIRROR ALTERNATE BLANKET DESIGNS}

Several variations of this blanket and first-wall design should be examined. Instead of the lobed first wall with hellum ducted separately to each axial lobe, it might be less costly to have two concentric cylinders spaced apart by periodic axial fins. The inner cylinder faces the plasma. Helium coolant flows in the space between the cylfinders. The outer cylinder is perforated to permit flow of coolant into the pebble bed. The axial fins, which tie together the inner and outer cyinders, provide buckling stiffness to the assembly. It is still likely that some radial support from the shield will be required, probably by radial tie rods.

Another interesting concept is the variant of the double first wall, already described, in which the coolant is fed to the wall in a different fashion. If radial support rods are necessary for buckling stability of the double first wall, why not flow coolant to the first wall through tubes that replace those rods? The design at the first-wall connection for sucn a tube was studied and appears quite feasible, permitting a reliable structural connection and well distributed coolant. Instead of an end plate that doubles as a coolant inlet duct, we would need an end plate whose only function is to restrain coolant pressure. As noted previousiy, the axial load transfer and distribution will certainly affect the shape of the end plate, and it is not clear whether its mass, hence parasitic capture, will be any lower than the design that doubles as a coolant duct. We still do not expect the first wall to carry axial load because of provisions for neutron-induced swelling.

\section{Alternate Tube Arrangement}

For some alternate designs, we handle the salt tubes quite differently. If the tubes tend to run axially (rather than azimuthally), then the blanket can be segmented intc, identical wedge-shaped pods (see Fig. z-5). The end-plate problem benefits from the pod side plates, which now can carry tensile load. The neutronics of the blanket will show parasitic capture because of the many pod boundary plates. We doubt there are advantages to such tube orientation. One clear disadvantage is the tube-draining requirement. The orientation of some of the tubes will prevent simple gravity draining. A more complex purging method using pressurized gas blow-down would be necessary. 


\subsubsection{TOKAMAK BLANKETS}

For the tokamak configuration, the pods can have orientations related to the above, namely ruining toroidslly (similar to axially in a mirror) or pololdally (similar to azinuthally in a mirror). The toroidal pod oriantatinn is shown in Fig. 2-6.

If the salt tubes run poloidally around the torus (as in Fig. 2-3), disassembly of the torus into wedge segments or modules would be possible. The blanket sections would be very large and sifficult to handle. They would completely encircle one segment of the plasma. In top view the module would be wedge shaped. The poloidal direction for the salt tubes does permit gravity drain of the salt.

The poloidal pod orientation - salt tubes also running poloidally - is strwn in Figs. 2-7 to 2-9. Very large modules are required since the plasma must be completely encircled, as before. Each module would be 13-m tall, as shown in Fig. 2-7. The first wall can be well cooled as shown in Fig. 2-8. A separate feed tube at the top of each pod provides for beryllium pebble filling. A similar but larger drain tube at the bottom of each pod would be joined to a large manifold to permit pebble extraction. The module must be continuous from top to bottom of the reactor to allow beryllium pebble addition and removal. Horizontal divisions preclude draining pebbles from a "flat fioor".

If the tubes carrying sait run in the toroidal direction, a tube drainage problem must be solved. Some pods will be oriented so gravity aids salt drainage. Those on the upper portion of the blanket will have to be drained by some gas blow-down procedure, because their tube feed lines point: upward to varying degrees.

Toroidal salt tubes are limited in length to a pod that can be assembled between toroldal field coils. Depending on design details, this toroidal tube length cannot exceed $30 \mathrm{deg}$ of arc for a twelve-magnet systern. More realistically, the angle will probably be 15 to $20 \mathrm{deg}$.

The preferred tokamak configuration is toroidal pods and poloidal tubes (see Fig. 2-6). 


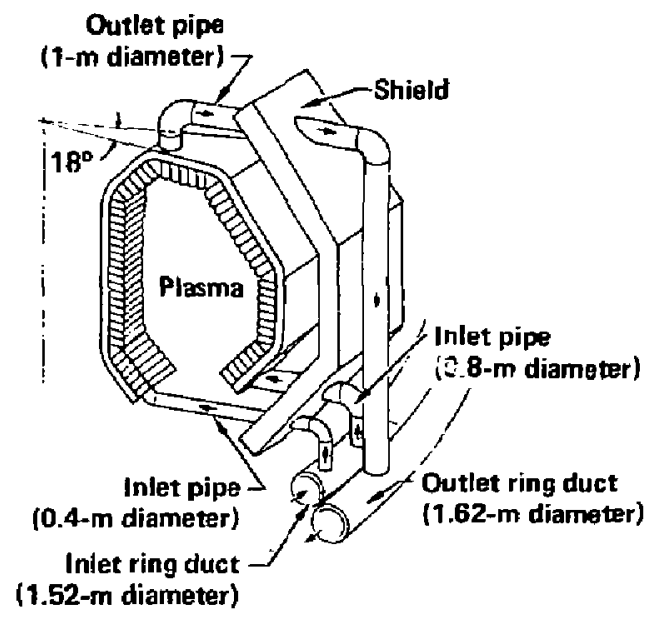

Figure 2-6. Tokamak module and piping arrangements. 


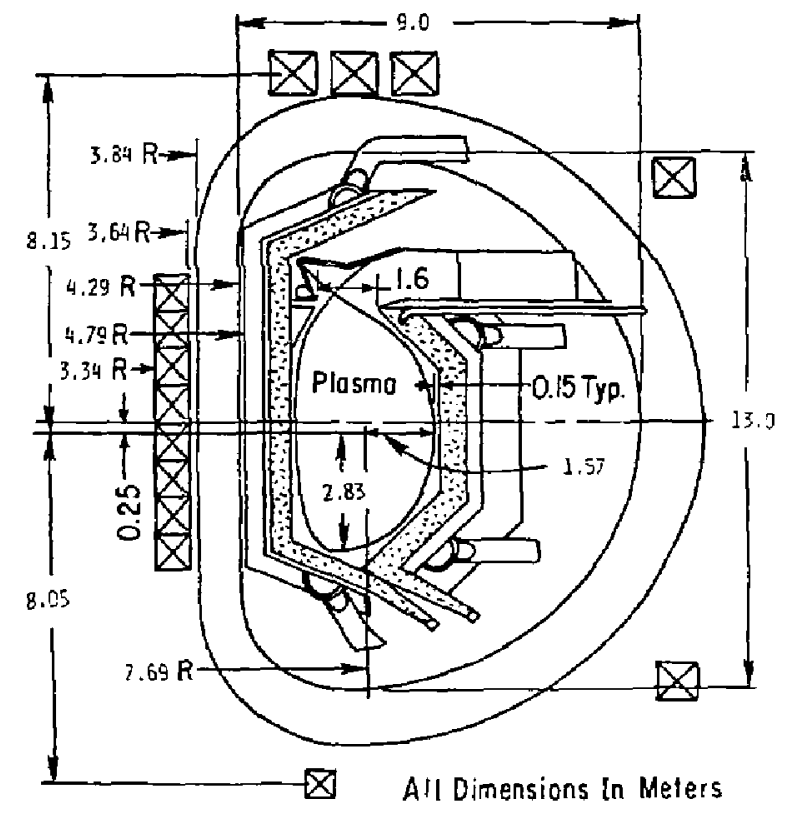

Figure 2-7. Poloidal pod orientation. 


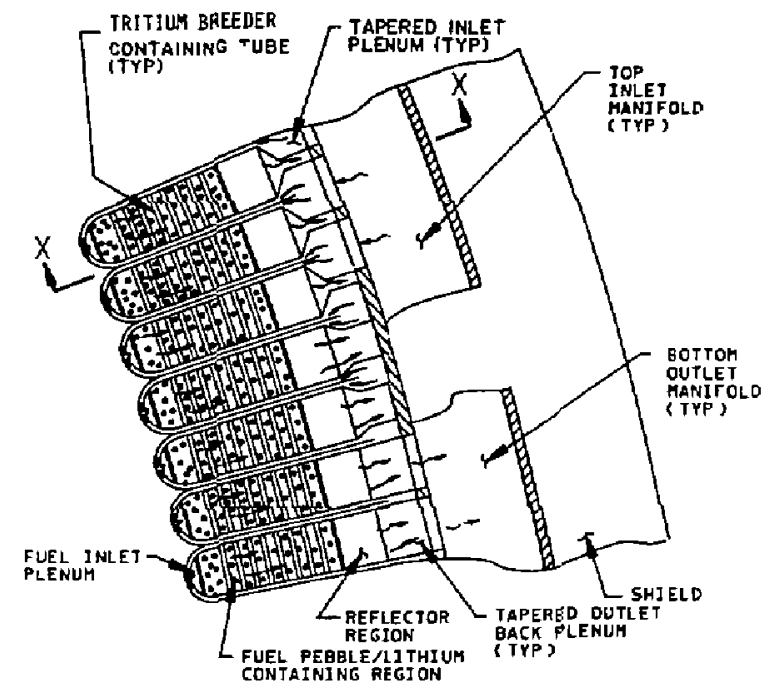

Figure 2-8, Poloidal pod orientation - blanket cross section enlarged to show lobe detail (not to scale). 


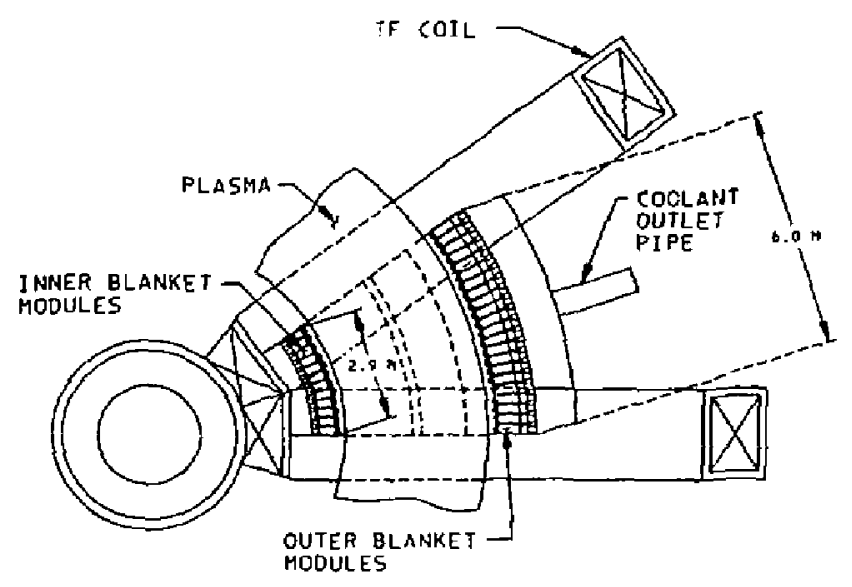

Figure 2-9. Blanket cross section (A-A of $F i g .2-8$ ) of poloidal pod orientation. 


\subsubsection{BERYLLIUM PEBBLE FABRICATION TECHHOLOGIES}

In this section, the technology reguired to produce and recycle beryllium pebbles for the fusion breeder blanket is described. Beryllium availability is reviewed, a production process is proposed, its cost is estimated, and process development issues aro discussed. The beryllium pebble design and 1 ifetime considerations are iscussed in Ref s. 2-2 and 2-3. The lifet ime of the beryilium pebbles is presantly quite uncertain (five years assumed in this analysis which is $7 \mathrm{MW} \cdot \mathrm{y} / \mathrm{m}^{2}$, but is, to a large extent, dependent on the fabricated properties described below.

\section{Requirements}

As described in Section 2.1., each beryllium pebble is a solid, 1-cm-diam sphere. The pebbles orcupy one fuel zone $60 \mathrm{~cm}$ in thickness. The volume of this zone, for a $127-m$ central-cell length, is $860 \mathrm{~m}^{3}$. For an appruximate $60 \%$ pebble-packing fraction outside of the tubes that occupy $10 \%$ of the volume, the pebble volume is $470 \mathrm{~m}^{3}$. Therefore, $890 \times 10^{6}$ pebbles will be required for the initial inventory. The net beryllium mass is 860 tanne $\left(1.84 \mathrm{~g} / \mathrm{cm}^{3}\right)$. For an assumed average pebble lifetime of five calendar years, the annual throughput of the hot beryllium fabrication plant will be $180 \times 10^{6}$ pebbles/yr or 170 tonne/yr. The above quantities were summarized in Table 2-2.

Beryllium Availability

Our FYBI assessment of long-term bery?lium availability $2-1$ indicated that the amount of beryllium required for the reference blanket would represent about $3 \%$ of the known beryllium reserves in the U.S. (Bureau of Mines estimate). Similarly, the same 860 tonne requirement represents about $1 \%$ of the total estimated U.S. beryllium resource, about $0.24 \%$ of the known world beryllium reserves, and about $0.07 \%$ of the total estimated world beryllium rescurce. A more recent assessment was provided in Ref. 2-4.

Our energy growth projections of the same study $2-1$ indicated that on the order of 40 fusion breeders might eventually be built orior to 2050 . On this basis, we conclude that the U.S. berylitum resource will be marginally adequate for this application without a definitive requirement for imported beryllium. 
Currently, the only source of beryllium metal in the free world is Brush Wellman, Inc. They produce $\mathrm{Be}(\mathrm{OH})_{2}$ at a mill in Delta, Utah. The beryllium source is bertrandite ore, which contains $\approx 4 \mathrm{lb} /$ tome of beryllium per year. They are planning to jncrease production by about $60 \%$, using Chinese ore (40 to $50 \mathrm{lb} /$ tonne of beryllium) to satisfy their projected needs for BeO and $\mathrm{Cu}-\mathrm{Be}$ alloys.

In 1982, Brush Wellman converted 227 tonne/yr of the beryllium from the mill in Delta, Utah, to beryllium metal in a plant at Elmore, Ohio. They estimate the maximum capacity of the metal production capability of the plant to be 2115 torne/yr.

Recognizing the current production capability, it is of interest to consider Brush's capability to expand capacity. To produce one entire berylitum inventory during a four-year period (i.e., for the first commercially sized fusion breeder), a beryllium requirement of 215 tonne/yr woulo require Brush to expand operations as follows:

1. Develop a source of high-grade ore (perhaps Chinese).

2. Expand the mill at Delta, Utah, by about $70 \%$.

3. Increase the metal production capability at Eimore by 2.6 fold.

It is quite clear that the beryllium-production capacity would have to be carefully coordinated with fusion-breeder development to assure that a supply bott leneck does $n$ ot occur.

\section{Fabrication Process}

The selected pebble-fabrication process involves the development of an autonated line that will cold press pebbles, vacuum sinter them, hot forge them essentialiy to $100 \%$ of theoretical density, and vaculim anneal them. Brush currently uses the first three steps of this process to produce aircraft brake segments - the only difference is that the present process is manually of arated because current beryllium powder is not free flowing and not amenable to automated operations. In order to automate this process, a free flowing beryllium powder is required.

The brake parts produced by Brush have properties as good or better than S-200-E.

$\begin{array}{ll}\text { Ultimate tensile strength } & 40 \mathrm{ksi} \\ \text { Yield strength } & 30 \mathrm{ksi} \\ \text { Elongation } & 1 \% \\ \text { Densicy } & 1.84 \mathrm{~g} / \mathrm{cm}^{3}\end{array}$


We do not expect a free flowing powder to degrade these mechanical properties. In fact, some of the manufacturing processes currently being discussed with Brush would be expectud to increase both the tensile strength and elongation.

The equipment needed for production is simple: mechanical presses and powder feeders to make cold-pressed compacts, automated vaculum sintering furnaces for pressureless sintering, mechanical presses for hot sizing the sintered compacts, and an automated vacuum furnace for annealing the forged compact.

For fabrication of pebbles too damaged to reinsert into the blanket after an irradiation period, we would vacuum melt the hot pebbles and use an automated atomization process (modeled after the Brush Wellman process; to first remanufacture the beryllium powder prior to the cold-press step.* The entire process will require provision for shielding and remote maintainability. In addition, hooding requirements as per OSHA 1 imits $\left(2 \mu \mathrm{g} / \mathrm{m}^{3}\right)$ must be maintained to limit airborne contamination. A beryllium decontamination step (e.g., electro-refining) is not assumed but might simplify the shieiding and remoting requirements.

Given a five-year beryllium lifetime and assuming an automated plant that operates 24 hours/day and 7 days/week and operates $85 \%$ of the time with no rejects, we must have a production rate of 400 balls per minute. While this is a high production rate for beryllium parts, it is low for some powder metal industries (e.g., tantalum capacitor manufacturers produce thousands of parts/ per minute). The beryllium reprocessing line is estimated to lose 7 to $10 \%$ of the beryllium ihroughput, so a sma11 feedstream is required. With a freeflowing powder, the losses might be reduced perhaps as low as $1 \%$.

As an alternative, lower density parts can be made by cold pressing and sintering. If the parts are sintered to $90 \%$ of the theoretical density, they are predicted to have 70 to $80 \%$ of their full density conductivity. Some $90 \%-$ dense beryllium parts made in this manner have been tested at LLNL. These were characterized with respect to mechanical properties, porosity, etc. It is possible that the lower density parts will swell less and, consequentiy, have longer life.

* We do not exclude the possibility of removing the helium gas by vacuum heating, which would resuit in about $30 \%$ volumetric swelling. These enlarged pebbies zould then be pressed back into size. 


\section{Process Cost Estimate}

The beryllium fabrication-process components and their estimated costs were developed in the 1982 tandem mirror fusion breeder-design study ${ }^{2-2}$. These costs, corrected for inflation to 1984 dotlars, are listed in Table 2-3. The listed equipment is sufficient to produce or recycle 18 million pebbles per year, 3-cm 0.d., or the entire berylitum inventory in two years. The cost attributed to remoting the process is a guess.

These costs were adapted to the present blanket requirements $(180 \mathrm{mi} 1)_{\text {ion }}$ pebbles per year, $1 \mathrm{~cm}$ o.d.) by scaling the above component costs by throughpu* and by the characteristic parameter of the pebble (diameter, area, or volume) that drives the magnitude of a specific process and/or cost. For example, the amount of beryllium makeup and the cost of volumetric furnaces is assumed to scale directly with the pebble volume at a fixed process rate (pebbles/yr). Similarly, the cost of pressing, air-handling systems, and plant staff (assumed to be $\$ 2 \mathrm{M} / \mathrm{yr}$ for the 1982 blanket requirements) is assumed to scale as the pebble area at a fixed process rate. The cost of transfer 1 ines is assumed to scale as the pebble diameter, and the cost of inspection is assumed to scale directiy as the process rate (pebbles/yr). For the newer analysis, the cost of milling machines (which would scale as the pebble diameter) was deleted as the pebbles for the molten-salt blankets do not have the cut groove of the beryllium/thorium snap ring design of Ref. 2-2. A new cost, inspection, was introduced. We assumed that an inspection test assembiy, performing a relatively simple mechanical operation (e.g., a compression test) could be developed to test one pebble per 15-second interval for a capita? equipment cost of $\$ 400,000$. Approximately 100 such assemblies ( $\$ 40$ million) would be required for the molten-salt blanket. 
Table 2-3. Estimated costs of components for processing beryllium pebtles.

No. of

units

Process Components

Presses with feeders

4 Sintering furnaces

$4 \quad$ Sizing presses

4 Annealing furnaces

$4 \quad$ Milling machines

1 Transfer line

12 Inspection lines

Air handling, filters, etc.

Subtotal

Remoting (100\%)

TOTAL
Cost

$\$ 3.4 \mathrm{M}$

1.7

1.7

1.7

1.7

2.5

4.8

4.3

$\$ 21.8 \mathrm{M}$

21.8

$\$ 43.6 \mathrm{M}$ 
The cost of beryllium fabrication as a functian of the blanket pebble inventory $(1$, grams), 1 ifetime (L,years), and radius $(r, c m)$ is estimated to be

$$
\operatorname{Cost}(\mathrm{SM} / \mathrm{yr})=0.13 \frac{I}{L}\left[0.221+\frac{0.184}{r}+\frac{0.054}{r^{2}}+\frac{0.153}{r^{3}}\right] .
$$

This cost estimate, shown graphically in Figure 2-10., assumes a capital cost of $15 \% / \mathrm{yr}$ and includes makeup of $7 \%$ of the beryllium throughput at $\$ 350 / \mathrm{kg}$. If the loss can be reduced from $7 \%$ to $1 \%$, the leading term of the sum $(0.221)$ is reduced to 0.059 . For the molten-salt blanket ( $I=860$ torne, $L=5 \mathrm{yr}$, $r=0.5 \mathrm{~cm})$, the annual cost becomes $\$ 45 \mathrm{M} / \mathrm{yr}$. This relatively large cost represents roughly $6 \%$ of the overall annual cost. It is dominated by inspection and would be reduced to less than $\$ 18 \mathrm{M} / \mathrm{yr}$ if the inspection 1 ines can be el iminated.

\section{Development Issues}

The oniy special equipment needed for the process line is the airhanding system needed to contain the beryllium powder. The die life should be comparable to other powder metallurgy products $(500,000$ to $1,000,000$ parts/die, with punches redressed every $\sim 50,000$ parts).

Production of a free-flowing bery? 1 ium powder suitable for automated operations requires further development. This might be achieved by a new powder manufacturing technique at Brush Wellman (spherical powder) or the use of binders that can be totally removed during a bake-out prior to sintering.

Development of a pressing technique to produce a uniformly dense sphere that can be pressurelessly sintered to 90 to $95 \%$ of theoretical density is also required. The pressed sphere must be strong enough to permit automated handling. An efficient inspection test capability may need to be developed if an adequate process reljability cannot be achieved. 


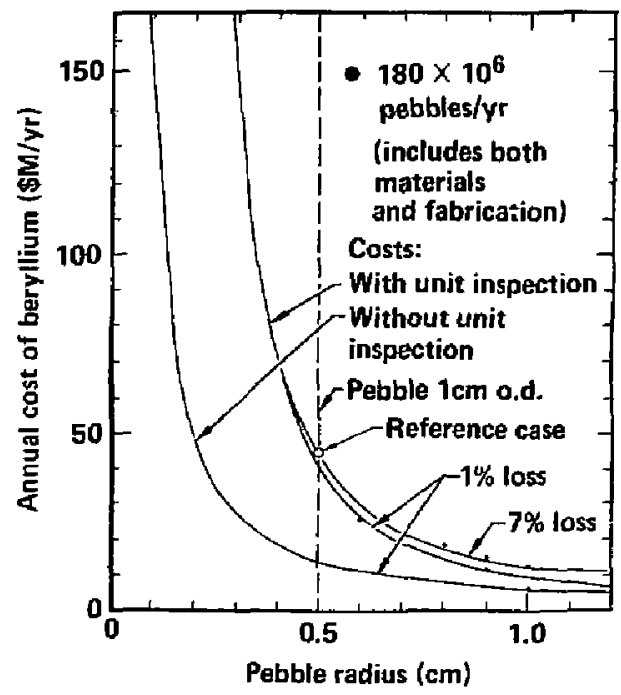

Figure 2-10. Annual beryilium cost versus pebble size. 


\subsection{NUCLEONICS}

\section{2.i. INTRODUCTION AND SUMMARY}

In this section we describe the nucleonic appraisal of this blanket concept (helium-cooled beryllium-pebbled, fertile molten salt in tubes) as an aid in determining its potential and if future work is justified.

The first step in this appraisal, we will calculate the nuclear parameters of a representative unit cell and compare results with the lithium-cooled beryllium thoriun pebble-bed reference blanket of last year. The unit cell model is an infinite assembl; and contains no structure other than the tubes containing the molten salt. Thus the results represent an upper limit of performance. To appraise the effects of finite thickness and first wall and other structures on performance, a cylindrical model is used. The cylindrical model is also used to estimate energy deposition versus radius.

The Monte Carlo neutron-transport codes TART and ALICE with ENDL nuclear data are used for this analysis. ALICE is a version of TART that uses the Probability Table Method to treat resonance effects.

Results indicate that the neutronic performance of this blanket concept should be good. Total tritium + net fissile breeding $(T+F$ iet $)$ in the unit celi is 2.16 compared to 2.32 for the reference blanket. Net fissile breeding $\left(F_{n e t}\right)$ equals $\operatorname{Th}(n, \gamma)-U(n, f i s s)-U(n, \gamma)$ reactions per source 14-MeV reutrons; and $T$ is defined as the number of tritors produced per 14-MeV neutrons. Energy multiplication $(m)$ is 1.95 versus 2.32. The cylindrica? mode 1 has a $T+F_{\text {net }}$ of 1.85 compared to 1.83 for the reference case. On correcting the cylindrical model resuits for heterogenous effects, we find $T+F_{\text {net }}$ is 1.75. When $T$ ( 1.06 as in reference case) is subtracted, the b lanket fissile-breeding ratio ( $F_{\text {net }}$ ) is 0.69 compared to 0.62 for the reference case. When addjtional structure and other effects are considered $F_{\text {net }}$ may drop to about that of the reference case. Energy muitiplication $M$ of this blanket is estimated to be 1.6 compared to 1.8 for the reference case. The nuclear design and analys is of this blanket concept has just begun and much needs to be done to optimize the design and improve the analysis. Integration of heat transfer and structural requirements must also be undertaken. Resonance, as well as heterogeneous effects, appears significant and needs to be included in the analysis. 
The results given above are for a 27 moly $\mathrm{ThF}_{4}$ salt. Replacing it in

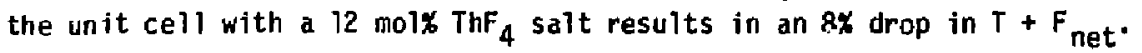
If blanket $T+F_{\text {net }}$ drops $8 \%$ to $1.62, F_{\text {net }}$ drops $20 \%$ to 0.56 . Increasing the molten-salt volume fraction may reduce the effect of changing salt composition.

While these initial results are encouraging, more rigorous analys is and optimization are needed before we can say with reasonable assurance that this blanket concept has good nuclear perfornance potential.

The following subsections describe the analysis in more detail.

\subsubsection{UNIT CELL}

The blanket interior consists of a bed of beryliium pebtles plus molten salt in tubes. The unit cell model shown in Fig. 2-11 is used to assess the nuclear potential of this configuration. The cell is driven by a $x y$-planar, isotropic, 14-MeV neutron source located at $z=0+$. All exterior planes of the cell are reflecting, therefore, the cell is in effect an infinite assembly of unit cells. Results with this model give an upper limit because finite thickness, first walls, and other structures are not included. Results of the various cases calculated with this model are given in Tabie 2-4. Most calculations were done with the TART code and 175 group nuclear data. Two cases ( $7 \mathrm{a}$ and 8 ) were run with ALICE to estimate the importance of resonances. The parameter 'pitch' is the $x$ and $z$ separation of the moltensalt tube center lines. Cell $x$ and $z$ dimensions are one-half the pitch. The beryllium contains 0.1 at.\% Fe impurity. The standard deviation is less than $2 \%$. Some general observations: As the 10 amount drops (cases 1 to 3 ) so does total breeding $\left(T+F_{N}\right)$ because parasitic captures increase. As the pitch is decreased (cases 4 to $4 b$ ), neutron multiplication, represented by total captures, decreases but breeaing increases. A 7-by-7 cm pitch was chosen as a preliminary design point, bu: further optimization is needed.

The effects of resonance self shielding was important, reducing $F$ while increasing $T$ by about the same amount. Since $T$ should stay constant, the ${ }^{6} L i$ amount must be reduced, which wilt reduce $T+F_{N}$ because of increased parasitic capture. Obviously, resonance self shielding must be included when pitch optimization is oone. Tube size should be varied as well. Tube size and pitch may also need to be varied to achieve the correct interface temperatures beiween the molten salt and tube wail. In Table 2-5, results are 


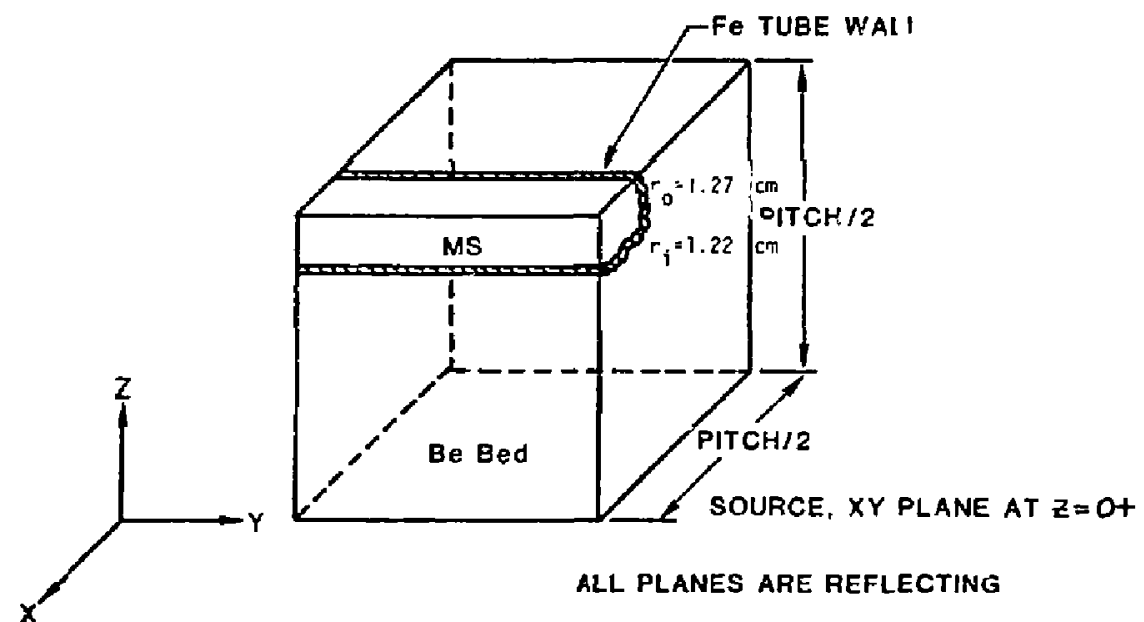

MS Composition $(a=4.5$ a/cc)

$\begin{array}{lr}\text { Lif } & 71 \mathrm{~m} / 0 \\ \text { BeF }_{2} & 2 \pi / 0 \\ \text { IhF }_{4} & 27 \mathrm{~m} / 0\end{array}$

BE Bed Composition

Be 50 vio

Fe 0.1 vio

Figure 2-11. Unit celJ calculational model for molten sait (MS in $\mathrm{Fe}$ )

+ beryllium + helium blanket. 
Table 2-4. Nuclear performance of the unit cell (MSHE series), ${ }^{a}, b, c$

\begin{tabular}{|c|c|c|c|c|c|c|c|c|}
\hline Case No. & $\begin{array}{l}\text { Pitch }(x z) \\
(c m)\end{array}$ & ${ }^{6} \mathrm{LI} / \mathrm{Li}$ & $\mathrm{U} / \mathrm{Th}$ & $T$ & $\mathbf{F}$ & $\begin{array}{l}T+ \\
F_{\text {net }}\end{array}$ & $\begin{array}{l}\text { Total } \\
\text { captures }\end{array}$ & $E(M)$ \\
\hline $\mathbf{l}$ & $14 \times 14$ & 0.10 & 0.01 & 2.15 & 0.267 & 2.34 & 2.86 & $33,1(2,36)$ \\
\hline 2 & $14 \times 14$ & 0.05 & 0.005 & 1.98 & 0.325 & 2.25 & 2.79 & $30.7(2,18)$ \\
\hline 3 & $14 \times 14$ & 0.02 & 0.005 & 1.77 & 0.477 & $2+13$ & 2.87 & $-\cdots$ \\
\hline 4 & $14 \times 74$ & 0 & 0 & 0.005 & 1.31 & 1.31 & 2.68 & -- \\
\hline $4 a$ & $3.74 \times 14$ & 0 & 0 & 0.021 & 1.71 & 1.73 & 2.49 & $r-$ \\
\hline $4 b$ & $3.74 \times 7$ & 0 & 0 & 0.038 & 1.75 & 1.79 & 2.25 & -- \\
\hline $5 a$ & $3.74 \times 14$ & 0.01 & 0 & 1.16 & 0.94 & $2.1 \mathrm{~J}$ & 2.51 & -- \\
\hline 6 & $7 \times 7$ & J.01 & 0 & $i .08$ & 0.99 & 2.07 & 2.45 & $21.4(1.52)$ \\
\hline 7 & $7 \times 7$ & 0.013 & 0.0011 & 1.22 & 0.97 & 2.16 & 2.56 & $27.4(1.95)$ \\
\hline $7 a$ (ALICE) & $7 \times 7$ & 0.073 & 0.0011 & 1.50 & 0.69 & 2.15 & -- & $26.7(2.04)$ \\
\hline 7HO & $7 \times 7$ & 0.013 & 0.0011 & 0.967 & 1.34 & 2.28 & 2.59 & $26.2(1.86)$ \\
\hline 8 (AL ICE) & $7 \times 7$ & 0.0059 & 0.0011 & 1.43 & 0.59 & 1.9 & $=$ & $27.0(1.92)$ \\
\hline
\end{tabular}

Abbreviations: MSHE = Molten-salt/beryllium/helium; $T=$ tritans

bred/triton consumed; $F=f i s s t l e$ atoms bred/triton consumed; $E$ = energy

released in blanket (MeV)/triton consumed; $M=E / 14 ; 7 H O=$ homogenized

version of Case 7.

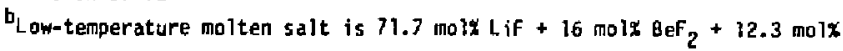
$\operatorname{ThF}_{4}$.

'Standard deviation $<2 x_{\text {. }}$. 
Table 2-5. Comparison of the molten-salt/beryllium/helium unit cell values with those for the reference beryllium/thorium/lithium unit cell (values in parentheses). a,b

\begin{tabular}{|c|c|c|c|c|c|c|}
\hline \multirow[b]{3}{*}{$T$} & \multirow[b]{3}{*}{$\mathbf{F}$} & \multirow[b]{2}{*}{$T+$} & \multirow[b]{3}{*}{$M$} & \multicolumn{3}{|c|}{ Partitioning of energy in } \\
\hline & & & & MS & & Fe tube \\
\hline & & $F_{\text {net }}$ & & (or Th) & $\mathrm{Be}$ & (or Li) \\
\hline 1.22 & 0.97 & 2.16 & 1.95 & $72 \%$ & $23 \%$ & $4 \%^{C}$ \\
\hline$(1.28)$ & $(1.11)$ & $(2.32)$ & $\{2.32\}$ & $\langle 47 x\rangle$ & $\{26 \%\}$ & $(27 \%)$ \\
\hline
\end{tabular}

$a_{U / T h}=0.11 \%(0.25 \%)$.

babreviations: $T=$ tritons bred/tritons consumed; $F=$ fissile atoms bred/triton consumed; $M S=$ molten salt.

Neutron transport only. 
compared for the 7-by-7 pitch case (\$7) and the unit cell of last year's reference blanket. Also listed in Table 2-5 is the partitioning of energy in the various materials. The molten-salt values may change somewhat when gamma transport is included. Aiso activation-product decay heating is not yet inciuded. Th-233 and Pa-233 should be the major contributors. Case $7 \mathrm{HO}$ is a homogenized version of Case 7. Comparing the two cases (7 and 7H0) gives an estimate of the error introduced by homogenizing the blanket for calculational simplification. The homogenized case over-predicts $T+F$ by $6 \%$.

Case 8 is the same as Case $7 \mathrm{a}$ except the $27 \mathrm{~mol}^{\mathrm{T}} \mathrm{ThF}_{4}$ salt is replaced by the lower melting point 71.7 mol\% $\mathrm{LiF}+16 \mathrm{~mol}^{\circ} \mathrm{BeF}_{2}+12.3 \mathrm{~mol} \mathrm{ThF}_{4}$ salt. This change results in an $8 \%$ drop in $T+F$.

\subsubsection{CYLINDRICAL MODEL}

We initially used a simple radial-zoned cylindrical model to study the effects on performance of a finite-thickness blanket and first-wall structure. The model consists of an iron ( $F e$ ) first wall (1-cm thick and an inner radius of $150 \mathrm{~cm}$ ) that is followed by a $59-\mathrm{cm}-$ thick zone containing a homogenized mixture of the bed materials, as did Unit Cell 7HC. The outer radius of the bed (at $210 \mathrm{~cm}$ ) is a radial leakage boundary. The DT plasma is modeled as a volumetric, cylindrical, isotropic, 14-MeV neutron source with a radius of $60 \mathrm{~cm}$. Results of a TART calculation with this model are listed in Table 2-6. These results show that the $\sigma_{L i}$ concentration must be increased to increase tritium breeding $(T)$. This should also increase $T+F$.

The homogenized bed of the cylindrical model includes 0.8 vol\% Fe to account for the molten-salt-containing tube walls. The few additional structure required for strurtural support and for helium ducting is not expected to reduce breeding $(T+F)$ by more than a few percent, and its effect will be partially compensated for by reducing first-wall thickness, from the $1.0 \mathrm{~cm}$ assumed to a more reasonable value. These assumptions will be tested with a more exact model that will include the heterogeneous nature of the structure as well as the tubes.

It is also apparent that a thicker blanket including a moderator and/ar reflector is needed to utilize the rather large radial leakage found in this case. For estimating $T+F$ with this case, it is assumed that $80 \%$ of the leakage can be utilized. 
Table 2-6. Cylindrical-model TART calculations. a

\begin{tabular}{ll}
\hline$T$ & 0.62 \\
Th $(n, y)$ & 1.04 \\
Leakage (radial) & 0.26 \\
$U(n$, fission) & 0.016 \\
$T h(n$, fission) & 0.008 \\
$U(n, \gamma)$ & 0.0021 \\
Tota) captures in bed & 1.87 \\
Energy (MeV) & $21.6(M=1.54)$ \\
Total captures in first wall & 0.122 \\
$T+F_{\text {net }}{ }^{2} 0.62+1.02+(0.8)(0.26)$ & 1.85 \\
\hline
\end{tabular}

$a_{A T 1}$ values are per $14 \mathrm{MeV}$ source neutron. Standard deviation < $2 \%$.

\subsubsection{BLANKET PERFORMANCE ESTIMATE}

A preliminary estimate of performance is made by combining results from the unit cell and the cylindrical models. This is done by weighting the cylindrical $T+F_{\text {net }}$ results by the $T+F$ ratio from the heterogeneous (HET) unit-cell calculation and from the homogenecus (HOM) unit-cell calculation.

$$
\left(T+F_{n e t}\right)_{\text {blanket }}\left(T+F_{n e t}\right) c y 1 \frac{\left(T+F_{n}\right)_{H E T}}{\left(T+F_{n}\right)_{H O M}}=1.85 \times \frac{2.16}{2.28}=1.75( \pm 10 \%) .
$$

Net fissile breeding can now be estimated by subtracting the required tritium breeding $\left(T_{\text {req }}\right)$, assuming $T_{\text {req }}$ is 1.06 ,

$$
F_{\text {net }}=\left(T+F_{\text {net }} d_{\text {blanket }}-T_{\text {req }}=0.69( \pm 25 x) .\right.
$$

The percent uncertaintis s listed are only a crude estimate and are not based on uncertainty analysis. Performing a similar exercise for blanke: nnergy multiplication $M$ resulted in an estimate for $\langle M\rangle$ of 1.60 .

The next round of performance estimates for this blanket will be made with a more rigorous model that incorporates the heterogeneous ature of the molten salt in tubes and in a fintte-thickness model that includes $\vec{i}$ irst walls, structure, moderators, and/or reflectors. 


\subsubsection{HEATING PROFILES}

The cylindrical model was also used with TART to estimate the $(n+\gamma)$ heating profiles in the blanket. The profiles are tabulated in Table 2-7 and disprayed in Fig. 2-12. For this case, the tubes have a $2.54 \mathrm{~cm}(0 . \mathrm{d}$.) with a 7-by-7-cm pitch, thus the molten sait-containing tubes occupy 10\% of the volume. The curve labeled $P_{\text {avg }}$ is the result of a homogeneous calculation in cylinorical geometry. The curves labeled $P_{\text {tube }}$ and $P_{B e}$ are estimates of volumetric heating profiles in the tubes and the beryllium pebbles. They are calcuiated by weighting $P_{\text {avg }}$ by unit-cell derived energy partitioning and volume fractions. Volume fraction of the beryllium is $45 \%$. The fourth curve on the figure is the integrated energy deposition vs $r$ in kilowatts per centineter $(\mathrm{kW} / \mathrm{cm})$ of module length. This can be used to determine bulk temperature rise in the helium coolant. All curves are normalized to $1.0 \mathrm{~mW} / \mathrm{m}^{2}$ wall loading. The dashed portiuns of the curves are estimates of what will happen when the blanket is made thicker and a reflector is added. When doing the initial cut at the thermal hydraulics (TH), the dashed part of the curves were followed out to $210 \mathrm{~cm}$.

The rigorous model will also be used to accurately determine the heating profiles. 
Table 2-7. Power density in new Be-MS-Fe blanket at unit first-wall (FH) loading (first estimate)

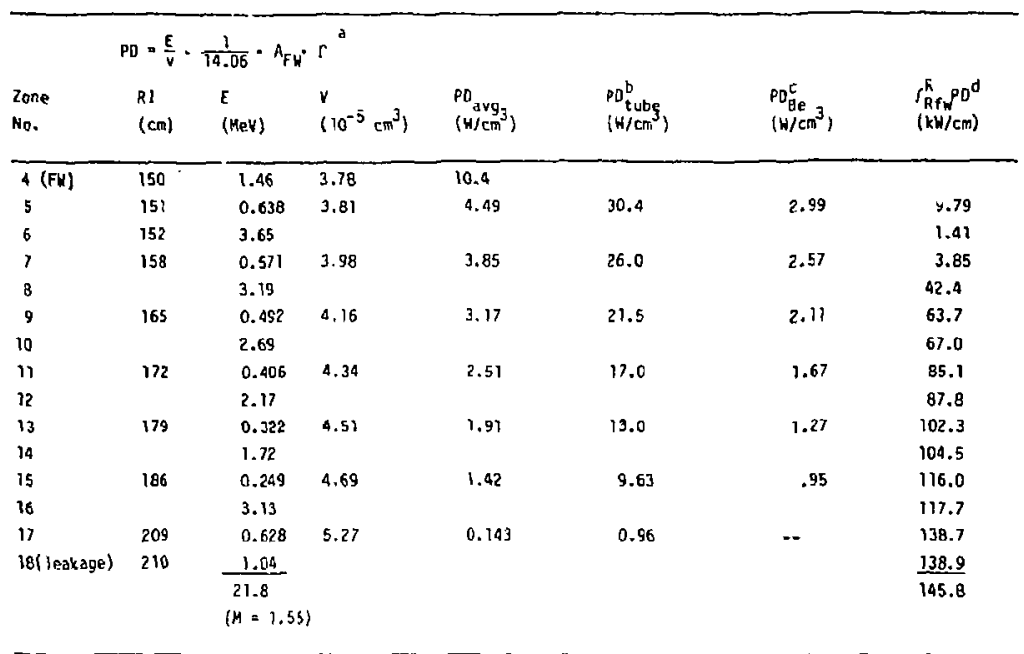

${ }^{a_{A_{H}}} \cdot \Gamma=(2 \pi 150 \times 400) 100=3.77 \times 10^{7}$.

$\mathrm{b}_{\mathrm{PD}}$ tube $=P D_{\text {avg }} \times E F_{\text {tube }} / V F_{\text {tube }}=P D_{\text {avg }} \times 0.7 / 0.103=P D_{\text {avg }} \times 6.77$.

${ }^{2} P_{B E}=P_{\text {avg }} \times E_{B e} / V F_{B e}=P_{\text {avg }} \times 0.3 / 0.45$.

(4) $\int_{R_{F W}}^{R} P D=\frac{R}{14.05} A_{F H}+\Gamma=\sum E \frac{R}{14.06} \times 1 \times 100=\sum E 0.6703$. 


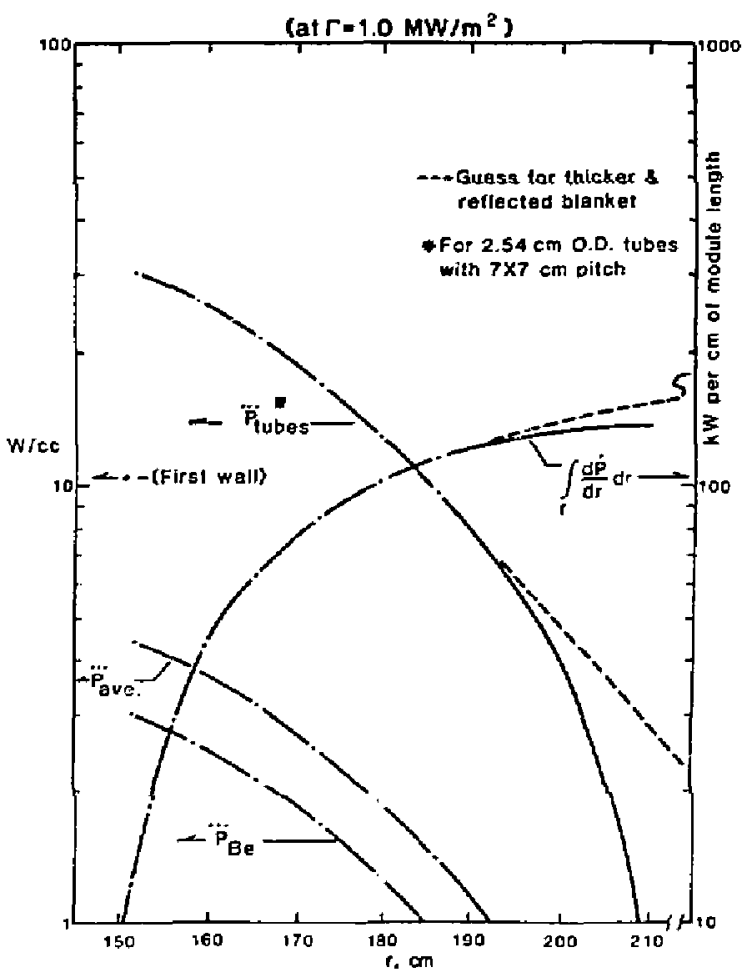

igure 2-12. First estimate of power densities in beryllium/molten-salt blanket. 


\subsection{THERMAL HYDRAULICS}

\subsubsection{SALT IN MOLTEN STATE (NO FROZEN LAYER)}

It is possible to arrange the chemical constituency of the mo? ten salt ( $L$ jF $70 \mathrm{~m} / \mathrm{o}+\mathrm{BeF}_{2} 12 \mathrm{~m} / \mathrm{o}+\mathrm{ThF}_{4} 18 \mathrm{~m} / \mathrm{o}$ ) so that its melting point is $530^{\circ} \mathrm{C}$. This may permit operation of the salt-tube in beryllium-pebbles blanket at conditions where no frozen salt layer exists on the inside surface of the salt tubes.

The variation of volumetric power generation with distance from the first wall is shown for a $1 \mathrm{MH} / \mathrm{m}^{2}$ first-wall flu: in Fig. 2-I3. Because our design is for $2 \mathrm{~mW} / \mathrm{m}^{2}$, all values read from this curve must be doubled.

Estimation of temperatures in the blanket involves the following relationships:

- How much of the total blanket energy is deposited in the coolant when it reaches tine radia] location of interest? This allows calculation of the coolant temperature at that point.

- What is the film coefficient of heat transfer on the outside of the tube? This permits calculation of the film temperature drop corresponding to the rate of energy deposited in the salt $\left(q_{s}\right)$.

- What thermal resistance does the tube wall offer? This allows calculation of the wall drop corresponding to the same $\ddot{q}_{S}$ as in the foregoing.

- What temperature difference develops from the tube centerline to the tube wall? This permits estimation of the maximum salt temperature for a given $\ddot{q}_{s}$. This salt iemperature should be at a safe margin from the boiling point. The boiling point of flibe at atmospheric pressure is $1267^{\circ} \mathrm{C}$. At 50 atm it is about $1810^{\circ} \mathrm{C}$. We assume our salt composition has similar boiling points.

The temperature difference through the helium-coolant film on the outside of the steel tube varies with the tube diameter, so long as the film coefficient may be assumed constant in the tube size range of interest -. namely 0.5 to $2.0 \mathrm{~cm}$ in diameter. We believe this assumption is valid, since the independently $c$ alculated $h_{c}$ values for balls and for tubes in that size range are very close, $0.2( \pm 20 \%) \mathrm{W} / \mathrm{cm}^{2} \cdot{ }^{\circ} \mathrm{C}$ when surface roughening is taken into account. There is significant variation of $h_{c}$ around each tube; 


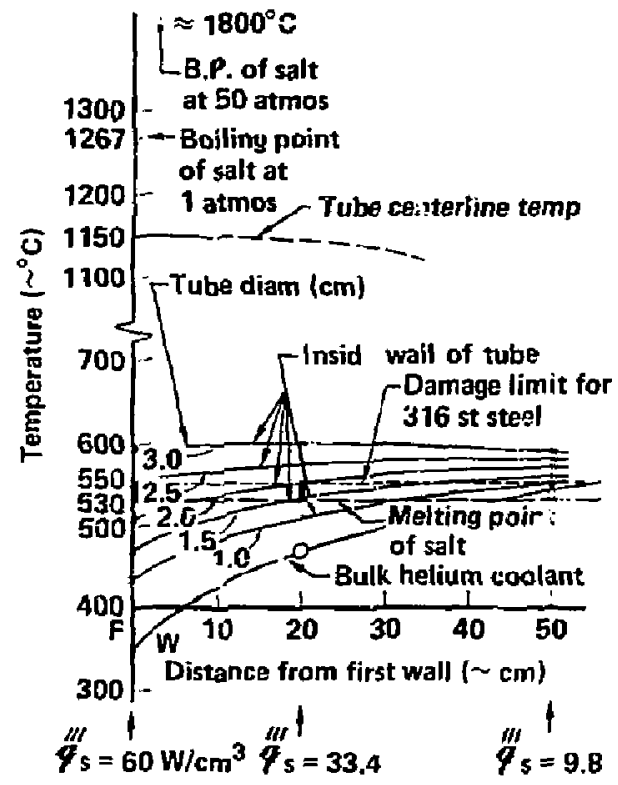

Figure 2.13. Helium coolant and salt-tube temperature versus position in blanket. 
however, the slowly flowing salt will average this variation. Since our packed bed is a mixture of balls and tubes of comparable size we believe that the same surface heat-transfer coefficient should apply to ali surfaces in the bed.

Heat renoved from the sait crosses four thermal resistances:

(1) conductive resistance of the salt, (2) the tube wall, and (3) two film drops (one outside and one inside the tube). If the salt were in the solid state, its own low thermal conductivity would result in large temperature differences between the salt near the tube centerline and the sait near the wall. But our salt is liquid, hence mobile. Its density varies approximately as

$$
\rho\left(\frac{\mathrm{g}}{\mathrm{cm}^{3}}\right)=3.87-8\left(10^{-4}\right) \mathrm{T}\left({ }^{\circ} \mathrm{C}\right)
$$

We have calculated the expected rate of circulation within the salt tubes. If one assumes a temperature difference from tube centerline to wall of $500^{\circ} \mathrm{C}$ -- a to'erable number to stay far from the salt's boiling point -- it can be shown that circulation rates across the tube have characteristic velocities of 30 to $40 \mathrm{~cm} / \mathrm{s}$. These flows will be somewhat suppressed by MHD forces since the salt is an electrical conductor. Even if the true circulation rates are one-tenth those calculated, i.e., $4 \mathrm{~cm} / \mathrm{s}$, this rate of circulation inside a 1- to 2-cm-diam tube represents a substantial mixing mechanism. He believe temperature differentials within the molten salt can be maintained under $500^{\circ} \mathrm{C}$ by this natural convection process.

Sait throughput ve ocity is $10 \mathrm{~cm} / \mathrm{s}$. The vortex velocity because of density difference is approxinately $15 \mathrm{~cm} / \mathrm{sec}$ perpendicular to the tube ax is. Total velocity near the tube wall is then about $17.5 \mathrm{~cm} / \mathrm{s}$. With laminar bourdary-layer theory, we calculate a surface coefficient of about $0.22 \mathrm{~W} / \mathrm{cm}^{2}{ }^{\circ} \mathrm{C}$. Near the first wall this converts to $67^{\circ} \mathrm{C}$ film drop for a 1-cm-diam tube and $135^{\circ} \mathrm{C}$ for a $2-\mathrm{cm}-\mathrm{diarn}$ tube. The relationship is Iinear between tube diameter and $f i l m \Delta T$ for a given volumetric heating rate in the salt.

If the salt internal temperature difference is less than $500^{\circ} \mathrm{C}$, the circulation rate will be smaller. That will cause a lower surface film coefficient and a higher film temperature drop at the tube's inside surface. These opposing effects lead us to conclude that $600{ }^{\circ} \mathrm{C}$ is a high (conservative) estimate of the temperature difference between salt at the tube 
centerline to that at the tube inner surface, for tubes near the first wall. As tubes further back in the blanket are considered, the free convection velocity within a tube will probably be lower, since the volumetric piwer into the salt is less. This reduces the film coefficient at the tube's inner surface, but since fewer watts per unit area need be transmitted, the film temperature drop will be little changed.

We have assumed coolant inlet temperature at $300^{\circ} \mathrm{C}$ and have estimated that in flowing radially inward to the first wall and in cooling that first wall the bulk coolant temperature increases $55^{\circ} \mathrm{C}$.

The expression for the average teraperature drop in the coolant film on the outside of the salt tube becomes

$$
\Delta T_{f}=75 d\left({ }^{\circ} \mathrm{C}\right) \text {, }
$$

where $d$ is the salt tube diameter in centimeters. Similarly the tube-wall temperature drop is expressed as

$$
\Delta T_{t}=3.7 d \text {. }
$$

This assumes constant wall thickness of $0.05 \mathrm{~cm}$ and thermal conductivity for thp Type 316 stainless steel at $0.21 \mathrm{~W} / \mathrm{cm}^{\circ} \mathrm{C}$.

When all the temperature differences are summed, a plot such as that shown in Fig. 2-13 results. On this plot, we show points for a range of tube diameters at various depths into the blanket. The shaded area defines a "window" of acceptable tube sizes, bounded by the melting temperature of the sait $\left(530^{\circ} \mathrm{C}\right)$ and the acceptable operating temperature for the stainless stee 1 as a result of neutran-incuced damage effects that are a function of temperature. That temperature of $550^{\circ} \mathrm{C}$ is not a "sharp" limit. Temperatures as high as $600^{\circ} \mathrm{C}$ may be tolerated.

The power per unit volume $\left(\dddot{q}_{5}\right)$ deposited in the salt can be obtained from Fig. 2-14, remembering that our first-wall flux is $2 \mathrm{MW} / \mathrm{m}^{2}$ and that values read from the curve must be doubled. At the first-wall, $\dddot{q}_{s}$ is $60 \mathrm{~W} / \mathrm{cm}^{3}$; at $20 \mathrm{~cm}$ from the first wall, it is $33.4 \mathrm{~W} / \mathrm{cm}^{3}$; and at $50 \mathrm{~cm}$, it is $9.8 \mathrm{~W} / \mathrm{cm}^{3}$.

Figure 2-13 is interpreted as follows: just behind the first wall, the tube diameter must be between 2.2 and $2.4 \mathrm{~cm}$. Twenty centimeters further back in the blanket, the tube size must 1 ie between 1.4 and $1.9 \mathrm{~cm}$. Near the back of the blanket, the tubes must be quite sma11... no larger than $1 \mathrm{~cm}$. A practical lower 1 imit is from 0.5 to $0.8 \mathrm{~cm}$ in diameter.

At the back of the blankei, the present design restricts the temperature of the bulk coolant entering the return plenum to $545^{\circ} \mathrm{C}$. Reduction in $\mathrm{film}$ 


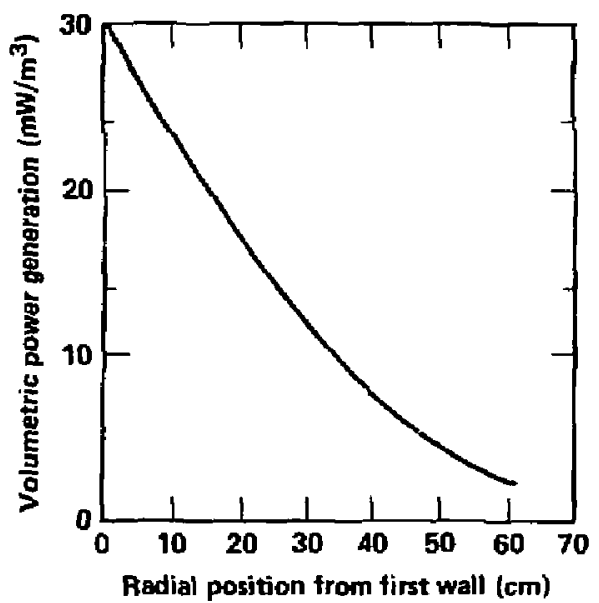

Figure 2.14. Spatial volumetric power $g$ eration in molten-salt tube at neutron wall loading of $1 \mathrm{MW} / \mathrm{m}^{3}$. 
temperature drop would allow higher-bulk coolant temperature without exceeding tube material temperature 1 imits. This larger coolant temperature rise equates to lower coolant flow rate. Both effects promote higher plant electrical output. Higher temperature improves cycle efficiency. Lower flow rates reduce coolant pumping power ( $\left.M H=k \times Q^{3} !\right)$.

The film temperature drop inside and outside the tubes can be reduced by decreasing the power density in the salt. This can be simply accomplished by increasing the fraction of salt in the desired zone. Virtually the same totzl amounc of enorgy would be deposited in the zone, so that the $\ddot{q}_{5}$ would be inversely proportional to the amount of salt present. Larger diameter tubes at a greater grid spacing (to maintain free ber: $\rceil$ lium pebble flow) accomplishes this. More salt results in less beryllium in a specified zone. Breeding will be slightly reduced because of lower neutron multiplication.

The tube diameters probably need not exceed 3 to $4 \mathrm{~cm}$ so as not to experience excessive temperature difference from tube centerline to wall. As previously discusscd, a strong convective mixing will be caused by temperatureinduced density difference. The salt electrical conductivity is quite low. If the convection is greatiy reduced by MHD effects, the temperature difference determined only by thermal conductivity might exceed 700 or $800^{\circ} \mathrm{C}$ between a tube centerline and the steel wall. We have not yet attempted to ilrlude MHD effects in our thermal-hydraulic calculations.

\subsubsection{THERHALL HYMRAULICS FOR CASE OF FROZEN SALT LAYER}

Early in this study we chose a 27 mol\% $\mathrm{ThF}_{4}$ salt with a melting point of $565^{\circ} \mathrm{C}$ because of high breeding as a result of less parasitic neutron capture. Later, to get a lower melting-point salt, we compromised and chose the $18 \%$ salt. The thermal hydraulic analysis for the frozen salt layer case is included here, because we may wish to return to the frozen layer concept.

The volumetric power generation in a molten-salt tube as a function of radial position from the first wall is given in Fig. 2-14, which is a replot of Fig. 2-12, for a neutron-wall roading of $1 \mathrm{mw} / \mathrm{m}^{2}$. (Note: the design value is $2 \mathrm{MH} / \mathrm{m}^{2}$.)

Using this power generation distribution, we give in Fig. 2-15 the temperature of the molten-salt center]ine and of the tube wall at the hottest 


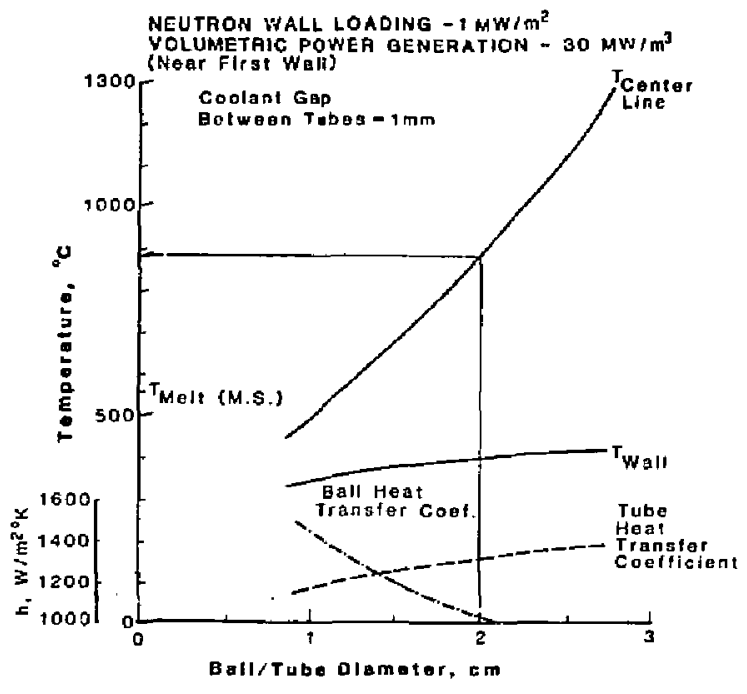

Figure 2.15. Tube wall and centerline temperatures as a function of tube d iameter. 
location near the first wall as a function of tube dianeter. The heattransfer coefficient for a single row of tubes spaced $1 \mathrm{~mm}$ apart is used for the calculation. The dimension of $1 \mathrm{~mm}$ is selected as a reasonable minimum gap that can be maintained by wire-wrap. The coolant used for this calculation is helium at 50 atmospheres, with an inlet/ouclet temperature of $285 / 550^{\circ} \mathrm{C}$, which can give a thermal cycle efficiency of $39 \% .{ }^{2-5}$ As indicated in Fig. 2-15, the average tube-heat transfer coefficient is similar to that of a packed bed of $1.3-\mathrm{cm}$ diam balis. Fig. 2-15 shows th-' at a neutron wall loading of $1 \mathrm{MW} / \mathrm{m}^{2}$, the tube wall temperature is well below the melting point of molten salt at $565^{\circ} \mathrm{C}$, indicating a frozen salt layer on the wall, which may help to protect the wall from corrosion. In this and the following calculations, the corresponding thermal conductivities used for beryllium, molten-salt (?? LiF-2 $\mathrm{BeF}_{2}-27 \mathrm{ThF}_{4}$ ) and tube-wall $(2-1 / 4 \mathrm{cr}-1 \mathrm{Mo})$ are $75.0,0.7$, and $33.0 \mathrm{~W} / \mathrm{m} \cdot \mathrm{K}$, respectively. Elsewhere we have chosen type 316 stainless steel for the tubes. Perhaps the choice should be given more thought.

As indicated in Fig. 2-15, at a fixed gap width of $1 \mathrm{~mm}$, the cross-flow parked-tube heat-transfer coefficient ${ }^{2-6}$ increases as a function of tube diameter and for a packed bed of fixed void fraction of 0.4 , its heat-transfer coefficient ${ }^{2-5}$ decreases as a function of ball diameter.

For a tube diameter of $2 \mathrm{~cm}$, the temperature distribution of the moltensalt tube is given in Fig. 2-16 as a function of blanket radial position. The tube centerline t.mperature decreases as a function of distance from the first wall because of the decrease in volumetric power generation. The wall temperature increases toward the back of the blanket ard is less than $10^{\circ} \mathrm{C}$ above the helium outlet temperature at the exit. At a coolant outlet temperature of $550^{\circ} \mathrm{C}$ the molten-salt tube at the back of the blanket will exceed $550^{\circ} \mathrm{C}$. To reduce this temperature, the helium outlet temperature can be reduced to somewhat below $550^{\circ} \mathrm{C}$ without severely impacting the thermal cycle efficiency. To reduce the reactor size, it is aiso of interest to increase the neutron wall loading. At a wail loading of $2 \mathrm{~mW} / \mathrm{m}^{2}$, Fig. 2-17 shows the molten-salt tube temperature at the centerline and wall as a function of tube diameter and tube radial position. As indicated in Fig. 2-17, with the tube sizes considered and a coolant outlet temperature of $500^{\circ} \mathrm{C}$, the tube wall temperature always stays below the melting cemperature of the molten salt. 


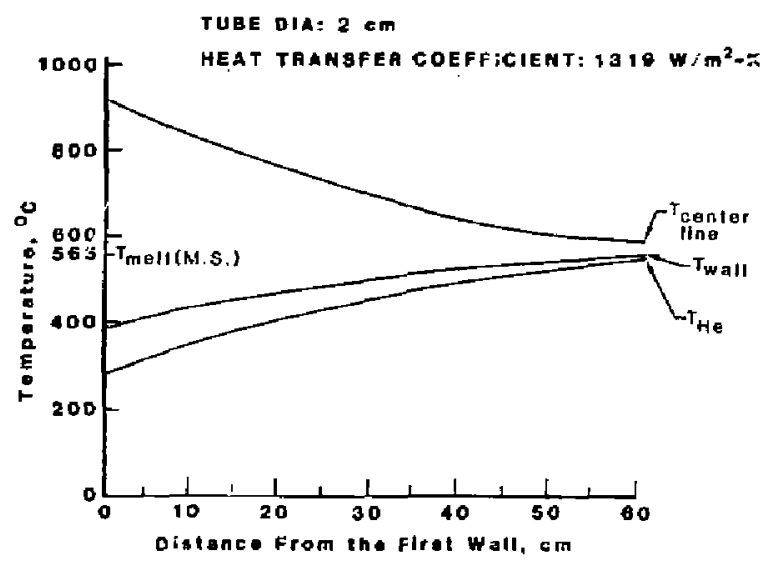

Figure 2-15. Temperature distribution for molten-sait tube at a neutron wall loading of $1 \mathrm{Mk} / \mathrm{m}^{2}$. 


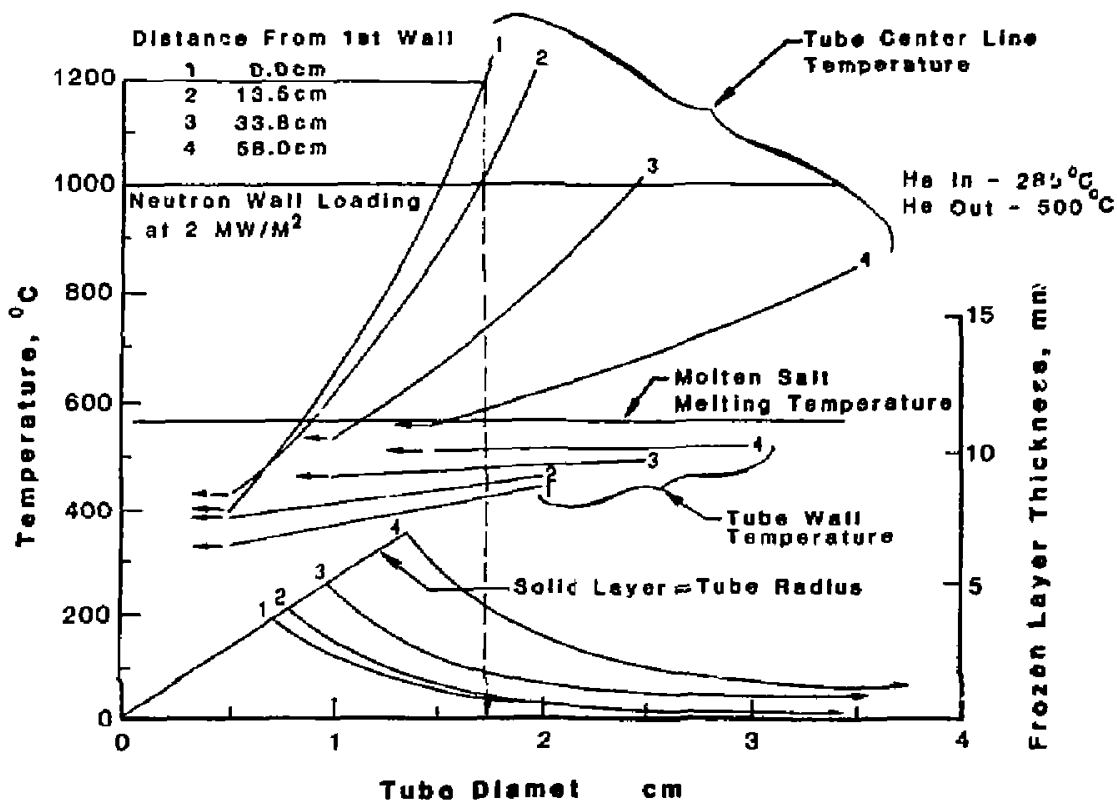

Figure 2-17. Temperzture of molten-salt tube and thickness of molten layer as functions of tube diameter. 
This means that a solid layer of the salt would be formed on the inside of the tube. The thickness of the molten-salt solid layer inside the tube as a function tube diameter and radial position is also indicated in Fig. 2-17.

In calculating the solid layer thickness, we approximated the natural convective heat transfer of electrically conducting fluid in a magnet ic field by assuming a magnetic-laminar-f low Nusselt number of $8.23 .^{2-8}$ Convection would enhance the fluid heat transfer by a factor of 2 over purely conductive heat transfer. This interpretation was compared by calculating the modified Peclet number $\mathrm{Pe}^{2-9}$, which gives the ratio of convective to conductive heat transfer in a uniform magnetic field. At a magnetic $\dot{r}$ ield of $A T$ and a characterist $: c$ dimension of $2 \mathrm{~cm}, \mathrm{Pe}=2.15$ wac $r \geq ?$ Luiated for FLiBe, which agrees well with the above model. Note from $\mathrm{Fig.} \mathrm{2-17}$ that with a tube diameter of $1.75 \mathrm{~cm}$, the maximum molten-salt temperature is $1200^{\circ} \mathrm{C}$, the maxim.um cube-wall temperature is less than $550^{\circ} \mathrm{C}$, and the solid layer ma: Imum thickness is $4 \mathrm{~mm}$.

A potential heat-transfer problem for this design is that hot spots may be generated near or at the contacts bet:een the ba!?s and tubes. A possible way of relieving the problem is by ribbing the tubes as shown in Fig. 2-18. This can reduce the solid-contact area and at the same time increase the heattransfer surface area of the moiten-salt tubes.

For the blanket configuration considered here, the pumping power for the helium bianket loop, including the steam generator side, can amount to $24 \%$ of the reactor thermal power. This would give a net thermal-cycle efficiency greater than $36 \%{ }^{2-5}$ The estimated percent age of pumping power fraction breakdown of the helium power conversion loop is given in Table 2-8. The blanket pumping power dominates the total helium loop pumping power. 


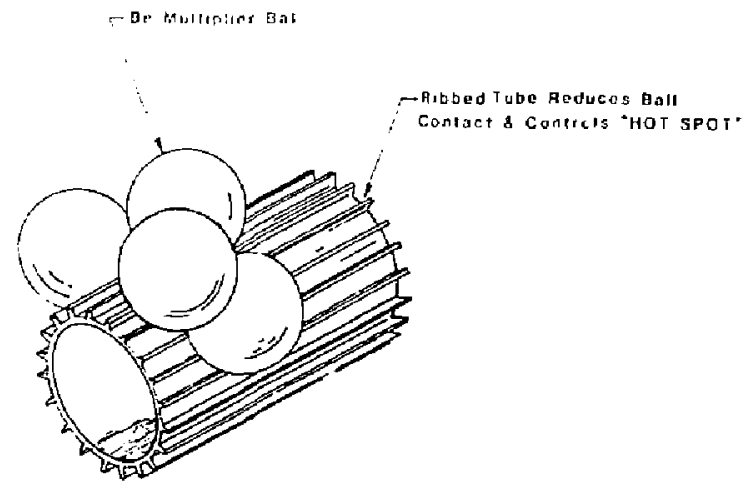

Figure 2-18, Ribbed-tube design. 
Table 2-8. Estimated helium-loop pumping-power distribution.

\begin{tabular}{|c|c|c|}
\hline Components & & $\begin{array}{c}\text { Punping-power fraction } \\
(\%)\end{array}$ \\
\hline Blanket & & 3.1 \\
\hline Frictiont & $1.4 \%$ & \\
\hline Turning, joining, and dividing & $1.3 \%$ & \\
\hline Expansion and contraction & $0.4 \%$ & \\
\hline Sector 1 ines; collection-ring ducts & & 0.1 \\
\hline Steam-generator piping & & 0.2 \\
\hline Steam generator & & $\underline{0.7}$ \\
\hline TOTAL & & 4.1 \\
\hline
\end{tabular}

Apumping-power fraction = pumping power/reactor therma $\mathrm{i}$ power. 


\subsection{SELECTION AND PROPERTIES OF MATERIALS}

\subsubsection{SALT COMPOSITION AND PROPERTIES}

From a neutronics point of view we would like to maximize the $\mathrm{ThF}_{4}$ concentration; however, higher $\mathrm{ThF}_{4}$ concentrations raises the melting temperature (see Table 2-9). The Molten Salt Reactor Experiment work was all with $i 2 \%$ (molar). We have considered using $27 \% \mathrm{ThF}_{4}$. The present design uses an intermediate composition of $18 \%$ which gives a melting point of $530^{\circ} \mathrm{C}$.

Table 2-9. Composition and properties of the blanket salt, using three concentrations of $\mathrm{ThF}_{4}$.

\begin{tabular}{|c|c|c|c|c|}
\hline \multirow[t]{3}{*}{ Composition (mol\%): } & $\mathrm{LiF}$ & 72 & 70 & 71 \\
\hline & $\mathrm{BeF}_{2}$ & 16 & 12 & 2 \\
\hline & $\operatorname{ThF}_{4}$ & 12 & 18 & 27 \\
\hline Liquidus $\left({ }^{\circ} \mathrm{C}\right)$ & & 500 & 530 & $565 \pm 5$ \\
\hline \multicolumn{5}{|l|}{ Properties it $600^{\circ} \mathrm{C}$ : } \\
\hline Density $\left(\mathrm{g} / \mathrm{cm}^{3}\right)$ & & 3.35 & 3.87 & 5.04 minus $8 \times 10^{-4} \mathrm{~T}$ \\
\hline Liquid heatcapacity & & & & where $T$ is in ${ }^{0} C$ \\
\hline$\left(\mathrm{cal} / \mathrm{g}^{\circ} \mathrm{C}\right)$ & & 0.33 & - & $0.23 \pm 5 \%$ \\
\hline Viscosity (centifoise) & & 12 & & 15 to 25 \\
\hline Vapor pressure (torr) & & $<0.1$ & & $\because$ \\
\hline Thermal conductivity $\left(\mathrm{W} / \mathrm{cm}{ }^{\mathrm{D}}\right)$ & & 0.011 & & $0.007 \pm 258$ \\
\hline Heat of fusion(cal/g) & & 63 & & 54 \\
\hline Electrical conductivity $(\Omega \cdot \mathrm{cm})$ & & 2.12 & & -- \\
\hline Expansion on melting (volw) & & & & 25 \\
\hline
\end{tabular}




\subsubsection{RADIATION DAMAGE AS BASIS FOR CHOICE OF AUSTENITIC STEEL}

Austenitic steel was chosen for this design. Tine arguments are discussed in 1983 by Abdou et al. $2-4$ The maximum operating temperature is $550^{\circ} \mathrm{C}$, which is somewhat arbitrarily chosen to avoid excess helium embrittlement. The lifet ime is $100 \mathrm{dpa}$ (about $8 \mathrm{MW} \cdot \mathrm{y} / \mathrm{m}^{2}$ or 5.7 years at $2 \mathrm{MH} / \mathrm{m}^{2}$ and $70 \%$ availability), after which time runaway swelling is predicted. With the austenitic steel there is no minimum temperature and no ductile-brittle transition above room temperature. Also, no special heat treatment of welds is necessary. The corrosion aspects are discussed in the next two sections.

\subsubsection{ANALYSIS OF RELEVANT CORROSION DATA}

The first nuclear reactor fueled by a molten salt, the Aircraft Reactor Experiment, was operated in 1954. The reactor circulated a molten mixture of $\mathrm{NaF}, \mathrm{ZrF}_{4}$, and $\mathrm{UF}_{4}$, using Inconel 600 as the containment material. Further development lec to the operation of the Molten Salt Reactor Experiment (MSRE) in 1965. This reactor was fueled with the molten salt mixture

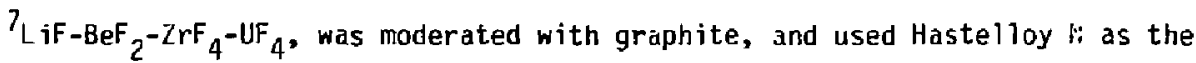
containment material. In the period between 1965 and the termination of the project in 1973, development studies were ajmed at a moiten sait breeder reactor (MSER) b:sed on a $\mathrm{Li}_{2} \mathrm{BeF}_{4}$ solvent containing $0.3 \mathrm{~mol}_{6} \mathrm{UF}_{4}$ and $12 \mathrm{mo}_{1 \%} \mathrm{ThF}_{4}$ * Hastelloy $\mathrm{I}$, the reference material for the MSBR, was used for constructing the supporting engineering and fuel-reprocessing test assemblies. This latter testing experience, combined with four years of operational experience in the MSRE and some eight years or developmental testin, prior to the MSRE, provides one of the largest data bases ever assembled for a reactor material ahead of commercialization.

The suitability of Hastelloy $N$ for MSBR service largely pre-empted the testing of alternative alloy systems. Limited irradiation tests of type 316 stainless steel were completed to compare the degree of embrittlement induced by themal neutrons with that induced in Hastelloy $N$. A type 316 stainless steel thermal-convectiun loop (TCL), discussed below, was operated with $\mathrm{L}_{2} \mathrm{BeF}_{4}$ to determine the suitability of stainless steels for concainment of nonfuel-containing salt. Two other stainless steel TCLs, one of $304 \mathrm{~L}$ and the other of 316 , were operated with $U_{4}$-containing salt to provide a 
baseline corrosion rate for iron-based alloys under nominal MSBR operating conditions. The latter loops provide a relevant, if limited, set of corrosion experiments from which to assess the potential of austenitic stainiess steels as containment materials for the molten-salt fusion reactor blarket. However, even more import ant is the detailed understanding of the corrosion mechanisrs and $k$ inetics acquired in the testing of Hastelloy $N$, which can be used to predict the corrosion behavior of alternative alloy chemistries.

The selection of a practical containment material for molten fiuoride salts begins with a consideration of the reduction-oxidation potentials of the component elements of the container with respect to components of the salt. Table 2-10 shows the electrode potentials of relevant alloying elements compared against a standard $\mathrm{HF}(\mathrm{g}) / \mathrm{H}_{2}$ electrode. We see that molybdenum and nickel each have lower oxidation potentials than iron and that al1 three of the latter elements have considerably lower potentials than chromium. Thus, in the absence of passivation, chromium will be the most reactive toward fluoride ions among the major al foying elements used commercially for high temperature alloys. The electrode potentials of various couples of thorium, protactinium, uranium, and plutoniur in molten $\mathrm{Li}_{2} \mathrm{BeF}_{4}$ are indicated in Fig. 2-19. ${ }^{2-10}$ The salt oxidation potential for which Hastelloy $\mathrm{N}$ was developed (and that maintianed in the MSKE) is shown by the shaded region in Fig. 2-19. Under the latter condition, the prefominant ionic species are $\mathrm{Th}^{4+}, \mathrm{Pa}^{4+}, \mathrm{U}^{4+}$, with some $\mathrm{U}^{3+}$ and $\mathrm{Pu}^{3+}$. Figure $2-20^{2-10}$ shows a Pourbaix diagram in which solubilities of $\mathrm{Cr}$. $\mathrm{Fe}$, and $\mathrm{Ni}$ in LiF-BeF $2-\mathrm{ThF}_{4}$ (72 Nb-12 rol\%) are shown as a function of the redox potential of the salt, expressed as the. ${ }^{n+} j^{3+}$ molar ratio. Also chown are the oxygen solubility limits for the formatior. of oxides of $\mathrm{Cr}, \mathrm{Fe}, \mathrm{Ni}, \mathrm{Th}$, and $\mathrm{U}$, respectively. Note that only chromium can exist at measurable concentrations in the meit when the $\mathrm{U}^{4+} / \mathrm{U}^{3+}$ ratio is below about $1 \mathrm{~m}$. Note aiso that precipitztion of structural metal or fuel component uxides is not significant at $\mathrm{U}^{4+} / \mathrm{U}^{3+}$ ratios below 100 unless the oxide mole fraction exceeds $10^{-3}$.

The chemictry of astelloy $N$ has been tailored tn achieve compatibility with $\mathrm{UF}_{4}$ - and $\mathrm{InF}_{4}$-containing salt mixtures by simply allowing the salt to "equilibrate" with the alioy. In any heat transfer system, true equilibrium between the salt and the alloy can never be attained because of temperature differences in the system. Nevertheless, it. a hastelloy $N$ closed-loop sys.em 
Table 2-10. Electrode potentials ${ }^{\mathrm{a}}$ of container materials in $\mathrm{Li}_{2} \mathrm{BeF}_{4}\left(600^{\circ} \mathrm{C}\right)$.

$$
\mathrm{Cr}^{2+} / \mathrm{Cr}^{\circ} \quad \mathrm{Fe}^{2+} / \mathrm{Fe}^{\mathrm{O}} \quad \mathrm{Mo}^{3+} / \mathrm{Mo}^{\mathrm{O}} \quad \mathrm{Ni}^{2+} / \mathrm{Ni}^{\mathrm{O}}
$$

$\begin{array}{lllll}\text { Potential (V) } & -0.45 & -0.08 & w 0 & 0.37\end{array}$

$a_{H F(g) / H_{2}}=$ zero volts.

charged with $\mathrm{UF}_{4}$-containing salt at 600 to $700^{\circ} \mathrm{C}$, a steady-state $\mathrm{U}^{4+} \mathrm{N}^{3+}$ ratio (shown experimentally to be in the range 100 to 350 is attained within a iew hundred hours. Under these conditions, corrosion proceeds by the selective oxidation of chromium at the hottest loop surfaces and by reduction and deposition of chromium at the colder loop surfaces as a consequence of the redox reaction

$$
2 \mathrm{UF}_{4}+\mathrm{Cr}=2 \mathrm{UF}_{3}+\mathrm{CrF}_{2} \text {. }
$$

In the case of the MSRE and MSBR fuel saits, the resultant maximum corrosion rate of liastelloy $N$ is well below $2 \mu \mathrm{m} /$ year at $704^{\circ} \mathrm{C}\left(1300^{\circ} \mathrm{F}\right)$.

If a 300-series austenitic stainless steel is exposed to $\mathrm{UF}_{4}$-containing salts under the same closed-system conditions described above, corrosion again is manifested by the selective removal of chromium from hot-leg surfaces and concommitant chromium deposition at cooler surfaces. However, because of the much higher chromium activity in the stainless steel compared with that in Hastelloy $\mathrm{N}$, the extent of chromium mass transport for stainless steels is considerably greater than for Hastelloy $\mathrm{N}$. Table 2-11 lists the operating conditions of two stainless steel thermal-convection $100 \mathrm{ps}^{2-6}$ that circulated lithium-beryllium salts containing 1 mol\% and $0.3 \mathrm{~mol}_{\mathrm{H}} \mathrm{UF}_{4}$, respectively. The former loop was constructed of type $304 \mathrm{~L}$ stainless steel and yielded corrosion data over a nine-year period. Corrosion was selected toward chromium and was controlled by the solid-state diffusion rate of 


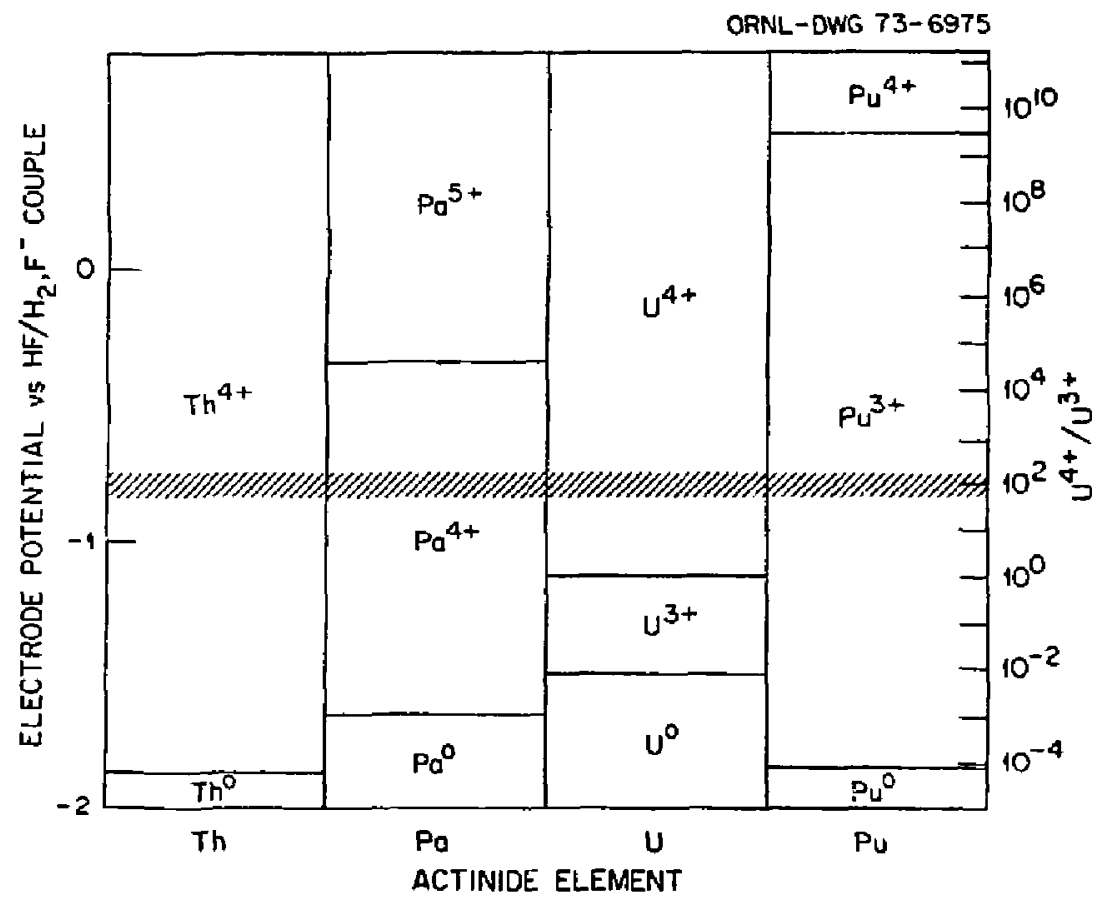

Fig. 2-19. 0xidation states of the actinides in $\mathrm{Li}_{2} 8 \mathrm{eF}{ }_{4}$ at $600^{\circ} \mathrm{C}$. (Ref, 2-10). 


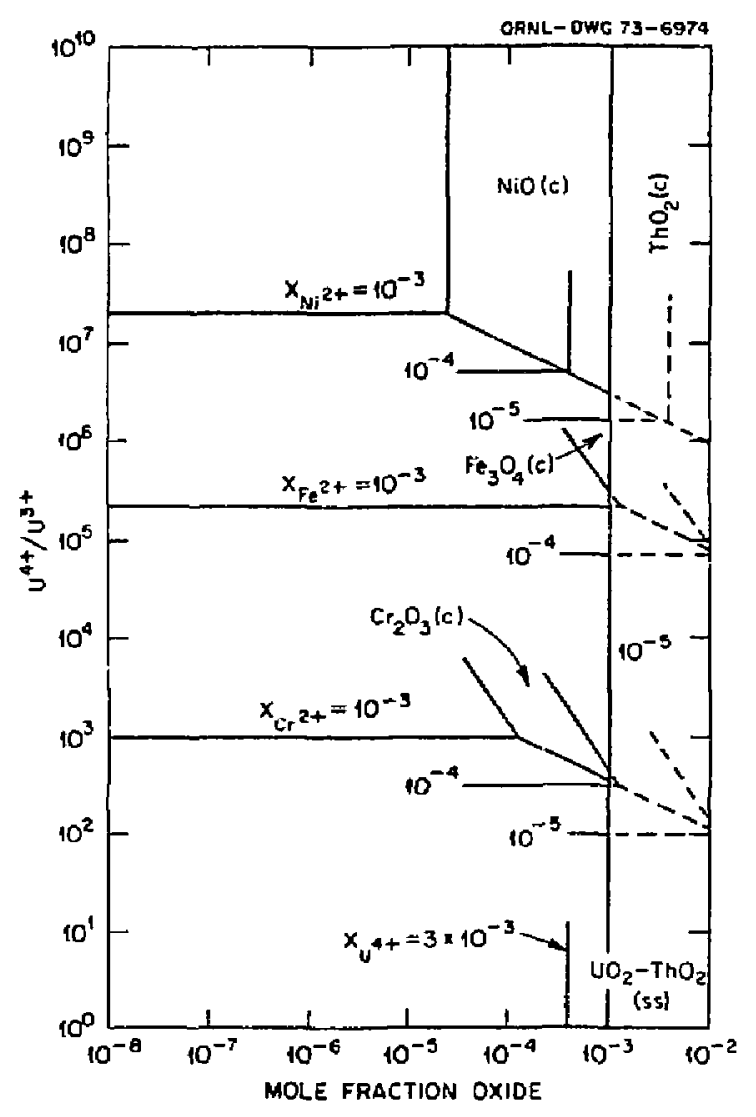

Fig. 2-20. Pourbaix diagram for structural metals in Lif-BeF $2-\mathrm{ThF}_{4}$ (72-16-12 mol\%) at $600^{\circ} \mathrm{C}$ (Ref. 2-10). 
Table 2-11. Operating congitions of stainless steel thermal-convection loops involving $L$ if $-B_{e} F_{2}$-based molten salts (Refs. 2- $T 1$ and 2-12).

\begin{tabular}{|c|c|c|c|c|}
\hline \multirow[b]{2}{*}{$\begin{array}{l}\text { Loop } \\
\text { material }\end{array}$} & \multirow{2}{*}{$\begin{array}{c}\text { Salt } \\
\text { composition } \\
(\text { molo })\end{array}$} & \multicolumn{2}{|c|}{ Temper ature } & \multirow[b]{2}{*}{$\begin{array}{r}\text { Time } \\
\text { (h) }\end{array}$} \\
\hline & & $\begin{array}{l}\text { Maximum } \\
\qquad\left({ }^{\circ} \mathrm{C}\right)\end{array}$ & $\begin{array}{c}\Delta \mathrm{T} \\
\left({ }^{\circ} \mathrm{C}\right)\end{array}$ & \\
\hline $304 \mathrm{~L} 5 \mathrm{~S}$ & $\begin{array}{l}\mathrm{LiF}-\mathrm{BeF}_{2}-\mathrm{ZrF} \mathrm{F}_{4}-\mathrm{ThF}_{4}-\mathrm{UF}_{4} \\
\quad(70-23-5-1-1)\end{array}$ & 688 & 100 & 83,520 \\
\hline $316 \mathrm{SS}$ & $\begin{array}{l}\text { LiF-BeF } 2-\mathrm{ThF}_{4}-\mathrm{UF}_{4} \\
(68-20-11.7-0.3)\end{array}$ & 650 & 110 & 4,490 \\
\hline 316 SS & $\begin{array}{r}\mathrm{LiF}-\mathrm{BeF}_{2} \\
(66-34)\end{array}$ & 650 & 125 & 25,100 \\
\hline
\end{tabular}

chromium (parabolic time dependence). Although the weight loss over the nine-year perioo was relatively small (equivalent to an average uniform corrosion rate of $21.8 \mu \mathrm{m} /$ year at $688^{\circ} \mathrm{C}$ ), corrosion was manifested as subsurface voids that extenced several millimeters below the surface. The second loop shown in Table 2-11 was constructed of type 316 stainless stee and operated for 4490 hours. The corrosion rate of this loop was slightly lower than the $304 \mathrm{~L}$ stainless steel loop during the equivatent time periad. However, corrosion again was lianifested by subsurface voids, in this case to a depth of $26 \mu$ m at $650^{\circ} \mathrm{i}$.

\subsubsection{CORROSION PROPERTIES OF THE TMHR BLANKET}

The corrosion aata discussed above indicate that the rate of thermal grawient mass transport of austenitic stainless steels caused by the $\mathrm{Cr}$-UF 4 reaox reaction is solid-state diffusion 1 imited and, theretore, is relatively 
slow. Nevertheless, the depletion of chromium at the hotter surfaces can be expected to degrade the mechanical properties of the steels as the operating period exceeds about one year. It is possible, howev's, to significantiy lawer these rates by (1) reducing the chromium concentration of the steel and (2) reducing the redox potential (i.e., $U^{4+} / U^{3+}$ ion activity ratio) in the salt. The effectiveness of the first approach can be seen by examining the corrosion rate of a maraging steel $(12 \% \mathrm{Ni}, 5 \% \mathrm{Cr}, 3 \% \mathrm{Mo}$, balance $\mathrm{Fe})$ that was tested $^{2-6}$ as a coupon in the 304L loop listed in Table 2-11. The average corrosion rate of this steel during a $5700 \mathrm{~h}$ exposure at $662^{\circ} \mathrm{C}$ was a factor of 2 lower than that of 304L stainless steel at the same loop position. The effectiveness of controlling the redox potential of the salt is illustrated by corrosion-rate data obtained fron the third stainless steel 100p ${ }^{2-12}$ with operating conditions 7 isted in Table 2-11. In this latter type 316 stainiess steel 10op. no uranium was contained in the salt, and the redox potential was adjusted by buffering the salt with metallic beryllium. Before adding the beryllium. Lile corrosion rate of the 316 stainless steel under closed system conditions averaged $8 \mu \mathrm{m} /$ year at $650^{\circ} \mathrm{C}$. After contacting the salt with a small metallic beryllium rod, the corrosion rate was lowered to $2 \mu \mathrm{m} /$ year over a 2000-h test period.

Corrosion may also be induced by the intense radiation fields within the blanket (e.g., through radiolytic decomposition of the fluoride salts) or by neutronic transmutations involving lithium, beryllium, and fluorine. Fortunately, $\mathrm{LiF}_{-\mathrm{BeF}_{2}}$ based salts appear to have good radiation stability provided the salts are kept at temperatures in excess of $150^{\circ} \mathrm{C}$, and it has been shown by means of extensive in-reactor testing that under these conditions radiolytic decomposition processes do not lead to enhanced corrosion of structural metals. ${ }^{2-13}$ Chemical transmutations iead to production of excess fluorine in the molten salt (thereby iendering it more oxidizing towards its container), however this increase in corrosion potential can be avoided by inclusion of a suitable redox buffer $\left(e . g ., c_{e}^{3+} / c_{e}^{4+}\right)$ in the me 1 t. $2-14$

The selection of type 316 stainless steel as the reference material for the TMHR piping is predicatcd (1) on acceptable mechanical properities following high-fluence neutron exposures and (2) on acceptable corrosion resistance in $\mathrm{LiF}_{-\mathrm{BeF}_{2}}$ salts containing uranium under controlled oxidation conditions. Based on the corrosion studies discussed above, the $\mathrm{UF}_{4}: \mathrm{UF}_{3}$ 
molar ratio in the salt must be maintained at a somewhat lower value than that which occurs naturally in a closed system charged with UF ${ }_{4}$-containing sajt. This can be accomplished by chemical buffering, e.g., contacting the salt with a reactive metal such as chromium. (Such a buffering step is also required to control the buildup of oxi.iants in the salt that accrues from transmutation reacions, as discussed in Section 2.2.) There is, however, a lower limit on the $\mathrm{UF}_{4}: \mathrm{UF}_{3}$ ratio that is set by the disproportionation of $\mathrm{UF}_{3}$ through the reaction $3 U_{3}+4 U_{4}+U^{0}$. The lowest $U_{4}$ : UF $_{3}$ ratios attained during sustained exposures of $\mathrm{Li}_{2} \mathrm{BeF}_{4}$ salts have been on the order of 10 , and no measurable $U_{3}$ disproportionation has occurred under these conditions. Lower ratios may, therefore, be feasible; however, a ratio of 10 represents a relatively reducing condition from the standpoint of $\mathrm{UF}_{4}-316$ stainless steel chemical interactions (ses, for example, Fig, 2-20) and $i$ : considered adequate for TMHR at the proposed time and temperature conditions.

In summary, corrosion tests of 316 stainless stee 1 have not yet been conducted under the exact conditions and salt chemistries specified for the TMHR. Nevertheless, there is an extensive background of relevant information, concerning molten-fluoride salt-corrosion mechanisms and operating requirements, that provides a rational basis for the TMHR blanket desigi.

\subsection{Siñ̃i-UP SCENARIO}

The problem of start-up of molten-salt systems results from the large difference between the inlet helium coolant temperature of around $300^{\circ} \mathrm{C}$ and the melting point of the salt at $530^{\circ} \mathrm{C}\left(490\right.$ to $565^{\circ} \mathrm{C}$ for the range of compositions under consideration). If the molten salt were pumped into the blanket with the fusion neutron source off, the salt would freeze in the pipes. Later melting could break the steel pipes because of the $5 \%$ volumetric expansion upon melting. Once the reactor is operating, the nucitar heat generation in the salt keeps its temperature above the melting point. At the front of the blanket where the helium is coldest $\left(300^{\circ} \mathrm{C}\right)$ the heat generation is highest, and we predict helium film drops (not to mention the film drop in the salt) of over $200^{\circ} \mathrm{C}$. So, in principle, if one can start up, there is no problem under normal conditions. At shut down the problem is fundamentaliy easier to handle than start-up because of the decay nuclear heating. However, freeze-up still can occur. 
Two possible approaches to start-up will be discussed. The first (reference case) is to raise the helium inlet temperature to just over $530^{\circ} \mathrm{C}$, introduce the salt and then program tine inlet temperature down as the neutron source is brought on. The second case (backup) requires introducing the salt at the same time as the neutron source is brought on. In either start-up approach, the salt would be drained at shut down. If the salt will gravity drain at $0.1 \mathrm{~m} / \mathrm{s}$ and the mean pipe length is $20 \mathrm{~m}$, then the entire blanket can be drained in $200 \mathrm{~s}$. We propose to force circulate the salt with pumps at over $0.1 \mathrm{~m} / \mathrm{s}$ to process out the tritium; hence the pipe system will be so constructed as to allow rapid circulation and drainage. The important point seems to be to keep the steam generator operating near its design point ( 2 $500^{\circ} \mathrm{C}$ helium inlet and $2300^{\circ} \mathrm{C}$ helium outlet). This can be done with a helium preneater as shown in Fig. 2-21, which is valved out of the circuit after start-up.

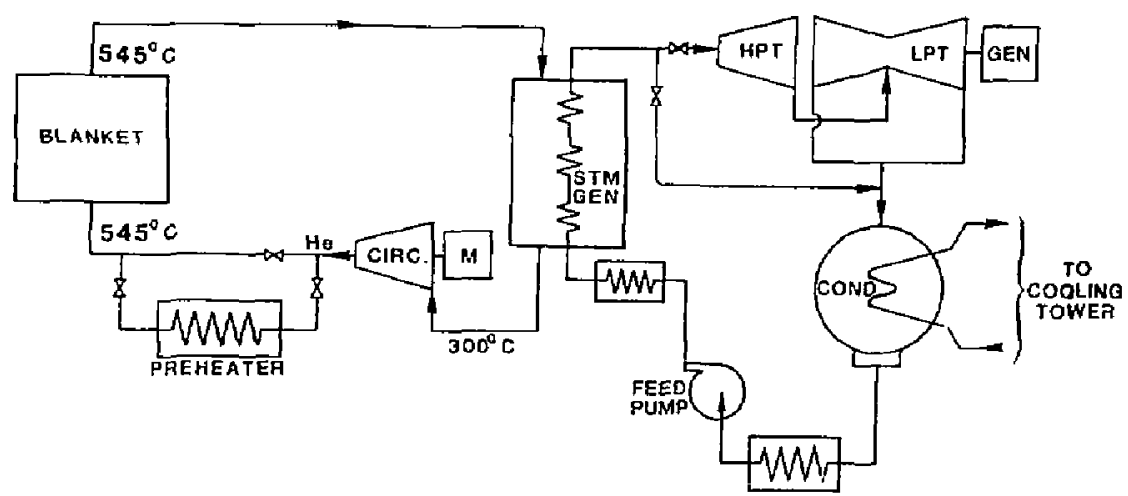

Figure 2-21. Start-up scenario. 


\section{Reference Start-Up Method}

This method invoives preheating the entire bianicet to a temperature $15^{\circ} \mathrm{C}$ above the melting point of the sait $\left(530^{\circ} \mathrm{C}+15^{\circ}=545^{\circ} \mathrm{C}\right.$, for example $)$. The sequence is as follows:

1. The blanket is preheated (over a period of hours) by circulating helium through a preheater: The helium inlet temperature is $545^{\circ} \mathrm{C}$ and finally the outlet will be $545^{\circ} \mathrm{C}$. Steam is generated in the steam generator at a low rate to reduce the helium temperature to $300^{\circ} \mathrm{C}$ at the circulator inlet.

2. The preheated salt is introduced into the blanket and continues to circulate.

3. The neutron source is brought on slowiy.

4. Simultaneously, the inlet temperature of the helium is lowered by controlling the amount of helium preheat.

5. The helium circulator speed is controlled to keep the outlet temperature of the helium at $545^{\circ} \mathrm{C}$.

6. For pianned shutdown the salt would be drained and the helium circulators slowed down to remove decay heat from structural material.

7. Steam generated in the stean generator would be condensed in the condenser.

\section{Backup Method for Start-Up}

In this method we simultaneously introduce the salt as the neucron source is brought on. The sequence is as follows:

1. The blanket is preheated over hours by circulating helium. Fricticr, losses will be sufficient to warm up the helium and blanket mass to $300^{\circ} \mathrm{L}$. No steam would be generated in the steam generator.

2. The neutron source is slowly brought on, perhaps by starting up the plasma to a fraction of full density and temperature and raising the ratio of deuterium to tritium.

3. The preheated salt is introduced into the blanket at a temperature $20^{\circ} \mathrm{C}$ or so above the melting point.

4. The helium circulators are speeded up as the power increases, keeping the out?et helium temperature close to the $545^{\circ} \mathrm{C}$ design value.

5. For planned shut down, the salt would be drained and the helium circulators slowed down to remove decay heat from structural material. 


\section{Rapid Shutdown}

1. Begin salt draining.

2. Slow down circulators. (Some salt freezes on walls while the neutron source is off, and cool helium is circulated).

3. Allow any frozen layer to meit and drain.

\subsection{SAFETY}

In the moiten-salt fusion-breeder, we have come very close to achieving a design that can be completely and passively cooled during an accident, without any damage occurring to the reactor.

A predominant safety concern in fusion breeders has been the accident where loss of cooling causes riolting and release of radioactive nuclides. Suppression of fission greatly reduces the production rate of fission products. With the molten-salt fusion breeder, we have a design wherein the salt will drain into holding tanks and can be cooled passively by, for example, heatpipes, which dump the heat into the atmosphere. After an accident or off-normal situation occurs and the neutron source is turned of $f$, the reactor can cool itself by passive means. For this to be true, we must show that the blanket will not melt because of induced radioactivity of the steel structure alone.

Some of the fission products and actinides in the salt are continuously removed and, hence, their inventory quickly reaches a steady-state value. other fission products are not removed and their inventory increases linearly with time; the only loss being radioactive decay. Since there is so little si 't in the reactor, it can be disposed of every few years, thus limiting the inventory of the few radionuclides that are hard to extract.

\subsection{FROZEN SALT-LAYER ISSUES}

At one point in the design iterations of the helium-cooled molten-salt bianket, the design called for steel tubes cooled to a temperature somewhat below the salt melting point. It was feit this would heip reduce corrosion. The 27-mol\% $\mathrm{ThF}_{4}$ salt melted at $565^{\circ} \mathrm{C}$. Later in the design cycle, we realized the corrosion with 316 stainless steel was low if the salt is kept reducing. Further, we were concerned that even if we wanted a frozen layer, 
some places would be under-cooled and these walls would not have a frozen layer. To keep the wall temperature down, we lowered the meiting point to $530^{\circ} \mathrm{C}$ by going to the $18-\mathrm{mo} 1 \% \mathrm{ThF}_{4}$ salt and selected a no-frozen-layer design.

Even so, some areas will be over-cooled, so we will likely have a frozen layer in a few places. To cover the case where some frozen layers exist and the case where we might want to go back to a full-coverage frozen layer, we will discuss some of the issues on frozen-salt layers.

\section{SOME THOUGHTS ABOUT A TMHR WITH FROZEN-SALT WALLS}

The question "How often do you need to thaw the frozen layer?" involves many complexities and, in our view, not completely answerable without a great deal of experimentation. The question of fluorine generation is not the only issue involved, and it may very well not be the most important one.

The MSR salt ( $69 \mathrm{LiF}, 29.1 \mathrm{BeF}_{2}, 5 \mathrm{IrF}_{4}$, zero UF ${ }_{x}$ ) did not generate $F_{2}$ while molten and under its (relatively low) full fission power. And it did not generate $F_{2}$ when solid and above about $150^{\circ} \mathrm{C}$ while exposed to the radiations from fission product decay. The fact that it did generate $F_{2}$ at temperatures below about $150^{\circ} \mathrm{C}$ under fission-product-decay energy may wel 1 have been due to the presence of a complex and exotic crystalline $L \mathrm{iF}-\mathrm{BeF}_{5}-\mathrm{ZrF}_{4}$ compound, and the MSRE fuel be a special case. But we do not know whether MSRE fuel or any other fluoride - would generate ano release fluorine when soitd and under very high radiation levels. This must be tested; we did not test this because we had no need to do so.

The proposed Tanden Mirror Hybrid Reactor (TMHR) is to generate $5.4 \times 10^{-3} \mathrm{~g} / \mathrm{s}$ of $T$, essentially all by reaction of neutrons with ${ }^{6} \mathrm{~L} i$. After the reaction products equilibrate with a well stirred melt (which the TMHR bianket fluid may not be) the overall reaction (in the absence of reducing agents) presumably is as follows:

$$
n+{ }^{6} \text { LiF }^{4} \mathrm{He}+\mathrm{T}^{+}+\mathrm{F}^{-} \text {, }
$$

with TF dissolved in the malten salt. We propose to keep the TF reduced to $T_{2}$ (in the molten portion of the blanket) by

$$
2 \mathrm{UF}_{3}+2 \mathrm{TF}+2\left(\mathrm{UF}_{4}\right)+\mathrm{T}_{2}
$$


Generation of $5.4 \times 10^{-3} \mathrm{~g} / \mathrm{s}$ of $T$ is equivalent to generation of $2.77 \times 10^{-11}$ g-mol/s. $\mathrm{cm}^{-3}$ TF of the $65 \mathrm{~m}^{3}$ of TMHR salt along with an equal qu: itity of He. If all $65 \mathrm{~m}^{3}$ of active salt were molten, reduction of Tf at this generation rate (with $6 \%$ of the $U$ as $U F_{3}$ entering the system and $5 \%$ as $U F_{3}$ leaving the system) would require some 820 litres/min to the reducer and a reducer cycle time of about $1.4 \mathrm{~h}$. This is probably all right. The gcnerated $T_{2}\left(1.385 \times 10^{-11} \mathrm{~mol} / \mathrm{s} \cdot \mathrm{cm}^{-3}\right)$ must be removed, along with the $\mathrm{He}$, at a more rapid rate, because in $1.4 \mathrm{~h}(5040 \mathrm{~s})$ the effective pressure of $\mathrm{T}_{2}$ would be about $1.93 \mathrm{~atm}$ and that of He would be near 1.6 atm at $500^{\circ} \mathrm{C}$. The TMHR salt will be under 500 psi or greater, so there should be no gas bubbles until the salt is depressurized.

None of this seems out of the question. Stripping of the $T_{2}$, He, and $\mathrm{Kr}+\mathrm{Ke}$ on 8000 litres/min ( $8.13-\mathrm{min}$ resicience time) would be at effective $\mathrm{dT}_{2}$ pressure of 145 torr, He pressure of 117 torr, and $\mathrm{Kr}+\mathrm{Xe}$ at about 40 torr. One should be abie to add I rol\% of He (before pressurizing the salt) and have no bubbles in the 500 psa system. Ali of this may be feasible.

The discussion immediately above is based on the assumption that the frozen-salt film effectively prevents diffusion of tritium into the coolant helium. We doubt seriously whether this will prove to be the case in any realistic system such as that with an 8 -min tritium cycle time.

What sort of flow rate does-this imply in the tubes? We cannot answer this without some further assumptions. To confine $65 \mathrm{~m}^{3}$ of salt within 0.5-in.-dian tubes requires $5.13 \times 110^{7} \mathrm{~cm}\left(5.13 \times 10^{5} \mathrm{~m}\right)$ of tubing. These are presumably distributed equally among 40 to 50 modules, so each module contains at least $1.030 \times 10^{4} \mathrm{~m}$ of tubing. If we assume the average tube length is $100 \mathrm{~m}$ (which may welt be awkwardly long) we have a total of 5130 entrances and exits (ca. 100 each per module).

To flow 80001 itres/min, therefore, presumes a flow rate of about $0.2 \mathrm{~m} / \mathrm{s}$ in each of the tubes. [We have for the moment ignored the frozen film.] This sluggish flow will almost certainly mean that the salt in some tubes will be stagnant. Faster flow with the same number of tube sections (perhaps with only an 8000 litre/min stipstream through the stripper) may be feasible, as may longer and fewer tubes. There are obviously difficuit design questions here that can be addressed only after detailed analysis and modeling of the system. 
The priposed TMHR is to generate about $0.25 \mathrm{~g} / \mathrm{s}$ of ${ }^{233} \mathrm{Th}$. After equilibration, the $65 \mathrm{~m}^{3}$ of active salt will contain some $3612 \mathrm{~g}$-mol of

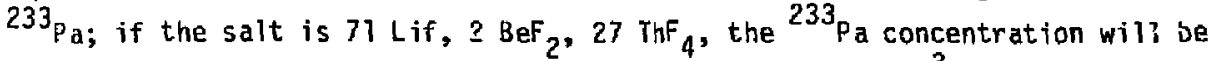
about $0.125 \mathrm{~mol} \%$. If the uranium content is to be $1.1 \times 10^{-3}$ times the thorium content, the salt carries about $0.03 \mathrm{mo} 1 \% \mathrm{U}$, corresponding to $858 \mathrm{~mol} / 65,000$ litres of uranius or some $3.08 \mathrm{~g}$ of ${ }^{233} \mathrm{U} / \mathrm{ittre.} \mathrm{If} \mathrm{we} \mathrm{assume} \mathrm{that} \mathrm{a}$ fluorinator of reasonable size can remove $75 \%$ of the uranium, we need to

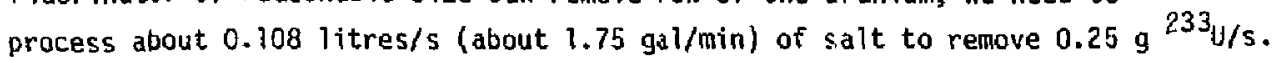
This corresponds to a $\mathrm{U}-\mathrm{C} / \mathrm{cle}$ time $\mathrm{f}$ about 7 days and represents a tiny fraction of the stream to be stripped of $T_{2}$. Sich a continuous fluorinator must be developed and demonstrated, but all in all the uranium removal should be feasible.

Note that, for the ?iquid portion of the blanket sal:, the rate of generation of $233_{U}$ per unit volume will be mearly uniform throughout the b]anket. This uniformity is due to the 27 -day half-life of the $233^{\text {Pa }}$ plus the fact that, at least in the discussion above, sparging cf the tritium entails mixing of the riquid blanket (on the average) ever, 8 min or so. Since the liquid portion of the blanket is maintained at a constant $6_{l . i}$ concentration, the rate of tritium generation per unit volume of liquid will be a function of the neutron flux and will presumably diminish with distance from the front waj1. Presumably, to the extent practicable, the path length of the liquid could be made shorter for tubes near the first wall so that tritium concentrations in the exit salt would be reasonably uniform.

Again, there are serious design questions (prcblems) that must be modeled and addressed before one car say anything for sure about the system.

Assuming a uniform, trozen, 0.5-mm thick layer of sult on the walls of the $0.5-i n c h(7.27-\mathrm{cm})$ pipes means that abuit $15 \%$ of the $65 \mathrm{~m}^{3}$ of saic is to be solid. Presumably this considerable fraction of the total volume is to be maintained in the solid state for long times. We know virtually nothing about the behavior to be expected of this solid. Its situation will differ in several ways from that of the liquid portion of the blanket. Some speculations. about the approximate magnitudes of tiese differences follow.

Let us assume that the $0.5 \mathrm{~mm}$-thick frozen layer resides within the blanket for 60 ciays. Let us further assume that 711 neutronic products formed within the film remain within the film. If so, the concentration of ${ }^{23} \mathrm{U}$ within the film will be markedly higher than that within the liquid, as will 
the fission rate, and both will be functions of the neutron flux within the blanket. How large is this effect? Assume the film is laid down from "equilibrium" salt with $1.32 \times 10^{-5} \mathrm{~g}-\mathrm{mol}{ }^{233} \mathrm{U}$ and $5.56 \times 10^{-5} \mathrm{~g}$-mol $233 \mathrm{pa} / \mathrm{cm}^{3}$. Assume that $1.65 \times 10^{-11} \mathrm{~g}-\mathrm{mol} 233 \mathrm{~J} / \mathrm{cm}^{3} \mathrm{~s}^{-1}$ is generated uniformly throughout the solid volume. Assume that 3 motes of $233 \mathrm{U}$ (of 858 moles total) fission per day and that this rate $(0.25 \%$ per day) is a function only of $233_{u}$ concentration. If so, at the end of 60 days, each cubic centimeter of the film will contain (on the average) $8.80 \times 10^{-5}$ moles $233 \mathrm{U}$. This is some 6.7 times the nominal concentration $\left(1.32 \times 10^{-3} \mathrm{moles} / \mathrm{cm}^{3}\right)$ in the liquid, and the average fission rate after 60 days will exceed that in the $l$ iquic by a similar factor. The ${ }^{233} \mathrm{U}$ concentration in the $\mathrm{f} i \mathrm{~lm}$ exposed to the highest neutron flux will be moderately higher, and the fission rate there will be considerably higher. We do not know what power generation level will melt the film; certainly the highest power levels (near the first wall) are the best cooled and vice versa. Maybe this situation is not terribly distressing, especially since, during the 60-day interval, some of the $233 \mathrm{U}$ may be lost to the liquid by recoil and by diffusion.

The discussion immediately above hardly represents even a "zeroth" approximation of the real situation, which depends upon the flux distribution, time temperature, geometry, etc. A careful, detailed, and difficult task of computer modeling of the system must be completed to establish what the key parameters are and what compromises must or can be made.

Let us examine the situation (again on the average) insofar as generation of TF and $\mathrm{He}$ is concerned. We assume that the deposited film contains 71 mol\% $L i F$ with $7 \%$ of the $L i$ as $G_{i} i$, that all TF is generated from $G_{i}$, and that the neutron flux is uniform with in the volume; this latter assumption is manifestly incorrect.

The overall generation of tritium within the blanket, with $1 \% \sigma_{L}$ if, is to be $5.4 \times 10^{-3} \mathrm{~g} \mathrm{~T} / \mathrm{s}$, corresponcing to $2.77 \times 10^{-11}$ moles $\mathrm{Tf}$ (and He) produced $/ \mathrm{cm}^{3} \mathrm{~s}^{-1}$ of salt. Since each cubic centimeter contains $3.157 \times 10^{-4} \mathrm{~g}$-mol of ${ }^{6} \mathrm{Li}$ (at $1 \%$ of the $L i$ as ${ }^{6} \mathrm{Li}$ ) the fraction of ${ }^{6} \mathrm{Li}$ consumed each secund is $8.77 \times 10^{-9}$, on the average over the entire blanket. This ${ }^{6} i$ will be replenished in the liquid on a relatively short time cycle ( 1 day?). Assuming that the ${ }^{6} \mathrm{LiF}$ from the liquid is ignored and that TF gener ation is proportional to the ${ }^{6} L ;$ remaining, the fraction (on the average) of ${ }^{6} \mathrm{~L} i$ remaining in the solid will be about 0.635 . This may be tolerable, although the ${ }^{6} \mathrm{~L}$ will be depleted more than this in the high-flux regions. 
He have no information about how the generated $T F$ and He will behave in this solid. Except by (presumably slow) Iiffusion from the liquid, we cannot replenish $\mathrm{UF}_{3}$ in the solid; this $\mathrm{UF}_{3}$ will presumably be consumed within a few hours, and no mechanism will exist for reduction of the TF to $T_{2}$. We have no knowledge about what the energetic $\mathrm{T}^{+}$and $\mathrm{F}^{-}$ions as well as the $\mathrm{He}$, will do in the solid. Some fraction (unknown) will presumably leave the solid by recoil or by diffusion in one direction or the other. If we assume that all the He and alt the $\mathrm{T}^{+}$and $\mathrm{F}^{-}$remain in the solid and that the solubilities of TF and He are the same in the solid as in liquid $\mathrm{Li}_{2} \mathrm{BeF}_{4}$, the effective pressures of TF and $\mathrm{He}$ in the solid after 60 days would be (on the average) $16 \mathrm{~atm}$ and nearly $2000 \mathrm{~atm}$, respectively. Such figures suggest strongly that, unless diffusion of TF and He (or some other escape mechanism) is very rapid, the generated gases will blow the film from the wall after a relatively short time. Since the film would be rapidiy replenished, such blow-off may be beneficial.

However, since we do not know, we could assume that the He and Tf diffuse readily from the film and do not spall it off. Diffusion of He to the liquid would seem to pose no problem; its diffusion to the metallic wall would seem to generate bubbles at high pressure and cause blow off of the frozen layer. Diffusion of TF to the 1 iquid permits its reduction by the UF 3 there, with no particular problems. But diffusion to the metal wall results in reudction of the metal by the steel (i.e., corrosion) and results in generation of $T_{2}$ at the wall, the $T_{2}$ readily diffusing through the wall, how serious is this corrosion possibility? Assume that the film lasts 60 days and is replenished after that interval. During each 60 days each $1 \mathrm{~cm}^{3}$ of film generates (on the average) $1.759 \times 10^{-4} \mathrm{~g}$-mol of TF or, during a 4-year wall lifetime, aach cubic centimeter of frozen salt generates $2.82 \times 10^{-3}$ g-mol of IF. Each cubic centimeter of $0.5-\mathrm{mm}$ thick film corresponds to a $5.2-\mathrm{cm}$ length of $1 / 2$ in. tube. Such a 5.2-cm length of tubing contains $1.08 \mathrm{~cm}^{3}$ of metal or about $8.36 \mathrm{~g}$. Assume it to be Fe; if so, some $0.15 \mathrm{~g}$-mol of metal are involved. Assume half of the TF ( $1.41 \times 10^{3}$ moles) diffuses to the metal wall and reacts as follows:

$$
2 \mathrm{TF}+\mathrm{Fe}+\mathrm{FeF}_{2} * \mathrm{i}_{2} .
$$


If so, some $7.05 \times 10^{-4}$ moles of Fe would be converted to Fef 2 . This is less that $0.5 \%$ of the $\mathrm{Fe}$ wall, again on the average. If the attack were uniform, which it probably would not be, such corrosion would not seem to be devastating.

However, as we have said several times in the foregoing, we have no real information about how radiation, fission, and transmutation occur in a frozen wall and no real notion as to how the products behave. A very large and diff icult reasearch program will be required.

Concerning the fraction of tritiun that will penetrate the frozen-salt film: A diffusion coefficient of $2 \times 10^{-4} \mathrm{~cm}^{2} / \mathrm{s}$ has been used for tritium in the frozen-salt $\mathrm{film}$ at $500^{\circ} \mathrm{C}$ (assumed to be $0.5 \mathrm{~mm}$ in thickness). This value is equal to that of hydrogen in molten FLINAK at $500^{\circ} \mathrm{C}$, the only measured value ${ }^{3-19}$ we know of that could possibly be relevant.

Intuition says that the diffusion coefficient for tritium in solid $L i f-B_{2}-T_{h F}$, with a much higher freezing point, will be less (possibly much less) than this. This diffusion coefficient must certainiy be measured: If the value for L iF-BeF ${ }_{2}-\mathrm{ThF}_{4}$ is markediy lower, the estimate of $12 \%$ of the tritium diffusing through the 0.5-mm filin is too high. However, for a pipe length of only $20 \mathrm{~m}$, we assumed a flow rate through the pipe of $1 \mathrm{~m} / \mathrm{s}$. To meet these conditions would require that we process at least $65 \mathrm{~m}^{3}$ of satt each 20 seconds $(50,000$ gailons per minute); such a feat seems essentially impossible. We apparently require a considerably tower processing rate (probably by 25 -fold). Accoroingly, in any reasonable scenario, unless the L if - BeF ${ }_{2}-\mathrm{ThF}_{4}$ film is much more resistart to diffusion than assumed, a large fraction of the tritium will permeate to the helium coolant.

\subsection{TECHNOLOGY OF TUNGSTEN PERMEATION BARRIERS}

A frequently used and commercial deposition process for coating and lining substrates is the hydrogen reduction of a gaseous halide, particularly in the case of tungsten and other refractory mietals..$^{2-15}$ Tungsten hexafluoride is readily available and transported in containers approved by the Department of Transportation for toxic materials. It is a liquid at usual atmospheric conditions, and its vapor pressure can be usefuliy and easily manipulated for ready dispensing with simple feed systems. Virtually no 
partial rafucticn problems are experienced, i.e., formation of solid subfluorides. Its present commercial cost, in $1001 \mathrm{~b}$. containers, from domestic manufacturers (Air Products and Chemicals, Inc., Mountain View, $\mathrm{Ca}$ ) is about $\$ 50 / 1 b$. for the commercial grade cammanly used for producing thin layers or free-standing shapes having properties comparable to powder-consolidated, arccast, wrought tungsten.

Tungsten may be deposited on heated substrates in accordance with the following reaction over a wide range of conditions:

$$
\mathrm{WF}_{6}+3 \mathrm{H}_{2}+\mathrm{W}+6 \mathrm{HF}
$$

The reactants are continuously injected into a chamber, and the products of reaction are continuously removed. The process is conducted in an anhydrous and anaerobic environment, frequently at subatmospheric pressure. Impurtant controllable variables affecting deposition rates are temperature, pressure, molal ratio $\mathrm{WF}_{6} / \mathrm{H}_{2}$, and gas-flow rates.

Measurable deposition rates yielding dense deposits are obtained at temperatures as $10 \mathrm{w}$ as $250^{\circ} \mathrm{C}$. Sound deposits can be made at temperatures exceeding $1000^{\circ} \mathrm{C}$ at a rate of approximately $25 \mu \mathrm{m} / \mathrm{min}$. System pressure may vary fron fractions of a torr to atmospheric and is easily contralled with aspirators and mechanical vacuum pumps. If need be, blawer-type vacuum pumps are used for cases requiring high throughput of feed gases at low and moderate subatmospheric pressures. Hydrogen $/ \mathrm{WF}_{6}$ mola 1 -mixture ratios from 0.5 to several hundred produce satisfactory deposits and substantial inert gas diluents to the feed gas may be used. Thick deposits, i.e., $25 \mu \mathrm{m}$ or more, are highly oriented, with a preferred orientation of 100 . Deposits of $10 \mathrm{um}$ thickness would be expected to still remain in a relatively random orientation; because, at this point in growth, the nucleated grains with the fastest growing directions have not yet completely taken over to predominate alt growth.

Deposition from an alternate source, tungsten hexachloride, which is carried out in a similar manner but at about $400^{\circ} \mathrm{C}$ higher than the fluoride process, generally results in a different preferr ad orientation, i.e, 110. But, again, at $10 \mu \mathrm{m}$ the grain orientations are stiil largely randomized. 
Thus, no distinct advantage would be obtained if it were experimentally demonstrated that preferred grain orientation had the beneficial effect of inhibiting tungsten dissolution and mass transfer from cold to hot regions during lifetime operation. We expect that resistance of tungsten to corrosion by the molten-flouride salt is at least equivalent to stainless steel if not better. Should mass transfer occur, some measurabie difference over long time periods may be evidenced between the fluoride and chloride tungsten; definitive experiments on this need to be done. Another point of concern here is that tungsten deposited from the hexachioride is generally very low in residual chlorine (i.e., 2 ppm), whereas tungsten deposited from the flouride may contain from 2 to $100 \mathrm{ppm}$ residual fluorine, which is somewhat dependent on depasition temperature (i.e., high flourine at low temperature and tow flourine at higher temperature).

No inherent negative effects are anticipated with regard to heat removal

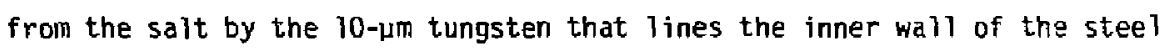
tubing. Tungsten is a good heat conductor and is about six times better than stainless steel, so its influence would be positive.

A well known difficulty in applying tungsten to steel is the achievement of adherence by means of a good metallurgical tond. Both naturally protective oxide and the reaction between iren and halide to form a stable compound act essentially to produce parting layers that are detrimental to the adherence of tungsten on steel. Generally, flash nickel coating (one thousand angstrom or less) is applied to steel surfaces before chemical-vapor deposition of tungsten, as it has been found this effectively circumvents the difficulty. With the likely generation of helium in nickel, a degenerate bond may ensue as a result of helium bubble formation at one or both dissimilar metal interfaces. The use of an electroplated copper flash is the best alternative here. AT LLNL tungsten is often applied on critical copper assemblies that need high conductivity and resistance to certain hightemperature corrosives. Reliance on a strictly mechanical bond (no bonding layer present) may also be a viable alternative. The greater thermal contraction of the steel on cooling from the tungsten-deposition temperatura would force a compression state onto tungsten, thereby benefitting intimate dissimilar metal contact. The Chenical Vapor Deposition (CVo) prucess temperature selected would substantially exceed the operating temperature of the tube wall so such a favored condition for tungsten, with or without a 
flash-bonding layer would always be maintained. The deposition of a $10 \mu \mathrm{m}$ tungsten liner on individual straight or circularly shaped 11-m-long pipes should not offer any particularly difficult fixturing situations. Straight tubes with an internal deposit of tungsten can be formed to shape at $300^{\circ} \mathrm{C}$ or above, if necessary, to façlitate deformation in tungsten above its ductile-brittle temperature. Induction, furnace or self electrical-resistance heating migh: be employed as all have been used commercially on tubing. Considerable production of reletively thick internal deposits with somewhat more difficult metal depositions (i.e.. Nb-1\%, $\mathrm{Zr}$ alloy, Ta) have been used commercially on common and stainless steel (Refs. 2-16 to 2-18). Serpentine passages of the order of $0.5 \mathrm{~m}$ in length and a small diameter $(0.5 \mathrm{~mm})$ have been lined with films of tungsten on massive substrates at Bendix, Kansas City, Mo. (Ref. 2-19). Most such products have employed periodic, alternate gas flows to achieve thickness uniformity, varying no more than $10 \%$ from end to center of length.

The major difficulty is thought to be in joining individual tubes to manifolds and headers while still maintaining, in the joint vicinity, a coating of high integrity and good mechanical properties. For this reason, we shouTd pursue a serious investigation, perhaps in discrete stages, into the prospect of lining the tubing and manifoid walls with tungsten as a semifabricated integral unit, before shrouding and loading with reflectors and moderators. The vent valves included at the top of each pipe loop to aid gravity drainage of salt may be used for ingress or egress of feed gas to coat individual loops, hearters, and manffolds. The desirability of such an approach and accomplishment. would be the benefit of ensured liners over the entire wetted surface, including joints. For CVD, furnace sizes approaching those needed here are used in coating large pipe and reaction vessels (Ref. 2-18). A company concentrating on chemical-vapor deposition and capable of accomplishing the task is Chemetal (Div. of Dart Ind.) in Poicoima, CA. Another company is Ultramet. To provide the source material for lining the tubes and manifolds, the major material procurement cost is for $65,0001 \mathrm{bs}$. of $\mathrm{WF}_{6}$ at $\$ 50 / 1 \mathrm{~b}$. The est imated material cost $\left(\mathrm{WF}_{6}+\mathrm{H}_{2}\right)$ is $\$ 4 \mathrm{M}$. 
2-1. 3. D. Lee et al., Feasibility Study of a Fission Suppressed Tandem Mirror Hytrid Reactor, pp. V-41 to V-63, Lawrence Livermore Nationa] Laboratory, UCID-19327 (1982).

2-2. D. H. Berwa]d et al., Fission-Suppressed Hybrid Reactor--The Fusion Breeder, Lawrence Livermore National Laboratory, UCIO-19638 (1982).

2-3. L. G. Milier et a7., Special Topics Report for the Reference Tandem Mirror Fusion Breeder: Beryllium L ifetime Assessment, Lawrence Livermore National Laboratory, UCID-20166, Voi. 3 (1984).

2-4. it. A. Abdou et a1., "Blanket Comparison and Selection Study," Chapter V, Argonne National Laboratory, ANL/FPP-83-1 (1983).

2-5. M. A. Abdau et a1. : 1 lanket Comparison and Selection Study, Argonne Nationa 7 Laboratory, ANL/FPP-83-1, 0ctober 1983.

2-6. W. H. MCAdans, Heat Transmission, (MCGraw-Hi11, NY, 1954), 3rd ed, p. 272 .

2-7. H. Fenech, Heat Transfer and Fluid Flow in Nuclear Systems, (Pergamon Press, NY, 1981).

2-8. M.A. Hoffmen, Magnetic Field Effects on Heat Transfer of Potential Fusion Reactci Coolants, Lawrence Livermore Nationa] Laboratory, UCRL-73993 (June, 1972).

2-9. P.J. Gierszewski, B. Mikic, and N.E. Todreas, "Natural Circulation in Fusion Reactor B1ankets," ASMA/AIChE National Heat Transfer Conference, Orlando, Florida, Jury 1980.

2-10. C. F. Baes, Jr., "The Chenistry and Thermodynamics of Molten Salt Reactor Fuels," J. Nucl. Mater. 51 (1), 149-62 (1974). 
2-11. J. W. Koger, Alloy Compatibility with LiF-BeF, Salts Containing $\mathrm{ThF}_{4}$ and $\mathrm{UF}_{A}$, Oak Ridge National Laboratory, ORNL/TM-5286, (December 1972).

2-12. J. R. Keiser, J. H. DeVan, and E. J. Lawrence, "Compatibility of Molten Salts with Type 316 Stainless Steel and Lithium," J. Nucl. Mater. $85 \&$ 86 (1979) 295-98.

2-13. W. F. Grimes, "Chemical Research and Development for Molten Salt Breeder Reactors,", Oak Ridge National Laboratory, CF-66-7-41 (1966), pp $45-55$.

2-14. W. R. Grimes and 5. Cantor, "Molten Salts as Blanket Fluids, "The Chemistry of Fusion Technology, ed. D. M. Gruen (Plenum, New York, 1972).

2-15. C. F. Powe11, J. H. 0xley, and J. M. Blocher, Jr., Vapor Deposition (John Wiley \& Sons Inc., NY, 1966).

2-16. F.A. Glaski, "Survey of Refractory Composites Furmed by Chemical Vapor Deposition Techniques," 12th Refractory Composites Working Group Meeting, Denver, CD, Dct. 17-19, 1966.

2-17. F. A. Glaski, "A Report on the Current Role of Chemical Vapor Deposition as a Manufacturing Process," Proc. Conf. Chemical Vapor. Deposition of Refractory Metals, Alloys, and Compounds, Gat?inburg, TN, Sept. 12-14, 1967.

2-18. F. A. Glaski, "Bonded CVo Tantalum Coatings on Steel Substrates," Fourth Intn. Conf. Chemical Vapor Deposition, Boston, MA, 0ct. 8-11, 1973.

2-19. J. G. Gowan and R. A. Hami1, Corrasion Resistant Laser Mirror Heat Exchanzer," U. S. Patent 4,387,962 (1982). 


\section{ABSTRACT}

We present a new conceptual design for a fusion reactor blanket that is intenoed to produce fissile material for fission power plants. Fast fission is suppressed by using beryliium instead of uranium to multiply neutrons. Thermal fission is suppressed by minimizing the fissile inventory. The molten-salt breeding miedium ( $L$ if $\left.+B e F_{2}+i h F_{4}\right)$ is circulated through the b] anket ana to the on- 1 ine processing system where ${ }^{23} \mathrm{U}$ and tritium are continuously removed. Helium cools the blanket and the austenitic steel tubes that contain the molten salt. Austenitic steel was chosen because of its ease of fabrication, aoequate radiation-damage lifetime, and low corrosion by molten salt. We estimate that a breeder having $3000 \mathrm{MH}$ of $\{u$ sion power will produce $5400 \mathrm{~kg}$ of ${ }^{233} \mathrm{U}$ per year. This amount is enough to provide makeup for 20 GWe of light-water reactors per year or twice that many ia igh-temperature gas-cooled reactors or Canadian heavy-water reactors. Safety is enhanced because the afterheat is low and blanket materials do not react with air or water. The fusion breeder based on a pre-MARS tandem mirror is est imated to cost $\$ 4.98$ or 2.35 times a light-water reactor of the same power. The estimateo cost of the ${ }^{233} \mathrm{U}$ produced is $\$ 40 / \mathrm{g}$ for :usion plants costing 2.35 times that of a light-water reactur if utility owned or $\$ 16 / 9$ if governnient owned. 


\subsection{TRITIUM PERHEATION AND RECOVERY}

\section{SYMUPSIS}

Design concepts are presented to control tritium pemeation from a moltensalt helium-cooled fusion breeder reactor. This study assumes tritium to be a gas dissolved in molten sait, with TF formation suppressed. Tritium, which permeates readily through the rot steel tubes of the reactor and steam generator, will leak into the steam system at the rate of about $1 \mathrm{~g} / \mathrm{d}$ in the absence of special permeation barriers. This assumes that $1 \%$ of the heliumcoolant flow rate is processed for tritium recovery at $90 \%$ efficiency per pass. Tritiated water in the steam system is a personnel hazard at concentration levels well below 1 ppm. This tevel wouid soon be reached without costly isotopic processing. Alternatives, including a combination of permeatic: barriers on reactor and steam-generator tubes and moiten-sait processing, are estimated to reduce the leak rate into the steam system by over two orders of magnitude. For the option with the lowest estimated leak rate, $55 \mathrm{Ci} / \mathrm{d}$, it may be possible to purge the steam system continousiy to prevent tritiated-water buildup. At best, isotopic separation of dilute tritiated water inay not be necessary, and for higher leak-rate options the isotopic processing rate can be reduced.

The proposed permeation barrier for the reactor tubes is a $10-\mu m$ iayer of tungsten, which in principle will reduce tritium-blanket permeation by a factor of about 300 below the bare-steel rate. A research and development effort is needed to prove feasibility or to develop alternative barriers. The partial pressure of tritium gas dissolved in molten salt is high, easing the recovery process for which a flash separ ator has been chosen. A i-mm aluminum sleeve is proposed to suppress permeation through the steam generator tubes. Relative to bare steel, this gives a calculated eduction factor of more than 500 , including a factor of 30 due to an assumed oxide layer.

The permeation equations are developed in detail for a multilayer tube wal1, including a frozen-salt layer and two fluid-boundary-layer resistances. Conditions are discussed for which Sievert's or Herry's Lan materials become f]ux limiters. An analytical model is developed to establish the tritium split between wall permeation and reactor-tube flcw. Nomenclature used in Section 3.0 is given in Table 3-1. 
Table 3-1. Nomenclature and symbols for Section 3.0.

\begin{tabular}{|c|c|c|}
\hline Symbol & Definition & Unit \\
\hline a & Inner radius of frozen salt layer & $m$ \\
\hline A & Tota 1 reactor-tube area & $\mathrm{m}^{2}$ \\
\hline$A_{j}$ & Area for helium/steant heat exchanger $j$ & $m^{2}$ \\
\hline b & Inner radius of steel-reactor tube & m \\
\hline c & Outer radius of steel-reactor tube & m \\
\hline$c_{\mathbf{j}}$ & Tritium concentration in material $i$ & $\mathrm{C} i / \mathrm{m}^{3}$ \\
\hline d & $\begin{array}{l}\text { Outer radius of coating (permeation barrier) } \\
\text { or oxide layer }\end{array}$ & m \\
\hline$D_{i}$ & $\begin{array}{l}\text { Diffusion coefficient for tritium in } \\
\text { material } i\end{array}$ & $m^{2} / s$ \\
\hline$D_{1 m}$ & $\begin{array}{l}\text { Diffusion coeffic ient (molecular, not eddy) } \\
\text { for tritium in molten salt }\end{array}$ & $m^{2} / s$ \\
\hline$f$ & $\begin{array}{l}\text { Tritium flux, raferred to inner tube } \\
\text { radius b }\end{array}$ & $\operatorname{li} /\left(\mathrm{s} \cdot \mathrm{m}^{2}\right)$ \\
\hline$f(r)$ & Tritium flux at radius $r$ & $C j /\left(5 \cdot m t^{2}\right)$ \\
\hline$g$ & Fraction of helium flow rate that is processed & \\
\hline G & Tritium voluntetric generation rate & $c i /\left(s \cdot m^{3}\right)$ \\
\hline$H_{i}$ & $\begin{array}{l}\text { Henry's Law cnefficient for tritium in } \\
\text { material } i\end{array}$ & $c i /\left(\pi^{3} \cdot P a\right)$ \\
\hline$i$ & Subscript denoting material (see Fig. 3-2) & \\
\hline$I_{i}$ & Inventory of tritium in material $i$ & $\mathrm{Ci}$ or $\mathbf{g}$ \\
\hline j & $\begin{array}{l}\text { Subscript denot ing helium/steam heat } \\
\text { exchanger type }\end{array}$ & \\
\hline$k_{i}$ & $\begin{array}{l}\text { Boundary-layer mass-transfer coeffic ient for } \\
\text { tritium in fluid medium } i\end{array}$ & $\mathrm{~m} / \mathrm{s}$ \\
\hline $\mathrm{K}_{\mathrm{He}}$ & $\begin{array}{l}\text { Sievert's Law leak-rate coefficient throlgh } \\
\text { helium/steam-heat exchanger tubes } \\
\text { (see Eq. }(58) \text { ) }\end{array}$ & $C i /\left(s-P_{a}^{1 / 2}\right)$ \\
\hline$K_{M S}$ & $\begin{array}{l}\text { Sievert's Law leak-rate coefficient through } \\
\text { molten-salt reactor tubes (see } E q .(52))\end{array}$ & $\mathrm{Ci} /(\mathrm{s} \cdot \mathrm{Pa} / / 2)$ \\
\hline
\end{tabular}


Table 3-1 (cont.)

\begin{tabular}{|c|c|c|}
\hline Symbo 1 & Definition & Unit. \\
\hline$K^{\prime}{ }_{M S}$ & $\begin{array}{l}\text { Henry's Law leak-rate coeff ic ient through } \\
\text { molten salt reactor tubes (see Eq. (54)) }\end{array}$ & $C i /(s \cdot P a)$ \\
\hline$\ell$ & Length of reactor tube & $m$ \\
\hline $\mathrm{L}_{\mathrm{He}}$ & $\begin{array}{l}\text { Tritium-permeation (leak) rate from helium } \\
\text { system (see Eq. (57)) }\end{array}$ & $\mathrm{Ci} / \mathrm{s}$ or $\mathrm{Ci} / \mathrm{d}$ \\
\hline $\mathrm{L}_{M S}$ & $\begin{array}{l}\text { Tritium permeation (leak) rate from molten- } \\
\text { salt reactor (see Eq. (49)) }\end{array}$ & $\mathrm{Ci} / \mathrm{s}$ \\
\hline$p$ & See $p(z)$ & \\
\hline$p(z)$ & $\begin{array}{l}\text { Tritium partial pressure in molten salt at } \\
\text { axial loration } z\end{array}$ & $\mathrm{~Pa}$ \\
\hline$p_{j}$ & Tritium partial pressure in material $i$ & $\mathrm{~Pa}$ \\
\hline$p_{j}(r)$ & $\begin{array}{l}\text { Tritium partial pressure at radius } r \\
\text { in material } j\end{array}$ & $\mathrm{~Pa}$ \\
\hline$P_{\max }$ & $\begin{array}{l}\text { Maximum tritium partial pressure in } \\
\text { molten salt at tube outlet (see Eq. (36)) }\end{array}$ & $\mathrm{Pa}$ \\
\hline$Q_{5}$ & Flow rate of recirculating helium gas & $\mathrm{m}^{3} / \mathrm{s}$ \\
\hline$r$ & Radial position in reactor tube & in \\
\hline$s_{i}$ & $\begin{array}{l}\text { Sievert's Law coefficient for tritium in } \\
\text { material i }\end{array}$ & $\mathrm{Ci} /\left(\mathrm{m}^{3} \cdot \mathrm{pa}^{1 / 2}\right)$ \\
\hline $\mathrm{T}$ & Absolute temperature in kelvins & k \\
\hline $\mathrm{U}$ & $\begin{array}{l}\text { Mass-average velocity of molten salt in } \\
\text { reactor tube }\end{array}$ & $\mathrm{m} / \mathrm{s}$ \\
\hline V & Total irradiated molten-salt volume & $m^{3}$ \\
\hline$w_{j}$ & $\begin{array}{l}\text { Steel wall thickness of helium/steam heat } \\
\text { exchanger } j\end{array}$ & $\mathrm{~m}$ \\
\hline$y(z)$ & $\begin{array}{l}\text { Dimensionless tritium partial pressure } \\
\text { at } z \text { (see Eq. (41)) }\end{array}$ & \\
\hline$z$ & $\begin{array}{c}\text { Axial location in reactor tube, } \\
\text { measured from fluid inlet }\end{array}$ & ตा \\
\hline$\alpha$ & $\begin{array}{c}\text { Fraction of generated tritium that } \\
\text { permeates reactor tube wall }\end{array}$ & -- \\
\hline
\end{tabular}


Table 3-1 (cont.)

\begin{tabular}{lll}
\hline Symbol & Definition & Unit \\
\hline$\varepsilon$ & $\begin{array}{l}\text { Partial-pressure drop ratio (see Eq. (23)); } \\
\text { aiso, dimensionless wall-loss parameter } \\
\text { (see Eq. (44)) }\end{array}$ \\
& $\begin{array}{l}\text { Fractional recovery per pass through } \\
\text { molten-salt processor }\end{array}$ \\
$n_{5}$ & Fractional recovery per pass through helium \\
& slipstream processor
\end{tabular}




\subsection{INTRODUCTION}

This section deals with tritium permeation and recovery from a moltensalt/helium-cooled fusion breeder reactor. The design concept assumes that tritium is present as a gas dissolved in the molten salt and that if formation has been suppressed by reduction with UF $_{3}$. These states are both a blessing and a curse. On the blessing side, tube-wall corrosion from TF is suppressed, and the very high partial pressure of cissolved $T_{\text {, gas makes recovery }}$ relatively easy. Moreover, thé desired fuel (rather than an undesired and corrosive fluoride compound) is recovered directly. On the negative side, tritium gas tends to permeate quite easily through steel walls at elevated temperatures, and a high tritium partial pressure worsens che situation.

The froduction rate of tritium is $0.35 \mathrm{~kg} / \mathrm{d}$, * perhaps better expressed from a safety and environmental perspective as about 3 megacuries/day ( $M C \mathrm{i} / \mathrm{d})$. To keep environmental losses low, say $30 \mathrm{Ci} / \mathrm{d}$, requires a "j-nines" recovery, i.e., a recovery fraction of 0.9999s! This cannot be accomplished from the molten salt alone and requires staged recovery, processing, at ieast the molten salt and the intermediate helium coolant and, probably, the steam/water system also.

To keep process rates down, distributed permeation barriers ars needed to impede permeation between the fluid systems. Assuming the need to use stainless steel tubes for strength, permeation barriers wili iikely be applied as a coating or cladding on the steel tube walls. Tritium permeates through all metals and, to a lesser extent, through ceramics. We will facus here on the low-permeability metais.

Figure 3-I shows the temperature variation of the permeation coefficieni of yarious low-permeability metals, including representative data for austenitic stainiess steels for comparison. ${ }^{j-1}$ A recent steel-alloy data survey ${ }^{3-2}$ recommends an equati 1 for PCA (316 5S), which agrees witn Ref. 3-1 within 10 to $20 \%$ in the temperature range of interest. Table $3-2$ gives the permeation-equation coefficients and literature references for $F i g .3-1$, together with a numerical comparison of the permeation coefficients at $540^{\circ} \mathrm{C}$. A dramatic improvement is seen in going down the list from steel

*The appropriate tritium consumption rate for $3000 \mathrm{MW}$ of fusion powss is $0.46 \mathrm{~kg} / \mathrm{d}$. We used $0.35 \mathrm{~kg} / \mathrm{d}$ in this section. The leakage by permeat ion can be kept the same by increasing the barrier thickness somewhat. Also, the salt volume is $77 \mathrm{~m}^{3}$ rather than the $65 \mathrm{~m}^{3}$ used in this section. 


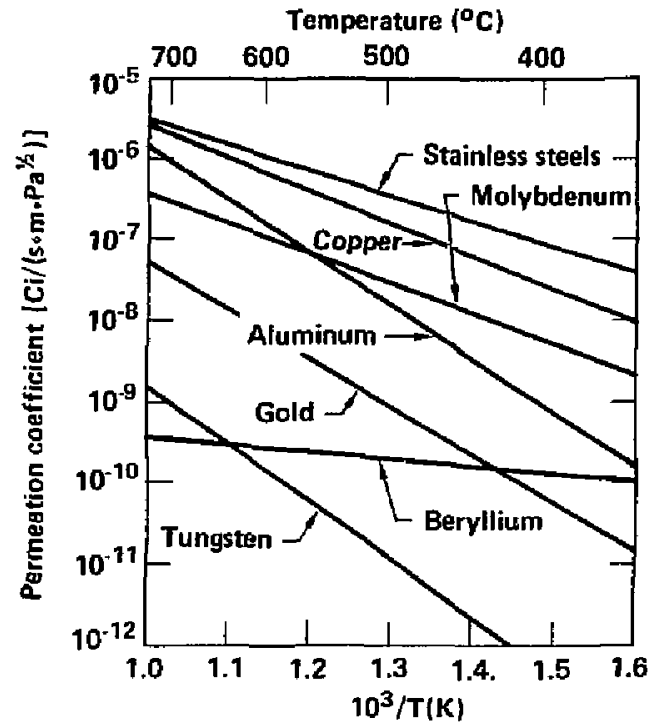

Figure 3-1. Permeability of various materials. 
Table 3-2. Equations representing tritium permeation data in metals. Most data are for hydrogen or deuterium permedtion, corrected by the square-root-of-mass ratio. ${ }^{\text {a }}$

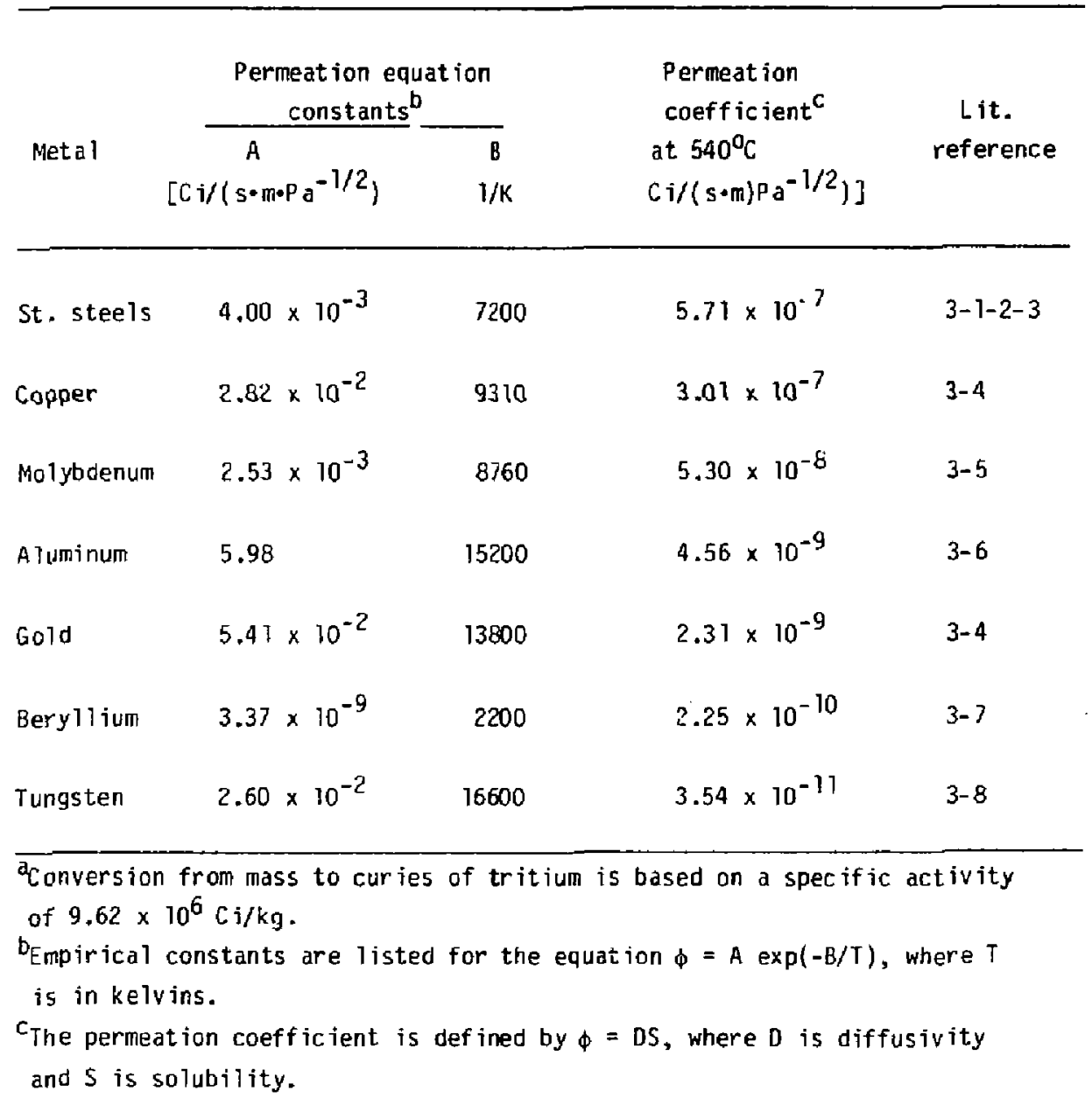


towards tungsten, with the reduction exceeding four orders of magnitude for tungsten. There is some disagreement in permeation equations in the literature, especially for materials of lower permeability, and a recent review cites alternate literature sources. ${ }^{3-3}$ Beryllium is an exception; there can be no disagreement since there seems to be only one reference.

There are two reasons for wanting to keep tritium out of the steam system: first, any tritium leakage from there becomes a low-leve1 environmental pollutant. This is a matter for concern, even though some consider it to be mainly a public-relations hazard. Second, tritiated water in the steam system, at seemingly low concentrations, can definitely be a personnel hazard as will be discussed in the next section.

In subsequent sections, we develop the permeation mathematics at some length. Our purpose is to show the somewhat subtie consequences that follow from combining the solubility laws of sievert and Herry and from the competing effects of permeation and forced convection.

A wide range of exploratory design options are then considered. These will need to be pruned down, assuming feasibility, based on considerations of safety, ALARA, cost, etc. The intent is to show that there are many choices in tritium handling for this reactor concept. It is probably too early to focus on one favorite.

\subsection{TRITIUM TOXICITY}

Some years ago, in an invited paper on the history of tritium, Willard Libby ${ }^{3-9}$ referred to tritium as a "very benign isotope." His reasons were, first, that the 5.7-keV, mean, beta-decay energy is "one of the softest radiations known" and, second, the 12.3-year half-life is short enough so that "we do not permanentiy contaminate the landscape." He then went on to express concern for tritium pollution from fusion power plants in which the time scales of interest are less than the half-century or so needed for radioactive decay.

The words "benign" and "soft" are relative and can perhaps be misleading. Tritiated water vapor is readily absorbed by the human body by means of respiration or skin contact. A one-Curie intake gives a whole-body dose of 
approxinately 82 rem, ${ }^{3-10}$, half of which is delivered in the first reek or two. Since pure $T_{2} 0$ contains over $3000 \mathrm{r}, \mathrm{i} / \mathrm{cm}^{3}$, it can be argued that a drop of water constitutes a lethal dose. So $\mathrm{T}_{2} \mathrm{O}$ is certainly not "soft" water and Libby's friendly words do not apply, nor did he intend them to, until we ailute the tritium to trace levels with ordinary water.

On the other hand, tritium gas is virtually nontoxic, at least as long as you can hold your breath. Even if inhaled, disintegrating gas atoms deliver a relatively mild dose to lung tissue, and most of the rest are exhaled with only about $0.01 \%$ retained as tritiated water ${ }^{3-10}$. So perhaps tritium gas might fairly be called "benign." An important question is how fast tritium gas converts to water in the presence of water vapor and oxygen.

Unfortunately, there is no simple answer. The conversion half-time can range from seconos on a catalytic surface $e^{3-11}$ to years ${ }^{3-12}$ in a Pyrex flask.

Tritium that is not recovered by processing in the molten-salt and heliumcoolant loops will enter the steam system where it will tend to accumulate as tritiated water. Will this water be benign or hazardous? For permeation scenarios to be discussed below, we might expect HTO concentration to rise to, say, $1 \mathrm{Ci}$ /itre. This corresponds to less than $i \mathrm{ppm}$ and could be considered a low level of contanination by ordinary standards. Let us assume a confined working area where a small amount of water leaks from the steam system and reaches equilibrium with water vapor in the air at $25^{\circ} \mathrm{C}$. A worker breathing this air will be exposed at the rate of about 3 rem/h (based on equilibrium HTO-vapor concentration of $0.023 \mathrm{Ci} / \mathrm{m}^{3}$ and a dose conversion factor ${ }^{3-10}$ of $130 \mathrm{rem} / \mathrm{h} / \mathrm{C} \mathrm{i} / \mathrm{m}^{3}$ ) (i.e., that person will reach the 1 rem annual occupational dose limit in only 20 minutes). Any leakage from a $1 \mathrm{Ci} /$ Titre tritiated-water system is definitely going to represent a serious personnel hazard. For this reason alone, it is desirable to design permeation barriers and to process so that the tritium input into the steam loop will be minimized. In contrast, a small amount of leakage from the helium-coolant loop will not be as hazardous to personnel, assuming that tritium present there is mainly in the hydrogen-gas form. 


\subsection{TRITIUM-PRESSURE DISTRIBUTION IN MULTILAYER CYLINDRICAL WALLS}

F igure 3-2 shows the permeation geometry near the wall of a moiten-salt reactor tube in radial cross section. One might approximate the radial geometry with a slab; instead we solve the problem exactly and then introduce approximations. Five material regions are inciuded: (1) molten salt in the central region of the tube; (2) a frozen salt layer at the inner wall of the tube; (3) the stainless steel tube itself; (4) a coating or oxide layer at the outer wall; and (5) heliull gas outside the tube. In addition, we allow boundary lajers of finite mass-transfer resistance, but with negligible thickness, at the tiwo fluid/solid interfaces. These represent the mass-transfer analog of a thermal-boundary layer in heat flow. Boundary-layer thickriess must, of course, be finite and will depend on fluid properties, mainly the Reynolds Number. The mass-transfer coefficient incorporates the boundary-layer thickness, since it is, like the heat-transfer coefficient, a lumped parameter.

\subsubsection{PERMEATION EQUATIONS FOR STEADY-STATE WITHOUT AXIAL FLOW}

Assume that tritium is generated at a constant rate $G$ per unit volume in Regions 1 and 2 and that the mass flow is radial and at steady state. Neglect radioactive decay compared to production. The time constant to reach steady state is about an hour for steel tube at $500^{\circ} \mathrm{C}$ and roughly a day at $300^{\circ} \mathrm{C}$. Assume Fick's Law diffusion in Regions 1 to 4 and assume the helium in Region 5 is well-mixed from turbulent flow. He will eventually examine the mixing in the molten-salt region; for now, assume a finite diffusivity in Region 1.

For simplicity, we write the equation for mass conservation in the same form for Regions 1 to 4 :

$$
r^{-1} d\left[D_{i} r\left(d C_{i} / d r\right)\right] / d r+G_{i}=0(i=1,2,3,4),
$$

where

$$
G_{i}=\begin{aligned}
& G, i=1,2 \\
& 0, i=3,4
\end{aligned}
$$



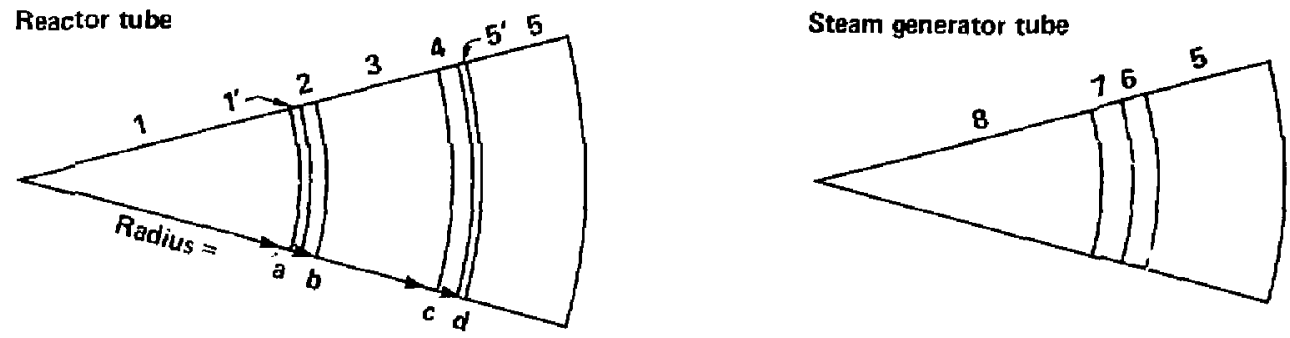

$\begin{array}{ll}1 & \text { Molten salt } \\ 1 & \text { Molten salt boundary layer } \\ 2 & \text { Frozen salt } \\ 3 & \text { Stainless steef tube } \\ 4 & \text { Permeation barrier (tungsten) } \\ 5 \cdot & \text { Helium gas boundary fayer } \\ 5 & \text { Helium gas }\end{array}$

$5 \quad$ Helium gas

6 Permeation barrier (aluminum)

7 Stainless steel tube

8 Water/steam

Figure 3-2. Permeation geometry and materials. 
$C_{i}=C_{j}(r)$ is the tritium concentration in region $i$ at radius $r$. Diffusivity $D_{j}$ is a function of temperature and, therefore, ifiplicitly is a function of radius through the steady-state temperature profile, $0_{i}=0_{i}[T(r)]$. One can define an appropriate average $D_{\mathfrak{i}}$ by means of the first integral of Eq. (1), anu we will interpret $D_{i}$ in this averaged sense.

The four constants that arise from the first integral of Eq. (1) are found by applying the following boundary conditions: the concentration gradient is zero at the center of the tube, and the flux $-D_{j}\left[d C_{j} / d r\right]$ is continuous at radius $a, b$, and $c$. The interface fluxes turn out to be:

$$
\begin{aligned}
& f(a)=G a / 2, \\
& f(b)=G b / 2, \\
& f(c)=b f(b) / c, \\
& f(d)=b f(b) / d,
\end{aligned}
$$

and the concentration profiles may be written:

$$
\begin{aligned}
& c_{1}(r)=c_{1}(a)+G\left(a^{2}-r^{2}\right) /\left(40_{1}\right), 0 \leq r<a, \\
& c_{2}(r)=c_{2}(b)+G\left(b^{2}-r^{2}\right) /\left(4 D_{2}\right), a<r<b, \\
& c_{3}(r)=c_{3}(c)+G b^{2} \ln (c / r) /\left(2 D_{3}\right), b<r<c, \\
& c_{4}(r)=c_{4}(d)+G b^{2} \ln (d / r) /\left(2 D_{4}\right), c<r<d .
\end{aligned}
$$

The result, so far, is the same as the solution to the steady heat-flow problem. If we were considering heat $f$ low, we would next assumite local thermal equilibrium at material interfaces and equate interface temperatures. For diffusion, we instead assume local chemical equilibrium at interfaces and equate the chemical potentials of the diffusing substance. Since chemical potential is linear in the logarithm of partial pressure for an ideal gas, we can equate interface partial pressures:

$$
p_{i}=p_{i}+1, \quad i=1,2,3,4 .
$$

If tritium remains a diatomic gas upon dissolving in a particular m cerial, then the equilibrium concentration is related to the gas phase Jartial pressure by Henry's Law: 


$$
C_{i}=H_{i} p_{j}
$$

where $H_{i}$ is a temperature-dependent solubility constant and $p_{i}$ is tritium gas partial pressure. This linear relation between concentration and partial pressure always holds at low concentrations, provided that dissociation or other chemical reaction does not occur. ${ }^{3-13}$ For example, the solubility of hydrogen and deuterium in molten $\mathrm{Li}_{2} \mathrm{BeF}_{4}$ obeys Heriry's Law. ${ }^{3-14}$ In contrast, the solubility of hydrogen isotopes' in metals obeys Sievert's Law,

$$
C_{i}=S_{i} \sqrt{P_{i}}
$$

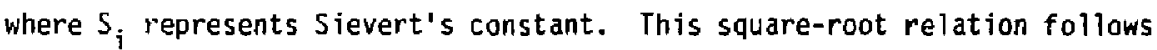
from thermodynamic arguments if gas-phase tritium is completely undissociated and solid-phase tritium is completely dissociated into atoms. Intermediate cases of partial dissociation in the gas-phase ${ }^{3-15}$ and in the condensedphase ${ }^{3-16}$ have been considered, and the relation between concentration and partial pressure is not as simple as in the limiting case of Henry's or Sievert's Law.

We assume Henry's Law applies for tritium in molten and frozen salt, and also in relium, while Sievert's Law applies in steel and the coating or oxide layer on the steel. Note that solubility constants, in general, for each material. This implies a discontinuity in concentration at material interfaces, even those without fiuid-boundary layers. Across a boundary layer we have an additional concentration change,

$$
\Delta C_{i}=f / k_{i}
$$

where $f$ represents the local mass $f l u x$, and $k_{j}$ is a mass transfer coefficient. By means of Eqs. (11) to (14), we can solve for the four unknown interface concentrations in Eqs. (7) to (10). Expressing the results, for convenience, as interface partial pressures gives,

$$
\begin{aligned}
& p_{1}(a)=f(a) /\left(k_{1} H_{1}\right)+G\left(b^{2}-a^{2}\right) /\left(4 D_{2} H_{2}\right)+p_{2}(b), \\
& p_{2}(b)=\left[G b^{2} \ln (c / b) /\left(2 D_{3} S_{3}\right)+\sqrt{p_{3}(c)}\right]^{2}, \\
& p_{3}(c)=\left[G b^{2} \ln (d / c) /\left(2 D_{4} S_{4}\right)+\sqrt{p_{4}(d)}\right]^{2}, \\
& p_{4}(d)=f(d) /\left(k_{5} H_{5}\right)+p_{5},
\end{aligned}
$$


where $p_{5}$ represents tritium partial pressure in well-mixed helium gas.

Finally, the tritium partial-pressure profile at any radial position follows from Eqs. (7) to (10) as,

$$
\begin{array}{ll}
p_{1}(r)=p_{1}(a)+G\left(a^{2}-r^{2}\right) /\left(4 D_{1} H_{1}\right), & 0 \leq r<a, \\
p_{2}(r)=p_{2}(b)+G\left(b^{2}-r^{2}\right) /\left(40_{2} H_{2}\right), & a<r<b, \\
p_{3}(r)=\left[\sqrt{p_{3}(c)}+G b^{2} \ln (c / r) /\left(2 D_{3} S_{2}\right)\right]^{2}, & b<r<c, \\
p_{4}(r)=\left[\sqrt{p_{4}(d)}+G b^{2} \ln (d / r) /\left(2 D_{4} S_{4}\right)\right]^{2}, & c>r>d .
\end{array}
$$

The set of eight equations listed above constitutes a formal solution to the problem of steady-state radial diffusion through four material regions having different properties, with generation in the two innermost regions, and with boundary-layer resistance at the two fluid/solid interfaces.

\subsubsection{MASS TRANSFER RESISTANCES IN MOLTEN SALT}

Since the solid regions will have thin walls, the radial dependence given by Eqs. (20) to (22) will not be needed for most calculations. Equation (19), on the other hand, applies to molten salt over the entire central region of the tube from centerline to the boundary layer at radius a. It is of interest to estimate the partial-pressure change across this region and compare it with the drop across the boundary layer. Define $e$ as a ratio of partial-pressure drops,

$$
E=\left[p_{1}(0)-p_{1}(a)\right] /\left[p_{1}(a)-p_{2}(a)\right]
$$

Using Eqs. (3), (15), (19), and (20), it follows that

$$
\varepsilon=a k_{1} /\left(2 \nu_{1}\right)
$$

We know intuitively that in highly turbulent. flow the malten salt will be well mixed, which amounts to saying that the effective diffusivity, $D_{1}$, must be large and that $\varepsilon$ will be a smali number. Even in the absence of axial flow, we expect some natural convection because of the high heat generation and associated temperature gradients in the molten salt. Suppose, conservatively, that the natural circulation velocity is small and generates only a lazy, laminar flow. For this case, the mass-transfer coefficient is

$$
k_{1}=2 D_{1 m} / a,
$$


where $D_{1 m}$ represents the molecular diffusivity of $T_{2}$ in molten salt. Equation (25) is equivalent to a heat-transfer Nusselt number of 4, a value which is correct to one digit for laminar flow. ${ }^{3-17}$ for $D_{1}$, we use the laminar-flow axial dispersion coefficient

$$
0_{1}=D_{1 m}+\left(U_{a}\right)^{2} /\left(480_{1 m}\right)
$$

where $U$ is the mean flow velocity. ${ }^{3-18}$ We do not know of any measurements of $T_{2}$ diffusivity in molten $\mathrm{F}_{3}$ ibe, with or without a $\mathrm{ThF}_{4}$ loading. However, Katsura and Furukawa ${ }^{3-19}$ have measured the diffusivity of $\mathrm{H}_{2}$ in molter Flinak, and we lise their result:

$$
D_{1 m 1}\left[\mathrm{~m}^{2} / \mathrm{s}\right]=(7.0[-06) \exp (-4530 / T[K]) .
$$

With a i/2-inch tube at $600^{\circ} \mathrm{C}$ and with an assumed velocity of $1 \mathrm{~mm} / \mathrm{s}$, the pressure drop ratio $\varepsilon$ turns out to be $2 \times 10^{-3}$. For all practical purposes, we can assume the tritium partial pressure in the molten salt is unifo:m from the tube centerline out to the fluid/solid boundary iayer where there is a sudden discontinuity. Equation (19) has 1 aw served its purpose, and the four interface Eqs. (15) to (18) are all we need for calculations.

\subsubsection{PRESSURE PROFILES IN ABSENCE OF MOLTEN SALT}

To make use of the results of the last section, a large number of parameters must be estimated. Many of these are temperature sensitive, especially diffusivity and solubility that depend exponentially on temperature. We first establish the thermal profile for a tube with given heat generation rate, outside helium temperature, etc. Table 3-3 shows the canculated results for three reactor tubes located at $1.5,1.8$, and $2.1 \mathrm{~m}$ from the plasma centerline, where the local heat generation rates are 60,20 , and $6 \mathrm{MW} / \mathrm{m}^{3}$, respectively. Calculated temperatures and frozen-salt layer thickness are sensitive to tube location. Other parameters, such as the helium boundary-layer film coefficient, can also change the results. Table 3-3 is based on a 1/2-inch tube. Tailoring the tube size to radial position may be a useful ay to adjust the thermal profile and frozen-layer thickness. 
Table 3-3. Thermal regime for molten-salt reactor tube. Calculated ${ }^{a}$ mean temperatures and frozen-salt-layer thickness for spec if ied heat-generation rate and outside helium temperature.

\begin{tabular}{|c|c|c|c|c|c|c|}
\hline \multirow{3}{*}{$\begin{array}{l}\text { Heat } \\
\text { generation } \\
\text { rate } \\
\left(\mathrm{MW} / \mathrm{m}^{3}\right)\end{array}$} & \multirow{3}{*}{$\begin{array}{l}\text { Outside } \\
\text { helium } \\
\text { temp. } \\
(\mathrm{C})\end{array}$} & \multicolumn{4}{|c|}{ Calculated mean temperature $\left({ }^{\circ} \mathrm{C}\right.$} & \multirow{3}{*}{$\begin{array}{l}\text { Thickness } \\
\text { of frozen- } \\
\text { s.tlt layer } \\
\text { (mm) }\end{array}$} \\
\hline & & $\begin{array}{l}\text { Helium } \\
\text { boundary }\end{array}$ & Stainiess & Frozen & $\begin{array}{l}\text { Molten-salt } \\
\text { boundary }\end{array}$ & \\
\hline & & layer & steel tube & salt layer & layer & \\
\hline 60 & 285 & 394 & 504 & 536 & y 16 & 0.0805 \\
\hline 20 & 470 & 506 & 543 & 554 & 682 & 0.0875 \\
\hline 6 & 550 & 561 & 572 & 572 & 604 & 0.0 \\
\hline
\end{tabular}

${ }^{a}$ Calculations based on a 1/2-inch 0.d. tube with a 20-mi] wall thickness; a heljum-side film coefficient of $7.4 \times 10^{2} \mathrm{~W} / \mathrm{m}^{2} \cdot k$ based on a packed-bed Reynolds number of 3000 ; stainless stee 1 conductivity of $20 \mathrm{~W} /(\mathrm{m} \cdot \mathrm{K})$; frozen salt conductivity of $0.24 \mathrm{~W} /(\mathrm{m} \cdot \mathrm{K})$; salt melting point of $565 \mathrm{C}$; salt-side film coefficient of $\left.2.5 \times 10^{-2} \mathrm{~W} / \mathrm{m}^{2}+K\right)$ based on a molten-salt Nusselt number of 4; and well-mixed salt (infinite conductivity) in the central region of the tube. 
Table 3-4 shows tritium permeation calculations based on the thermal profiles established in Table 3-3, and without axial flow so that all generated tritium permeates through the wall. The frazen-salt layer is assumea to have the same diffusion and solubility parameters as molten sait, $D_{1}$ and $D_{2}$ being given by $E q .(27)$ and Henry's Law solubility $y^{3-14}$ expressed by

$$
H_{1}\left[\mathrm{Ci} /\left(\mathrm{m}^{3} \cdot \mathrm{Pa}\right)\right]=\mathrm{H}_{2}=1.19 \times \exp (-3530 / T[\mathrm{~K}]) .
$$

The molten-salt boundary-layer mass-transfer coefficient, $k_{1}$, is estimated by means of Eq. (25) (i.e., based on laminar flow). A nominal l-um tungsten coating is used for Region 4. Permeation coefficients for tungsten and stee? are as given in Table 3-2. The helium boundary-layer mass-transfer resistance turns out to be negligible at an assumed Reynolds number of 3000 .

The main point of Table 3-4 is to show that, for a fixed-tube geometry, the tritium partial-pressure distribution can be significantly altered by tube Jocation because of clianges in the generation rate and the temperature distribution. The change of the relative permeation resistance of different portions of the multilayered wall is also interesting. This behavior is unlike relative thermal resistances in heat flow, which are nearly independent of the flux. If we had chosen to use, say, a 10-um tungsten coating rather than a $?, 1 \mathrm{~m}$, then the tungsten barrier would have been the dominant permeation resistance under all conditions. Note that neither the steel tube nor the frozen-salt ?ayer offer very much heip, while the molten-salt. resistance can be significant based on the small mass-transfer coefficient in laminar flow. We may have understated the frozen-salt-layer resistance, since one would expect the solid to have a lower diffusivity than the liquid. The diffusivity of tritium in both solid and liquid Flibe will certainly need to be nieasured as this reactor concept is developed. Even if the frozen-layer diffusivity was much smaller, it seems unwise to count on a dynamic layer that is sensitive to thermal alteration and disruption for other reasons, e.g.: periodic blowoff from iselium buildup.

For design calculations below' w, 11, therefore, consider oniy two simple pxtremes where the permeation resistance is dominated either by molten salt alone or by a tungsten barrier. A1so, the material temperatures in Table 3-3 for the intermediate tube at $1.8 \mathrm{~m}$ from the plasma centerline $\left(20 \mathrm{~m} / \mathrm{w} / \mathrm{m}^{3}\right)$ 
Table 3-4. Tritium permeation from molter-salt reactor tubes without axial flow. ${ }^{\mathrm{a}}$

Parameter

Three design options

$\# 1+\# 2$

Distance of tube from plasma

$$
\text { centerline }(m)
$$

Heat generation rate $\left(M W / m^{3}\right)$

Tritium:

\begin{tabular}{|c|c|c|c|}
\hline Generation rate $\left(\mathrm{Ci} / \mathrm{s} \cdot \mathrm{m}^{3}\right)$ & 1.24 & 0.414 & 0.124 \\
\hline \multicolumn{4}{|l|}{ Partial pressure } \\
\hline in molten salt $(\mathrm{Pa})$ & $6.33 \times 10^{4}$ & $3.03 \times 10^{3}$ & $1.27 \times 10^{3}$ \\
\hline \multicolumn{4}{|c|}{ Partial-pressure drop ( $\mathcal{G}$ of total): } \\
\hline Molten-salt boundary layer & 1.7 & 62.6 & 98.2 \\
\hline Frozen salt layer & 1.2 & 7.1 & 0.0 \\
\hline Stainless steel tube wall & 3.6 & 2.0 & 0.2 \\
\hline Tungsten coating $(1 \mu \mathrm{m})$ & 93.5 & 28.3 & 1.6 \\
\hline Helium-gas boundary layer & 0.0 & 0.0 & 0.0 \\
\hline
\end{tabular}

1.5

1.8

2.3

60

20

6

\section{3}

${ }^{\mathrm{a} C a}$ aculated values based on data in Table 3-3. Tritium generation rate is scaled to the heat-generation rate for the tube. We assume $100 \%$ permeation through the tube walis (no axial flow). Tritium partial pressure is assumed to be $10^{-2} \mathrm{~Pa}$ in helium coolant. 
will be taken as representative for design calculations, because the tritium generation rate for this tube is not far from the reactor mean-generation rate, $G=0.596 \mathrm{Ci} /\left(\mathrm{s} \cdot \mathrm{m}^{3}\right)$.

We should emphasize two important messages gained from Tables 3-3 and 3-4:

- Although we know the reactor mean tritium generation rate, we do not have a corresponding mean tube-wall temperature distribution such that permeation from a representative tube will represent the correct integrated average over the whole assembiy.

- Even if we did, lhe change in relative importance of wall resistance terms for tubes at different locations implies that exploratory calculations for a "representative" tube should be scaled to other conditions with caution.

\subsubsection{RADIAL FLUX EQUATION FOR TRITIUM}

If molten salt is flowing in the reactor tube, then the radial tritium flux is not proportional to production rate 6 , as in Eqs. (3) to (6), and instead aepenos on the loral tritium concentration in molten salt and other system parameters. We dill focus on the flux at b, the inner radius of the steel tube, and from now on denote $f(b)$ as $f$. We will assume the 10:al tritium concentration is wel! mixed as previously discussed and denote $p_{1}(a)$, the tritium partial pressure in the sait, as $p$. From Eqs. (15) to (18), replacing $\mathrm{G}$ by means of Eq. (4), we can write

$$
\begin{aligned}
p & =f a /\left(b k_{1} H_{1}\right)+f\left(b^{2}-a^{2}\right) /\left(2 b D_{2} H_{2}\right)+ \\
& +\left[f b \ln (c / b) /\left(D_{3} S_{3}\right)+f b \ln (d / c) /\left(D_{4} S_{4}\right)+\sqrt{\left.f b /\left(d k_{5} H_{5}\right)+p_{5}\right]^{2}} .\right.
\end{aligned}
$$

Equation (29) cannot be solved explicitly for $f$. This is tyrical of reatistic permeation conditions with multiple layers where Henry's-Law and Sievert's-Law regions are coupled.

Consider two simplified cases: (1) where the permeation resistance is dominated either by the molten salt or (2) by the coating. For the case of molten-salt resistance only, neglecting $\mu_{5}$ and assuming thin walls, solving Eq. (29) for $f$ gives

$$
f=\left[20_{]_{11}{ }^{H} / \mathrm{b}} / \mathrm{p},\right.
$$


where we have assumed the laminar-flow approximation of Eq. $\{25\rangle$ for $k_{1}$. For the case of coating resistance only, the flux is given by

$$
f=\left[D_{4} s_{4} /(d-c)\right] \sqrt{p} .
$$

Note that the tritium flux is directly proportional to partial pressure when the material with the limiting permeation resistance has a Henry's-Law solubility, while the flux is proportional to the square root of partial pressure for a Sievert's-L aw material. The net effect is to make the Sievert's-Law material the flux limiter if tritium partial pressure is high and the Henry's-Law material the flux limiter at low partial pressures. Table 3-4 illustrates these two extremes as well as the intermediate case where both materials serve to impede the flux.

\subsection{TRITIUM SPLIT BETWEEN WALL-PERMEATION AND REACTOR-TUBE FLOW}

We want to remove most of the tritium before it permeates through the reactor tube walls into the heljum coolant. To do this, the molten salt must be circulated rapidly through an external process unit where tritium can be recovered. For now, we will assume a recovery system can be designed and will focus on the required permeation characteristics and recirculation rate needed to guarantee that only a small fraction of generated tritium will permeate the tube walls.

\subsubsection{MODEL ASSUMPTIONS AND MASS-BALANCE INTEGRAL}

As discussed earlier, tritium tends to mix well in the molten salt because of natural convection. Good mixing is reasonable on a length scale of the order of the tube size. To model the behavior of flow in a long tube, we assume that tritium is well-mixed radially while the partial pressure changes continuously in the axial direction $z$, that is,

$$
p=p(z)
$$


Let $U$ represent the mean velocity along the $Z$ axis. As before, $G$ is the volumetric generation rate, $f$ is the local permeation flux, and $H_{1}$ is Henry's constant for molten salt. A mass balance on a differential volume element, as sketched in Fig. 3-3, yields:

$$
-U H_{T} d p / d z-2 f / b+G=0
$$

Steady state is assumed, and axjal diffusion has been neglected on the grounds that it is small compared to the bulk transport. Rearranging $\mathrm{Eq} .\langle 33\}$ and integrating over the tube from the molten salt inlet at zero to the out let at \& gives,

$$
H_{1} \int_{p(0)}^{p(l)}[G-2 f / b]^{-1} d p=l / U \text {. }
$$

This expression can be integrated numerically to find out let pressure $p(l)$ for the general case, discussed in the last section, where $f$ is not a simple sunction of the tritium partial pressure. The tube inlet pressure $p(0)$ is related to $p(\ell)$ by

$$
p(0)=(3-n) p(l),
$$

where $n$ represents the single-pass recovery fraction in the molten-salt processing loop. For the limiting case of perfect containment, we can calculate the maximum tritium pressure at the tube exit by integrating Eq. (34). Let's call this pressure $p_{\max }$ :

$$
p_{\max }=G \ell /\left(n_{1} H_{1} U\right)
$$

We are interested in the escape fraction $\alpha$, which represents the fraction of tritium generated $i_{i \prime}$ the tube that escapes through the wall before leaving the tube. An overall mass balance tells us that

$$
\alpha=1-p(\ell) / p_{\max } .
$$




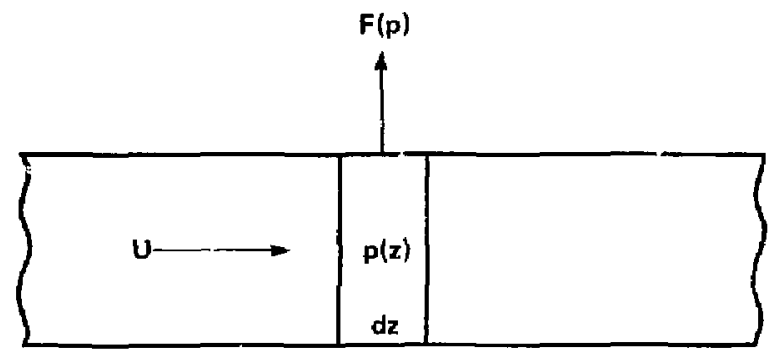

Figure 3.3. Model for tritium split in reactor tube. Molten salt flows at velocity $U$ and is well mixed radially. Local tritium partial pressures at $z$, $p(z)$ or ives the radial permeation $f l u x f(p)$. 


\subsubsection{A HENRY'S LAW BARRIER AS FLLUX LIMITER}

For the special case of the linear flux-pressure relation in Eq. (30) with only molten-salt resistance, the result of integrating Eq. (34) and then solving for the escape fraction by means of $\mathrm{Eq} .(37)$ is

$$
\alpha=1-(n / v)[1-\exp (-v)] /[1-(1-n) \exp (-v)],
$$

with parameter $v$ defined as

$$
v=40{ }_{1 m^{5}}{ }^{-2} \ell / U
$$

If the permeating fraction is to be small, then we must have $v \ll 1$, in which rase the exponentials can be expanded, and then $\alpha$ is simpty

$$
\alpha=v[1 / 2+(1-n) / \pi]+\ldots .
$$

The ratio of tube length to mean velocity, $\ell / U$, that appears in parameter $\checkmark$ represents the residence time of fluid passing through a tube, in other words, the ratio of $f l u$ io volume to volumetric flow rate for that tube. If we neglect variations in tube length at different radi and possible variations in tube diameter, then tube residence time also represents the ratiu of total molten-salt volune to total volumetric flow rate. Nominal tube iength varies from 9 to $13 \mathrm{~m}$, with an average of, say, $12 \mathrm{~m}$. There will be additional manifolding length, which we will neglect, since it will not be part of the $65 \mathrm{~m}^{3}$ * design-basis volume of molten salt in the reaction zone. We pick a velocity of $0.1 \mathrm{~m} / \mathrm{s}$, which corresponds to a tube Reynolds number of about $3 \times$ $10^{2}$. The tube residence time, on this basis, is 2 minutes and the total volume flow rate of molten salt is $0.54 \mathrm{~m}^{3} / \mathrm{s}(8600 \mathrm{gin} / \mathrm{min}$. Assuming a recovery fraction of 0.9 and calculating molten-salt diffusivity based on a temperature of $680^{\circ} \mathrm{C}$ gives $v=0.86$. If we use the exact analytical solution for $\alpha$, since $v$ is not small in this case, the fraction of generated tritium that escapes through the tube walls is 0.37 . This $37 \%$ los

* The salt volume in the rest of the report is $77 \mathrm{~m}^{3}$ rather than $65 \mathrm{~m}^{3}$ used liere. 
could be reduced to a $15 \%$ loss by increasing the velocity by a factor of 3 . The process ing rate would then be $1.6 \mathrm{~m}^{3} / \mathrm{s}(26,000 \mathrm{gal} / \mathrm{min})$, which is starting to be uncomfortably high.

\subsubsection{A SIEVERT'S LAW BARRIER AS FLUX LIMITER}

Define a normalized pressure $y(z)$ at any position $z$ along the tube axis,

$$
y(z)=p(z) / p_{\max }
$$

We assume that the coating-resistance term dominates in the general flux relation, Eq. (29), in which case the wall flux is given by

$$
f=D_{4} S_{4} \sqrt{p /}[b / n(d / c)]
$$

This equation reduces to Eq. (31) in the thin-wall approximation, a step that will be deferred for now since one might wish to consider a wide range of coating thicknesses. After substituting flux Eq. (42) into the integral in Eq. (34), the resulting integral equation can be written as follows:

$$
\int_{(1-n) y(l)}^{y(l)}[1-\varepsilon \sqrt{y}]^{-1} d y=n,
$$

where the dimensionless wall-loss parameter $E$ is defined by

$$
\varepsilon=2 D_{4} S_{4} \sqrt{P_{\max }} /\left[b^{2} \ln (d-c) 6\right] \text {, }
$$

and all other symbois have been defined. Note that the operational parameter of direct interest to us, i.e., the tritium escape fraction dc, is reiated simply to $y(\ell)$ by:

$$
\alpha=1-y(l) .
$$

The point in writing Eq. (43) in the particular form given above, is as follows. First of a11, we note that it can be integrated exactly but the 
result is transcendental in $y(\ell)$ and thus rather opaque for computational purposes. So we resort to a series expansion of the integrand followed by term-by-term integration. We proceed by noting that $\varepsilon$ is a small number, generally much less than unity for the low-permeability materials of interest to 11 . The varibie $y$ is also less than unity, and so we can expand the integrand of Eq. (43) in the form

$$
[1-x]^{-1}=1+x+x^{2}+\ldots .
$$

Keeping only the first two terms, integrating, and soiving for the tritium escape fraction, we obtain

$$
\alpha=2\left[1-(1-n)^{3 / 2} j \varepsilon /(3 n)+\ldots .\right.
$$

We can see that $\varepsilon$ is roughly equal to $\alpha$, and since we are going to demand that $\rightarrow$ be small, it follows that our expansion to terms of order $\varepsilon$ will be accurate.

Combining Eqs. (36), (44), and (47) gives the final working equation for the tritium escape fraction for a Sievert's Law flux limit, in terms of ali the system parameters:

$\alpha=(4 / 3) n^{-3 / 2}\left[1-(1-\pi)^{3 / 2}\right] b^{-2}\left[\ell / H_{1} G\right]^{1 / 2} D_{4} S_{4} /\left[u^{l / 2} \ell n(d / c)\right]$.

The permeation ccefficient $D_{4} S_{4}$ has the most important effect, because it varies by orders of magnitude among materials. Once the material is specified, the main variables in process design are wall thickness, velocity, and process recovery efficiency. Althulgh it's a little hard to see in Eq. (48), the product nu is nearly constan' at fixed $\alpha$, and so a decrease in process efficiency can be compensated for by a corresponding increase in flaw velocity.

Evaluating the above expresssion using a $10-\mu m$ tungsten coating at $540^{\circ} \mathrm{C}$, with other parameters the same as the previous linear cuse, gives a calculated escape fraction equal to 0.08 . The 10-jm tungsten barrier reduces the permeation rate below that of the $20-\mathrm{mil}$ bare stainless steel tube by a factor of about 300 . This is a substantial improvement, yet not so high as to defy credibility. Coatings are inevitably imperfect. Asking for a permeation reduction factor of 300 over the base metal implies that an 
uncoated portion (cracks, pinholes, etc.) of only about 1 part in 1000 of the bare tube area can be tolerated without degrading performance. To do the same job with beryllium requires a $64-\mu m$ layer, based on resists of Table 3-2. Gold is next in 7 ine in permeability and is an easily applied, non-brittle coating material. Unfortunately, to match $10 \mu \mathrm{m}$ of tungsten would require an $0.65-\mathrm{mm}$ layer of gold and cost about 54 billion: The effectiveness of tungsten or other low-permeability barriers must be assessed by an experimental research and development program. Tungsten powder can be melted and applied to tube exteriors by a commercial plasma-spray process. Tungsten can also be coated on surfaces by chemical vapor ceposition from the volatile hexafluoride, ${ }^{3-20}$ which might permit the inside of the reactor tubes to be coated as wel1.

\subsection{TRITIUM PERMEATION RATE TO HELIUM COOLANT LOOP}

\subsubsection{THEORY}

The essential results of the last section are contained in Eqs. (38) and (48) for the tritium escape fraction in the Henry's or Sieveri's Law flux limit. The leak rate (permeation rate) of tritium from the nolten-salt loop is the product of escape fraction, volumetric production rate, and total molten-salt volume in the reactor tubes,

$$
L_{M S}=\alpha V
$$

For both the Henry's and Sievert's Law cases, assuming as usuar a small escape fraction, the outlet tritium partial pressure is to a goog approximation given by Eq. (36), $p_{\max }=\mathrm{Gl} /\left(\mathrm{nH}_{j} \mathrm{U}\right)$. By using this relation, we can write the permeation rate in a more familiar fashion in terms of partial pressure. The total tube area $A$ can alsa be introdused by recognizing that

$$
A=2 V / b \quad .
$$

For a Sievert's Law barrier as flux limiter, assuming a thin-walled tube, Eq. (49) can be written

$$
L_{M S}=K_{M S} \sqrt{D_{\text {max }}} \text {, }
$$


where the Sievert's Law leak-rate coefficient from the molten-salt loop KMS is

$$
K_{M S}=\left\{(2 / 3 \eta)\left[1-(1-\eta)^{3 / 2}\right]\right\} D_{4} S_{4}^{A /(d-c)} .
$$

The terms following the curly bracket are what we would expect in a permeation equation: diffusivity, solubility, area, and wall thickness. If we had ignored the axial gradient and assumed the tube was a well-mixed tank (as wili be cone in the helium section to follow) the result looks exactly iike Eq. (52) except the quantity in the curly brackets is unity. This factor, which depends only on process efficiency, is the correction for the axial gradient arising from the tritium processor. The tritium processor recycies molten salt with a low tritium partial pressure back to the reactor-tube in let.

Going through a similar procedure for a Henry's Law barrier as the flux limiter, we can write the leak rate

$$
L_{M S}=K_{M S}^{\prime} P_{\max },
$$

where Henry's Law leak-rate coefficient $K_{M S}^{\prime}$ is:

$$
K_{M S}^{\prime}=\{T-n / 2\} k, H, A,
$$

and again the curly-bracket factor represents the axial-gradient correction to a well-mixed-tank model.

\subsubsection{DESIGN OPTIONS}

We now consider a range of feasible design alternatives:

Option A. Process molten salt, restricted perneation. option B. Process molten salt, unrestricted permeation. Option C. No salt processing, 100\% permeation.

A 10 $\mu \mathrm{m}$ tungsten barrier [as discussed in the paragraphs following Eq. (48)j is used in Option A, while option B and C have only the molten salt boundary-layer resistance. The process recovery fraction is 0.9 for cases $A$ and $B$, while case $C$ has no tritium recovery system for the molten salt. The 
temperatures for permeation are 540 and $680^{\circ} \mathrm{C}$ for tungsten and molten salt, respectively. Other parameters are given in Table 3-5 alang with calculated results. For case A, Eq. (51) is used for the leak rate. For case $B$, the leak rate is too large for $E q .(53)$ to be accurate, instead $E q . ~(49 ;$ is used, along with Eqs. (38) and (39), to obtain the exact solution to the linear problem. For case $C$, the tritium pressure in molten salt is obtained from Eq. (29) rather than Eq. (36). The leak rate to the helium $100 p$ is $7.6 \%, 37 \%$, and $100 \%$ for Options $A, B$, and $C$, respectively.

Table 3-5. Permeation from the molten-salt loop for three design options.

\begin{tabular}{|c|c|c|c|}
\hline \multirow[b]{2}{*}{ Parameter } & \multicolumn{3}{|c|}{ Lesign option } \\
\hline & A & $\underline{B}$ & $c$ \\
\hline ก & 0.9 & 0.9 & 0.0 \\
\hline$e / U(5)$ & 120 & 120 & - \\
\hline$(\mathrm{d}-\mathrm{c})(\mathrm{um})$ & 10 & - & - \\
\hline $\mathrm{P}_{\max }(\mathrm{Pa})$ & 2710 & 2710 & 3050 \\
\hline$\alpha$ & 0.0759 & 0.367 & 3.000 \\
\hline$p(l)$ & 2500 & 1720 & 3050 \\
\hline$L_{M S}(L i / s)$ & 2.94 & 14.2 & 38.7 \\
\hline
\end{tabular}




\subsection{TRITIUM PERMEATION INTO THE STEAM/HATER LOOP}

From the point of view of tritium permeation, the helium-coolant loop is in a crucial position between the molten salt and steam systems. Figure 3-4 shows a sketch of the three tritium processing loops. Tritium is generated at a high rate in the molten salt, and it will be difficult to recover much more than $90 \%$ of the tritium produced there. Tritium that permeates through the reactor tubes will enter the helium heat-transfer loop. Table 3-6 gives approximate figures on amounts and flow rates in the three loops. The mass of molten salt is large because of its high density. However, punining power and equipment size and cost scale with volumetric flow rate. The bottom line on Table 3-6 shows why it is unreasonable to process for tritium recovery more than a small fraction of the helium flow, which amounts to $800 \mathrm{~m}^{3} / \mathrm{s}$ or nearly 2 milition atmospheric $\mathrm{ft}^{3} / \mathrm{min}$ at $450^{\circ} \mathrm{C}$ and $60 \mathrm{~atm}$.

A steady-state concentration will quickly be reached that will depend on the helium volume and helium-processing rate, assuming that processing is the main removal mechanism. There will also be a tritium permeation loss through the walls of the helium/steam heat exchanger, and perhaps some conversion of tritium gas by homogeneous-phase oxidation to water or chemical exchange with water vapor in the circulating helium. Direct conversion in the helium is an intriguing possibility. Maroni ${ }^{3-22}$ presented the thermodynamic arguments showing that tritium gas partial pressure (and therefore the permeation loss) will be very smalt if a modest oxygen partial pressure is maintained and tritiated water vapor is adsorbed at a reasonable rate, assuming equilibrium prevails. Unfortunately, the kinetics are too $510 \mathrm{w}$ without a catalyst, and a conventional catalytic converter to handle $800 \mathrm{~m}^{3} / \mathrm{s}$ would be absurdly large. The design challenge is to get a large catalytic surface area into the helium without introducing any significant pressure orop $\left(\mathrm{e} .9 ., 10^{3} \mathrm{p}\right.$ a at $800 \mathrm{~m}^{3} / \mathrm{s}$ requires $1 \mathrm{MW}$ ef pumping power at $80 \%$ efficiency). Perhaps very small catalytic particles could be distributed and maintained in the flowing gas. For design calculations below, we will simply use a conventional catalytic reactor in a relatively low-flow bypass loop.

\subsubsection{FOR WELL-MIXED TANK MODEL}

For this study, we assume that tritium entering the helium system is either recovered in a helium slipstream processor or purmeates to the steam 


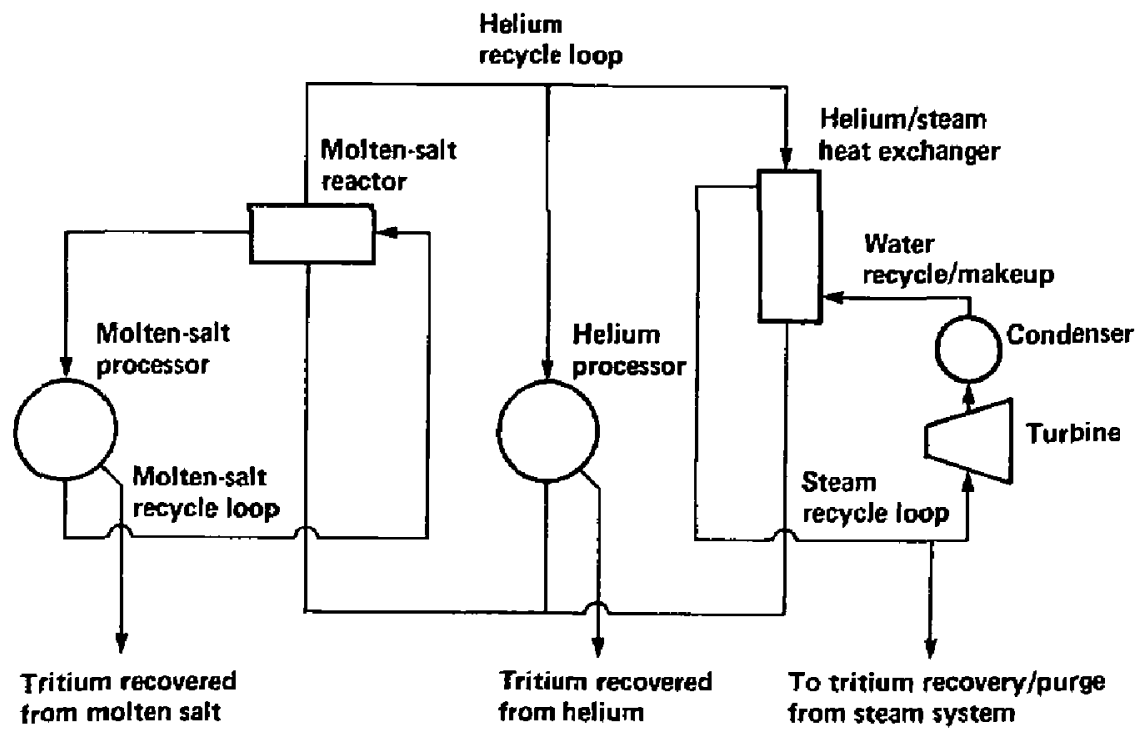

Figure 3-4. Diagram of tritium processing loops, showing principal flows only. Losses from process $l$ ines and equipment housings not shown. 
Table 3-6. Size comparison of loops for malten-salt reactor, processing, and coolant.a

\begin{tabular}{llll}
\hline Parameter & Molten salt & He 1jum & Steam \\
\hline Mass $(\mathrm{kg})$ & $4.6 \times 10^{5}$ & $1.3 \times 10^{4}$ & $3.8 \times 10^{5}$ \\
Volume $\left(\mathrm{m}^{3}\right)$ & 100 & 3200 & 10,000 \\
At T $(O C)$ & 600 & 450 & 340 \\
At $P(\mathrm{MPa})$ & 5.1 & 6.1 & 8.4 \\
Mass flow rate $(\mathrm{kg} / \mathrm{s})$ & $2.5 \times 10^{3}$ & $3.2 \times 10^{3}$ & $1.6 \times 10^{3}$ \\
Voiume flow rate $\left(\mathrm{m}^{3} / \mathrm{s}\right)$ & 0.54 & 800 & 43
\end{tabular}

CCoolant loop flow-rate data from Ref, 3-2 7 ; mass and volume values are estimates. 
system, in which case the mass balance reads:

$$
L_{M S}=\pi_{5} g 0_{5} H_{5} p_{5}+L_{H e} \cdot
$$

The fractional efficiency of slipstream processing is $n_{5}$; the fraction of helium that is processed is $g ; H_{5}$ and $p_{5}$ are the Henry's Law constant and partial pressure for tritium in helium; and $L_{H e}$ is the permeation rate out of the helium system. The assumption of a well-mixed tank is implicit in the above equation. Assuming that $L_{\text {He }} \ll L_{M S}$, we neglect the second term in Eq. (55) and solve for the tritium partial pressure

$$
p_{5}=L_{M S} /\left(n_{5} g_{5} H_{5}\right) .
$$

The leak rate $L_{H e}$ is assumed to depend only on the helium-side partial pressure

$$
L_{H e}=K_{H e} \sqrt{F_{5}} \text {, }
$$

wher's $K_{H e}$ is a Sievert's Law leak-rate coefficient for the helium/steam heat exchanger tubes.

$T$ able 3-7 shows heat exchanger design data for the reactor of reference, ${ }^{3-21}$ which we have combined with permeation data ${ }^{3-1}$ for clean, unoxidized stainless steel to give i leak rate per unjt driving force. It is interesting to note that there is a considerable difference in the mean wall temperature of the four types of exchangers shown in Table 3-7. He define the mean wall temperature as the arithmetic average of helium and steam/water inlet and outlet temperatures. As a consequence of this temperature difference, the resuperheater accounts for $46 \%$ of the leakage although it has only $15 \%$ of the wall area and, in addition, has thicker walls.

The overall leak-rate coefficient is calculated from

$$
K_{H e}=\sum D S_{j} A_{j} / W_{j} \text {, }
$$

where the sum is over each heat exchanger with specified permeation coefficient $D S_{j}$, area $A_{j}$, and wall thickness $w_{j}$. 
Table 3-7. Tritium permeation through bare steel hel iun. stean-ineat exchangers. ${ }^{a}$ These values are based on data in Ref. 3-21 for 4480-MW design heat duty. Except for data in bottom row for the reactor with 12 generators, the data are for one generator set.

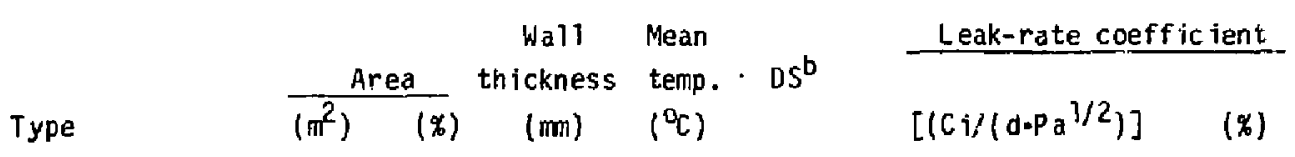

\begin{tabular}{|c|c|c|c|c|c|c|}
\hline Resuperheater & 512 & (15) & 2.54 & 488 & 27.1 & $5.46 \div 10^{3}$ \\
\hline Superheater & 385 & (12) & 1.78 & 432 & 12.8 & $2.77 \times 10^{3}$ \\
\hline Evaporator & 3409 & (42) & 1.57 & 355 & 3.66 & $3.28 \times 10^{3}$ \\
\hline Economizer & 1017 & (31) & $? .57$ & 275 & 0.678 & $0.445 \times 10^{3}$ \\
\hline 1 Generator & 3323 & $(100)$ & & $\langle 384\rangle^{c}$ & $\langle 6.11\rangle^{d}$ & $1.20 \times 10^{4}$ \\
\hline Reactor (x 12) & 3.99 & $10^{4}$ & & & & $1.44 \times 10^{5}$ \\
\hline
\end{tabular}

Note that $46 \%$ of the leakage goes through only $15 \%$ of the area, anc $69 \%$ of the leakage goes through only $27 \%$ of the area.

bermeation coefficient for clean steel (no oxide) at the specified temperat ure $\left(C i \cdot m \pi / d \cdot m^{2} \cdot p a^{1 / 2}\right)$.

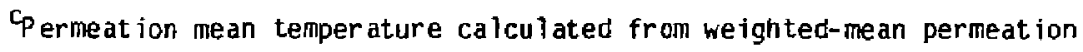
coefficient (05).

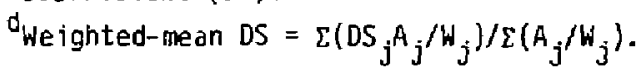




\subsubsection{PERMEATION RATES FOR RANGE OF DESIGN OPTIONS}

Two design alternatives are considered for the helium/steam-heat exchanger system:

- Option 1. Restrict permeation with a 1-mm aluminum sleeve.

- Option 2. Unrestricted permeation.

Unrestricted permeation (see Fig. 3-2) means that the only resistance comes from the stainless steel tube wall (Material 6 present, Material 7 absent), while restricted permeation implies that the aluminum permeation barrier (Material 7) is present and is the tritium flux limiter.

For Option 2, a sceel tube leak-rate coefficient of $1.44 \times 10^{4}\left[\mathrm{i} /\left(\mathrm{d}_{*} \mathrm{~Pa}^{1 / 2}\right)\right.$ is used. This is obtained from the temperature- and area-averaged coefficient given in Table 3-7 by dividing by a factor of 10 to allow for an oxide layer on the steam side. This is believed to be a conservative oxide-factor "credit." Much higher factors have somet imes been reported, but the effective permeation reduction by thin oxide layers is rather uncertain. We have ignored fluid boundary-layer resistances for these heat exchangers.

For Option 1 , we use a $1-$ mm aluminum sleeve as permeation barrier with the sleeving, for simplicity, assumed to enclose the steel tubes of Option 2. Aluminum has a larger thermal expansion coefficient than steel, and there may be less degradation of heat-transfer performance if the aluminum tube can be placed inside the steel tube. The same temperatures and areas in Table 3-7 are used, as a simplifying approximation. The aluminum sleeve leak-rate coefficient is $269 \mathrm{Ci} /\left(\mathrm{d} \cdot \mathrm{Pa}^{1 / 2}\right)$, obtained from the Table 3-2 data after allowing a factor of 30 credit for the aluminum oxide layer. We use a factor of 30 since hydrated oxides are known to form almost immediately on a cleanscraped aluminum surface, and these are both tenaceous and self-healing. 3-23

For both options, $8 \mathrm{~m}^{3} / \mathrm{s}$ (1\% of the helium flow rate) is prccessed with a $90 \%$ per-pass tritium renoval efficiency. Even at $1 \%$ of the helium flow rate, $8 \mathrm{~m}^{3} / \mathrm{s}\left(17,000 \mathrm{ft}^{3} / \mathrm{min}\right)$ requires a large gas processor.

Combining the two options above with the three cases of tritiun input rate from Table 3-5 gives six representative cases of tritiun permeation into the steam/water system. The calculated results are given in Table 3-8, and range from $55 \mathrm{Ci} /$ oay to $11,000 \mathrm{Ci} /$ day. It appears that permeation barriers between the helium/steam systems are more effective than between the 
salt/helium systems. This important fact follows from combining permeationrate equations to show the dependence on leak-rate coefficients ${ }^{4}$,

$$
\mathrm{L}_{\mathrm{He}} \approx \mathrm{K}_{\mathrm{He}}\left(\mathrm{K}_{\mathrm{MS}}\right)^{1 / 2} \text {, }
$$

i.e., the permeation reduction from the molten-salt tubes (see the bottom 1 ine in Table 3-5) is suppressed by the Sievert's Law square-root effect of the next stage. This is unlike the more usual linear effect of staging multiple barriers, where the decontamination factors of each stage multiply directiy to give the overall effect. 
Tabje 3-6. Comparison of the rates of tritium permeation into the steam/water system under different design uptions.

\begin{tabular}{|c|c|c|}
\hline $\begin{array}{l}\text { Design } \\
\text { option }\end{array}$ & Description of process & $\begin{array}{l}\mathrm{L}_{\mathrm{He}} \\
(\mathrm{C} i / \mathrm{d})\end{array}$ \\
\hline 1 & $\begin{array}{l}\text { Process helium, l-mm aluminum sleeve, with: } \\
\text { A. Process malten salt, 10-pm tungsten coating } \\
\text { B. Process molten salt, fluid b.l. resistance only } \\
\text { C. Molten salt not processed, } 100 \% \text { permeation }\end{array}$ & $\begin{array}{r}55 \\
120 \\
200\end{array}$ \\
\hline 2 & $\begin{array}{l}\text { Process helium, steel tube resistance on ly, with: } \\
\text { A. Same as above } 1 A . \\
\text { B. Same as above } 1 B . \\
\text { C. Same as above } 1 C \text {. }\end{array}$ & $\begin{array}{r}3,000 \\
5,500 \\
11,000\end{array}$ \\
\hline $\begin{array}{l}\text { Aritiur } \\
\text { A, B, } \\
n=0.9 \\
\text { The res }\end{array}$ & $\begin{array}{l}\text { put to the helium system is taken from Table } 3-5 \text { for proce } \\
C \text {, Partial pressure in hel ium is calculated from Eq. }(56) \\
=0.01, Q_{5}=800 \mathrm{~m}^{3} / \mathrm{s}, \mathrm{H}_{5}=5980 / \mathrm{T}(\mathrm{K}) \mathrm{C} \mathrm{i} /\left(\mathrm{m}^{3} \cdot \mathrm{Pa}\right) \text {, and } \mathrm{T}= \\
\mathrm{s} \text { are } 0.042,0.20 \text {, and } 0.55 \mathrm{~Pa} \text { for options } \mathrm{A}, \mathrm{B} \text {, and } \mathrm{C} \text {, re }\end{array}$ & $\begin{array}{l}\text { esses } \\
\text { with } \\
=723 \mathrm{~K} \\
\text { espectiv }\end{array}$ \\
\hline
\end{tabular}




\subsection{PROCESS CONCEPTS FOR TRITIUM RECOVERY FROM FLUID LOOPS}

We briefly outline some prccess design conrepts for recover ing tritium from the three fluid systems; molien salt, helium, and water.

\subsubsection{TRITIUM RECOVERY FROH MOLTEN SALT BY FLASH VAPORIZATION}

An estimate of the tritium pressure at the tube outlet is given by Eqs. (36) and (37). Using the data in Table 3-5, the resist comes to at least 12.9 Torr. This is a very high pressure compared to most breeder designs, and is due to a combination of very low tritium solubility in the salt, moderate wall losses, and a reasunably long residence time. A high tritium partial pressure makes recovery relatively easy and is an important fringe benefit of keeping tritium in the dissolved $T_{2}$ gas form, rather than as if.

Figure 3-5 shows : schematic of the proposed molten-salt processing system. We chose a flash vaporization unit, similar to the concept of Johnson. 3-22 The liquid enters the vaporizer (or disengager to use Johnson's terminology) and expands through jet nozzles (essentially a shawerhead) into a large disengaging tank where liquid droplets settle to a liquid sump at the tank bottom. The pressure in the tank is maintained at the desired level by an external pumping system that carries the effervescing gas out of the chambir. The desired pressure level is set by the design recovery efficiency together with the assumption that residual dissolved tritium in the tank $l$ iquid is in equilibrium with the partial pressure of gas-phase tritium. With a design efficiency of $90 \%$, the pressure level would be 1.29 Torr, assuming the temperature in the salt loop is constant and provided there were no ather evolved gases. Allowing roughly 3 moles of other gases (primarily helium) per mole of $\mathrm{T}_{2}$ generated ${ }^{3-22}$, the pressure level in the disengager must ther be 5.2 Torr. The total gas rate leaving the disengager is essentially 4 times the $T_{2}$ generation rate, or $2.67 \mathrm{inmol} / \mathrm{s}$. This rate corresponds to a volumetric flow rate of $12.8 \mathrm{~g} / \mathrm{s}$ at $600^{\circ} \mathrm{C} 13.9 \mathrm{~g} / \mathrm{rin}$ at $20^{\circ} \mathrm{C}, 1 \mathrm{~atm}$ ) - a very mocest gas flow rate, even by tritium pumping standards. Assuming that the oxygen level is maintained at a low level with a separate slipstream processor, the $25 \% T_{2}$ in He mixture is cooled to near room temperature, compressed to about $1 \mathrm{~atm}$ and passed over a powdered uraniun bed to recover the bulk of the tritium as a hydride. The tritium-contaminated helium stream will need a final cleanup step before release, such as the 


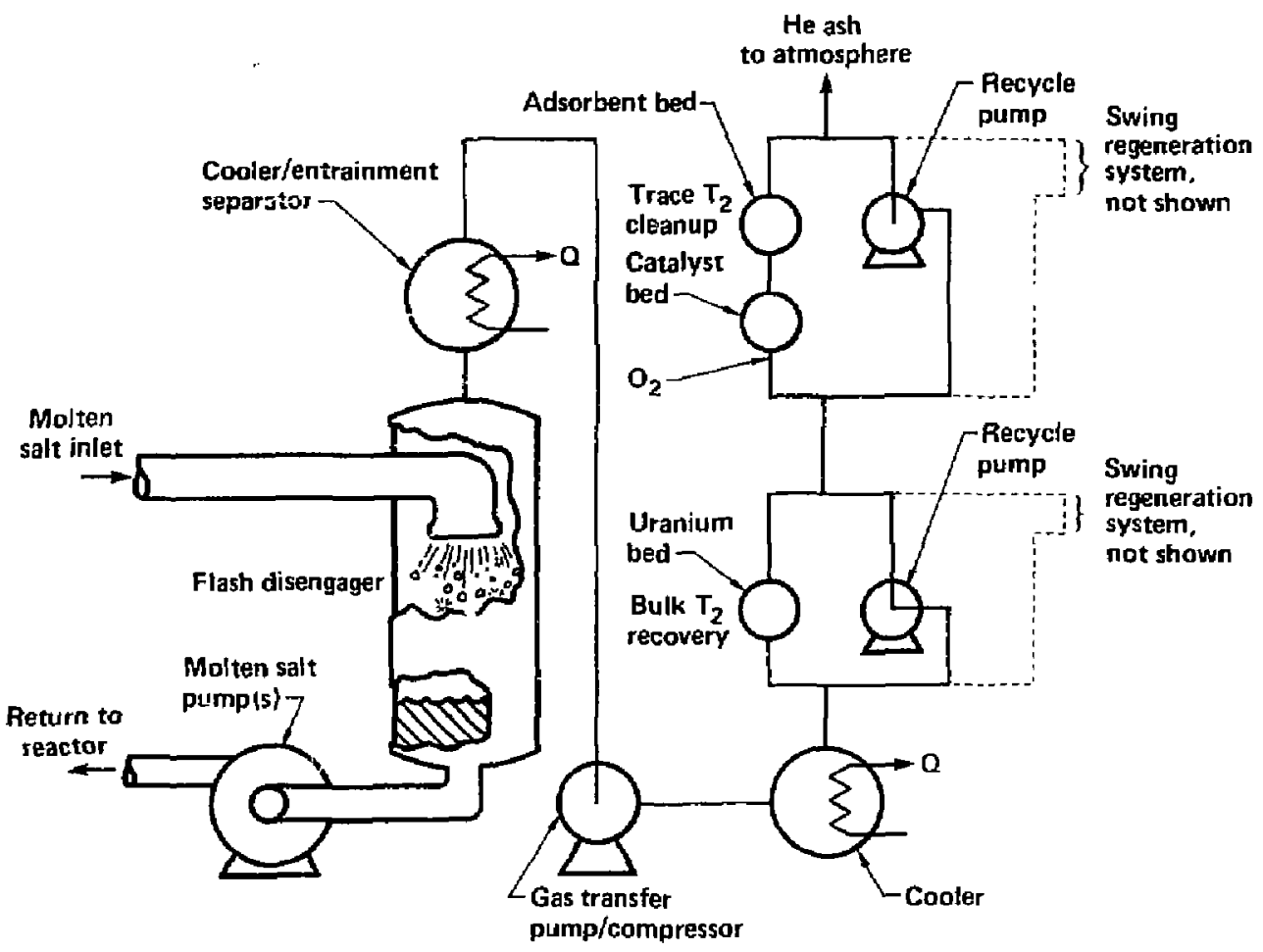

Figure 3.5. Tritium recovery-system flow sheet. 
introduction of a little oxygen followed by catalysis/adsorption. The recovery beds will be paralleled, to allow cyclic operation, changeouts, etc.

Returning to the molten salt, we next estimate the pumping requirement. The flash disengager operates at near zero pressure compared to the salt tubes, which at muximum will operate at pressure balance very near to the helium heattransfer- loop pressure of $50 \mathrm{~atm}$. At $0.54 \mathrm{~m}^{3} / \mathrm{s}, 50-3 \mathrm{tm}$ pressure rise, and 70\% pump efficiency, the worst-case power requirement is $3.9 \mathrm{MH}$ (some $500 \mathrm{~Hz}$ ). This does not seem unreasonable, leaving pump technology as ide as a separate issue.

The size of the $\mathrm{flash}$ disengager is also reasonable at the design recirculation rate for molten salt. Allow a 3 -second liquid residence time and a 50\% void fraction for gas. This gives a $3.2 \mathrm{~m}^{3}$ tank volume. With a nominal jength to diameter ratio of 3 , the tank has a diameter of $1.1 \mathrm{~m}$ and is $3.3 \mathrm{~m}$ high. To give some perspective, the pipe diameter for this salt recirculation loop will need to be in the neighborhood of $0.4 \mathrm{~m}$ in order to keep the pressure drop near 1 atm and the pump power less than $0.1 \mathrm{MH}_{\mathrm{e}}$.

It may be helpful to provide the reader a "nearest-integer exponent" cost estimate. This is a very rough estimate; less refined than the back-of-theenvelope method. In our judgment, the molten-salt processor as sketched on Fig. 3-5 has a nearest-integer exponent of 6 , i.e., the capital cost may $r$ ange from $\$ 0.32 \mathrm{M}$ to $\$ 3.3 \mathrm{M}$.

\subsubsection{TRITIUM RECOVERY FROM HELIUIM BY OXIOATION/ADSORPTION}

Tritium can be nemoved from he?ium by adding a few parts per million of oxygen, converting to tritiated water in a packed-bed catalytic reactor, and aosorbing the water vapor on a zeolite molecular-sieve adsorbent bed. 3-21,-24,-25 Two adsorbent beds are required; one on-line while water is being desorbed from the ather. The desorbeo water then goes to an electrolysis unit for tritium recovery. At $8 \mathrm{~m}^{3} / 5$ helium flow, and at 60 atni pressure, the reactor and adsorbers will be substantial vesse 15, larger than any now in tritium service. Nevertheless, a 90\% per-pass recovery shouid not be difficult. We estimate a nearest-integer cost exponent of 7 for this system. 


\subsubsection{TRITIATEO HATER PURGE OR ISOTOPIC SEPARATION}

Tritium gas permeating into the steam generation loop will be converted to tritiated water by exchange with the overwhelming supply of hydrogen atoms in hot steam. According to experience with the $C$ anadian heavy-water reactor (CANDU), most of the tritium entering their steam generator leaves as tritium oxide in boiler blowdown and less than $1 \%$ as gas or water vapor in turbine off-gas. 3-26 For simplicity, we will assume the residual HT gas partial pressure is low enough so that permeation loss through condenser-tube walls can be neglected. This means that tritiated water concentration is determined simply by a balance betiseen tritium input and removal rates. Removal may be accomplished either by purging to the environment, as at CANDU, or by processing, as at Grenoble. 3-27

\section{Lrge Rate and Concentration for Low Tritium-Input Rates}

The CANDU purge rate is $7.5 \%$ of the steam circulation rate; or 0.06 and

$0.10 \mathrm{~m}^{3} / \mathrm{s}$ at the $\mathrm{Pickering-A}$ and Bruce-A reactors, respectively. 3-26 Let's suppose that $0.1 \mathrm{~m}^{3} / \mathrm{s}(1600 \mathrm{GPM})$ represents a reasonable upper limit on the steam-system purge rate. For the lowest tritium input rate shown in Table 3-8 ( $55 \mathrm{Ci} / \mathrm{d})$, the steady-state water concentration is $6.4 \mu \mathrm{Ci} / \mathrm{R}$. This is about 300 times the EPA drinking water 1 imit of $20 \mu \mathrm{Ci} / \mathrm{m}^{3}$, which in turn is equivalent to $4 \mathrm{mrem} / \mathrm{y}$ for continuous exposure. This modest level of environmental pollution just might prove acceptable, given a long outfall pipe to a large and rapidly moving body of water.

Process Rate and Concentration for High Tritium-Input Rates

Most of the design options caiculated in Table $3-8$ give tritium input rates that will probably prove too high to allow environmental purging to be acceptable by present or future U.S. standards. Excepting case $1 A$, the range of tritium input rates is from about $10^{2}$ to $10^{4} \mathrm{Ci} / \mathrm{d}$. If the tritium input was allowed to accumulate in the water system, assuming no losses and with the water mass from Table 3-6, a concentration level of $16 \mathrm{C} / \mathrm{R}$ would be reached in on $1 y 38$ days for the $h$ igh end of the input range. As discussed earlier, this tritiated water level is a personnel hazard if the steam/water system has any leaks. 
Suppose we process water from the steam system at a modest rate of $41 /$ min and, by isotopic separation, remove $50 \%$ of the tritium per pass (we pick these design numbers since a process cost estimate is available). The steady-state concentration depends inverse $1 y$ on the tritium input rate and will be $0.03,0.3$, and $3 \mathrm{Ci} / \mathrm{l}$ for $10^{2}, 10^{3}$, and $10^{4} \mathrm{Ci} / \mathrm{d}$ input, respectively. The cost to extract tritium from Savannah River heavy-water reactors, using the Grenoble Sultzer Process ${ }^{3-27}$ and for the process conditions above, is about $5130 \mathrm{M}$ according to the Savannah River Reactor "high spot" estimate..$^{3-28}$ Th is pracess involves catalyzed hydrogen gas/water vapor exchange followed by cryogenic distillation of tritium-enriched gas. Since $3 \mathrm{C} / / /$ tritiated water is very hazardous, as discussed earlier, it may be desirable to increase the process rate for the worst case input to prevent the system from reaching the $3 \mathrm{C}$ i/l level. This will cause a corresponding increase in process cost. Moreover, the time constant to reach steady state, for the proposed process rate, is only about 4 months.

\subsection{TRITIUM INVENTORY IN FLUIO SYSTEMS AND TUBE WALLS}

Inventory estimates are summarized in $\Upsilon$ able 3-9 for the fluid systems and steel tube walls. The basis for the numbers is discussed below.

Tritium inventory in the molten-salt tubes is calculated from

$$
1_{1}=\mathrm{VH}_{1} \mathrm{P}_{1}
$$

where $p_{1}$ is an integral average partial pressure along the length of a reactor tube. We take the average to be $[p(0)+p(2)] / 2$, use Eq. (35) for $p(0)$ and the $p(\ell)$ values from Table 3-5. Equation (28) is used for $\mathrm{H}_{1}$, tritium solubility at $680^{\circ} \mathrm{C}$ in molten salt. Calculated inventor ies amount to only a fraction of a gram for options $A, B$, or $C$. The numbers are sma 1 because of the low estimated solubility of tritium in molten salt.

The estimated tritium inventory in the helium system is also small for the three options. Tritium inventory in the water system can range from negligible to large $(120 \mathrm{~g})$ over the wide range of tritium input and of process rates discussed in Sections 3.3 .1 and 3.3 .2 above.

Tritium inventory in the reactor tube walls is calculated from

$$
I_{3}=v\left[(c / b)^{2}-1\right] S_{3} \sqrt{\bar{p}_{3}}
$$


Table 3-9. Tritium inventory in fluid systems and in steel tube walls.

\begin{tabular}{|c|c|c|c|}
\hline \multirow[b]{2}{*}{ System } & \multicolumn{3}{|c|}{ Tritium inventory $(g)$ for options: } \\
\hline & $\dot{A}$ & B & $\mathrm{C}$ \\
\hline Molten-sait system ${ }^{\mathrm{a}}$ & 0.4 & 0.3 & 0.6 \\
\hline Helium-gas systemb & 0.1 & 0.6 & 1.8 \\
\hline Steel walls of molten-salt & & & \\
\hline reactor tubes ${ }^{c}$ & 200 & 2.4 & 4.0 \\
\hline Steel walls of steam-generator & & & \\
\hline tubes ${ }^{d}$ & 5.1 & 11 & 19 \\
\hline $\begin{array}{l}\text { [Tritiur input rate }(C i / d) \text { to } \\
\text { steân/water system] }\end{array}$ & $\left(10^{2}\right)$ & $\left(10^{3}\right)$ & $\left(10^{4}\right)$ \\
\hline Water system $^{\mathrm{e}}$ & 1.2 & 12 & 120 \\
\hline
\end{tabular}

For options $A$ and $B$, a $100-m^{3}$ salt volume is used to allow for the process loop, while option $C$ uses a volume of only $65 \mathrm{~m}^{3}$.

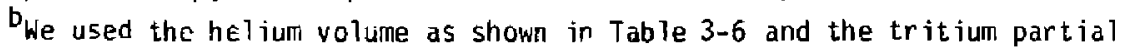
pressures given in footnute to Table $3-8$.

$\mathrm{C}_{\mathrm{D} a t a}$ is for $1 / 2$-inch $0 . \mathrm{d}$. tubes with 20 -mil-thick walls; tritium solubility a: $540^{\circ}$ is from Ref. 3-1; partial pressures are from $T a b l e s \quad 3-5$ and $3-8$.

'The tube sizes and temperatures are from Table 3-6 (weighted according to $\left[A_{j} \mathrm{~W}_{j} \mathrm{~S}_{j}\right)$; tritium partial pressures are given in footnate to Table 3-8. Values given are for options $1 \mathrm{~A}, 1 \mathrm{~B}$, and $\mathrm{CC}$; divide by 2 for $2 \mathrm{~A}$, 28 , and $2 C$.

$\mathbf{e}_{\text {Data }}$ are based on Table 3-6. Water volume and tritiated water concentrations are given in Sections 3.3.2. For the low-input purge case of 3.3.1, the inventory is on 1 y $2.5 \times 10^{-4}$. 
where $p_{3}$ is a radial, average, tritium partial pressure. The solubility of tritium in stee $1^{3-1}$ is calculated from:

$$
S_{3}\left[C i /\left(m^{3} \cdot P a^{1 / 2}\right)\right]=\left(1.04 \times 10^{4} \exp (-705 / T[K])\right.
$$

The amount of tritium contained in the stee 1 reactor tubes for option $A$ is a large number $(200 \mathrm{~g})$ for several reasons. The permeation barrier is on the outside of the tube wall, which keeps the tritium partial pressure in the steel essentially equal to the axial, mean, molten-salt partial pressure, which is quite high. In addition, tritium solubility in steel is exceptionally high. It is tzu arly in the design cycle to consider this to be a real problem, especially: ce the whole issue goes away if we put the low-permeability barrier on the ins ide of the tube.

aptions $B$ and $C$ have much lower inventories, since there is no tungsten layer and the partial-pressure drop is taken across the molten-salt boundary layer, leaving the steel at the relatively low tritium partial pressure in helium.

The steam generator tubes will store a moderate amount of tritium, somewhat larger than the reactor tubes for options $B$ and $C$ main!y because of the larger wall thickness.

\subsection{SUMMARY ANO RECOMMENDATIONS}

Tritium in the form of tritiated water is a personnel hazard at concentration levels well below $1 \mathrm{ppm}$, and steam-generator water will reach the $1 \mathrm{ppm}$ level within a few months of reactor operation unless a combination of perineation barriers and processing are employed.

To gain a better understanding of permeation effects, equations describing steady-state tritium permeation without axial flaw have been derived for a multilayer tube wall within the blanket region. A layer of frozen salt is included, along with fluid boundary-layer resistances. Calculations of the partial-pressure distribution show significant differences for tubes irradiated at different power densities. Molten-salt boundary-layer resistance can be important in the absence of a gosd permeation barrier, or for a low-power tube coated with a naminal l-um tungsten barrier. This nominal permeation barrier will dominate the flow resistance, however, for medium or high power-density 
tubes closer to the first wall. Examination of the radial flux equation shows a complicated dependence on upstream partial pressure, which reduces to a 1 inear dependence at low pressures where Henry's Law materials become flux limiters and a square-root dependence at high tritium partial pressures where Sievert's Law materials are flux limiting.

An analytical model was developed to establish the tritium spl it between wall permeation and reactor-tube flow. The tritium fraction escaping through the tube walls has been quantified for limiting cases of henry's Law and Sievert's Law barriers as flux 1 imiters. All paraneters of design interest are explicitly included: tritium generation rates and solubility in salt, tube geometry, barrier permeation parameters, and molten salt processing rate and recovery efficiency.

The intermediate, helium, heat-transfer loop has been treated as a wellmixed tank for analytical purposes, with input from the reactor, partial tritium recovery in a sipstream process loop, and Sievert's Law permeation loss to the steam system.

A combination of effective tritium permeation barriers are required on both blanket and steam-generator tubes (together with substantial process rates for molten salt and helium systems) in order to hold tritium permeation into the steam system to $55 \mathrm{Ci} / \mathrm{d}$, according to case $1 \mathrm{~A}$. If this can be done, it may be feasible to simply purge the steam system of incoming tritium with only minor environmental impact and personnel hazard from steam leaks, and without the necessity of costly and hazardous isotopic processing to separate tritiated and ordinary water.

A surprisingly th in $(10 \mu \mathrm{m})$ tungsten coating will, in principle, provide a good permeation barrier on the blanket tubes. The feasibility of, in fact, reducing tritium blanket permeation by a factor of 300 or so below the bare steel tube rate for some $1 \times 10^{4} \mathrm{~m}^{2}$ of tube area wilt require a research and development effort. Other materials or alloys may prove to be superior, probably at the price of greater thickness of coating.

A relatively thick $1-\mathrm{mm}$ aluminum sleeve was selected to suppress permea$t$ ion through the sieam-generator tubes. This gave a calculated reduction factor of more than 500 relative to bare stee 1 and including a factor of 30 because of an assumed oxide layer. This is essentially a brute force approach that may weTl be improved upon by the development of more sophisticated permeation barriers. 
Although we have focused attention on a tungsten barrier because of a remarkably low tritium permeabiiity, beryllium and ather low-permeability materials such as ceramics and cermets should be considered in a barrierdevelopment problem.

The diffusivity of tritium gas dissolved in molten salt will need to be measured, especially to verify whether or not the fluid-boundary-layer barrier of Option $B$ is realistic.

Fimally, some definitive experimental work. is called for on the kinetics of tritium gas conversion to tritiated water at low concentrations in helism. Popular opinion has oscillated over the last decade from an initial optimism that thermodynamics would reduce the gas concentration to $n i 1$, to a current pessimism that predicts no gas conversion at all in the main helium loop. The critical experiments remain ta be done, both with "clean" walls and particulate-free helium as well as in the presence of catalytic surfaces or other reaction promoters. The challenge is to demonstrate a method of drastically reducing tritium gas partial pressure in the intermediate helium loop and thus suppress permeation into the steam system. 
3-1 M. R. Louthan, Jr. and R. G. Derrick, Corrosicn Sci. 15, 565 (1975).

3-2 A. M. Hassanein and D. K. Sze, Data Survey and Recommended Values for Permeation of Hydrogen and Its I sotopes Through Steel Alloys, unpubl ished report, Argonne National Laboratory (1984).

3-3 S. A. Steward, Review of Hydrogen I sotope Permeability Through Materials, Lawrence Livermore National Laboratory, UCRL-53441 (1983).

3-4 0. R. Begeal, J. Vac. Sci. Technol., 15, 1146 (1978).

3-5 J. W. Guthrie et a)., 3. Nuc?. Mater., 53, 313 (1974).

3-6 W. Eichenauer and A. Pebler, Z. Metallkd. 48, 373 (1957).

3-7 P. M. S. Jones and R. Gibson, J. Nucl. Mater. 21, 353 (1967).

3-8 E. A. Aitken et al., Trans. Meta11. Soc. AIME, 239, 1565 (1967).

3-9 W. F. L ibby, "History of Tritium", in Tritium, A. A. Mcghissi and M. W. Carter, Eds. (Messenger Graphics, Phoenix, Arizona, 1971, p. 3).

3-10 G. F. Killough, Derivation of Cose Conversion Factors for Tritium, 0ak Ridge Nationa 7 Laboratory, ORNL-5853 (1982).

3- 11 A. E. Sherwood, Catalytic 0xidation of iritium in Air at Ambient Temperature, Lawrence Livermore Laboratory Report, UCRL-52811 (1979).

3-12 C. E. Easterly and M. R. Bennett, "Radiation Catalyzed Conversion of Tritiun Gas to Tritiated water, Proc. 5th Topical Meeting Technol. of Fus ion Energy, Knoxville, Tennessee, 116, 1983; Nuclear Technology/Fusion 4, (2) (1983), part 2 .

3-13 G. N. Lewis, M. Randa11, K. S. Pitzer, and L. Brewer, in Thermodynamics, in ppter 19, (McGraw Hill, New Yark, 1961), 2nd ed.

3-14 A. P. Mal inauskas and D. M. Rjchardson, Ind. Eng. Chem. Fund. 13, 242 (1974).

3-15 0. S. Shupe and R. E. Stickne; J. Chem. Phys, 51, 1620 (1969).

3-16 J. M. Prausnitz, Molecular Thermadynamics of Fluid-rhase Equilibria, Chapter 8 (Prentice-Hall, Englewood Cliffs, NJ, 1969).

3- 17 E. R. G. Eckert and R. M. Drake, Jr., Analysis of Heat and Mass Transfer, (McGraw Hi11, New York, 1972), pp. 338, 340, 731 .

3-18 G. I. Taylor, Proc. Roy. Soc. London, 219A, 186 (1953).

3-19 H. Katsura and K. Furukawa, J. Nucl. Mater. 71, 375 (1978).

3-20 W. P. Holman and F. J. Huegel, Proc. Conf. Chemical Vapor Deposition Refractory Metals, A I lous, and Campounds, USAEC (1967), p. 127. 
3-21 0. J. Bender, Ed., Reference Design for the Standard Mirror Hybrid Reactor, Chapter 9, Lawrence Livermare Laboratory and General Atomic Company Joint Report, UCRL -52478 and GA-A 14796 (1978).

3-22 R. G. Mills, Ed., A Fusion Power Plant, Chapters 14 and 15 by Maroni and Johnson, Plasma Phys. Lab., Princeton University, Princeton, Nev: Jersey (1974).

3-23 S. Steward, Lawrence Livermore National Laboratory, private communication (lanuary 1984).

3-¿4 C. C. Dam, et al., Preliminary Design of a Tandan-Mirror-Next-StepFacility, Lawrence Livermore National Laboratory, UCRL-53060 (1980).

3-25 1. A. Flanagan, D. Steiner, and G. E. Smith, Fusion Engineering Device Design Description, Vol. 2, Oak Ridge National Laboratory, ORNL/TM-7948/N2 (1981).

3-26 K. Y. Wong, et al., "Permeation of Tritium Through Steam Generator Tubes at CANDU Stations," loth Symp. Fusion Engineering, Philadelphia, PA, (19B3).

3-27 H. K. Rae, Ed., Separation of Hydrogen I sotopes, Am. Chem. Soc. Ser ies 68, Washington, D.C. (1978), p. 163.

3-28 J. Maienschein, Lawrence Livermore National Laboratory, private conmun ication (June 1984).

$$
-753-/-154
$$




\subsection{MOLTEN-SALT REPROCESSING}

We have selected the fluorination process to remove ${ }^{233} U$ from the salt slipstream. We find it unnecessary to use the more complex reductive extraction of fission products. Molten-salt reprocessing applied to the fusion breeder is well discussed in Ref, 4-1.

A study of three levels of molten-salt reprocessing was carried out recently. ${ }^{4-2}$ The simplest level is fluorination only, which removes $233_{\mathrm{U}}$ but not protactinium or many fission products. The next level is both fluorination and reductive extraction in which both uranium and proctact inium are removed along with small amounts of fission products. The final level is the addition metal-transfer treatment, which removes most of the rare earth fission products.

Employing the second and third levels of reprocessing had negligible effects on breeding rates and decay afterheat, except months after reactor shut down. Therefore, our choice of employing only the fluor ination process was reaff irmed.

\section{REFERENCES SECTION 4.0.}

4-1 J. D. Lee, et a1., Feasibility Study of a Fission-Suppressed Tandem Mirror Hybrid Reactor, Lawrence Livermore National Laboratory, UCID-19327 (1982), Section VIIB, "Molten-Salt Fue1 Reprocessing" by Warren Grimes.

4-2 F. A. Patterson-Hine, J. W. Davidson, and D. E. Klein, "Contributions t.l the Thermal Power of Continous $1 y$ irocessed TMHR Molten-Salt Blankets," Proc. IEEE 10th Symp. Fusion Engineering, Dec 5-9, 1983, Philade iphia, PA, p 988 .

$$
-155-/ 756
$$




\subsection{BNLANCE-OF-PLANT CONSIDERATIONS}

A brief discussion of . $\quad$... nlant (BOP) aspects of the Molten Salt fusion Breeder $D$, ar , is presented here. These aspects include: general

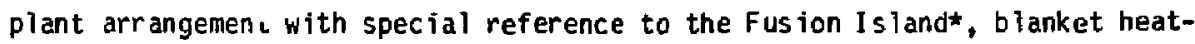
transport system with special reference to the piping and equipment designs, and steam-generator system with special reference to tritium permeation consider at ion through steam-generator tubes.

\subsection{GENERAL PLANT ARRANGEMENT}

The major $B O P$ buildings are shown in the Key $P 1$ an (Fig. 5-1). The buildings that constitute the Fusion Island are reactor building, steam generator building, molten-salt processing building, tritium processing building, and hot cell. The plant arrangement takes full advantage of the linear nature of the tandem mirror concept. One side of the reactor building is open for rapid construction access, which will impact favorably on plant construction schedule. For the sake of simplicity all the buildings are shown contiguous. Further analys is may favor separation of some of the bujidings for safety and cost effectiveness.

The reactor building, steam generator, and molten-salt processing buildings enclose the entire molten-salt and helium-coolant system. The Fusion Island buildings provide a leak-tight confinement for the radioactive materials and radiation protection for operating personnel and the public at 1 arge. These buildings are reinforcea concrete structures capable of withstanding credible natural and accidental conditions such as earthquake, tornado, or accidental tritium release.

The reactor vessel (including end cells) and its associated structural supports are located in the reactor bullding. The helium-cooling loops are located partly in the reactor building and partly in the steam-generator building. The steam generators and helium circulators (one of each in each

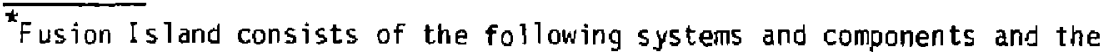
buildings in which they are located: the reactor, steam generators, molten-salt processing system, tritium processing system, and the hot cell.
} 


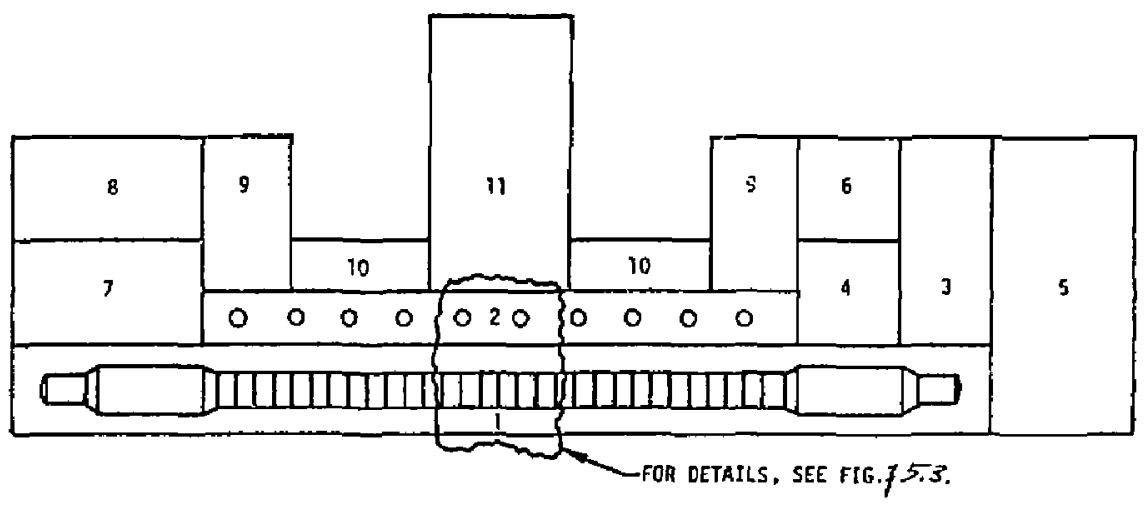

Fig. 5-1. Diagram of plant arrangement: (1) Reactor building, (2) steam generator bıilding, (3) tritium processing building, (4) molten salt processing building, (5) hot ce17, (6) radwaste building, (7) component cooling building, (8) plant auxifiary building, (9) power supply building, (10) cryogenics building, and (11) turbine building. Buildings 1 through 5 constitute the Fusion Is land. 
cooling loop) are located in the steam-generator building. The tritiumprocessing building primarily houses the equipment for processing plasma exhaust to recover tritium. The moiten-salt processing building houses the equipment for processing molten salt to recover uranium and tritium. The hot cell, which is provided for maintaining radiactive components, consists of a hot cell and a warm cell. The warm cell is provided for limited hands-on maintenance operations.

In molten-salt fusion breeder plants all the Fusion Island buildings contain radioactive materials and are thus safety-relaced structures. According to current fission-industry practice, these buildings are required to be nuclear-grade structures. In addition to meeting many industry codes and standards, nuclear-grade structures a e required to meet very stringent Nuclear Regulatory Commission (NRC) criteria. These NRC criteria make structures very expensive. Nuclear-grade structures are used in fission plants for high-pressure-containing (500 to $600 \mathrm{kPa}$ ) reactor containment building and its contiguous buildings for safety purposes primarily to contain, in case of an accident, the releasable $r$ adioactive materials. However, in the molten-salt fusion breeder plant, there are no such pressure-containment structures, and in addition, the after heat generated is much less than in fission plants.

In light of these unique safety features of fusion, a relevant question may be asked: Can the Fusion $[\mathbf{s}$ land bujldings be constructed to criteria that are less stringent than nuclear standards? In essentialiy all the fusion conceptual studies it has been assumed that all NRC regulations applicable to fission plants will also be applicable to fusion plants. It is too premature to determine whether this will indeed be the case. In the meantime the question raised here is an attempt to utilize fusion's safety features and to find ways to reduce fusion plant cost. Thus we propose that a new set of criteria be developed for fusion breeders. These new "safety" criteria will retain all NRC safety philosophy; systems and structures built to these standards will meet all NRC radiation-exposure criteria.

Another phenomenon observed in the fission industry indicates that, based on historical cost data, some nonnuclear-grade facilities cost more than comparable facilities on conventional (fossil) power plants. This is primarily because the nonnuclear-grade facilities are often 
unnecessarily constructed to nuc lear-grade requirements. Many builders find it convenient to build most facilities at one site to one set of standards. However, because of high costs of current fission plants, a trend is developing with in the fission industry to build safety-related structures to nuclear-grade standaros and nansafety-related structures to commercial-grade standards. A similar approach is proposed here for the molten-salt fusion breeder plant as indicated below:

- Fusion safety-grade standards:

Reactor building Molten-salt processing building

Tritium-process ing building

St sam-generator building

Hot cell

Radwaste building

- Commercjal-grade standards:

Component cooling building

Turbine building

Power-supply building

Plant-aux iliary building

Cryogenics building

other miscellaneous buildings

\subsection{BLANKET HEAT TRANSPORT}

The parameters for the blanket heat-transport system are listed in Table 5-1; schematic djagram is shown in Fig. 5-2; and the piping and equipment arrangements are given in Figs. 5-3 and 5-4. 
Table 5-1. Heat-transport system of blanket.

Therinal power:

Total blanket

Added by helium circulator

Blanket modules (no.)

Steam generators (no.)

Helium circulators (no.)

Thermal power of each stean generator

Helium temperature:

$B$ lanket out let/steam-generator inlet

$B$ lanket inlet/heliun-circulator outlet.

Steam-generator outlet/helium-circulator inlet

Helium pressure:

$$
\begin{aligned}
& \text { At circulator out let } \\
& \text { At circulator inlet }
\end{aligned}
$$

He lium pressure drop:

B lanket

Steam generator

Piping

Total

Helium pumping power:

Total

Per circulator

Heliun flow rate:

Total

Per module

Per circulator

Steam-outlet temperature

Steam-outlet pressure

Feedwater-inlet temperature

reeowatem-inlet pressure

Steam flow-rate per steam generator
$3,840 \mathrm{MH}_{\mathrm{t}}$

$110 \mathrm{MW}_{\mathrm{t}}$

30

10

10

$395 \mathrm{MN}_{\mathrm{t}}$

$545^{\circ} \mathrm{C}$

$300^{\circ} \mathrm{C}$

$293^{\circ} \mathrm{C}$

$5,000 \mathrm{kPa}$

$4,875 \mathrm{kPa}$

$55 \mathrm{kPa}$

$50 \mathrm{kPa}$

$20 \mathrm{kPa}$

$125 \mathrm{kPa}$

$110 \mathrm{MH}$

$11 \mathrm{MW}_{\mathrm{e}}$

(15,000-hp motor)

$3,000 \mathrm{~kg} / \mathrm{s}$

$100 \mathrm{~kg} / \mathrm{s}$

$300 \mathrm{~kg} / \mathrm{s}$

$510^{\circ} \mathrm{C}$

$16.9 \mathrm{ip}$ a

$193.3^{\circ} \mathrm{C}$

$19.0 \mathrm{ma}$

$159 \mathrm{~kg} / \mathrm{s}$ 


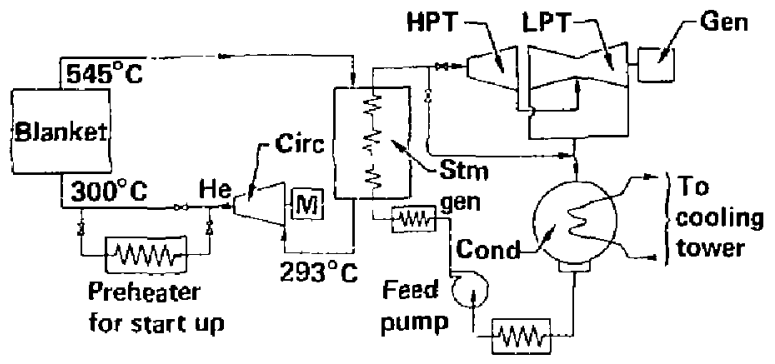

Fig. 5-2. Schematic of heat-transport and power-conversion systems of blanket. 


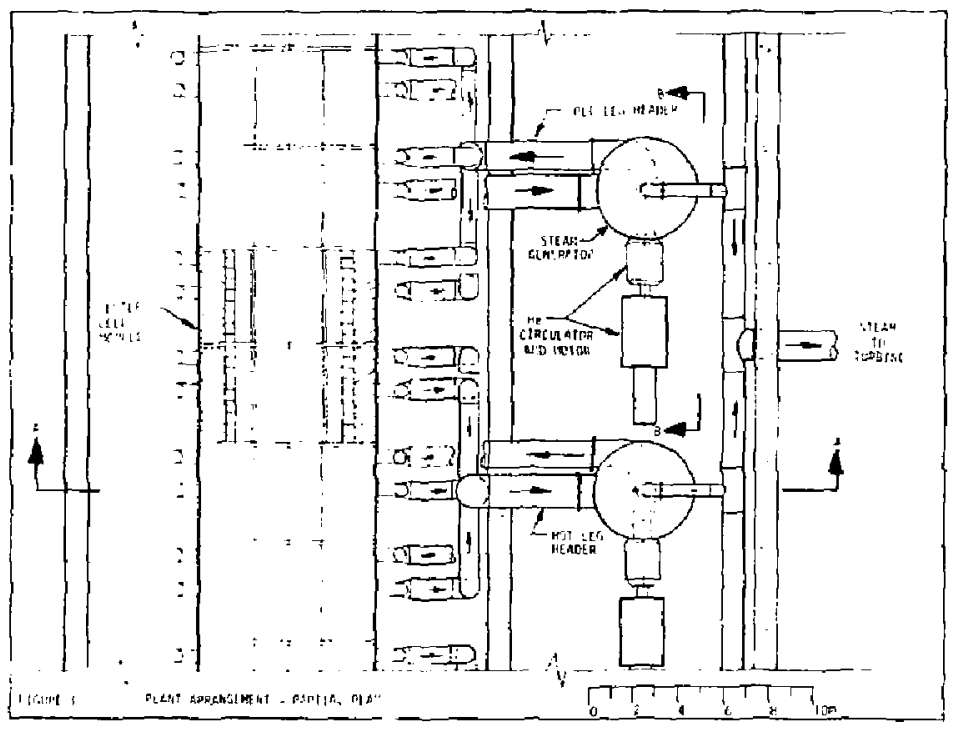

Fig. 5-3. Heat transport syctem, showing piping and equipment arrangement (overhead $v$ iew). 


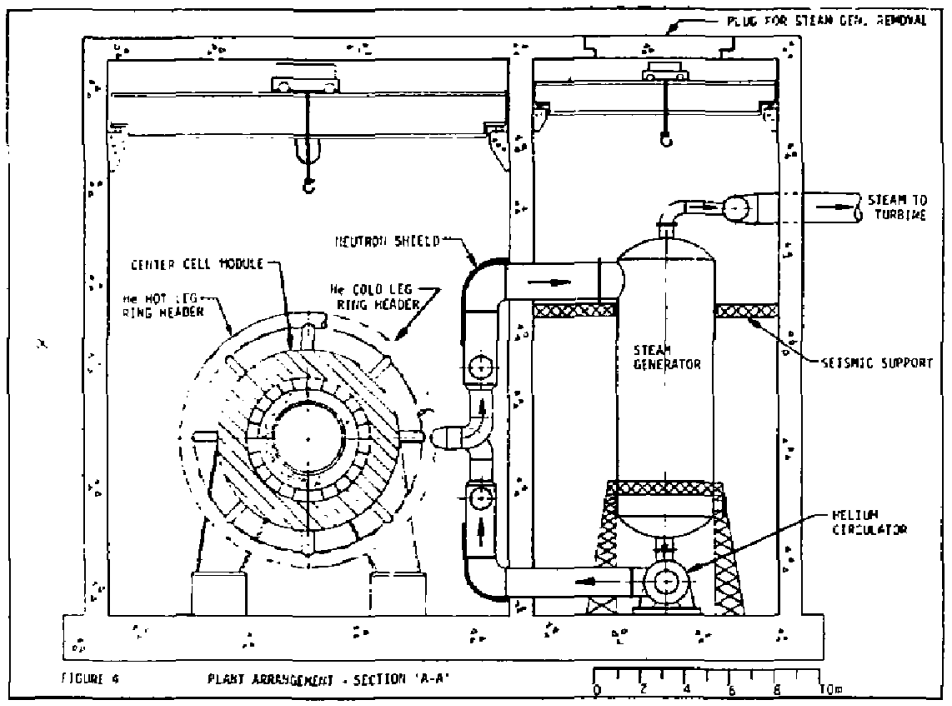

Fig. 5-4. Heat transport system, showing piping and equipment arrangement (sideview). 
For the blanket configuration considered, the entire central cell (127-m long) is divided into 30 modules. The size of each module is based on consigerations for shop fabrication, transportation, handling, and maintenance. To transport blanket thermal energy, each madule is provided with a cold-helium ring header and a hot-helium ring header. Radial supply and return 1 ines connect these headers to the blanket "pods" (see Fig. 3-2 in Section 3.0).

The central cell modules are grouped such that one steam generator serves three modules, which results in ten steam generators each having a capacity of $395 \mathrm{MW}_{t}$. Each generator is coupled with a helium circulator to supply cooled helium to the blanket at $5 \mathrm{MPa}$ and $300^{\circ} \mathrm{C}$.

The steam generators proposea here are based on design features similar to those already operating in the Fort Saint Vrain high-temperature-gas reactor (HTGR) plant near Denver, Colorado, and also as proposed for the gas-cooled fast reactor (GCFR) demonstration plant. $5-1,5-2$ However, the steam generators proposed in th is study are located in steel pressure vessels, whereas the fort Saint Vrain steam generators are located in monolithic prestressed concrete pressure vessels (PCRV). A steel pressure vessel for steam generators is a!sa proposed for modular HTGR concepts currently being considered. $5-3$

in the stearl generators proposed for fusion hybrids, hot helium $\left(545^{\circ} \mathrm{C}\right.$ ) enters at the top of the steam generator, flows downward on tne shell side of the tube bundle and gives up heat to water and steam, and exits at the bottom $\left(293^{\circ} \mathrm{C}\right)$. The water enters through a feedwater tubesheet located at the bottom, flows upward inside the tubes and exits at the top through a superheater tubesheet. An elevation view of the factory-assembled once-through steam generator along with some representat ive tube details is shown on Fig. 5-5. An internal view of the stean generator used at Fort Saint vrain plant ${ }^{5-4}$ is also given on Fig. $3-5$. Figure 5-6 shows an internal view of a steel vessel stean generator considered for the modular HTGR concepts. The pictures and sketches presented here demonstrate the current trends in steamgenerator design.

As seen in Figs. 5-4 and 5-5, the steam generator is supported at the bottom on a support structure and is provided with a lateral seismic restraint at the top. "flow-distribution device at the in let ensures uniform helium flow. Helical coiled tubes, whicl make up the heat-transfer section of the steani generator, are threaded through perforated tube-support plates, which 
(a)
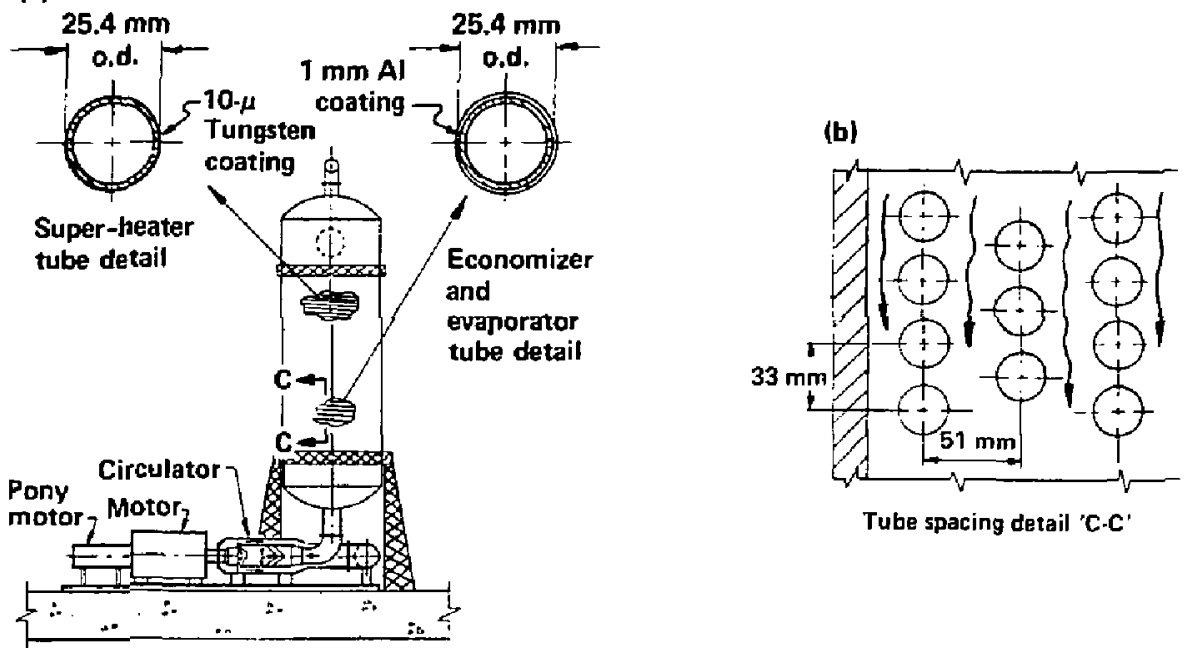

(c)

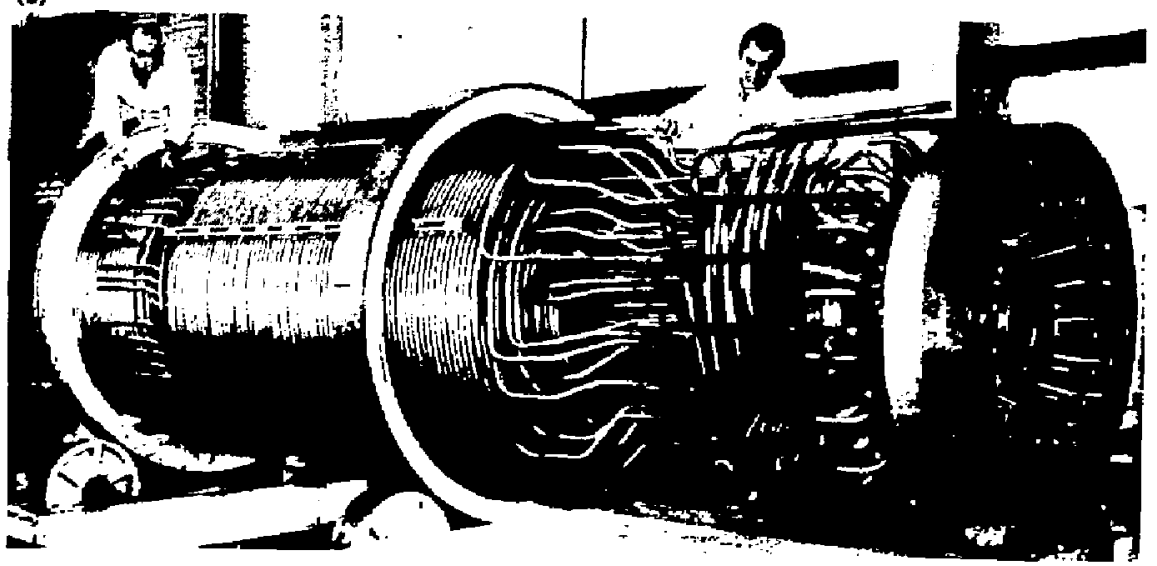

Figure 5.5. Steam generator arrangement. (a) Section 'B-B', (b) Typical tube sparing detai1. (c) Fort Sait Vrain stearn jenerator. 

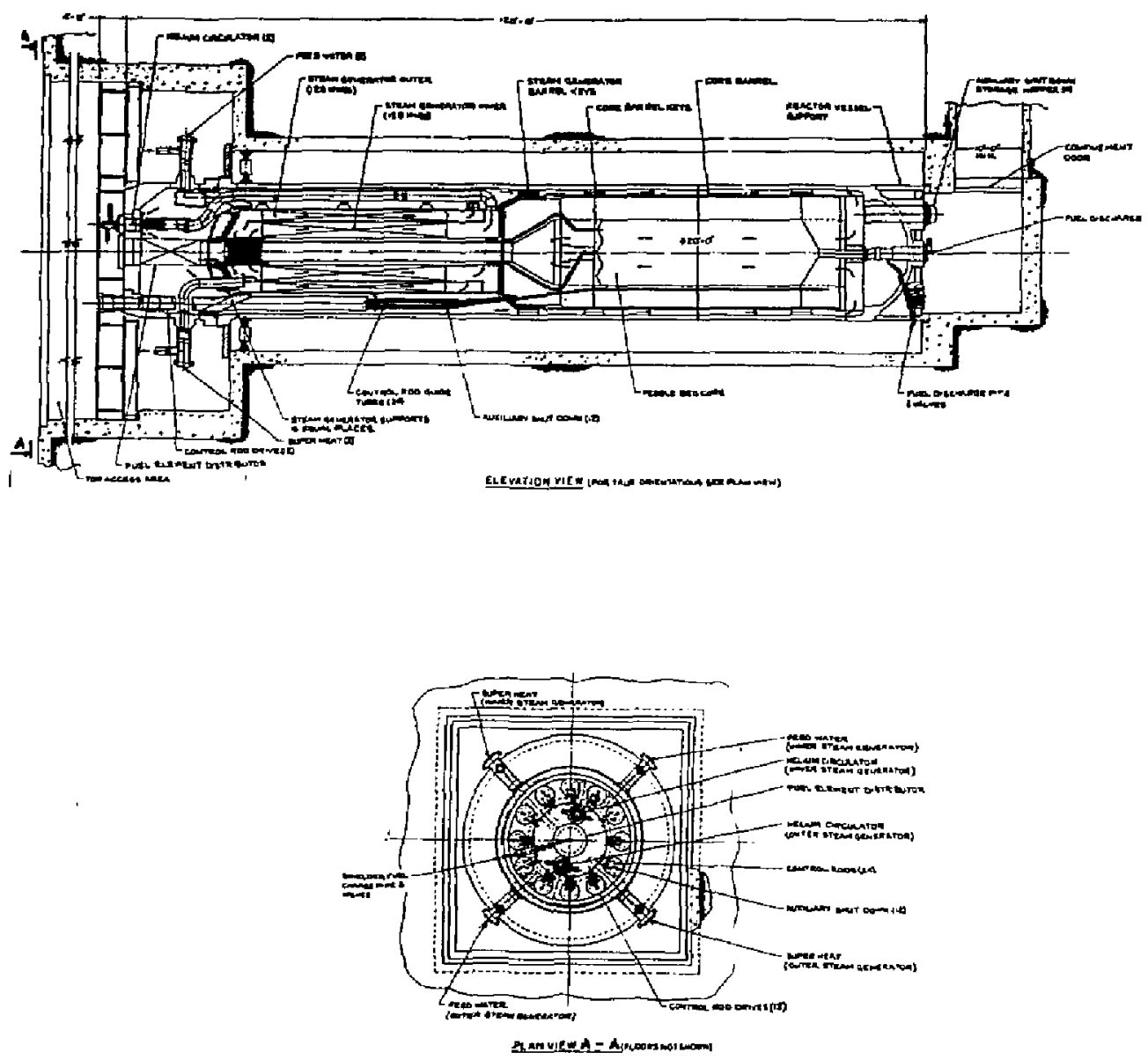

Figure 5-6. Steel vessel steam generator for a high-temperature gas reactor (HTGR). 
transmit dedd weight and seismic loads to the supporting shrouds. The heattransfer section of each steam generator is about $4 \mathrm{~m}$ in diameter, $8 \mathrm{~m}$ long, and is made up of tubes, 2.54-cm o.d.

The entire steam-generator assembly, which can accommodate in-service inspection and in-place tube plugging, is capable of being removed and reinstalled, if required, through a shielded opening plug in the roof of the steam-generator building.

As mentioned earlier, th: s steam-generator capacity selected for this study is $395 \mathrm{MW}_{t}$. This cajacity is dictated by two major factors:

- Physical size of steam generator.

- Pipe size for transporting heliun.

The largest practical size of stean generator is, in turn, dictated by factors such as thermal load, temperature and pressure of helium, log mean temperature difference (LMTD) acrass the neat transfer area, temperature and pressure of steam and temperature gradient across the tube. Induced stresses (thermal and pressure) in the tubes, tubesheets, and vessel walls put practical limits on the amount of heat-transfer area that can be accommodated in a single steam generator. The largest capacity currently being considered ror steel vessel steam generators for modular HTGR application ${ }^{5-3}$ is $250 \mathrm{MW}_{\mathrm{t}}$. For this HTGR, helium conditions are $688^{\mathrm{o}} \mathrm{L}$ and $8.7 \mathrm{MPa}$, and steam conditions are $547^{\circ} \mathrm{C}$ and $77,3 \mathrm{MPa}$, with an overall LMTD of about $98^{\circ} \mathrm{C}$. In the molten-salt fusion breeder plant, the heliufil conditions are $545^{\circ} \mathrm{C}$ and $5 \mathrm{MPa}$, the steam conditions are $510^{\circ} \mathrm{C}$ and $16.9 \mathrm{~Pa}$, and the overa 11 LMTD is approximately $62^{\circ} \mathrm{C}$. Thus, the largest capacity steam

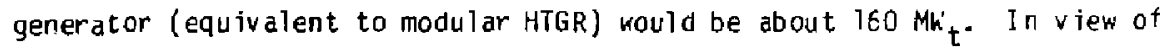
the time frame of fusion deployment, which is some years away, an extrapolation in size by a factor ranging from two to three is considerea reasonable. A capacity of $395 \mathrm{MH}_{t}$ capacity thus falis within this anticipated range.

As an example of the impact of helium pressure and temperature on steamgenerator design, let us consider the superheater section. In this section peak helium temperature and pressure are $545 \mathrm{ac}_{\mathrm{C}}$ and $4.945 \mathrm{MPa}$. For a vessel with an outside-diameter of $4 \mathrm{~m}$, the wall thickness required is about $20 \mathrm{~cm}$. This unusually heavy thickness is required because the allowable stress in the vessel material (2 $1 / 4 \mathrm{Cr}, 1 \mathrm{Mo}$ ) at $545^{\mathrm{o}} \mathrm{s}$ is only about $48 \mathrm{MPa}$ (ANSI 831.1). In the economizer section, on the other hand, the lowest helium temperature is 
$293^{\circ} \mathrm{C}$ and the ailowable stress is $118.6 \mathrm{Ma}$. The vesse $1-w 211$ thickness required is about $9 \mathrm{~cm}$.

Two potential alternatives may be considered to reduce wall thickness in the hotter sections of the steam generator vessel. First, the helium flow paths inside the steam generator may be arranged so that the vessel wall is in contact with the cooler helium (see Fig. 5mb). This may require slightly larger diameter vessel to accommadate the annular passage for the cooler helium. This method is used in the modular HTGR steam-generator design. $5-3$ Second, for this poiential alternative, the inside surface of the vessel wall may be lined with a thermal insulation such that the metal temperature is maintained at or below $340^{\circ} \mathrm{C}$ to take advantage of the max imum allowable stress (118.6 MPa, see ANSI B31.1). In this case, however, the inside surface of the therma insulation must be lined with steel to avoid contamination of helium by the insulating material.

Helium pipe size may alsco put a limitation on the steam-generator capacity. A larger steam generator requires a larger heljum flow through pipe headers connecting the steam generator with the reactor. High temperature and pressure of helium put practical limitation on pipe sizes. The largest pipe size considered in this study is $1.5 \mathrm{~m}$ o.d. I discussion on pipe size selection is given in the following paragraphs.

The piping system connecting the reactor and the steam generators constitutes an important element of the heat transport system because of its cost and its impact on the building size and helium pumping power. The piping arrangement shnwn in Figs. 5-3 and 5-4 is developed with a view to reducing these impacts. Fipe sizes are selected for reasonable flow velocities (50 to $70 \mathrm{~m} / \mathrm{s}$ ) to limit pressure drop in the piping system tr. a reasorable level $(20 \mathrm{kPa}$, which is about $15 \%$ of ile total pressure frop in the heat transpart loop).

Selection of pipe size is generally based on a cost irade-off between initial cost of pipe and operating cost due to pumping power. A larger pipe has a lower pressure drop, which results in lower pumping power. This implies higher initial cost of pipe but lower operating cost of pumping. A smaller pipe has an opposite effect. In the present study, results of existing design

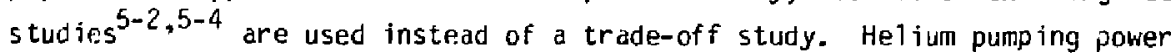
for the entire heat-transport loop is generally limited to $2.5 \%$ to $3 \%$ of total thermal power. Using this criterion and knowing pressure arop through bianket and steam generator ${ }^{5-5}$, we target the pressure drop in the piping system to 
Table 5-2. Parameters for hot- leg header of helium-transport loop.

\begin{tabular}{|c|c|}
\hline Par aneter & Value \\
\hline \multicolumn{2}{|l|}{ Pipe } \\
\hline Dutside diameter, $D_{0}$ & $1.50 \mathrm{~m}$ \\
\hline Wall thickness & $0.08 \mathrm{~m}$ \\
\hline Inside diameter, $\mathrm{D}_{\mathbf{i}}$ & $1.34 \mathrm{~m}$ \\
\hline Internal flow area & $1.41 \mathrm{~m}^{2}$ \\
\hline Pipe materiat & Alloy carbon steel $(21 / 4 \mathrm{Cr}, 1 \mathrm{Mo})$ \\
\hline \multicolumn{2}{|l|}{ Helium } \\
\hline Temperature & $545^{\mathrm{C}} \mathrm{C}$ \\
\hline Pressure, $P$ & $4.945 \mathrm{MPa}$ \\
\hline Density, $\rho$ & $2.9455 \mathrm{~kg} / \mathrm{m}^{3}$ \\
\hline$V$ iscosity, $\mu$ & $\begin{array}{l}3.92 \times 10^{-4} \text { poise (g/cm.s) } \\
\quad=3.92 \times 10^{-5} \mathrm{~kg} / \mathrm{m} \cdot \mathrm{s} \text { (Ref. } 5-5 \text { ) }\end{array}$ \\
\hline Flow rate, $m$ & $\begin{array}{l}300 \mathrm{~kg} / \mathrm{s} \text { (total for three modules) } \\
=102 \mathrm{~m}^{3} / \mathrm{s}\end{array}$ \\
\hline Flow velocity, $V$ & $\begin{array}{l}\text { flow rate/flow area }=102 / 1.41 \\
=72 \mathrm{~m} / \mathrm{s}\end{array}$ \\
\hline Reymold's number, $\mathrm{Re}=\rho V D / \mu$ & $\begin{array}{l}2.9455 \times 72 \times 1.34 / 3.92 \times 10^{-5} \\
\quad=7.25 \times 10^{6}\end{array}$ \\
\hline Friction factor, $f$ (Ref, $5-6$ ) & 0.01 \\
\hline \multicolumn{2}{|l|}{ Pressure drop } \\
\hline \multirow[t]{2}{*}{ Per meter of pipe length } & $f v^{2} / 2 D_{i}=\frac{0.01 \times 72 \times 72 \times 2.9455}{2 \times 1.34}$ \\
\hline & $260 \mathrm{~Pa}$ \\
\hline \multicolumn{2}{|c|}{$\begin{array}{l}\text { Tctal in } 20-m-\text { long trader } \\
\text { (including } 50 \% \text { al lowance for }\end{array}$} \\
\hline losses in the bends) & $1.5 \mathrm{kPa}$ \\
\hline
\end{tabular}


approximately 15\% of the total loop pressure drop. The pipe sizes thus estimated result in the flow velocities between 50 and $70 \mathrm{~m} / \mathrm{s}$, which are generally used in the industry. As an example, let us cansider the hot-leg header having the parameters shown in Table 5-2. Pressure drop in all segments of the piping system can be similarly evaluated. Alloy carbon steel (2 $1 / 4 \mathrm{Cr}, 1 \mathrm{Mo}$ ) is assumed for all helium piping.

The largest pipe sizes for helium flow between a steam generator and three central-cell modules combined are estimated to be 150 and $130 \mathrm{~cm}$ o.d. for the hot leg and the cold leg, respectively. The operating conditions in these pipes require large wall thicknesses. In the hot leg, for example, the $545^{\circ} \mathrm{C}$ and $5 \mathrm{Ma}$ (approx.) operating conditions lower the allowab le stress to about $48 \mathrm{MPa}(7,000 \mathrm{psi})$ requiring $8-\mathrm{cm}$ wall thickness. These unusually heavy pipes, which truly may be characterized as pressure vessels, ar very expensive. In addition, their seismic support and thermal expansion requirements will have adverse impact on the building sizes and costs. Several alternatives for alleviating these adverse impacts, such as the following, will be considered:

The pipes may be internally insulated so that the steel wail is subject to much lower temperature. A steel liner on the surface of the insulation and in contact with helium is required to ina intain purity of helium and possibly to reduce tritium permeation. The liner may be so provided that it is not subject to stress. A similar method is used in the steel industry, altinough there the hot gas is at much lower pressure $(0.1$ to $0 . ? \mathrm{MPa})$.

In contrast to a large single pipe, three smaller pipes may be provided, each serving a module. The econamics of the two approaches need to be evaluated. Une major disadvantage of the three-pipe over the single-pipe approach is the need for three times as many penetrations through the reactor building wall. This may degrade the leak-tightness of the building, and more shielding will be needed to prevent neutrons escaping through the penetrations.

The steam generators may be located in the reastor building very close to the reactor to minimize the pipe lengths. This arrangement exposes the steanrgenerator components to low-level neutron $r$ adiation and, consequently, nakes the stean-generator and reactor maintenance more difficult. Future stucies should focus on which of these alternatives is most cost effective.

Each of the heijum circulators is rigidly mounted horizontally on the f loor below the steam generator. Each is driven by an $11-\mathrm{MH}_{\mathrm{e}}(15,000-\mathrm{hp})$ electric motor, also mounted horizontally. Helium leaving the steam generator 
enters the circulator and is accelerated by a centrifugal impeller, passes into a series of pipe diffusers and then discharges into a plenum surrounding the circulator. Helium from this plenum then flows through the cold-leg header (Fig. 5-3) to the cold-leg ring header ( $F$ ig. 5-4) and is then distributed radially inwards into the blanket 'pods'.

The helium circulators are of single-stage radial-flow type. A variable frequency (thyristor type) controller provides for variable-speed operation of the circulator to provide the required cooling flow for part-load and full-load operation. In acdition, the circulators are capable of performing unger emergency conditions. Independently powered pony motors (10w-capacity motors) provide circulation for decay-heat removal.

The pumping power requirement for each circulator is estimated by using the following expression: ${ }^{5-7}$

$$
\text { Power }=m \frac{k}{k-1} P_{1} V_{1}\left[\left(p_{2} / P_{1}\right)^{(k-1) / k}-1\right] / n_{c}, M_{e} \text {, }
$$

where $m=$ helium flow-rate per circulator $(\mathrm{kg} / \mathrm{s}), k=$ ratio of helium specific heats $\left(C_{p} / C_{v}\right) ; P_{7}, P_{2}=$ in let and outlet pressures $(M P a) ; v_{1}=$ specific volume of helium at inlet $\left(\pi^{3} / \mathrm{kg}\right)$; and $n_{c}=$ overall compression efficiency.

$$
\text { If } \quad \begin{aligned}
m & =300 \mathrm{~kg} / \mathrm{s}, \\
k & =1.667, \\
P & =4.875 \mathrm{MPa}, \\
P & =5.0 \mathrm{MPa}, \\
\rho & =0.2383 \mathrm{~m}^{3} / \mathrm{kg}\left(\text { at } 4.875 \mathrm{MPa} \text { and } 293^{\circ} \mathrm{C}\right), \\
{ }^{\circ} c & =0.8,
\end{aligned}
$$

then power $=11$ liwe $(15,000-$ hp-rated motor $)$.

Steam power-cycle parameters, 1 isted in Table 5-1, are dictated by a large number of factors. The most important of them are hot and cold helium temperatures, steam-generator design (j.e., aväilable technologies for its structural and thermal design), and steam-generator cast. A detailed discussion of the stearn-generator design is not the purpose of this report. However, if helium is proposed for fusion reactor designs, it is important to pay serious attention to its impact on fusion plant design and economics. 
With the general objective of optimizing steam-cycle efficiency for a given hot-helium temperature, one likes to get as high a steam temperature as possible. However, a higher steam temperature implies a smaller log-meantemperature difference (LMTD), and as we know, a smaller LMTD implies a larger steam generator. Thus the added steam generator cost needs to be weighted against the added benefits from a higher steam cycle efficiency. For comparison, note that current helium steam-generator designs employ superheater LMTD's of about $160^{\circ} \mathrm{C}^{1}, 5-1$ whereas the design in this study employs a superheater LMTD of about $65 \%$. Thus, for the same $M W_{t}$ requirement, a much larger superheater section (about 2.5 times as much heat transfer area) is needed. Similar considerations also apply to the evaporator and economizer sections of the steam generator. The cost of this larger steam gener ator needs to be determined in future work.

The effect of pinch point also needs to be considered in selecting steam cycle parameters. The pinch point is the smallest temperature difference between helium and water which occurs in the evaporator section. The average value of pinch point commonly used in industry is about $30^{\circ} \mathrm{C}^{5-1}$. However, if desired, sfialler values may be used with higher heat-transfer area.

The helium and steam parameters at various stages in the steam generators are aresented in Fig.5-7. Standard steam and feedwater conditions that are currently in use in industry are assumed. Superheater-outlet steam conditions are $16.9 \mathrm{NPa}$ and $510^{\circ} \mathrm{C}$, and feedwater-inlet conditions are $19 \mathrm{MPa}$ and $193.3^{\circ} \mathrm{C}$. The diagram in $\mathrm{Fig} .5-7$ is also used to make a rough estimate of the heat transfer area neeced. The followmg express ion is used to estimate the heat transfer area:

$$
Q=U A(L M T D) \text {, }
$$

where $Q=$ heat transferred $(W) ; U=$ overal 1 heat-transfer coefficient across the stean-generator tube from the helium side to steam/water side $\left(w / m^{2} \cdot q\right) ; A=$ heat transfer area $\left(m^{2}\right) ;$ LMTO = log-mean-temperature difference in ${ }^{\circ} \mathrm{C}$. The above expression is applied to each section of the steam generator and an approximate heat-transfer coefficient, $1135 \mathrm{~W} / \mathrm{m}^{2} \cdot{ }^{\circ} \mathrm{C}$, is assumeo for the purpose $\mathrm{e}^{5-8}$ ). The following approximate heat-transfer areas are estimated for each steam generator: Economizer $-2,315 \mathrm{~m}^{2}$, Evaporator - $1,310 \mathrm{~m}^{2}$, Superheater - 1,715 $\mathrm{m}^{2}$. All the steam generator tubes are $25.4 \mathrm{~mm}$ 0.d. Estimated tube-wall thicknesses are $4 \mathrm{~mm}$ in the economizer and evaporator sections and $5 \mathrm{~mm}$ in the superheater section. 


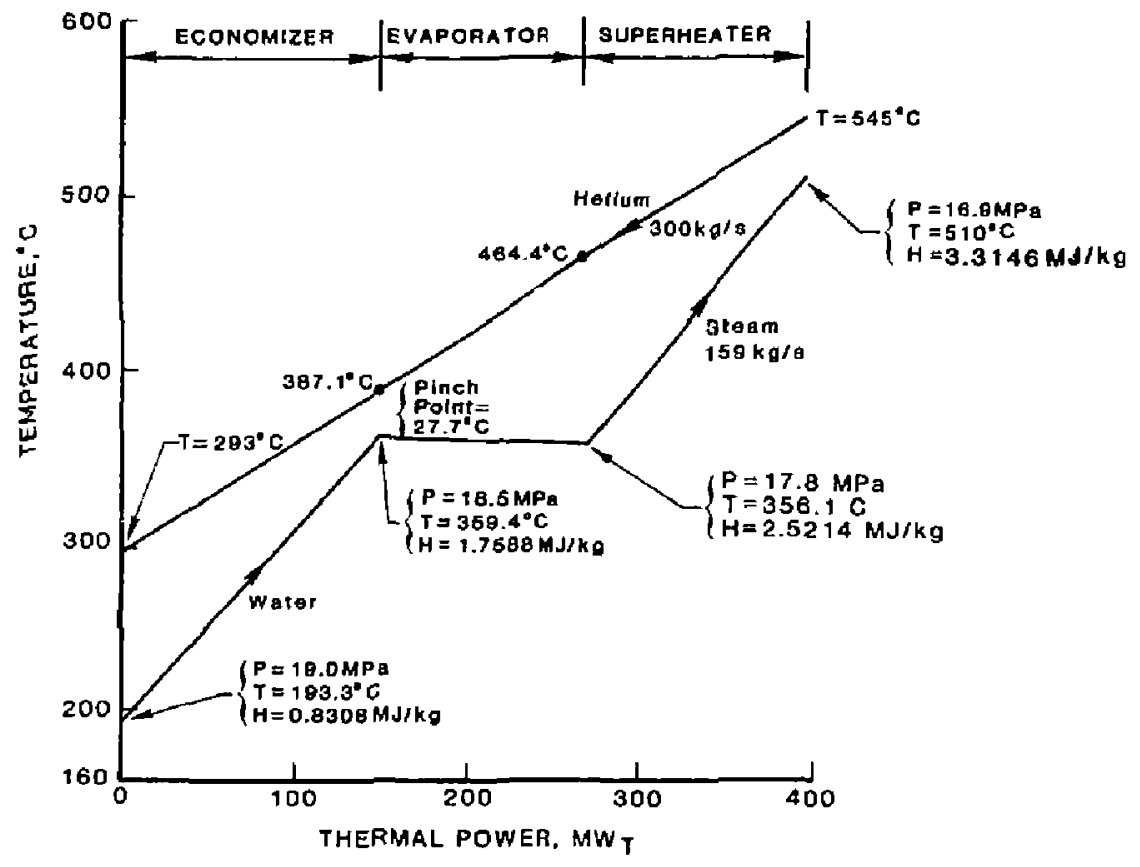

Figure 5.7. Temperature profile for steam generatol. 


\subsection{TFITIUM PERMEATION IN STEAM GENERATORS}

As previously discussed in Section 2.4, tritium permeation from helium to steam through steaiam generator tubes is a major safety and econamic concern. That permeation can be reduced by a factor of 300 by providing a permeation barrier on the tube surfaces also was mentioned in that section. The stated reduction factor can be achieved by either a 10-ym tungsten or a 1-min aluminum coating on the tube surface. We discuss the selection of the proposed barrier in the following paragraphs (also see Refs.).$^{5-9}$ to $5-13$

The permeation barriers may be provided either on the inside or on the outside surface of the tubes. Two potential problems are associatad with the inside barriers. First, high-temperature staam $\left(510^{\circ} \mathrm{C}\right)$ in contact with a luminum results in unacceptable currosion problems. Second, several problems are associated with the use of tungsten. Although technology exists frr mak ing tungsten-coated (internally) pipes, it may be difficult to ensure complete internal coverage. Incomplete coverage results in unacceptable tritium permeation, for example, loss of coverage occurs when tubes are prepared for welded joints. Flaking of tungsten off the tube wall may cause serious damage in the turbine compcnents. Thus, in view of the above potential problems, internal barriers are not proposed in this study. However, the choice should be revisited in the future as these problems may be overcome by improvement in design and/or technology. External barriers are proposed, as discussed below.

Several processes are available for providing an diuninui. barrier on the outside surface of a steam-generator tube wall. First, a methou known as 'cold extrusion' mav be used to form a duplex tube. Although technology exists, this specific combination (aluminum over alloy steel) has not been tried. Anothe: methrod is to use two separate tubes, one steel and one a) uminum. The aluminum tube is heated to a high temperature and pusired over the cold steel tube. The major uncertainty in the two above methods is the performance of the as-formed tube at operating temperature. Aluminum, with a coefficient of thermal expansion higher chan that of steel, may tend to separate, thus greatly lowering the heat-transfer coefficient. A third and relat ively new process known as 'Alonizing' is also available. ${ }^{5-14}$ This is a aiffusion process in which gaseous alumina $\left(\mathrm{Al}_{2} \mathrm{O}_{3}\right)$ is allowed to diffuse into the tube wall. Alumina concentrations up to about $40 \%$ and to a depth of up to about $1 \mathrm{~mm}$ may be obtained. However, it is not known if this will meet 
the tritium barrier requirements. Further information regarding diffusion bonding between aluminum and steel may be obtained from Ref, 5-15.

Tungsten coating, as a barrier, can also be applied in a number of ways. First, a process similar to 'Chromizing' may be employed. This is done by glacing the tube in contact with tungsten powder, heating it to a high temperature, and keeping it there for a long time in a reducing environment. This is a diffusion process. The major uncertaintios in this process are the achievable concentration and depth of tungsten on the tube wall. Another and more readily applicable process is plasma spraying or flame spraying. However, exfoliation ( $f$ laking off) at high temperature is a major concern. This may reduce effectiveness of tungsten as a tritium barrier and may cause damage to the helium circulator impeller. Another method is chemical vapor deposition as proposed for the salt-carrying tubes where $\mathrm{WF}_{5}$ is reducea by $\mathrm{H}_{2}$ at 550 to $640^{\circ} \mathrm{C}$. Th is process application is discussed in Section 2.7 .

In light of the above discussion, aluminum coating in the form of a duplex tube is proposed. However, in the superheater section of the stean generator, helium operating temperature $\left(545^{\circ} \mathrm{C}\right)$ is close to the melting point of aluminum alloy $6061-\mathrm{T} 6\left(582^{\circ} \mathrm{C}\right)$. Thus, it is proposed that tungsten coated tubes (using plasna spraying or flame spraying) be used in the superheater section and aluminum-coated tubes elsewhere (economizer and evaporator secions).

It is evident from the above paragraphs that the tritjum oarriers proposed are not entirely satisfactory bacause of the problems associated with then. Aluminum coating in the form of duplex tube nay ciegrade the heat-transfer coefficjent and is not suitable in the superheater section. Exfoljation of tungsten coating in the superheater-section tuies may cause damage to the helium circulator and may degrade the quality of tritium barrier. "Alonizing" may be a potential solution to these problems. Since aluminum forms an alloy with steel, $i t$ is suitatle in the superheater section and does uot clegrade tire hedt=transfer coefficient in the manner that an external sleeve ooes. Also exfoliation is not a problem with alonized steel. The major uncertaint.y, however, is its effectiveness as a tritium barrier. Thus, it is important to further investicate, both theoretically and experimentally, the effectiveness of alonized steel as a tritium barrier and to find methoos for improving resistance to tritium permeation.

As indicated earlier (Section 3.0.), tungsten is a better tritium oarrier than aluminum by a factor of about 100. Thus diffusion borioing of tungster and steei (similar to 'Chromizing') snould also be investigated. 


\subsection{INTEGRATED PERFOPMANCE AND ECOMOMICS}

\subsection{OVERVIEW}

In this section, the overall performance and cost figures for the moltensalt fusion-breeder reactor are est imated and are combined with similar data for ${ }^{233} \mathrm{U}$-burning LWR fission reactors. We can then estimate the costs of electricity and bred fue 3 for a symbiotic, electricity-generation system consisting of the fusion breeder, its LWR clients, and the associated fuel cycle facilities. Througiout the discussion, the results for tha molten-salt fusion breeder are compareo with those for a reference case, the liquidlithiunrcooled fusion breeder design of 1982. 6-1 Derived quantities (such as the plant capital cost, the plant net electricity and fissile-fuel production, the cost of bred fuel, and the symbiotic cost of electricity) are compared 0.1 a consistent basis for tandem mirror fusion breeders with the same fusion power but with different blanket designs and fuel cycles. The perforinance parameters used to describe the molten-salt fusion breeder are given in Table 6.1.

Table 6.1. Performance parameters.

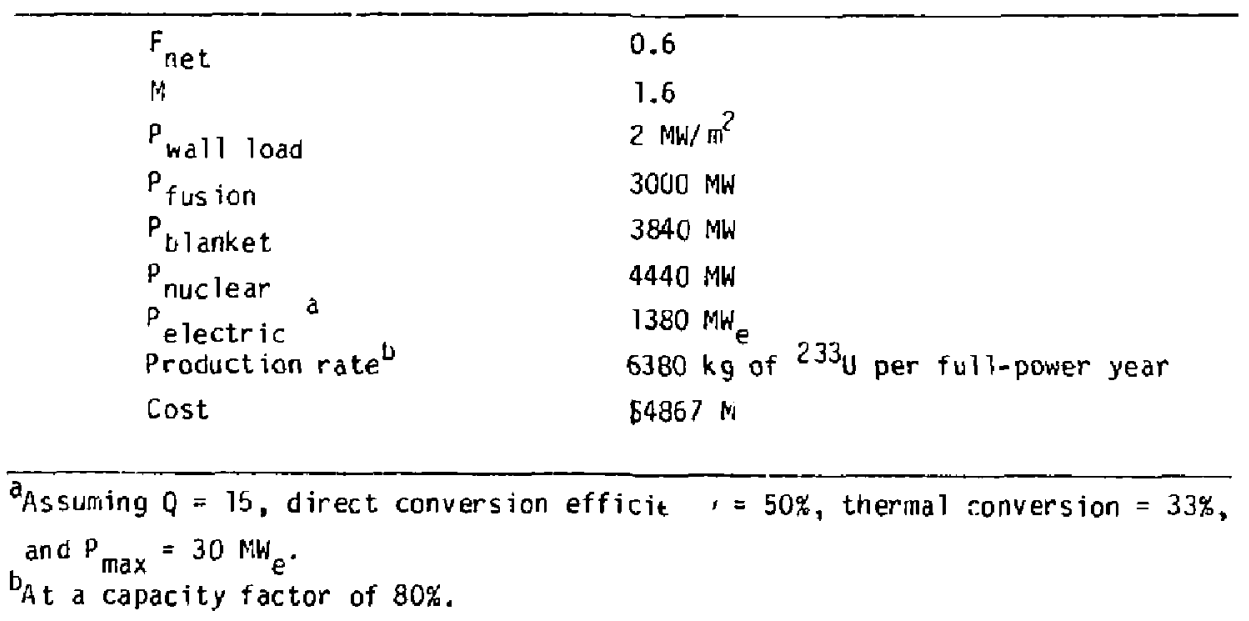


In addition to comparing the two fusion-breeder options, each option is compared with that of an al ternative LWR that is fueled with mined uranium and benefits from the full recycie of all fissile uranium and plutonium isotopes (i.e., fue 1 reprocessing is assumed to be available and to be economically advantaceous). The latter comparison provides some indication of the potuntial economic viability of the fusion breeder under government or witity ownersh ip and operation.

\subsection{SYMBIOTIC ECONOMICS}

Since the fusion breeder produces two principal products (fissile fue 1 and electricity), a method of economic assessment that equitably balances the cost of producing each must be established. The conceptual bas is for one such method is shown in Fig. 6-1. Specifically, an imaginary line is drawn that encloses the fusion breeder, its LWR clients (enough of them to consume al) of the bred fuel), and the associated fuel-cycle facilities. Then it is possible to construct an electricity-generation system that has no net fuel production or consumption and that produces only one net product, electricity. knowing the annual apital, operating, and fuel-cycle costs for both the breeder and its LkR clients and assuming that the fusion breeder and LWRs sell electricity at the same price, we can estimate the cost of symbiotic electricity on an annual basis. Further, a consistent unit cost of bred fissile fuel in any year of operation can be estimated by subtracting the eiectricity-production revenue of the breeoer (as derived above) from its overall annual operating cost (incluoing all components) and dividing by the net fissile-fuel production. It can be shown that LWRs consuming fuel at th is cost will also produce electricity at the same cost as the fusion breeder.

A detailed description of the methods of economic analys is used in developing the abive cost estimates is beyond the scope of this section but is provided in Ref. 6-1. A 7 ist of the general financial input data used in this analjs is is presented in Tible $6-1$.

For the fusion breeder, both government and ut ility ownership were considered. Governnent ownership may be the more likely option for several reasons. First, fusion breeaers effectively are a fissile enrichment technology, which (with fuel reprocessing) will eventually replace existing 


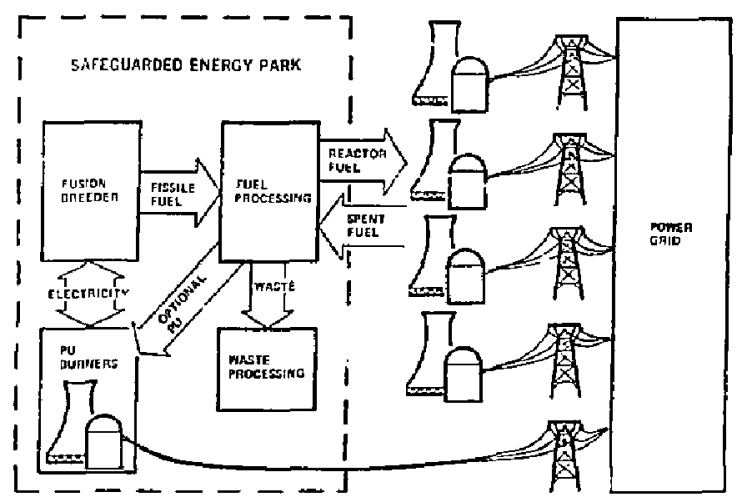

Figure 6-1. A fusion-fission electricity-generation system. Such a 5jstem would have only one net product--electricity. 
Table 6-2. Comparison of financial input data for breeder and light-water reactors (LWR).

\begin{tabular}{|c|c|c|c|}
\hline Financial input & $\begin{array}{l}\text { Util iv- } \\
\text { owned } \\
\text { breeder }\end{array}$ & $\begin{array}{l}\text { Gov't- } \\
\text { omned } \\
\text { breeder }\end{array}$ & $\begin{array}{c}\text { Utility- } \\
\text { owned } \\
\text { LWR }\end{array}$ \\
\hline Plant construction per iod $(y r)$ & 10 & Same & Same \\
\hline Plant lifetime $(y r)$ & 30 & Same & Same \\
\hline Inflation rate $(\boldsymbol{\alpha} / \mathrm{yr})$ & 5 & Same & Same \\
\hline General escalation rate $(\% / y r)$ & 5 & Sami: & Same \\
\hline Bond finance fraction $(\%)$ & 55 & 100 & 55 \\
\hline Tax-exenist bond rate $(\% / y r)$ & 8.2 & Same & Same \\
\hline Stock finance fraction $(x)$ & 45 & $N / A$ & 45 \\
\hline Taxab le stock rate $(\delta / y r)$ & 10.25 & $N / A$ & 10.25 \\
\hline Net discount rate $(x / y r)$ & 9.12 & 8.2 & 9.12 \\
\hline Income tax rate on stocks $\langle \%\rangle$ & 50 & $N / A$ & 50 \\
\hline Property tax rate $(\mathcal{x})$ & 1.45 & 0 & 1.45 \\
\hline Annual depreciation (\%) & 3.3 & N/A & 3.3 \\
\hline Wisc. fixed charge and ins, rate $(x)$ & 0.25 & 0 & 0.25 \\
\hline Decomnissioning cost ( $\%$ of original) & 5 & Same & Sanie \\
\hline Net total fixed charge rate $(\% / y r)$ & 15.05 & 9.05 & 15.05 \\
\hline $\begin{array}{l}\text { Fixed charge rate on fissile } \\
\text { inventory (\%/yr) }\end{array}$ & 7.9 & 3.0 & 7.9 \\
\hline $\begin{array}{l}\text { Net operation and ma intenari-e cost } \\
(\% / \mathrm{yr})\end{array}$ & 1.8 & Same & Same \\
\hline
\end{tabular}

$N / A$ indicates not applicable. 
Table 6.3. Market penetration analys is of economics for a $U_{3} 0_{8}$-fueled LWR with reprocessing (1982 U.S. dallars).

LWR capital cost $\left(\boldsymbol{\sigma} / \mathrm{kW}_{\mathbf{t}}\right)$

Total fixed charge $r$ ate $(\alpha / y r)$

Fuel cycle

$235_{U}$ consumption $\left(g / \mathrm{kH}_{\mathrm{t}} \cdot \mathrm{yr}\right)$

Avg. burn-up (MW-d/tonne of neavy metal)

Reprocessing cost ( $\$ / \mathrm{kg}$ heavy metal)

Fabrication cast ( $\$ / \mathrm{kg}$ heávy metal)

Enrichment cost ( $/ / \mathrm{kg}$ heavy metal product)

Transport and disposal cost ( $\$ / \mathrm{kg}$ heavy metal)

Year-one cost of $\mathrm{U}_{3} \mathrm{O}_{\mathrm{g}}(\mathrm{S} / \mathrm{kg})$

Year-one cost of elec. (mil/kW/ hour)

$\mathrm{U}_{3} \mathrm{O}_{8}$ escalation rate $(\mathrm{z} / \mathrm{yr}$ )

Avg. PV cost of elec. (mil/kW $e^{\text {hour })}$

Avg. PV cost of $\mathrm{U}_{3} \mathrm{O}_{\mathrm{g}}(\mathrm{G} / \mathrm{kg})$
467

15.05

Full recycle

0.194

30,400

558

554

130

97

55

47.3

7.1

31,0

76 
and advanced fissile-enrichment technologies as conventional ur anium resources become scarce and expensive. Enrichment facilities have historically been government owned and have been operated under government contract.

Second, to achieve economics of scale, fusion breeders will be large and expensive. Since one fusion breeder will serve 15 to 20 LWRs of equivalent thermal power, it is likely that most utilities would prefer to look to the federal government as a continual provider of fissile fuel.

Third, by controlling the production and processing of fissile fuel, the government can best implement a system of technical and institutional safeguards to prevent the illicit diversion of fissile materials. If the bred fuel is ${ }^{233} \mathrm{U}$ (the preferred option) a diversion resistant product can be provided to LWR operators by denaturing the $233 \mathrm{U}$ with $238 \mathrm{U}$ and/ or $5 p$ ik ing, Etc. The small quantities of plutonium produced from LWR neutron capture in the ${ }^{238} U$ could be designated for consumption at an "approved" LHR site, burned in LWRs co-locatea with in the safeguarded, fuel cycle center (as shown in Fig, E-1) or disposed of.

Referring to Table $6-1$, note that inflation and escalation rates of $5 \% / \mathrm{yr}$ are assumea in all cases. Also, plant construction periods and lifetimes $\mathrm{s} f 10$ and 30 years, respectively, are also assumed in all cases. For governinent financing, $100 \%$ debt financing at $3 \%$ above the inflation rate (i.e., 1.05 $\times 1.03=1.082$ ) is assumed. In this case, no federal, state, or local taxes, or insurance, or miscellaneous costs are applied, and the resulting net total fixed-charge $r$ ate of $9.05 \% / y r$ is $6 \% / y r$ lower than the $15.05 \% / y r$ cost of money for a utility. Consequently, the economics for government oumership will result in a marked advantage relative to thase for utility ownership of the fusion breeder. In all cases the client LWRs are assumed to be utility owned and oper ated.

Prior to presenting the results for symbiotic electricity-generation systems, we will develop a consistent electricity-cost estimate for an alternative $L W R$ fueleo by conventional uranium with fuli fis-ile recycle and reprocessing. An understanding of the cost of electricity for the above uption will provide a means to better undorstand the potential economic advant ges for a fusion breeder.

As shown in Table 6-3, it is assumed that the LWR capital cost in 1982 dollars is $\$ 467 / \mathrm{kW}_{t}$ (or $\$ T .48 / G \mathrm{H}_{\mathrm{e}}$ ). This value, used throughout the

* Higher LWR costs would increase the cost of electricity but also would make the fus ion breeder more attractive as a supplier of fuel. 
analysis, anticipates a stable nuclear economy and is consistent with longterm planning assumptions rather than with recent experience. ${ }^{\star}$ The fue 1 cycle costs shown in the table were taken from Raference 1 , but were originally adapted from the results of the NASAP study. ${ }^{6-2}$ The ${ }_{3}{ }_{3} 8$ escalation rato of $7.1 \% / y r$ (2\%/yr above general inflation) is used to model the increasing cost of mined uranilim over the 30-year life $0:$ an alternatively fueled LWR which operates during the time frame of conventional uraniumi depletion (e.g., beginning in the year 2020) but is not fueled by the fusion breeder. Specifically, $\mathrm{U}_{3} \mathrm{0}_{8}$ is assumed to cost $\$ 55 / \mathrm{l} \mathrm{g}(\$ 25 / \mathrm{lb})$ in the first year of operation, $\$ 59 / \mathrm{kg}$ in the second, and $\$ 402 / \mathrm{kg}$ in the thirtieth year. However, accounting for the $5 \% / y r$ inflation rate. the year-one worth (i.e., 1982 dollar yalue) of 402 dollars in year 30 is only $402 /(1.05)^{29}$ $=\$ 98$, or about a $75 \%$ uranium cost increase in constant dollars over 30 years. The average cost of $\mathrm{U}_{3} \mathrm{O}_{8}$ during this period is $\$ 76 / \mathrm{kg}$ in 1982 dollars.

The results shown in Table 6-3 indicate that the $U_{3} 0_{g}$-fueled LWR would produce electricity for $47.3 \mathrm{mil} / \mathrm{kW}_{\mathrm{e}} \cdot \mathrm{h}^{\mathrm{h}}$ during its first year of operation. The average present value cost of electricity over the 30 -year operating 1 ife, $31.0 \mathrm{mil} / \mathrm{kW}_{e^{-h}}$, is lower than the year-one value because the annual cost of electricity from the LWR increases less quickly than general inflation. The latter behavior is a well-known feature of ali capitalintensive power-production options - they are expensive to build but pay of in later years because of low operating costs.

\subsection{COMPARISON WITH REFEFENCE CASE}

For purpose of illustration, the performance and economics results for the milten-sait blanket fusion breeder are compared with those for a reference fusion breeder. ${ }^{6-T}$ The reference breeder would ut jlize the liquid lithiurcooled blanket shown ... ig. 6-2, but the fusion-driver components would be identical to those for a fusion breeder with a molter-alt blanket. This choice of the fusion driver allows a consistent compar.son of the two blanket t.ypes accounting for any differences in the areas of cost, breeding, power production/conversion, id fue 1 processing. 


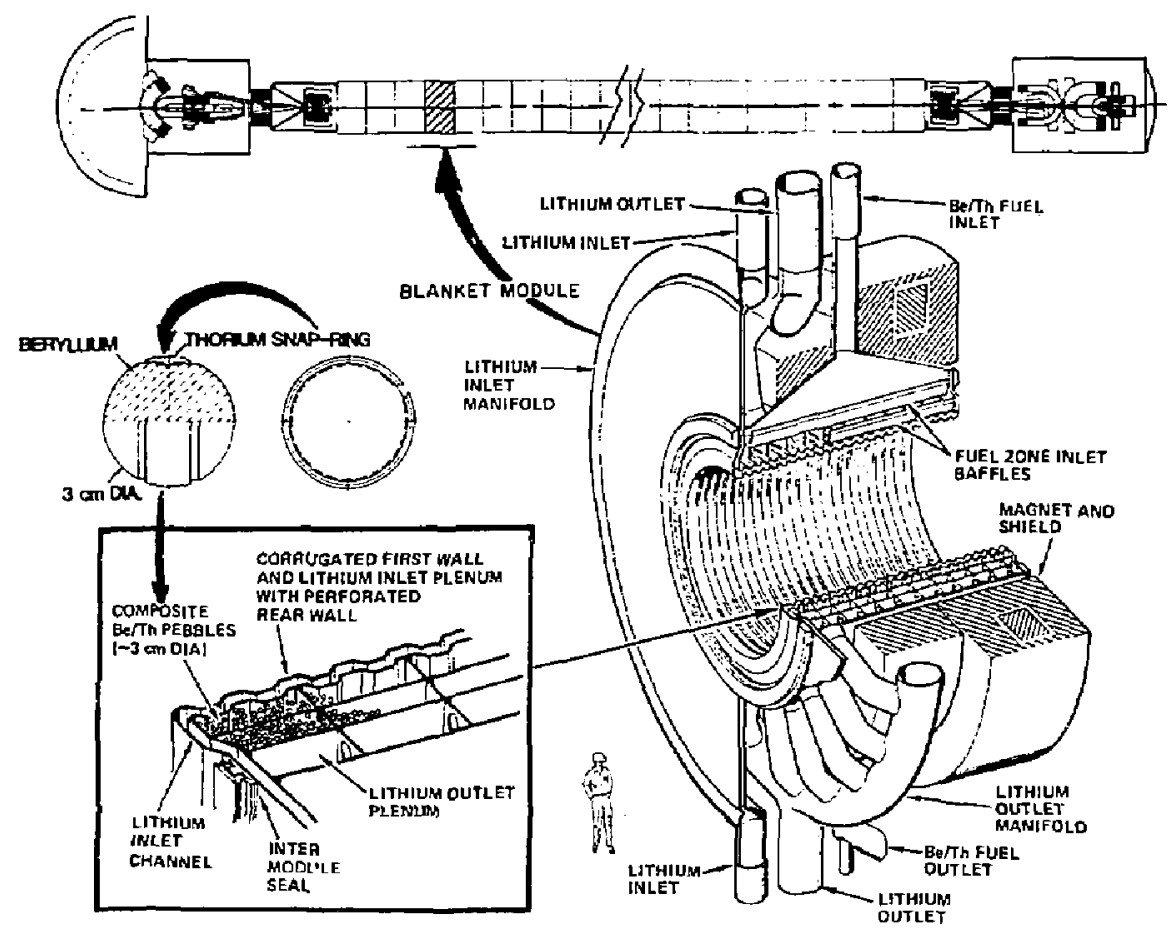

Figure 6-2. Schematic of reference fusion breeder with liquid-metal cooled b lanket. 


\subsubsection{MOLTEN-SALT ADVANTAGES}

Severai features of the molten-salt blanket can be expected to positively impact system economics. Most importantly, replacing aqueous THOREX-fue? reprocessing with direct fluorination of the motten salt gives the following advantages:

- Lower cost for fuel-reprocessing plant.

- El imination of thorium-metal fuel-fabrication plant.

- Lower blanket-anergy multiplication.

- Zero blanket-energy swing.

- Lower in-core and ex-core fissile inventor ies.

- Ligher plant-capacity factor.

The first of these is well known. As shown in Table 6-4, despite the added burden of maintaining a much lower fissile-discharge concentration, the moltensalt reprocessing plant is expected to cost about an order of magnitude lower thar that of the THOREX plant. ${ }^{6-3}$. The elimination of the requirement for a thorium-metal fuel-fabrication plant (and the remote operation of same) also represents a direct benefit of molten-salt reprocessing.

Because the moiten salt is maintained at a constant and low fissile concentration, the other important advantages iisted above also result. The Tower bianket-energy multiplication can result in an enhanced fissile-fue $T$ production per unit thermal power (i.e., higher support ratio). Although not an economics advantage per se, it is expected that fusion breeders with the lower blanket-energy multiplication will have higher safety margins and will also be inscitutionally favored, because less electrical power will be generated with in the remote fuel-cycle center.

Because the fissile concentration can be easily controlled in the moltensalt blanket, it is also possible to operate the blanket at higher than the min imum blanket-energy multiplication. For example, a blanket-energy multiplication of 2.5 rather than 1.5 (the lowest possible value) could be achieved by maintaining a siightly higher $(20.5 \%){ }^{233} \mathrm{u}$ concentration in the sait. Given that such an increase would not severely impact fissile production (i.e., by requiring a larger number of smaller tuoes), that blanket safety is not adversely impacted, and that the additional electricity can be sold at its 
Table 6-4. Typical reprocessing economics (1982 U.S. dollars).

Economic factors THOREX Moiten salt

\begin{tabular}{|c|c|c|}
\hline Throughiput (tonne/yr) ${ }^{a}$ & 510 & 5700 \\
\hline Fissile ais, harge, assay (at.\%) & 1.10 & 0.31 \\
\hline Plant capital cost (\$M) & $516^{b}$ & $61.5^{\mathrm{c}}$ \\
\hline Cost of capital (EM/yr) ${ }^{d}$ & 93 & 9.3 \\
\hline Plant operat ing cost $(\$ M / y r)$ & $38^{b}$ & $2.0^{c}$ \\
\hline Total annual cost ( $5 M / \mathrm{yr})$ & 131 & 11.3 \\
\hline Reprocessing cost (b/kg heavy metal) & 257 & 2.2 \\
\hline Unit $\cos t\langle\bar{\beta} / \mathrm{g}\rangle^{\mathrm{e}}$ & 23.4 & 2.0 \\
\hline Av. PV of unit cost $(\delta / g)^{f}$ & 15.3 & 1.2 \\
\hline
\end{tabular}

$a_{\text {At }} 5635 \mathrm{~kg} / \mathrm{yr}$ of ${ }^{233} \mathrm{U}$.

$b_{\text {Based on }} 1982$ General Atomic Co. assessment of Bechtel design.

${ }^{C}$ Presumed to be conservative on bas is of 1981 assessment of 0ak Ridge

National Laboratory.

dutility owmersnip.

eF irst year.

$f_{P V}$ factor 20.51 times fixed-charge $r$ ate. 
equilibrium market value (see above), it then follows that higher blanket multiplication can be economicaliy advantageous.

Specifically, nearly all of the incremental cost of the additional electricity generation would be associated with components sther than the expensive fusion driver. If we consider only the incremental costs, the cost of additional electricity generation is, most likely, less expensive than the capital-cost component of the client LWR electricity with which it conpetes. A decision on the optimal blanket-energy multiplication requires further consideration, but cases for $M=1.6$ and $M=2.5$ are presented in the next subsection.

In addition to tetter control of the average ${ }^{233} \mathrm{U}$ concentration to lower levels than possible with the liquid-metal-cooled reference design, the molten-salt breeder also benefits from the lack of a swing in the 233 $U$ concentration. That is, in a batch-fueled blanket such as the reference design, the blanket power increases over the fuel-residence $t$ ine. There are methods to limit the power swing, ${ }^{0-1}$ but in all cases a situation ar ises such that the plant must be sized and costed for an end-of-cycle (EOC) power level that is significantly higher than the average power level. Th is situation is avoided in molten-salt breeders that are subject to continuous reprocessing.

Another benefit of continuous (as opposed to batch) fuel reprocessing is the potential to achieve a slightly higher plant-capacity factor. In the case of batch reprocessing, periodic shutciowns are required to load and unload fuel. Typically, these operations would occur about three times per year for about one week each but could often be combined with other required na in tenance functions (e.g., turbine maintenance, blanket-structure replacement) which occur on an annual or semiannual basis. Nevertheles 5,3 molten-salt breeder with continuous fuel reprocessing would have a modest

( 22 to $4 \%$ ) advantage in this respect.

it is inportant to note that design features other than the use of moltensalt reprocessing also impact the performance and cost differences betweon the molten-sait and reference fusion breeder designs. One such design feature, the use of a helium rather than lithium coolant eliminates the cost of an intermediate heat-transfer loop and is expected to result in a lower overall capital cost. Because the molten-salt blanket also operates at a nigher neutron wall 
loading ( 2 vs $1.3 \mathrm{MW} / \mathrm{m}^{2}$ ), the first-wall radius decreases and the blanket/ magnet/shield costs decrease. This is partly compensated for by the thicker blanket and larger beryllium inventory in the molten salt blanket. The longer expected life of beryllium in the molten-salt design is expected to lower berylitum recycle costs.

\section{3.ं. FUSION BREEDER PERFORMANCE ANC COST COMPARISON}

The performance and cost of tandem mirror fusion breeders with the following three blanket types were estimated using the Tandem Reactor Systems Code (iMRSC) developec by TRW ${ }^{5-4}$ : the reference lithium-cooled blanket, an $M=1.6$ molten-salt blanket, and an $M=2.5$ molten-salt blanket. The results are shown in Tables $6-5$ and $6-6$.

As shown in Table $6-5$, despite hav ing the same fusinn power, the three breecer options differ widely in net electrical-power outputs. These can be attributed to the molten-salt blanket fuel-management features discussed in the previous section. Note also tha $i$ the helium-coolant loop pump-power requirement imposes an extra burden on the two molten-salt blankets. Nevertheless, the $M=2.5$ molten-salt breeder has the highest electricity production, $17 \%$ higher than the reference breeder and $55 \%$ higher than the $M=1.6$ moltensalt Lreeder.

The net fissile production of the three breeders is similar, but slightly higher for the molten-salt breeders. For the $M=2.5$ molten-salt breeder, it is assumed that higher blanket energy multiplication does not adversely impact breeding. This assumption is in general agreement with previous design work and analys is. 6-1

The fissile inventories for the molten-salt breeders are substantially lower than for tive reference breeder. This occurs for two reasons. First, the average in-core fissile enrichment is lower because of fissile recovery at a much lower concentration (i.e., 0.11\% vs 1.7\%). Second, the ex-core inventory is lower because the batch practice of holding the entire oischarge product (i.e., ${ }^{233} \mathrm{U}+{ }^{233} \mathrm{~Pa}$ ) for 26 months to allow for ${ }^{23} 3_{\mathrm{pa}}$ decay to $233_{\mathrm{U}}\left(\mathrm{T}^{1 / 2}=27 \mathrm{~d}\right)$ prior to reprocessing is avoided.

As shown in Table 6-6, the reference lithiun-blanket breeder is the most expensive. Comparing the reference breeder with the $M=2.5$ molten-sali 
Table 6-5. Fusion breeder performance comparison.

\begin{tabular}{|c|c|c|c|}
\hline \multirow[b]{3}{*}{ Parameter } & \multicolumn{3}{|c|}{ B I anket Type } \\
\hline & \multirow{2}{*}{$\begin{array}{l}\text { Lith ium } \\
\text { (reference) }\end{array}$} & \multicolumn{2}{|c|}{ Molten Salt } \\
\hline & & $(M=1.6)$ & $(M=2.5)$ \\
\hline Fusion power (MH) & 3000 & 3000 & 3000 \\
\hline \multicolumn{4}{|l|}{ Blanket energy multiplication } \\
\hline Miาimum & 1.25 & -- & -- \\
\hline Maximum & 2.50 & - & -- \\
\hline Average & 1.88 & 1.6 & 2.5 \\
\hline Gross nuclear power $(M h)^{a}$ & 5100 & 4440 & 6600 \\
\hline Gross electric power $(M W)^{a, b}$ & 2226 & 1895 & 2710 \\
\hline Driver recirculating power (MW') & 325 & 325 & 325 \\
\hline Additional recirculating power (MH) & 180 & 280 & 380 \\
\hline Net electric power (pis) & 1720 & 1290 & 2005 \\
\hline Net fissile production $(\mathrm{kg} / \mathrm{yr})^{\mathrm{C}}$ & 5635 & 5810 & 5810 \\
\hline Fissile inventory $(\mathrm{kg})^{c}$ & 3995 & 775 & 825 \\
\hline In-core $\mathrm{a}^{\mathrm{a}}$ & 1180 & 105 & 155 \\
\hline Post discharge & 2815 & 670 & 670 \\
\hline Plant capacity factor ${ }^{a}$ & 70.0 & 72.2 & 72.2 \\
\hline \multicolumn{4}{|c|}{ 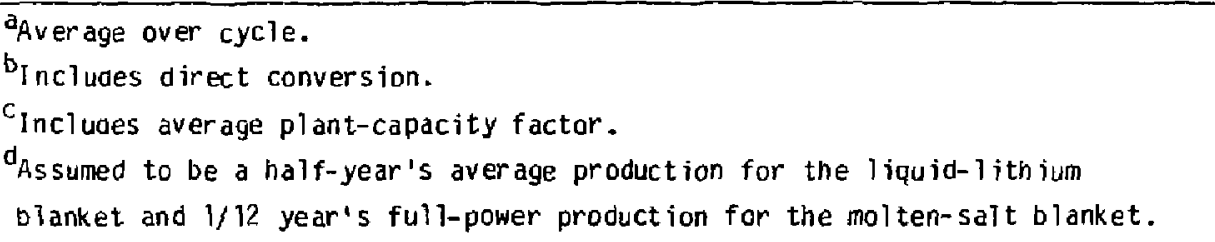 } \\
\hline
\end{tabular}


Table 6-6. Fusion breeder cost comparison (1982 U.S. 5M).

\begin{tabular}{|c|c|c|c|}
\hline \multirow[b]{2}{*}{ Facilities and equipment } & \multicolumn{3}{|c|}{ B]anket Type } \\
\hline & $\begin{array}{c}\text { (ithiom } \\
\text { (reference) } \\
\text { (\$M) }\end{array}$ & $\begin{array}{c}M=T .6)^{2} \\
(5 M)\end{array}$ & $\begin{array}{c}n \text { Salt } \\
(M=2.51 \\
(6 M)\end{array}$ \\
\hline Land and land rights & 86 & 56 & 56 \\
\hline Structures and site facilities & 536 & 422 & 461 \\
\hline Fusion or iver components ${ }^{a}$ & 822 & 679 & 805 \\
\hline First wall/b ? anket shield & 475 & 400 & 558 \\
\hline Heat transport components ${ }^{c}$ & 478 & 250 & 356 \\
\hline Misc. reactor equipment & 285 & 285 & 285 \\
\hline Turbine plant equipment & 352 & 258 & 350 \\
\hline Electrical plant equipment & 150 & 223 & 295 \\
\hline Misc. plant equipment & 18 & 11 & 18 \\
\hline Fuel cycle facjlities & 364 & 46 & 46 \\
\hline Total direct cost & 3486 & 2580 & 3180 \\
\hline Contingency & 697 & 516 & 636 \\
\hline Indirect cost & 1414 & 1046 & 1290 \\
\hline Total plant cost & 6577 & 4867 & 6000 \\
\hline
\end{tabular}

ancludes magnets, heat ing systems, and direct convertor.

bIncludes beryllium, lithium, and molten salt.

CIncludes circuiators for molten-salt helium loops.

Includes reprocessing, beryllium fabrication, and thorium fabrication. 
breeder (same thermal power $r$ ating), the largest cost differences occur in the following:

- Structures and site facilities

- First wall/blanket/shield

- Heat-transport components

- Electrical-plant equipinent

- Fuel-cycle facilities

\section{Reference breeder}

$75 \$ M$ more

83 bM less

122 SM more

145 БM less

318 SM more

The larger structures and site facilities and heat-transport component costs can be attributed to differences between the lithium and helium coolants (e.g., the expensive intermediate locp for lithium). The savings in the blanket/shield cost can be attributed to a lower requirement for expens ive beryllium in the lithium blanket. The savings in the electrical plant. equipment cost can be attributed to the cost of the molten-salt breeder clectrical bulks (which is conservatively taken to be directly proportional to the recirculating electrical power). Finally, the large fuel-cycle-facility cost for the lithium-blanket breeder reflects the cost of dedicated THOREX and thor ium-metal recycle plants.

\subsubsection{ECONOMICS OF SYMBIOTIC ELECTRICIT'i-GENERATION SYSTEMS}

We merged the performance and cost results (presented in the previous section) with similar data for LWRs and their fuel cycles to predict the symb iotic cost of electricity and the cost of bred fuel on a year-by-year and on a 30-year average present-value basis. The economics methodology useo in the analysis is described in Ref. $6-1$.

Table 0-7 shows the results of this anaiys is for the reference lithiumb? anket fusion breeder in symbiosis with ${ }^{233} \mathrm{U}$-burning LWRs operating on a denatured thorium-fuel cycle. ${ }^{6-1}$ The breeder cost per unit thermal power is about 2.8 times that of the LWR. However, the effective capital cust of the breeder decreases to 1.6 times the LWR cost when adjustments for government ownership of the breeder are made. As shown, ihhis difference has only a minor effect on the cost of electricity. Eecause most of the electricity ( $295 \%$ ) 
is penerated in LWRs that dominate the symbiotic system, the symbiotic cost of electricity is always quite insensitive to perturbations of the breeder cost and/or performance.

Nevertheless, slight changes in the cost of electricity represent large changes in the cost of bred fuel. This can be easily understood if one notes that at the current price of $\mathrm{U}_{3} \mathrm{O}_{\mathrm{g}}(2555 / \mathrm{kg})$, the cost of mined uranium is typically on $7 y$ about $3 \%$ of the overall cost of LWR electricity. Thus, an electricity cost increase of $6 \%$ would about triple the allowed cost of $\mathrm{U}_{3} \mathrm{O}_{8}$. Table 6-7 indicates a similar result - a $12 \%$ electricity-cost differential represents a $130 \% 233$-cost differential. 
Table 6-7. Comparison of utility owmership and government ownership for the litniumberyllium reference fusion breeder.

\begin{tabular}{|c|c|c|}
\hline Cost oata & $\begin{array}{l}\text { Utility } \\
\text { owned }\end{array}$ & $\begin{array}{l}\text { Government } \\
\text { owned }\end{array}$ \\
\hline Total plant capital cost (IM) & 6580 & 6580 \\
\hline Breeder $/$ LWR cost ratio ${ }^{a}$ & 2.76 & 2.76 \\
\hline \multicolumn{3}{|l|}{ Total fixed-charge rate on capital for } \\
\hline breeder plant $(\$ / y r)$ & 15.05 & 9.05 \\
\hline Effective Breeoer/LWR capital cost ratio & 2.76 & 1.60 \\
\hline Year-one cost of elec. $\left(m i l / k W_{e} \cdot h\right)$ & 54.1 & 48.5 \\
\hline$A v g . P V^{b}$ cost of elec. $\left(m i l / k w_{e}=h\right)$ & 33.0 & 30.2 \\
\hline Year-ane cost of ${ }^{233} U(\$ / g)$ & 109 & 46.9 \\
\hline Avg. PV cost of ${ }^{233} \cup(\$ / g)$ & 61.6 & 30.0 \\
\hline
\end{tabular}


In Tab le 6-8, we compare the results of the previous table with those for the $\mathrm{U}_{3} \mathrm{O}_{8}$-fueled LWR of Section 6.2. In comparison with the conventianaliy fueled $L W R$, the symbiotic system produces electricity more expensively dur ing the first year of operation.

If the fusion breeder is utility owned, its cost of electricity does not become equal to that of the conventional LUR until the twenty-fourth year of operation, the 30-year average present value of the cost of electricity is higher than that of the conventional LWR by $2.0 \mathrm{mil} / \mathrm{kW}_{\mathrm{e}^{-h}} \mathrm{~h}$, and a 30-year cumlative loss of 8.5 billion dollars results. Although this case does not indicate market penetration under the assumed conditione (i.e., $555 / \mathrm{kg}$ of $\mathrm{U}_{3} \mathrm{O}_{8}$ at the start of operation), further studies indicate a thirty-year breakeven ( $i$.e., zero benefit) if the starting price of $\mathrm{U}_{3} \mathrm{D}_{8}$ is $5110 / \mathrm{kg}$, or about twice the current price. Higher $\mathrm{U}_{3} \mathrm{O}_{8}$ costs would lead to a net benef it for the fusion breeder.

In the case of government ownership a year eight breakeven is achieved and an average $0.8 \mathrm{mil} / \mathrm{kW}_{\mathrm{e}^{-h}}$ benefit accrues aver the entire fusionbreeder operating life. This results in an integrated benefit of $\$ 3 . b$ billion over a 30-year period.

Tab?e 6-9 shows results for symbiotic electricity-generation systems that utilize $M=1.6$ molten-salt breeders. Compared with the reference system, the molten-salt breeder results show marginal electricity cost advantages but a substantial reduction in the cost of fissile material. Although utility ownership is more attractive in this case, there is a substantial benefit for government ownership.

Results are summarized in Table 6-10. If the molten-5ait breeder is government owned (Case 3), the electricity cost breakeven occurs during the first year of operation and an 68 billion benefit per fusion breeder accrues over its 30-year operation. If the molten-salt breeder is utility onmed (Case 4), breakeven occur's in the fourteenth year and the integrated benefit is only $\$ 200$ milition.

The Case 5 results indicate that a $20 \%$ increase in predicted fissile breeding gives an $250 \%$ increase in the integrated benefit. The case 6 results indicate that a $20 \%$ decrease in the predicted fissile breeding gives an $220 \%$ de:rease in the integrated benefit. The latter result indicates that the beryllium multiplier might be replaced with a less exotic option (e.g., lithium or lead) without prooucing an intolerable economic impact. 
Table 6-8. Comparison of cost data for a symbiotic system, including a liquid-1 ith ium blanket fusion breeder, and a $\mathrm{U}_{3} \mathrm{O}_{8}$-fueled I.WR.

\begin{tabular}{|c|c|c|}
\hline Cost data & $\begin{array}{l}\text { Utility } \\
\text { owned } \\
\text { (C ase 2) }\end{array}$ & $\begin{array}{c}\text { Government } \\
\text { owned } \\
\text { (Case 1) }\end{array}$ \\
\hline Delta year-one cost of elec. (mil/khe $e^{-h)^{2}}$ & 6.8 & 7.2 \\
\hline Breakeven year & 24 & 8 \\
\hline Delta avg. PV cost of elec. $\left(m i l / k H_{e} \cdot h\right)^{d}$ & 2.0 & -0.8 \\
\hline lntegrated benefit $(\overline{B M})^{\mathrm{C}}$ & $-\$ 500$ & 3500 \\
\hline
\end{tabular}


Table 6-9. Molten-salt fusion-breeder $\cos t$ data.

Cost data

$\begin{array}{cc}\text { Utility } & \text { Government } \\ \text { owned } & \text { owned } \\ \text { (Case 4) } & \text { (Case 3) }\end{array}$

\begin{tabular}{|c|c|c|}
\hline Total plant capital cost (\$M) & 4867 & 4867 \\
\hline Breeder/LWR cost ratio & 2.35 & 2.35 \\
\hline Total fixed-charge rate $(\% / y r)$ & 15.05 & 9.05 \\
\hline Effective breeder/LWR cost $r$ atio & 2.35 & 1.41 \\
\hline Year-one cost of elec. $\left(\mathrm{mil} / \mathrm{kW}_{\mathrm{e}} \mathrm{e}^{-\mathrm{h}}\right)$ & 50.8 & 46.9 \\
\hline Avg. PV cost of elec. $\left(m i l / \mathrm{kW}_{e} \cdot \mathrm{h}\right)$ & 31.0 & 28.9 \\
\hline Year-one cost of ${ }^{233} \mathrm{U}(5 / \mathrm{g})$ & 72.5 & 29.2 \\
\hline Arg. PV cost of $233 u(F / g)$ & 38.6 & 75.6 \\
\hline
\end{tabular}


Table 6-10. Comparison of data for 1 ithium-blanket or molten-salt reactor type and ownership.

\begin{tabular}{|c|c|c|c|c|c|c|}
\hline Case & $\begin{array}{l}\text { Govt./Ut il. } \\
\text { owned }\end{array}$ & $\begin{array}{l}\text { Reactor } \\
\text { type } \mathrm{e}^{\mathrm{a}}\end{array}$ & $\begin{array}{l}\text { Breakeven } \\
\text { year }\end{array}$ & $\frac{\text { Present }}{\text { Elec. }}$ & $\frac{\text { Value }}{\text { Fue? }}$ & $\begin{array}{c}\text { Benefit } \\
\text { BB }\end{array}$ \\
\hline 1 & Govt. & Lithium & 8 & 30.2 & 30.0 & 3.5 \\
\hline 2 & util. & Lith ium & 24 & 33.0 & 61.6 & -8.5 \\
\hline 3 & Govt. & $M S / 1.6$ & 1 & 28.9 & 15.6 & 8.0 \\
\hline 4 & Util. & MS/ 1.6 & 14 & 31.0 & 38.6 & 0.2 \\
\hline 5 & Govt. & $M S / 7.6 / F+20 \%$ & 1 & 28.7 & 13.5 & 11.8 \\
\hline 6 & Govt. & $M S / 1.6 / F=20 \%$ & 1 & 29.15 & 18.5 & 6.5 \\
\hline 7 & Govt. & $M S / 2.5$ & 1 & 28.2 & 7.8 & 12.5 \\
\hline
\end{tabular}

dif = molten salt; $M=$ labor ?.5; $F=$ fissile breeding ratio. 
Finally, Case 7 shows the potential advantage for an $M=2.5$ moltensalt blanket. With government ownership, the high-power molten-salt breeder achieves the highest potential benefit of the cases considered. A comparison of Cases 5 and 7 indicates that the economic value of $50 \%$ higher blanket-energy multiplication is roughly equivalent tc the economic value of an $20 \%$ higher fissile-fuel production. Because the energy multiplication of molten-salt blankets is easily adjusted in this range (see Section 6.2 discussion), the above trade could be quite valuable in defining the optimal system.

\subsection{CONCLUSIONS}

We conclude the following from the described nodeling of the potential economic performance of fus ion breeders:

- As an advancer enrichment facility, the reference $L i / B e$ fusion breeder with government ounership could be economical at today's price of $\mathrm{U}_{3} \mathrm{O}_{8}$.

- In the above case and with utility ownership, $\mathrm{U}_{3} \mathrm{O}_{8}$ must in itially cost $\$ 110 / \mathrm{kg}$ for a 30 -year breakeven.

- The molten-salt fusion breeder could be econonlical at today's price of uran ium regardless of ownership.

- With government ownership, the molten-salt fusion breeder could break even in year one and proouce a multibilition dollar benefit over its operating lifetime.

- Bigger benefits accrue for the molten-salt fusion breeder operation at higher breeding and/or higher blarket-energy multiplication.

- A $20 \%$ breeding decrease is clearly tolerable

- Some issues yet to be addressed include the potential impacts of lower L.WR separat ive work unit costs, higher LWR fuel-reprocessing costs, and the rike. 
5-1 J. King, GA Technologies, San Diego, CA, private communication (0ct. 1984).

5-2 Gas-Cooled Fast-Reactor Demonstration-P lant Design Description, Helium Breeder Associates, Fab. 1980).

5-3 Interim Evaluation Report - 4X250 MH HTGR P lant Vertical-Inl ine Stee I Vessel Concept, Gas-Cooled Reactor Associates, Report No. BNI/GCRA 84-006 (Sept. 1984).

5-4 D. E. Eavis and J. M. Krase, Fort St. Vrain Nuclear Generat ing Station-Nuc lear Components, Nuclear Engineer ing International, December 1969.

5-5 C.P. C. Wong, GA Technologies, San Diego, CA, private communication (Apr il 1984).

5-6 Flow of Fluids, Crane Co., Technical Paper No. 410 (1974).

5-7 Kent's Mechanical Engineers' Hanbook, Power Volume, Twelfth Edition, Page 1-42 (December 1954).

5-8 D. Carosella, GA Technologies, San Diegc, CA, private cominunication (0ct. 1984).

5-9 Y. Chung, Bechtel Group, Inc., San Frarcisco, CA, private cammunication (0ct. 1984).

5-10 D. Roberts, GA Technologies, San Biego, CA, private communication (0ct, 1984).

5-11 M. Gold, Babcock \& Wilcox, Barberton, Oh io, private communication (0ct. 1984).

5-12 A Blazewicz, Babcok \& Wilcox, Barberton, Dhio, private communication (Oct. 1984).

5-13 0. Schluderberg, Babcock \& Wilcox, Lynchberg, Virginia, private communication (Sept. 1984).

5-14 W. A. McGill and M. J. We inbaum, "Aluminum Diffused Steels Resist High Temperatures in Hydrocarbon Ervironments," Metal Progress (Feb. 1979).

5-15 P. D. Calderon, Evaluation of Oiffusion Bonded Aluminum Al loys to Stainless Steel, M. S. Thesis, University of California, Davis, CA; also L awrence $L$ ivermore National $L$ aboratory, UCRL-53428 (July 1983). 
REFERENCES SECTION 6.0 .

6-1. D. H. Berwald et at., Fission Suppressed Hybrid Reactor - The Fusion Breeder. Lawrence Livermore National Laboratory, UCID-19638 (1982).

6-2. U.5. Department of Energy, Non-Proliferation A1ternative Systems Assessment Program, DOE/NE-0001 (1980).

6-3. J. D. Lee, et al., Feas ibility Study of a Fission-Suppressed Tandem Mirror Hybrid Reactor, Lawrence Livermore National Laboratory, UCID-19327 (1982).

6-4. R. H. Whitley, Tandem Mirror Reactor Systems Code Manual, contact author at TRH, I Space Park, Redondo Beach, CA. 


\subsection{TRITIUM MANAGEMENT}

Permeation barrier development and demonstration is the critical $R$ \& 0 need. Tritium will need to be removed from both molten salt and helium loops. Recover ing tritiun from molten salt is yet to be domunstrated but should be manageable since the partial pressure is high. Process technology is known for recover ing tritium from helium, although a large increase in scale will be required. The key is to have good permeation barriers both on salt tubes and s team-generator tubes, thus easing requirements for both salt and for helium process systems. Single-pass process efficiencies can be moderate, and only a small fraction of the circulating helium must be processed. Failure to develop effective barriers shifts the burden of processing tritium into the stean/water system. Isotopic processing of tritiated water then becomes a high priority $R$ \& $D$ requirement. I sotope separation will be more difficult anc cost?y, and the steam system must be kept leak-free to avoid personne? hazards from tritiated water vapor. A successful barrier development effort coulo avoid both the need for water processing and the hazards that accompany tritiated water systems.

\subsection{BERYLLIUM FEASIBILITY}

Beryllium-beryllium self-welding and beryllium-steel welding at the contact points are issues needing experimental investigation. Ithis is the objective of a planned set of capsule tests at ORNL. The ability of the beryllium balls to stand up under neutron radiation is maximized by design (their small size); however, irradiation data are needed. Some of this can be done in fission reactors; for example, the tests carried out in $5 B R-11$ and the planned neutron radiation induced-creep tests.

\subsection{MATERIAL COMPATIBILITY}

We predict the steel (type 316 ) will have a long lifetime in contact with the salt, if it is kept in a reducing state. Corrosion tests with molten salt in a flowing loop would prove the predicted compatibility. Irradiation tests in a fission reactor should be carried out to verify the chemical compatibility of salt and steel. 


\subsection{REPROCESSING}

Removal of uranium by fluorination is fairly we 11 understood but neeos demonstrating at a reasonable scale. From a neutron economy point of view, removal of fission products is known to be unnecessary. Fror: a safety point of view, removal of fission products would be desirable but only partially effective. Removal would entail salt/metal pyrochemical reduction processing to be scaled up from small batch tests to larger contiruous processing and would require developing refractory metal piping. We do not believe this is necessary. Therefore, development and demonsiration of a continuous fluorinator is the only important reprocessing $R \& D$ need.

\subsection{NEUTRON ECOMOMY}

The breeding performance of the molten-salt design is very sensitive to parasitic absorption in structural material (principally iron). This is due to the low concentration of thorium in the salt (only $7 \%$ of the salt atoms are thorium). The neutronic calculations in this report include pipe walls but do not include other needed structural material; however, too much first-wali material was used which might provide sufficient compensation. We must make better calculations of the nuclear performance and emphasize designs that minimize structure material. Alternatives to steel should be considered. Finally, experimental verification of tritium and fissile breeding should be carried out with a point $14-\mathrm{MeV}$ neutron source.

$4358 \mathrm{t} \& 4359 \mathrm{t} / 0020 \mathrm{t}$, $4360 \mathrm{t} / 0021 \mathrm{t}$

$\mathrm{DB} / \mathrm{RP}$ 